\title{
Analyzing PTK7/RACK1 interaction in neural morphogenesis
}

\author{
Doctoral Thesis
}

\author{
Dissertation for the award of the degree \\ "Doctor rerum naturalium (Dr.rer.nat)" \\ in the GGNB program: "Genes and Development" \\ at the Georg August University Göttingen \\ Faculty of Biology
}

submitted by

Peter Wehner

born in Jena, Germany

Göttingen, April 2012 


\section{Members of the Thesis Committee:}

Supervisor:

Dr. Annette Borchers (Reviewer),

Developmental Biochemistry, Georg August University

Second member of the thesis committee:

Prof. Dr. Andreas Wodarz (Reviewer),

Stem Cell Biology, Georg August University

Third member of the thesis committee:

Junior Prof. Dr. Gregor Bucher

Department of Developmental Biology, Georg August University

Date of the oral examination: 30.05 .2012 


\section{Affidavit}

Herewith I declare that I prepared the PhD thesis "Analyzing PTK7/RACK1 interaction in neural morphogenesis" on my own and with no other sources and aids than quoted.

Submission date

Göttingen, 14.04.2012

Peter Wehner 


\section{List of Publications}

Peradziryi $\mathrm{H}^{*}$, Kaplan NA*, Podleschny M, Liu X, Wehner P, Borchers A*, Tolwinski N* (2011) PTK7/Otk interacts with Wnts and inhibits canonical Wnt signaling. EMBO J. 2011 Jul 19;30(18):3729-40. * co-last authors. *These authors contributed equally

Wehner $\mathbf{P}^{\star}$, Shnitsar $\mathrm{I}^{*}$, Urlaub H, Borchers A. RACK1 is a novel interaction partner of PTK7 that is required for neural tube closure. Development. $2011 \mathrm{Apr} ; 138(7): 1321-7$. * These authors contributed equally.

Wagner $\mathrm{G}^{*}$, Peradziryi $\mathrm{H}^{\star}$, Wehner $\mathbf{P}$, Borchers A. PlexinA1 interacts with PTK7 and is required for neural crest migration. Biochem Biophys Res Commun. (2010) 402(2):402-7.

* These authors contributed equally. 


\section{Table of Contents}

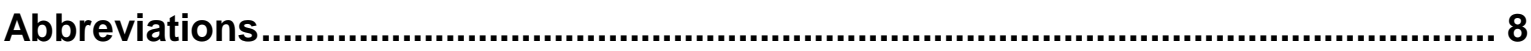

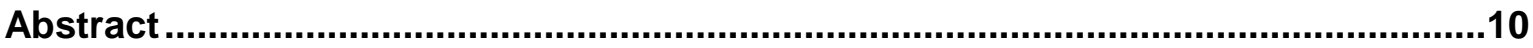

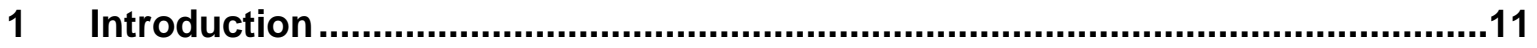

$1.1 \quad$ Neural morphogenesis: An overview .................................................. 11

1.1.1 Morphogenetic processes which are required for the generation of the

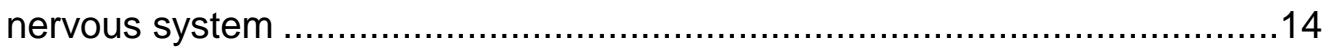

1.1.2 Neural crest development ............................................................... 17

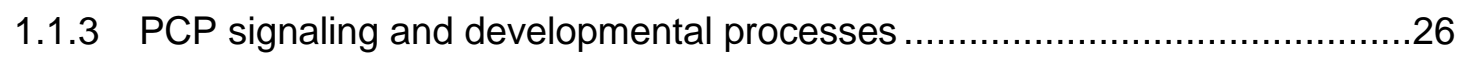

1.2 Protein tyrosine kinase 7 functions in PCP signaling and regulates neural tube closure and neural crest migration ......................................................... 36

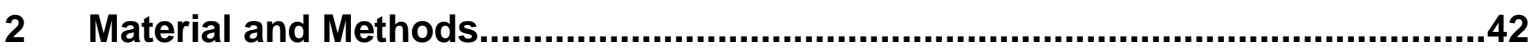

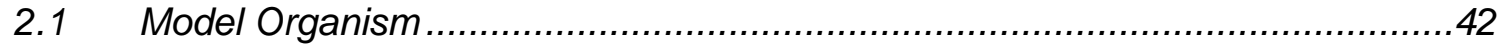

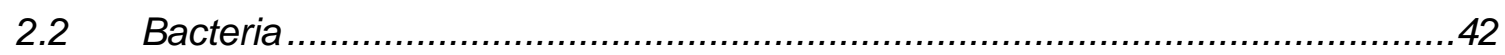

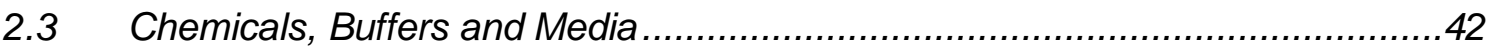

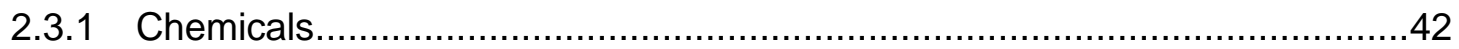

2.3.2 Additional chemical substances and reagents ........................................42

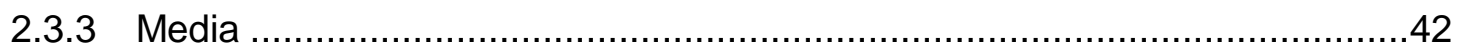

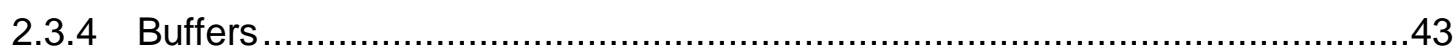

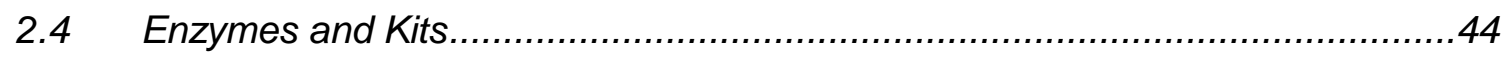

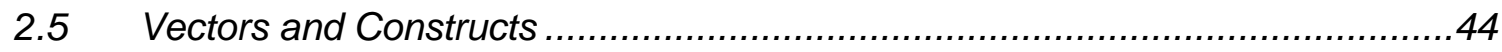

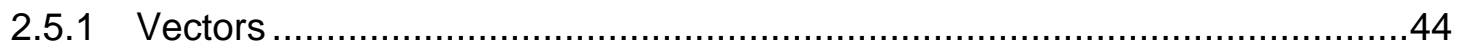

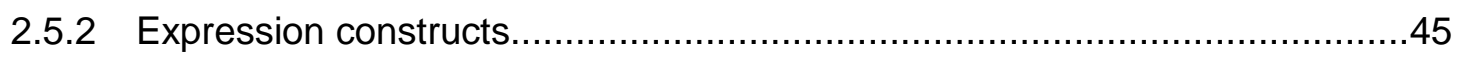

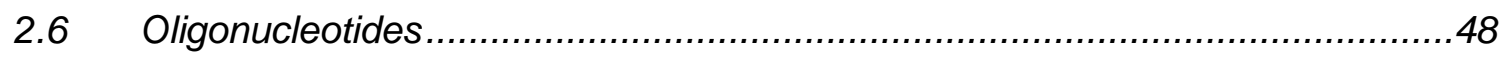

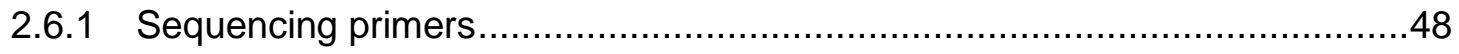

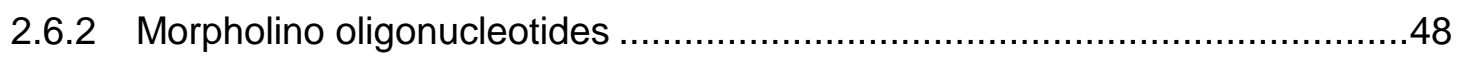

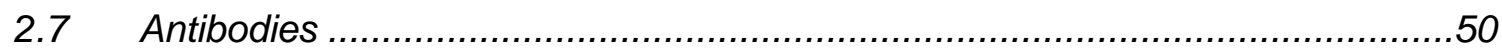

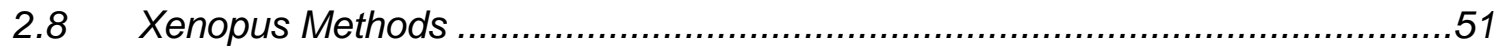

2.8.1 Xenopus embryo culture, micromanipulation and microinjection ..................51

2.8.1.1 Preparation of Xenopus laevis testis ...........................................51

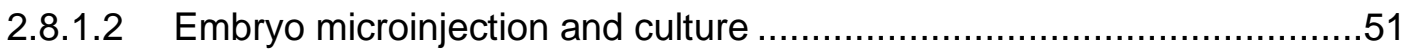

2.8.1.3 Xenopus ectodermal explant assay (animal cap assay) ........................52

2.8.1.4 Cranial neural crest (NC) explants ..................................................52

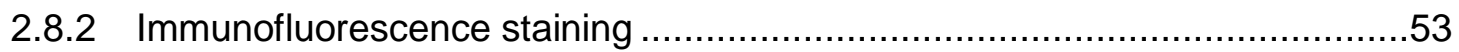

2.8.2.1 Immunostaining of the ectodermal explants (animal caps) ....................53

2.8.2.2 Immunostaining of the gelatin-albumin sections ...............................53

2.8.3 Whole-mount in situ hybridization (WISH) and X-gal staining ......................54 


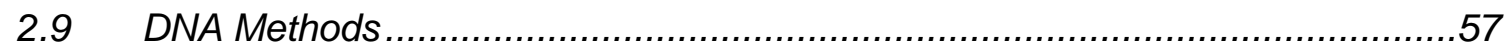

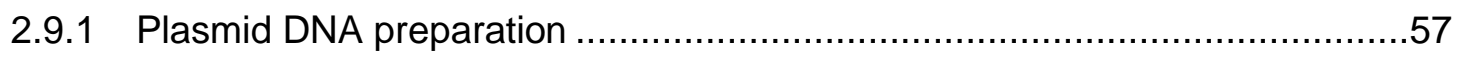

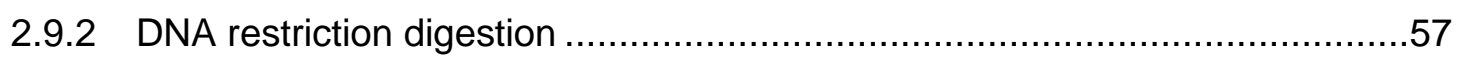

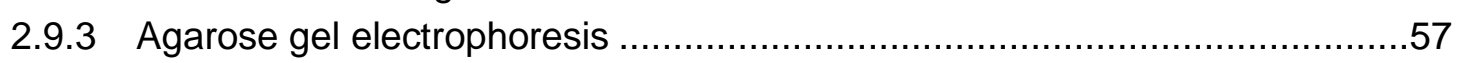

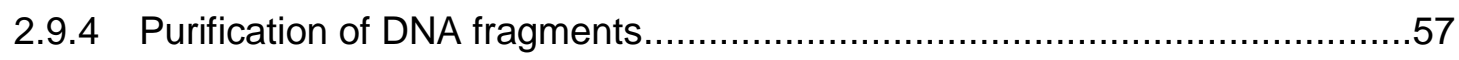

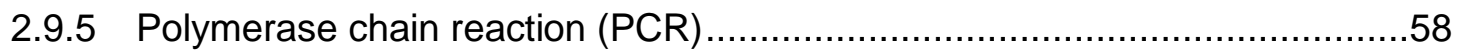

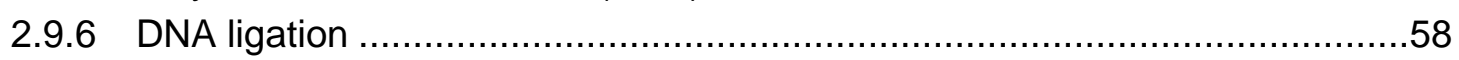

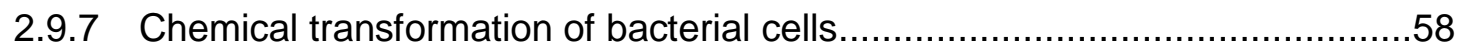

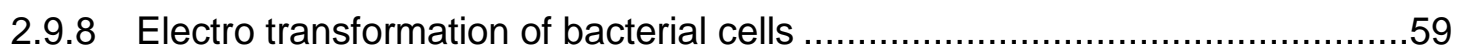

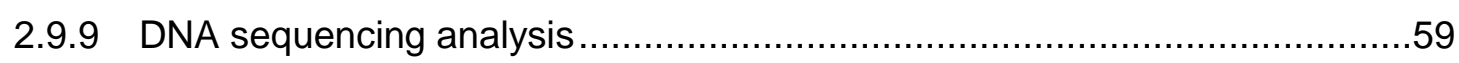

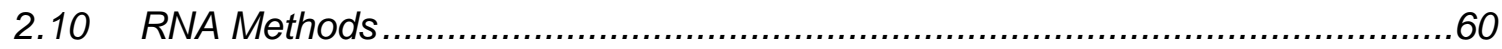

2.10 .1 In vitro synthesis of capped sense mRNA ..........................................60

2.10.2 In vitro synthesis of labeled antisense RNA ........................................60

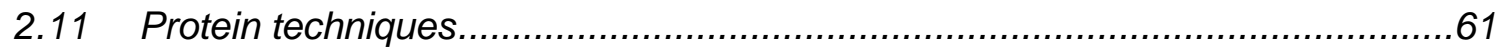

2.11.1 Lysis of Xenopus embryos for Western Blotting .................................61

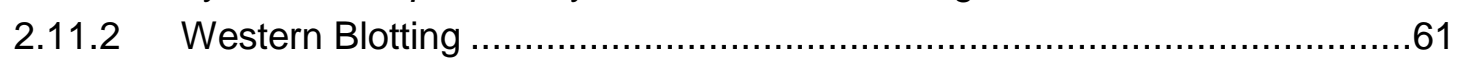

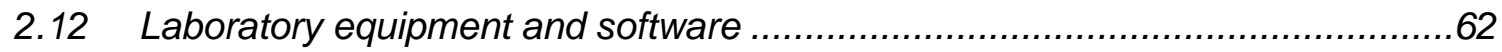

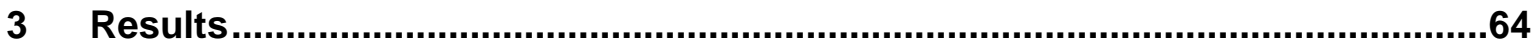

3.1 RACK1 loss-of-function causes neural tube closure defects..........................64

3.2 RACK1 and PTK7 loss-of-function lead to similar neural tube closure defects .67

3.3 RACK1 overexpression affects neural tube closure ...................................69

3.4 RACK1 and PTK7 affect convergent extension of the neural tube ....................70

3.5 PTK7 recruits RACK1 to the plasma membrane......................................73

3.6 Membrane recruitment of RACK1 by PTK7 is sufficient to translocate DSH to the

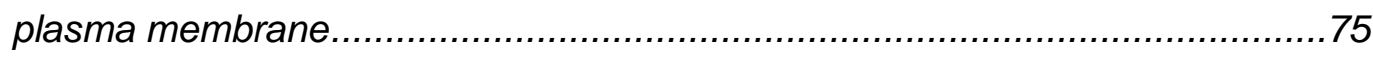

3.7 Verification of the PTK7/RACK1/PKC $\delta$ model..........................................

3.8 RACK1, PTK7 and PKC 81 interact in the regulation of neural morphogenesis .79

3.9 PTK7/RACK1-mediated DSH localization is independent of frizzled .................80

3.9.1 RACK1 is not required for Fz7-mediated DSH localization and

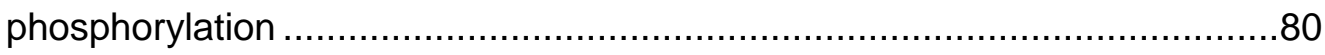

3.9.2 The RACK1 localization is not Fz7-dependent ....................................... 82

3.10 Is the PTK7/RACK1 interaction conserved during neural crest migration?........83

3.10.1 RACK1 and PTK7 are co-expressed in neural crest cells in Xenopus

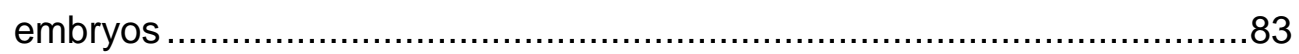

3.10.2 RACK1 regulates neural crest migration ............................................. 84

3.10.3 PTK7 shows a restricted localization pattern at cell-cell contacts in migrating neural crest cells.

3.10.4 PTK7 localizes at cell-cell contacts of two migrating single neural crest cells 
3.10.5 PTK7 localizes at cell-cell contacts in migrating single neural crest cells during contact inhibition of locomotion

3.10.6 $\triangle \mathrm{kPTK} 7$ accumulates at cell-cell contacts, in vesicles and at unspecific membrane parts

3.11 RACK1 and PTK7 co-localize in migrating neural crest (NC) cells..................96

3.12 PTK7MO and RACK1MO migration phenotype ........................................98

3.13 PTK7 but not RACK1 are required for Contact Inhibition of Locomotion ..........102

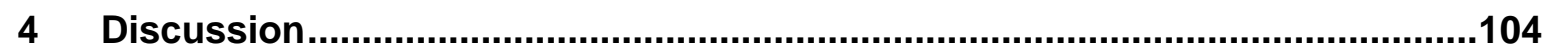

4.1 RACK1 and PTK7 mediate DSH localization and regulate PCP ...................104

4.2 RACK1 and PTK7 regulate neural morphogenesis...................................107

4.3 PTK7 and RACK1 function in neural crest migration................................110

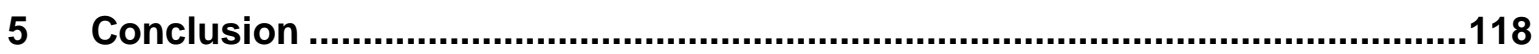

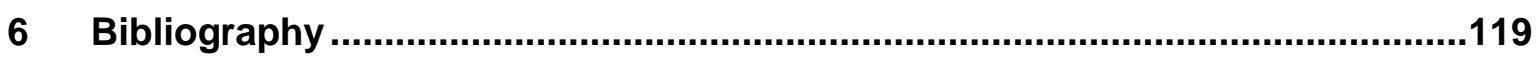

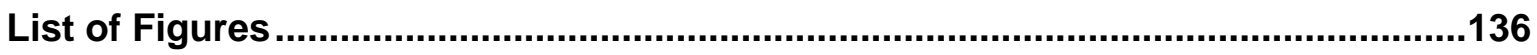

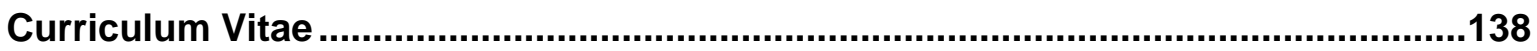

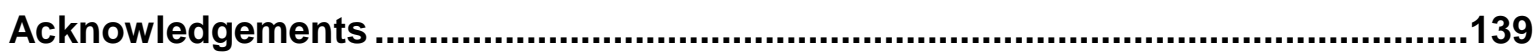




\section{Abbreviations}

A

APS

Aqua dest.

$\mathrm{Bp}$

BSA

C

${ }^{\circ} \mathrm{C}$

cDNA

CE

CHAPS

CIL

$\mathrm{cm}$

C-terminus

Cys

d

DAPI

DFA

dH2O

DNA

dNTP

DTT

E. coli

e.g.

EDTA

et al.

$\mathrm{EtBr}$

FCS

Fig.

fw

g

G

GFP

Gln

GOF

$\mathrm{h}$

HA

His

Hyb-mix

i.e.

$\lg$

$\mathrm{K}$

$\mathrm{kb}$

LOF

$\mathrm{M}$

$\mathrm{mA}$
Adenine

Ammonium Persulfate

aqua destillata

Base pairs

Bovine serum albumin

Cytosine

Degrees Celsius

Copy DNA

convergent extension

3-((3-Cholamidopropyl)dimethylammonio)-1-

Propanesulfonic Acid

contact inhibition of locomotion

Centimeter

Carboxy-terminus

Cystein

$\operatorname{day}(\mathrm{s})$

4',6-Diamidino-2-Phenylindole

Danylchik's for Amy

distilled water

Deoxyribonucleic acid

Deoxynucleotide triphosphate

Dithiothreitol

Escherichia coli

exempli gratia

Ethylendiamin-tetra-acetic acid

et alii

Ethidium bromide

Fetal calf serum

Figure

forward

Gram

Guanine

green fluorescent protein

Glycin

gain-of-function

Hour

HA-tag

Histidine

Hybridization mix

id est

Immunoglobulin

Lysine

Kilo base pairs

loss-of-function

Molar

Milliampere 


\begin{tabular}{|c|c|}
\hline $\mathrm{mg}$ & Milligram \\
\hline $\mathrm{MgCl}_{2}$ & Magnesium chloride \\
\hline $\min$ & Minute \\
\hline $\mathrm{ml}$ & Millilitre \\
\hline $\mathrm{mm}$ & Millimeter \\
\hline $\mathrm{mM}$ & Millimolar \\
\hline mRNA & messenger RNA \\
\hline MT & Myc-tag \\
\hline NT & neural tube \\
\hline NTC & neural tube closure \\
\hline$\mu g$ & Microgram \\
\hline$\mu l$ & Microlitre \\
\hline$\mu \mathrm{m}$ & Micrometer \\
\hline$\mu \mathrm{M}$ & Micromolar \\
\hline NEB & New England Biolabs \\
\hline $\mathrm{nm}$ & Nanometer \\
\hline $\mathrm{nM}$ & Nanomolar \\
\hline $\mathrm{N}$-terminus & Amino-terminus \\
\hline PBS & Phosphate buffered saline \\
\hline PCP & planar cell polarity \\
\hline PCR & Polymerase chain reaction \\
\hline $\mathrm{pH}$ & potentium hydrogenium \\
\hline Pol & Polymerase \\
\hline rev & reverse \\
\hline RNA & Ribonucleic acid \\
\hline rpm & Rounds per minute \\
\hline $\mathrm{RT}$ & Room temperature \\
\hline S & Serine \\
\hline s & Second \\
\hline SSC & Standard sodium citrate \\
\hline $\mathrm{T}$ & Thymine \\
\hline $\mathrm{T}$ & Threonine \\
\hline TAE & Tris-Acetate-EDTA \\
\hline Taq & Thermus aquaticus \\
\hline TBE & Tris-Borate-EDTA \\
\hline TBS(T) & Tris-buffered saline (with Tween) \\
\hline Temp. & Temperature \\
\hline Tris & Tris-hydroxymethyl-aminomethane \\
\hline$U$ & Units \\
\hline UV & Ultra violet light \\
\hline $\mathrm{V}$ & Volt \\
\hline $\mathrm{v} / \mathrm{v}$ & Volume to volume \\
\hline$w / v$ & Weight to volume \\
\hline wt & wild type \\
\hline X-Gal & 5-Bromo-4-chloro-3-indoxyl-D- galact \\
\hline
\end{tabular}




\section{Abstract}

One of the most critical events during embryonic development is the formation of the nervous system. This process requires morphogenetic movements like the formation of the neural tube and the migration of neural crest cells. Failure of these cell movements results in severe phenotypes like open neural tubes and neurocristopathies. Currently the understandings of the signaling mechanisms controlling neural morphogenesis are limited. One set of genes that is known to affect neural tube closure and neural crest migration are regulators of planar cell polarity (PCP). Protein tyrosine kinase 7 (PTK7) is a regulator of planar cell polarity that is required for neural crest cell migration and neural tube closure. Analyzing the signaling mechanism of PTK7, it was found that PTK7 interacts with RACK1 (receptor of activated protein kinase $C 1$ ). In the following work the in vivo function of the PTK7/RACK1 interaction was analyzed in neural tube closure and neural crest migration. Like PTK7, RACK1 is required for Xenopus neural convergent extension, a cell movement crucial for neural tube closure. Furthermore, RACK1 loss-of-function leads to similar neural crest migration defects as PTK7 loss-of-function. On a molecular level, PTK7 recruits RACK1 to the plasma membrane and is required for the PTK7-mediated membrane localization of DSH in ectodermal explants. RACK1 facilitates the PTK7-DSH interaction by recruiting $\mathrm{PKC} \delta 1$, a known effector of $\mathrm{DSH}$ membrane translocation and convergent extension movements. These data place RACK1 in a novel signaling cascade that translocates DSH to the plasma membrane and regulates vertebrate neural morphogenesis movements. Interestingly, RACK1 and PTK7 also co-localize in migrating neural crest cells at cell-cell contact sides suggesting that the PTK7/RACK1 interaction also plays a role for neural crest migration. Furthermore, life-cell imaging shows a dynamic localization of PTK7 during neural crest migration. PTK7 was enriched at distinct membrane sections during collective cell migration. Moreover, PTK7 accumulates at cellcell contacts during the process of contact inhibition of locomotion (CIL) in single migrating cells. Loss-of-function data support the notion that PTK7 but not RACK1 is required for CIL. This suggests that PTK7 may mediate CIL via a RACK1-independent mechanism. In summary this work presents new evidences for the important role of RACK1 and PTK7 in the regulation of neural morphogenesis movements. 


\section{Introduction}

\subsection{Neural morphogenesis: An overview}

The most important phase during our lifetime is our embryonic development. One of the critical events that occurs during this period is the formation of the nervous system. This includes morphogenetic movements like the formation of the neural tube (NT) and in consequence the specification and migration of the neural crest (NC) cell population. The development of the central nervous system in vertebrates, including humans, starts with an initially flat sheet of neuroepithelial cells. Failure of nervous system formation results in severe malformation. Developmental defects of the neural tube are called neural tube defects defects and incorrect neural crest development results in neurocristopathies.

NT defects are the most common human birth defects and affect approximately 0.5-2 per 1000 pregnancies worldwide (Botto et al. 1999). In Europe more than 4500 pregnancies each year result in neural tube closure defects. Different neural tube defects occur when various parts of the neural tube fail to close. As the anterior and the posterior neuropore of the NT are the last regions which closed most of the neural tube defects arise there. If the anterior region is affected this phenotype is called anencephaly, which means "without brain". In such a case the forebrain is degenerated resulting in a lethal condition. Failure to close the posterior region causes a phenotype that is called spina-bifida (Fig.: 1). When this has happened the spinal canal is not closed. The most severe phenotype is caused by failure to close the entire neural tube and is named craniorachischisis. The same phenotype also exists in mice. The reasons for such high numbers of malformations are based on environmental and genetic factors. For example the essential vitamin folic acid is known to be important during the first 9 days of embryonic development and a lack of it results in $50-70 \%$ of NT defects (MRC 1991). About 30\% may be caused by genetic reasons since they appear to be resistant to folic acid (Wallingford 2005).

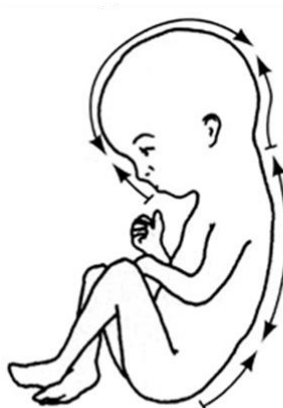

Normal

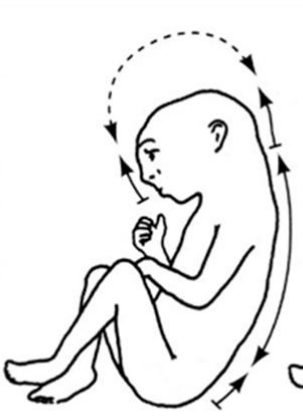

Anencephaly

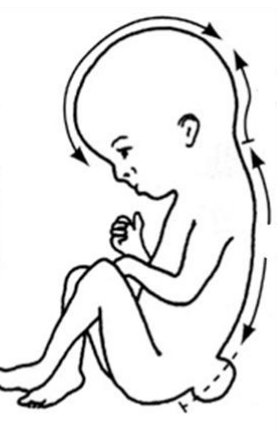

Spina bifida
Figure 1. Different neural tube defects in human development. Depiction of defects of neural tube closure in human embryos: Anencephaly if the anterior region is affected and Spina bifida in the posterior region (modified from (Gilbert 2000)). 
Currently our understanding of the genetics of human neural tube defects is limited. Over all, it is rather not possible to study such defects in humans but several animal systems could help to identify relevant genes. A primary goal is to gather a detailed understanding of the molecular mechanisms of NT defects, which genes are involved and how they are regulated. The challenge is that this complex network of processes integrates both precise timing and levels of signaling activity during the formation of complex tissues in vertebrates. The precise time and space dependent expression of genes could only be clarified with the help of several animal models. Thanks to their genetic and physiologic similarity to humans, mouse models represent a powerful tool to discover the complexity of NT defects (Harris and Juriloff 2007) and more than 240 mutants and strains that contribute to neural tube defects have already been discovered (Harris and Juriloff 2010). With the help of these mutants, genes were identified that are required for embryonic neural tube closure. Indeed, it could be shown that missense variants in the genes cadherin-EGF-LAG-seven-pass-G-type receptor 1 (CELSR1) and scribble (SCRIB) may represent a cause of craniorachischisis (CRN) in humans and in mice (Robinson et al. 2012). In mouse, protein trafficking to the plasma membrane is defective and represents a likely defect causing mechanism. It is surprising that from 150 genes in mouse known to be involved in NT closure, only genes associated with the planar cell polarity (PCP) pathway are linked to the CRN phenotype (Harris and Juriloff 2010). PCP is a prerequisite for organized cell movement and describes the polarity of cells in a plane of an epithelium which will be described later (Chapter 1.1.3). The PCP genes VANGL are the only genes in which mutations cause neural tube defects in human in several types of NT defects except CRN (Kibar et al. 2007; Kibar et al. 2009; Lei et al. 2010; Kibar et al. 2011). Several non-synonymous mutations in VANGL genes in patients with NT defects give evidence supporting the role of VANGL1 mutations as a risk factor in the development of spinal NT defects. Additional genetic factors could be involved to cause NT defect syndromes, consistent with a multifactorial model for NT defects. Other members of the PCP pathway are most likely candidates for involvement in NT defects. A systematic genetic and biochemical testing of their role in the etiology of NT defects is necessary (Bassuk and Kibar 2009).

An alternative animal model system which is also important to study NT defects is the African clawed frog Xenopus laevis. In Xenopus similar phenotypes exist where the embryos show open neural tubes. The PCP gene Strabismus regulates convergent extension and NT closure in Xenopus (Keller 2002). The analysis of such genes in Xenopus possibly identifies important other genes and molecules for the highly coordinated, complex and distinct processes during morphogenetic movements. As a model organism it offers many advantages. The most interesting advantage of Xenopus 
laevis is that the embryos develop outside of the living animal and their development can be easily followed by cultivation in a petri dish. The morphological changes that occur during embryonic development, like tissue movements and organ development, can be analyzed by various microscopic techniques. Also, the rapid embryonic life cycle till tadpole stage within four days offers outstanding opportunities in the range of the vertebrate animal models. Additionally, a large amount of embryos can be obtained from each frog and the size of the eggs with 1 to $2 \mathrm{~mm}$ offers advantages for manipulative experiments like tissue explantation and transplantation for example. After fertilization of the egg and many cleavage stages, gastrulation starts. One of the three formed germ layers during this early developmental phase evolves into the vertebrate nervous system. This work is focused on the following steps of embryonic development, especially the neural morphogenetic movements which influence the development of the nervous system. 


\subsubsection{Morphogenetic processes which are required for the generation of the nervous system}

\section{The mechanism of neural tube closure}

After several rounds of cleavage of the fertilized egg the embryonic cells divide and gastrulation starts. During gastrulation the three germ layers are formed. One of these layers is the ectoderm which develops into the vertebrate nervous system and the epidermis. A piece of the dorsal ectoderm is determined to become neural ectoderm and the development of the nervous system is initiated. This highly dynamic process starts with a flat sheet of thickened epithelial cells known as the neural plate. The formation and the following shaping of the neural plate tissue is called neurulation and forms the closed neural tube. The anterior region of the neural tube gives rise to the brain structures and the posterior region to the spinal cord. This period of embryonic development involves the coordination of cell shape changes, cell movements and genes that regulate morphogenesis by controlling the timing, direction and magnitude of cell behaviors that drive morphogenetic movements.

One complex process of neurulation is the primary neurulation, which is likely similar in all vertebrates (Harrington et al. 2009). It is mainly subdivided into formation of the neural plate, shaping and elevation of the neural plate, folding, bending and convergence of the neural plate and finally fusion and closure of the neural plate at the midline (Smith and Schoenwolf 1997; Colas and Schoenwolf 2001; Dias and Partington 2004). These different events are independent and controlled by distinct molecular pathways (Copp et al. 2003a; Wallingford and Habas 2005; De Marco et al. 2006). The formation of the neural plate starts with neural induction whereby the dorsal midline ectoderm differentiates into the neuroepithelium (Smith and Schoenwolf 1997; Colas and Schoenwolf 2001; Dias and Partington 2004). The following shaping of the neural plate involves conversion of this tissue into an elongated structure. The neural plate expands along the anterior-posterior axis and narrows by convergent extension (Keller 2002; Wallingford et al. 2002). Neural folds elevate and begin to move towards the midline (Fig.: $2 A)$. Bending of the neural plate includes formation of the neural folds and the elevation and convergence of these structures toward the dorsal midline (Fig.: 2B) (Colas and Schoenwolf 2001; Dias and Partington 2004). This movement involves the formation of hinge points at two specific areas. First the median hinge point (MHP), the only bending point at the upper spinal level, and second the dorsolateral hinge point (DLHP), which is formed in the lower spine and cranial region (Copp et al. 2003b). The MHP is located on top of the notochord and extends along the rostracaudal axis and the DLHP along the lateral sides of the folds and mainly at the future brain levels (Fig.: 2C) (Shum and Copp 
1996). After the hinge points are formed the folds on each side move up, rotate by elevation around the MHP to the dorsal surface and converge around the dorsolateral hinge points. The lateral folds from each side of the neural plate adhere to each other at the dorsal midline. This fusion process forms the roof of the neural tube and results in the formation of two different cells layers. One of them contributes to the skin of the back of the embryo and is called epidermal ectoderm and the other is the neuroepithelium where the neural crest derives from (Fig.: 2D) (Copp et al. 2003b). The neural tube is closed in a zipper-like fashion and forms a closed cylinder, which is separated from the epidermal ectoderm. The closure and forming of the neural tube does not occur simultaneously throughout the ectoderm. In mice (Copp et al. 2003b) and humans (Nakatsu et al. 2000; O'Rahilly and Muller 2002), multiple initiation sites of neural tube closure have been demonstrated.

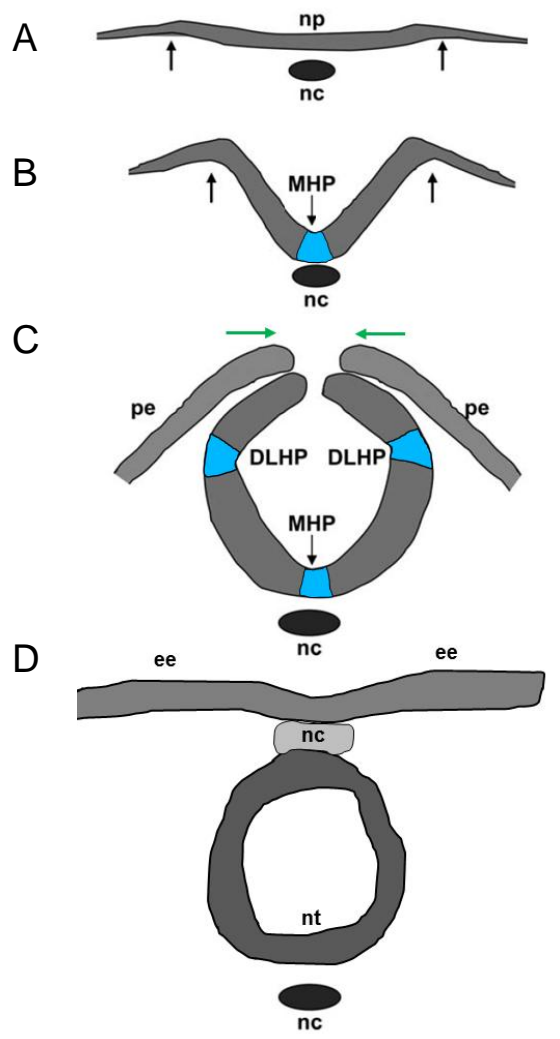

Figure 2. Schematic diagram of neural plate bending and closure of the neural tube. Neural folds form at the lateral extremes of the neural plate (A, arrows), elevate (B, arrows), converge toward the dorsal midline (C, green arrows) and form a closed neural tube (D). Bending or hinge points form at two sites: the median hinge point (MHP) overlying the notochord and the two dorsolateral hinge points (DLHP) at the lateral sides of the folds (C). The lateral folds adhere and result in the neural tube (D). nc, notochord; np, neural plate; pe, presumptive epidermis; ee, epidermal ectoderm; nc, neural crest; nt, neural tube (modified from (Kibar et al. 2007)). 


\section{The mechanism of convergent extension movements}

A crucial type of cell movement for NT closure is the convergent extension (CE) movement. This morphogenetic movement plays a basic role during early vertebrate development. For example, CE extends the anterior-posterior body axis during gastrulation and neurulation (Keller et al. 2000). Disturbance of this movement leads to several defects, like disruption of the anterior-posterior body axis elongation in mice (Wang et al. 2002; Lu et al. 2004; Ybot-Gonzalez et al. 2007), frogs (Glickman and Yelon 2002; Keller 2002; Myers et al. 2002; Keller and Shook 2008) and fish (Myers et al. 2002; Glickman et al. 2003) as well as gastrulation defects in amphibians (Schechtman 1942; Keller 1981; Cooper and Keller 1984). Additionally, failure of CE results in failure of neural tube closure in mice (Wang et al. 2002; Lu et al. 2004; Ybot-Gonzalez et al. 2007) and amphibians (Jacobson and Gordon 1976; Wallingford and Harland 2001; Goto and Keller 2002). On a cellular level CE describes the narrowing and lengthening of a field of cells (Kibar et al. 2007). In this complex process cells intercalate whereby a sheet of cells rearrange into a longer, narrowed array. At first the cells elongate mediolaterally and produce polarized cellular protrusions. This cell shape change enables the cells to move directionally and to intercalate with each other. The tissue along the midline converges and extends along the anteroposterior axis (Fig.: 3 left side). In the beginning, the wide and flat neural plate converts into a narrow and elongated one and extends the body axis (Keller 2002; Wallingford et al. 2002).

During embryonic development at the beginning of neurulation the embryo has a flat neural plate (Fig.: 3, upper picture). During this time the neural CE movement starts. This process contributes to the narrowing of the neural plate, thereby it enables NT fusion (Fig.:3, middle picture). At the same time the embryo starts to elongate (Fig.: 3 , middle picture compared to lower picture) (Wallingford et al. 2002).

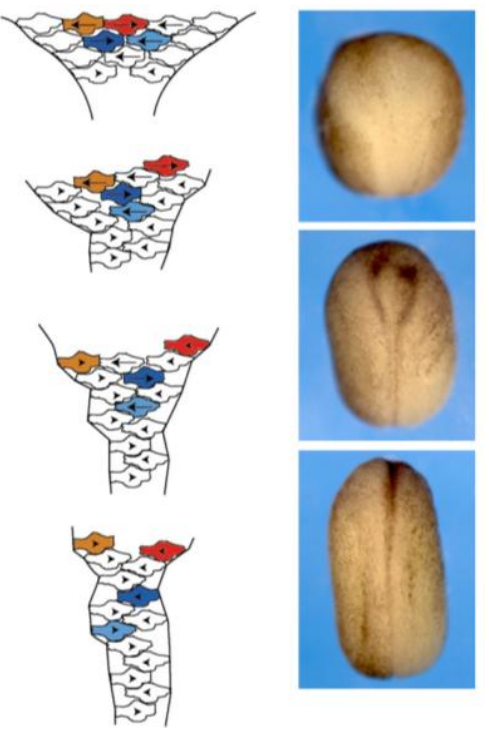

Figure 3. Schematic scheme of the morphogenetic process of convergent extension of the neural tube. Xenopus embryos at different stages of neurulation (right) compared to a scheme of the process of convergent extension movements (left) (modified after Wallingford et al. 2002). The cells get polarized, intercalate and converge relative to each other. These tissue rearrangements lead to the extension of the developing tissue in the anteriorposterior axis (from (Wallingford et al. 2002)). 


\subsubsection{Neural crest development}

Neural crest (NC) cell migration is another type of morphogenetic movement, which contributes to the development of the central nervous system. Neural crest cells provide an ideal model system to study cell migration as well as differentiation of pluripotent cells. The NC is a population of transient embryonic cells that originates at the dorsal part of the neural tube (Fig.: 4 A). They undergo an epithelial-mesenchymal transition (EMT) and start to migrate throughout the whole embryo and differentiate into various types of cells, like neurons, bone, connective tissue or pigment cells (Sadaghiani and Thiebaud 1987). These complex cell movements have to be precisely regulated by an evolutionarily conserved signaling network (Meulemans and Bronner-Fraser 2004; Sauka-Spengler et al. 2007; Sauka-Spengler and Bronner-Fraser 2008; Nelms and Labosky 2010). Indeed, missregulation in the complex sequence of events required for the induction, proliferation, migration and differentiation result in neurocristopathies, a large group of birth defects (Bolande 1997). Additionally, migrating neural crest cells show important similarities to cancer cell invasion and metastasis dissemination.

Neural crest cells migrate along precise pathways throughout the embryo (Serbedzija et al. 1989; Serbedzija et al. 1990; Serbedzija et al. 1992; Scherson et al. 1993; Knecht and Bronner-Fraser 2002). During these processes the neural crest cells migrate over long distances on defined pathways through the whole embryo (Fig.: 4 B) to give rise to a multitude of derivatives (Fig.: $4 \mathrm{C}$ ). While they migrate they are exposed to multiple factors including a large number of positive and negative regulators that control their motility and directionality to reach a precise location. These factors include positive and negative cell taxis, cell-cell interactions mediating cell sorting, cell cooperation, and contact-inhibition of locomotion (CIL). Although guidance cues have been identified, the signaling mechanisms that regulate neural crest migration and differentiation remain poorly understood. Understanding how NC cells interpret multiple inputs to regulate cell migration will help to clarify pathological situations. 


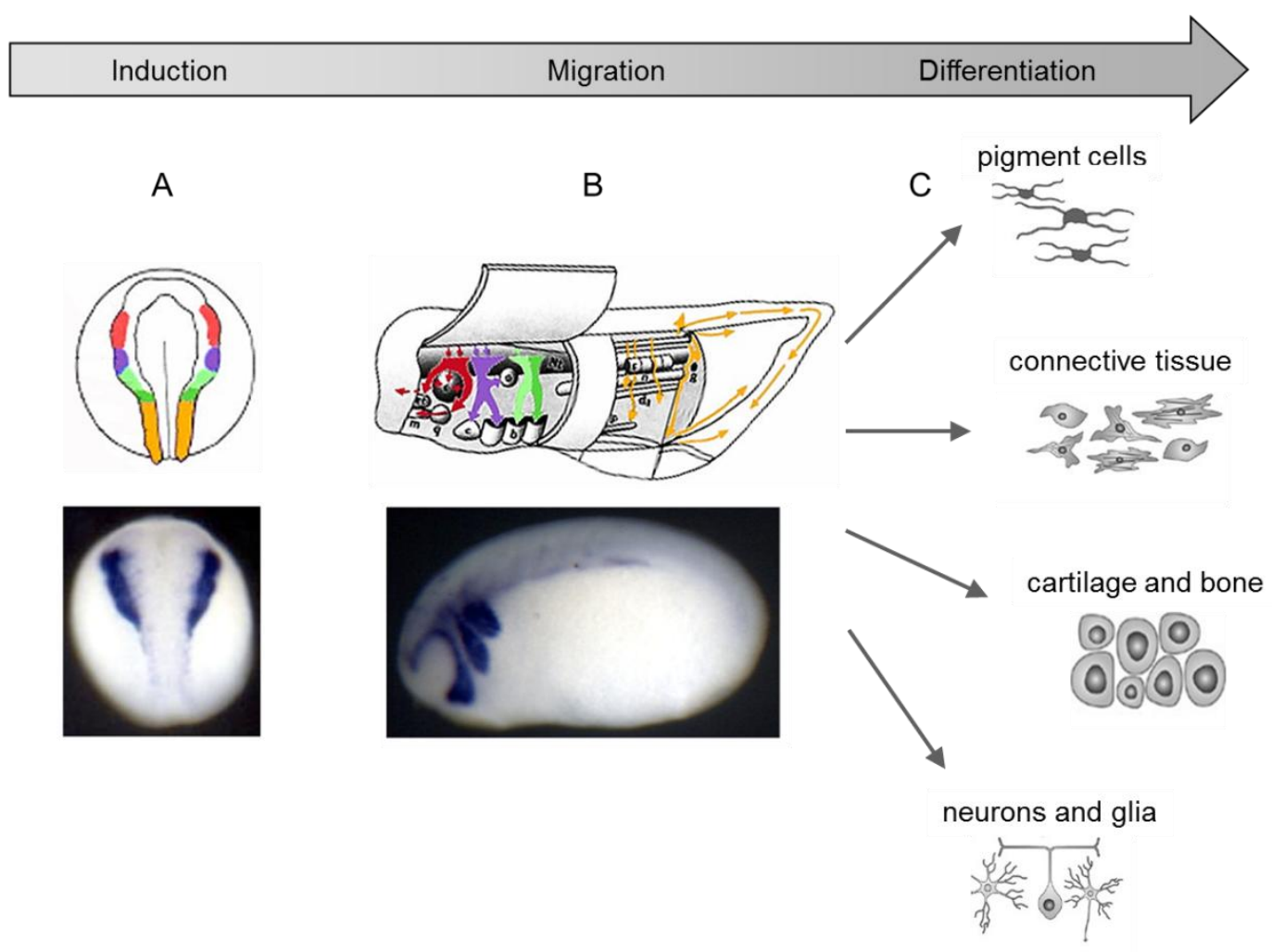

Figure 4. Cell migration of the pluripotent neural crest cells give rise to a variety of cell types. A) Neural crest cells are induced at the border of the neural plate migrate throughout the body (B) and develop into many different cell types (C). The cranial neural crest for example develops into neurons and glia, cartilage and bone as well as connective tissue or pigment cells. Lower pictures show in situ hybridization pictures of Xenopus embryos which show the expression pattern of a gene that is specifically expressed in the area of cranial NC cells (modified from (Mayor 1999 and Knecht and Bronner-Fraser 2002)). 


\section{The mechanism of neural crest induction}

Before migration can start the neural crest (NC) cells have to be induced at the border of the neural plate (NP) between the neuroepithelium and the prospective epidermis (E) along the antero-posterior axis. These formed boundaries between the two regions gives rise to neural crest (NC) precursor cells (Fig.: 5, left) and can be distinguished by the expression of diverse markers for example snail, slug and twist, which are specifically expressed in neural crest cells of mouse, chick, zebrafish and Xenopus (Thiesen and Bach 1993; Nieto et al. 1994; Mayor et al. 1995; Sefton et al. 1998; Linker et al. 2000). The process of induction is initiated by signals coming from the surrounding epidermis the neural plate and the underlying mesoderm (Raven 1945; Mayor et al. 1995; Selleck and Bronner-Fraser 1995; Mancilla and Mayor 1996; Bonstein et al. 1998).

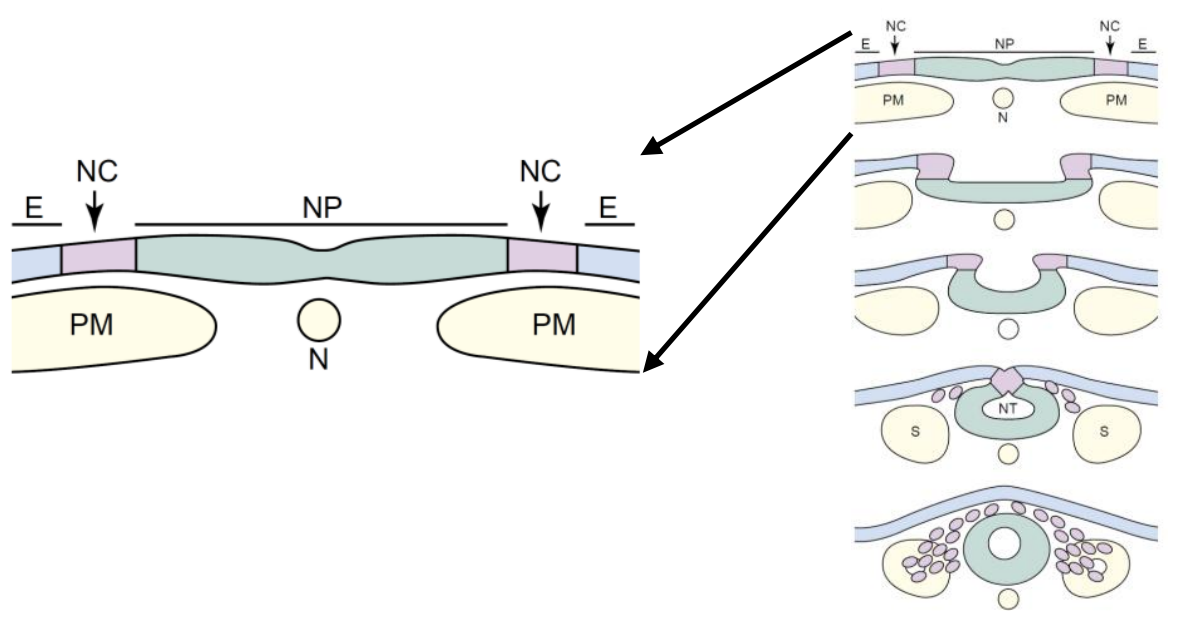

Figure 5. Schematic representation of neural crest formation in vertebrates. During neurulation, the ectoderm is divided into three sets of cells: the internally positioned neural plate $(N P)$, the externally positioned epidermis (E) and the prospective neural crest cells (NC) at the border between the two. Interactions between the neural plate and the surrounding epidermis are believed to specify the neural crest. Signals derived from the underlying paraxial mesoderm (PM) are also involved. During or after neural tube (NT) closure, neural crest cells migrate (the time of migration varies among different species) to diverse locations throughout the embryo. When they reach their destinations, neural crest cells differentiate into a large variety of cell types. $\mathrm{N}$ : notochord; S: somite (modified from (Wu et al. 2003)).

The border of the neural plate and the formation of neural tissue are specified by a gradient of bone morphogenetic proteins (BMP) (Neave et al. 1997; Wilson et al. 1997; Marchant et al. 1998; Nguyen et al. 1998; Knecht and Bronner-Fraser 2002). High levels of BMP signaling induce epidermis and if the BMP level is low or absent this leads to neural induction (Sasai et al. 1995; Wilson and Hemmati-Brivanlou 1995; Sasai and De Robertis 1997; Weinstein and Hemmati-Brivanlou 1997). Later a combination of Wnts, fibroblast growth factor (FGFs) and retinoic acid (RA) transform the border of the neural plate and induce NC cells (Barembaum and Bronner-Fraser 2005; Steventon et al. 2005). 


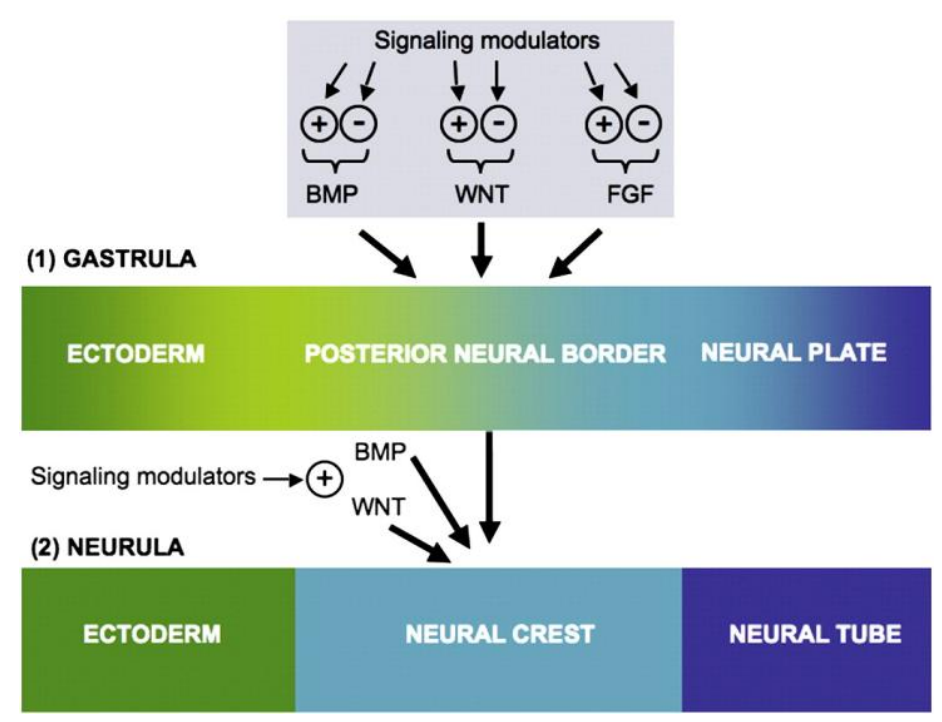

Figure 6. Combination of signals pattern the neural border during gastrulation and neurulation. Neural border and neural crest patterning is a highly dynamic process, which involves the action of secreted signals. Several signaling pathways (BMP, WNT, FGF, Notch) act together and define the posterior neural border and the neural crest. Modulators of these signals are activated during gastrulation or neurulation and their action is crucial to achieve correct spatial and temporal patterning (from (Milet and Monsoro-Burq 2012)).

A precise timing of all the signals is a prerequisite to establish the neural border and neural crest induction. Starting with a first set of genes induced at the neural plate border called cell specification or neural plate border specifier genes. They are expressed in a broader range that includes prospective epidermal and neural plate cells and are not only restricted to the prospective NC. During gastrulation the first phase of neural border and neural crest induction is initiated by BMP inhibition (Mayor et al. 1995; Marchant et al. 1998). This time dependent BMP activity is changed along the anterior-posterior axis and is partly regulated by BMP antagonists such as Noggin, Chordin, Follistatin, Cerberus secreted from the node/organizer (Harland 2000; Ohta et al. 2004), which shape the initial BMP gradient to improve neural border positioning (Fig.: 6) (Tucker et al. 2008). During this step other molecules than BMP, like FGF, RA and Wnt, also involved in the anteriorposterior patterning of the neural tube and able to induce the NC-fate in the neural folds. The fine-tuned modulation of these signals induces the expression of neural plate border specifier genes and further neural crest induction (Linker and Stern 2004; Delaune et al. 2005; Steventon et al. 2005; Sauka-Spengler and Bronner-Fraser 2008).

These second group of genes includes transcription factors, Msx, Dlx, Pax3, Myc, Zic and AP2- $\alpha$ and are called cell survival or NC specifier genes and their expression is restricted to the prospective NC cells and controls their survival (Steventon et al. 2005; SaukaSpengler and Bronner-Fraser 2008). Further NC specification requires concurrent increased BMP and Wnts (Patthey et al. 2009; Steventon et al. 2009). 
The third and last groups of genes have been called NC effector genes and are targets of the two earlier groups of genes. This gene group is involved in the last steps of migration and differentiation and encodes transmembrane signaling molecules, like cadherins, integrins and neuropilins, secreted matrix metalloproteases, and intracellular proteins for example RhoB, which is involved in cytoskeletal rearrangements. All of these molecules promote delamination and migration of the neural crest cells (Kuriyama and Mayor 2008; Sauka-Spengler and Bronner-Fraser 2008).

\section{The mechanism of epithelial-mesenchymal transition}

After induction, the premigratory NC cells emigrate from the neural tube (Fig.: 7A). Beforehand all NC cells undergo a process called epithelial-mesenchymal transition (EMT). They change from an epithelial to a mesenchymal phenotype, which is orchestrated by a series of events at the molecular level (Thiery et al. 2009). In general this process includes a breakdown of the epithelial adhesion components, loss of apicobasal polarity, and rupture of the basement membrane (bm) which lead to mesenchymal motility (Fig.: 7 B). Interestingly, this process shows parallels to cancer cells during tumor progression (Thiery 2002; Kuriyama and Mayor 2008). This complex process leads to changes in gene expression, cell morphology and cell surface and recognition molecules (Fig.: $7 \mathrm{C}$ ). After EMT the NC cells delaminate from the neuroepithelium and migrate along precise and specific pathways.

The NC specifier genes snail and snail2 (also called slug) are key inducers of EMT.

Down regulation inhibits the transition from an epithelial to a mesenchymal cell behavior phenotype in NC cells (Nieto et al. 1992; Nieto et al. 1994; Nieto 2002; Cheung et al. 2005). Snail/Snail2 hast two roles during NC EMT, the induction of NC and its subsequent migration (LaBonne and Bronner-Fraser 2000). For example, direct transcriptional repression of E-cadherin by Snail leads to a loss of adherens junctions and cell polarity (Cano et al. 2000). Other factors, like members of the Rho family which are small Gprotein signaling molecules participate in multi-cellular functions like cellular morphology and motility changes by controlling the cytoskeleton rearrangements (Wheeler and Ridley 2004). For example neural crest cell treated with Rho inhibitors fail to emigrate from neural plate explants (Liu and Jessell 1998). Additionally, RhoA negatively regulates the expression of the NC genes Snail1, Snail2 and FoxD3 in Xenopus (Rupp and Kulesa 2007). The same transcription factors seem to mediate multiple functions during specification, depolarization and migration of NC (Fig.: $7 \mathrm{C}$ ) (LaBonne and Bronner-Fraser 2000; Cheung et al. 2005). 
Epithelial cells are bound to each other with desmosomes, tight-, adherens-, and gap junctions. They form an organized coherent apicobasally polarized cell layer (Fig.: 7 B, upper picture). The adherens junctions are cell-cell adhesion complexes which include calcium dependent cadherins and catenins. The extracellular domain of cadherins form homophylic bonds with cadherins from neighboring cells and the intracellular domains form a complex with catenin proteins. Catenins are connected with the actin cytoskeleton, microtubule cytoskeleton or both to sustain adhesion (Etienne-Manneville 2011). The types of cadherins in epithelial and mesenchymal cells are different. The switch from cadherins expressed preferentially in stable epithelial cells to the expression of mesenchymal cadherins during EMT, drives increased cell motility (Fig.: 7 B, middle picture) (DeLuca et al. 1999). As an example, premigratory depolarized NC cells expressing $\mathrm{N}$-cad first to Cad6B and later to Cad7in chick and Cad 11 in Xenopus (Nakagawa and Takeichi 1995; Hadeball et al. 1998; Vallin et al. 1998; Borchers et al. 2001; Kuriyama and Mayor 2008). The neuroephithelial cells express a cadherin Cad6B which is crucial for loss of polarity in cells during EMT to transforms a cell into a mesenchymal cell type. The degradation of this protein is needed for proper migration of NC cells (Taneyhill et al. 2007; Park and Gumbiner 2010).

These complex changes at the cellular and molecular level during EMT lead to cells with less polarity which could now quickly respond to environmental cues. The cells move as individuals and communicate with neighboring cells to coordinate their movements.

A
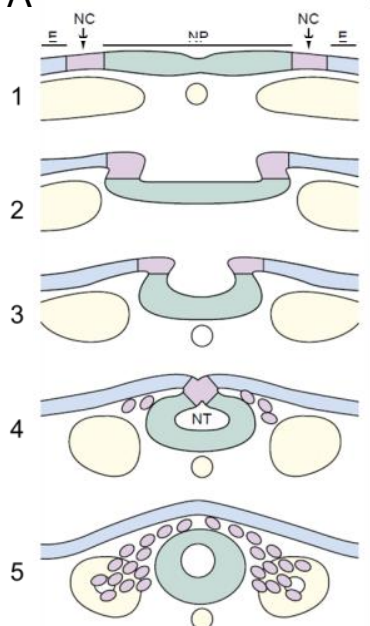

B

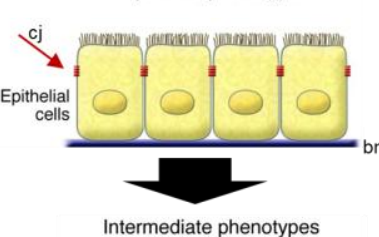

as cells transition
asmediate phenotypes

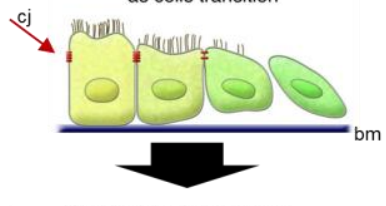

Mesenchymal phenotype
C

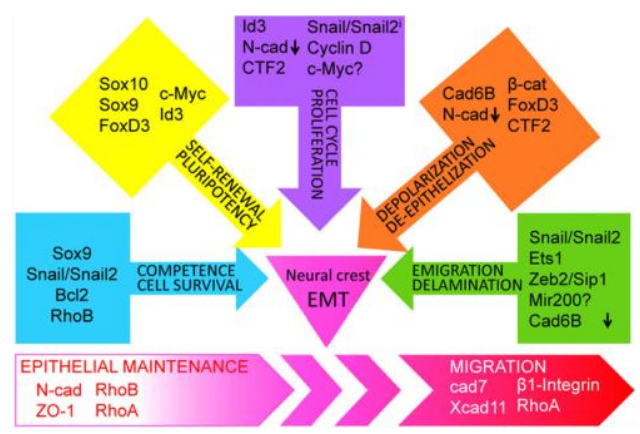

Figure 7. Steps till NC migration and the process of EMT. A) (A 1-5) Different steps till NC migration. 1) Induction; (2, 3) Loss of polarity; (4) changes in cell adherence and cytoskeleton; (5) epithelial mesenchymal transition and migration. (purple: NC cells; blue: epidermis (E); green: neural plate (NP) / tube (NT) (from (Wu et al. 2003)). B) Principle of the process during EMT. cj: cell junctions; bm: basement membrane (from Kalluri and Weinberg 2009). C) The separate subdivisions of EMT that all need to be completed for the proper amount of multipotent neural crest cells to emigrate from the neural tube and is an outline based the results of multiple studies obtained in several species (from (Kerosuo and Bronner-Fraser 2012)). 


\section{Neural crest cell migration}

After the NC cells have undergone EMT they separate from their surrounding tissues. The cells start to migrate following specific pathways throughout the whole embryo as a continuous wave of cells away from the neural tube (neuroepithelium) and split relatively quickly into distinct streams (Fig.: 8) (Horstadius 1950; Kalcheim et al. 1999; Hall 2008; Theveneau and Mayor 2011). The NC cells migrate not only in the branchial region but also in the trunk of the vertebrate embryo. The specific pattern formed differs slightly between different species. As we used Xenopus as a model system and we are especially interested in the cranial NC cells, the migration of Xenopus cephalic NC cells will be explained exemplarily.

Migration of Xenopus cephalic NC cells starts around stage 19 all over the cephalic region. Around stage 22, three clusters next to the neuroepithelium are formed. These clusters are reminiscent of streams although no clear NC-free regions in between are formed at this developmental time point. Later on at stage 25 the premigratory cephalic NC cells become segmented into three streams called mandibular ( $m$ ), hyoid (h) and branchial (b) streams, separated by NC-free regions (Fig.: 8) (Sadaghiani and Thiebaud 1987; Bradley et al. 1993; Smith and Schoenwolf 1997).

These organized cell movements where NC cells are restricted prior and during migration must be highly regulated. Mechanisms seem to exist to guide the cells into specific pathways.

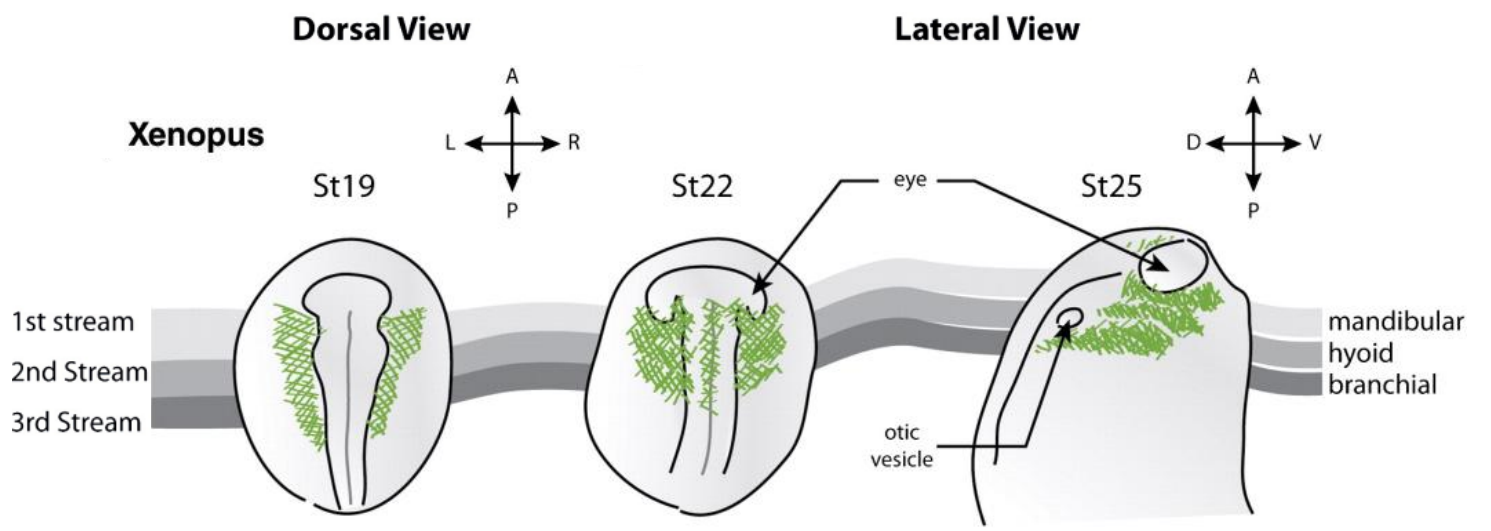

Figure 8. Early migration steps of cephalic NC cells in Xenopus. Stage 19) Migration of cephalic NC cells starts around this stage at the cephalic region. Stage 22) Three clusters of NC cells are visible but they are not yet separated. Stage 25) NC cells are now divided in three separated streams, the mandibular $(\mathrm{m})$, hyoid $(\mathrm{h})$ and branchial $(\mathrm{b})$ streams. Streams in Xenopus are coded in different levels of gray and the orientation of the embryos at different stages is indicated. Standard Nieuwkoop and Faber stages of Xenopus embryos were used (modified from (Theveneau and Mayor 2012)). 


\section{Molecular control of cranial neural crest cell migration}

During their migration through the cranial region of the embryo, the cells have to move in a tight environment between the epithelial and mesodermal sheets and split into separate subpopulations. During this migration the NC cells integrate external signals present in the surrounding tissue. This could be guidance cues and/or the contact with other NC cells, which express different proteins at their surface. Overall, a complex set of negative and positive external regulators controls the cephalic NC cell migration.

The set of negative regulators has been mainly attributed to two classes of signaling molecules: ephrin and their Eph receptors and class3-semaphorins and their neurophilin/plexin receptors. Ephrin/Eph belongs to the family of receptor tyrosine kinases, which are activated by binding of their specific ligand. This ephrin/Eph code regulates motility at the cellular level (Davy et al. 2004; Kuriyama and Mayor 2008). The NC cells have different ephrin/Eph profiles as the surrounding tissue. This separates the tissues into migratory stream areas and forbidden areas. Additionally, Ephrin signaling targets specific subpopulations of NC cell to a specific migratory stream. Inhibition of ephrin/Eph signaling results in disturbed migration outside of distinct streams (Smith et al. 1997). This signaling is required to form areas where no NC cells are present and target specific NC cells to a specific migratory stream.

The class3-semaphorins bind to neuropilins which are part of a receptor complex where neuropilin 1 and 2 (Nrp 1/2) are associated with members of the plexin family. Plexin is required for intracellular signaling in this complex (Kruger et al. 2005; Eickholt 2008; Jackson and Eickholt 2009). Several studies in different model organisms like mouse, chick and zebrafish show that several members of the class3-semaphorins are involved in the formation of discrete streams of NC cells (Eickholt et al. 1999; Osborne et al. 2005; Gammill et al. 2007; Schwarz et al. 2008). If this complex signaling is affected the NC cells migrate to areas in between the streams where normally no NC cells are present.

The set of positive regulators of cranial NC migration includes two types of molecules. First, the permissive factors that advance motility in a general manner and second, the chemoattractants, which drive NC cells to specific destinations. The chemokine stromal cell-derived factor 1 (Sdf1) is likely the best candidate for a NC chemoattractant (Theveneau et al. 2010). During migration Sdf1 is expressed in the head of Xenopus, zebrafish and chick and at the same time one of its receptors, Cxcr4 is expressed by the cephalic NC cells (Yusuf et al. 2005; Rehimi et al. 2008; Olesnicky Killian et al. 2009; Theveneau et al. 2010). Several studies could show that Sdf1 is an attractant for several migratory cell populations. For example, in zebrafish it is required for cranial neural crest migration (Olesnicky Killian et al. 2009) and in Xenopus sources of Sdf1 are sufficient to guide NC cells in vitro and in vivo (Theveneau et al. 2010). Additionally, the Sdf1/Cxcr4 
signaling is crucial for cephalic NC migration and stabilizes cell protrusions in NC cells via activation of small GTPase Rac1.

Another so called positive regulator of cranial NC migration is Cadherin-11. This molecule is expressed in Xenopus NC cells and its cleavage caused by ADAM13 is essential for NC migration (Vallin et al. 1998; Borchers et al. 2001; McCusker et al. 2009). It is likely that it is required during the establishment or reinforcement of cell polarity, because it might modulate RhoGTPases by binding to Trio, a Guanine nucleotide factor (Kashef et al. 2009). Although different attractant and repellent molecules, which are a prerequisite for normal development have been identified (Fig.: 9) many open questions remain.

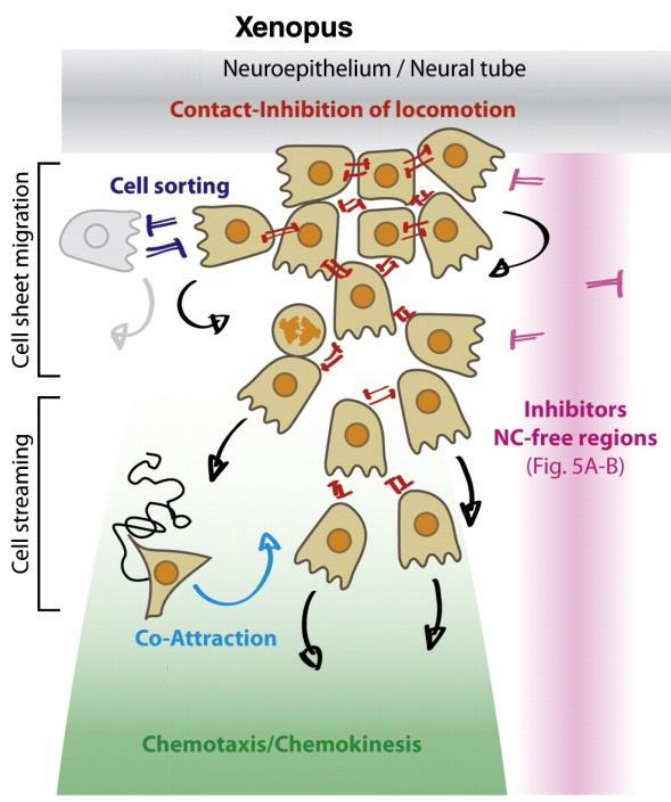

Figure 9. Cell-cell interactions and external signals regulating neural crest cell migration. Xenopus NC cells undergo EMT and start to migrate in a sheet of cells. The cells inside the cluster show no polarity. As migration starts, the cell population switches from epithelial to a mesenchymal. The cells located at the border of the cluster now show cell polarity including protrusion formation and migration turns into a cell streaming. Cell-cell contacts between cells and sensing of external cues is essential for coordinated migration. Different attractant and repellent molecules are depicted by different colors (modified after (Theveneau et al. 2010) and (CarmonaFontaine et al. 2011)). 


\subsubsection{PCP signaling and developmental processes}

A prerequisite for organized cell movement is that cells know their position within a tissue. This phenomenon is described as planar cell polarity (PCP) and describes the polarity of a cell in the plane of an epithelium. The cells are aligned from proximal to distal and this orientation is orthogonal to the apical basal polarity. Cells with such a polarity are highly organized in a regular pattern. The polarity is present in every cell, which leads for example to the asymmetric distribution of cell structures like hairs in the whole epithelium. The hairs in this polarized tissue are all located in the apical part of each cell at the distal side and additionally point all into a distal direction (Fig.: $10 \mathrm{~A}$ ). This type of polarity was first found and studied in Drosophila (Klein and Mlodzik 2005; Seifert and Mlodzik 2007; Bayly and Axelrod 2011).
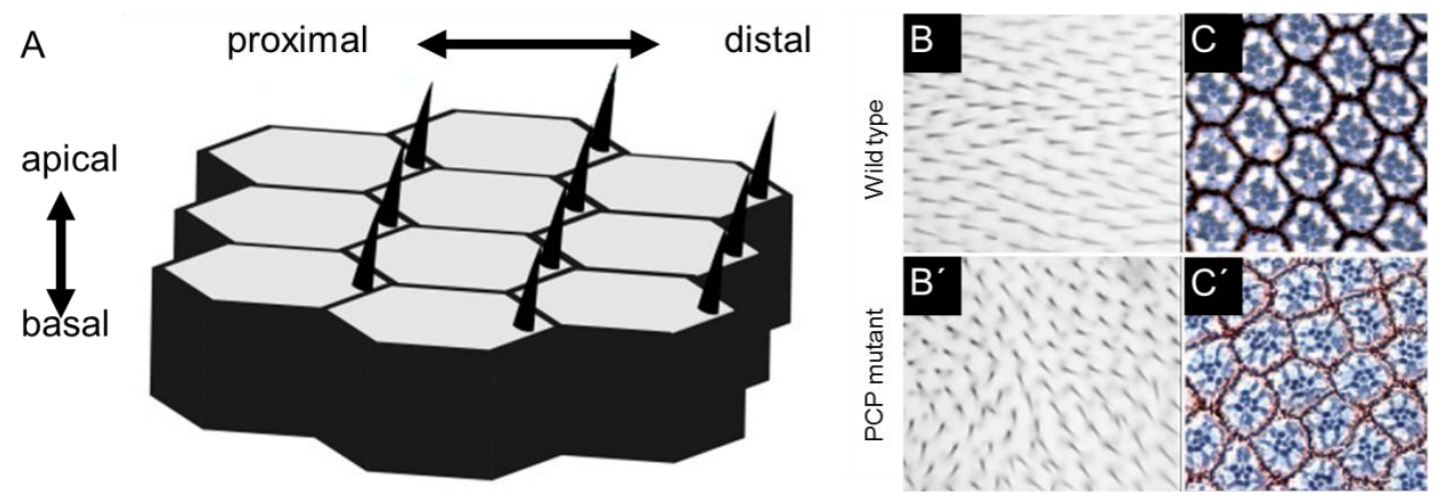

Figure 10. Planar cell polarity in the Drosophila wing and ommatidia. A) Epithelial tissues show orthogonal to the apical-basal the planar polarity. Hair structures demonstrating asymmetry along the apical-basal axis. The hair structures are generated at the top of the cells which is the apical surface. PCP is visualized by the fact that the hairs are only located at the distal side of each cell and point into the distal direction. (modified from (Marcinkevicius et al. 2009)) B, B') Proximaldistal orientation of Drosophila wing hairs (from (Zallen 2007)). B) In wild type wing hairs point distally. B') In PCP mutants wing hairs have disrupted orientation and form swirls and waves. C, C') Photoreceptor orientation in Drosophila eye ommatidia. C) Ommatidia in the Drosophila eye are arranged in a specific pattern. Each ommatidium in the Drosophila eye has eight photoreceptor cells, which are also specifically arranged. C') PCP mutant the arrangement of photoreceptors in each ommatidium and in the whole eye are disrupted (from (Seifert and Mlodzik 2007)).

PCP has been first documented in Drosophila, where it regulates the orientation of hair cells in the fly wing and ommatidia in the eyes (Vinson and Adler 1987; Adler 1992; Zheng et al. 1995). After analyzing these mutants, it was found that PCP is established by a noncanonical Wnt signaling pathway, which includes core components like frizzled (Fz) (Vinson and Adler 1987; Theisen et al. 1994), dishevelled (DSH) (Theisen et al. 1994), Vang-like (Vangl) (Taylor et al. 1998; Wolff and Rubin 1998) and prickle (Pk) (Gubb et al. 1999). A typical example could be shown in flies mutant for the membrane protein Frizzled (Fz). Such flies show a disturbed orientation of the hairs on the wing, which is a typical 
PCP phenotype (Fig.: $10 \mathrm{~B}^{\prime}$ ). The wings of wild type (WT) flies show that all the hairs in the epithelial cells are aligned to each other and point in the distal direction (Fig.: $10 \mathrm{~B}$ ). The same phenotypes occur if the PCP "core" proteins disheveled (DSH) and prickle (pk) are mutated (Wong and Adler 1993; Klein and Mlodzik 2004). Another example in flies is the ommatidial pattern in the Drosophila eye, were the ommatidia are arranged in a typical pattern. Each ommatidium has eight photoreceptor cells, which are also arranged to each other (Fig.: $10 \mathrm{C}$ ). PCP mutants do not show this specific pattern (Fig.: $10 \mathrm{C}^{\prime}$ ).

In higher vertebrates a phenomenon similar to PCP has been identified. Proteins related to members of the PCP pathway are asymmetrically distributed within the cells (Wang and Nathans 2007; Rida and Chen 2009) and inhibition of the PCP pathway leads to specific phenotypes. In mouse, PCP defects lead to misoriented hair follicle cells in the skin. In WT mice the hairs are aligned and have a distal orientation (Fig.: $11 \mathrm{~A}$ ), while in PCP mutant mice, with mutated $\mathrm{Fz}$ protein the hair orientation is disturbed and forms waves and swirls (Fig.: $11 \mathrm{~A}^{\prime}$ ). Additionally, in mice with disturbed PCP pathway the sensory bristles in the cochlea inner ear are not in line (Dabdoub et al. 2003; Dabdoub and Kelley 2005; Qian et al. 2007). These bristles generate bundles of actin-based stereociliar polarized in a structured pattern (Fig.: $11 \mathrm{~B}$ ). The polarity and distribution of these bundles is randomized in PCP mutants (Fig.:11 $\mathrm{B}^{\prime}$ ).

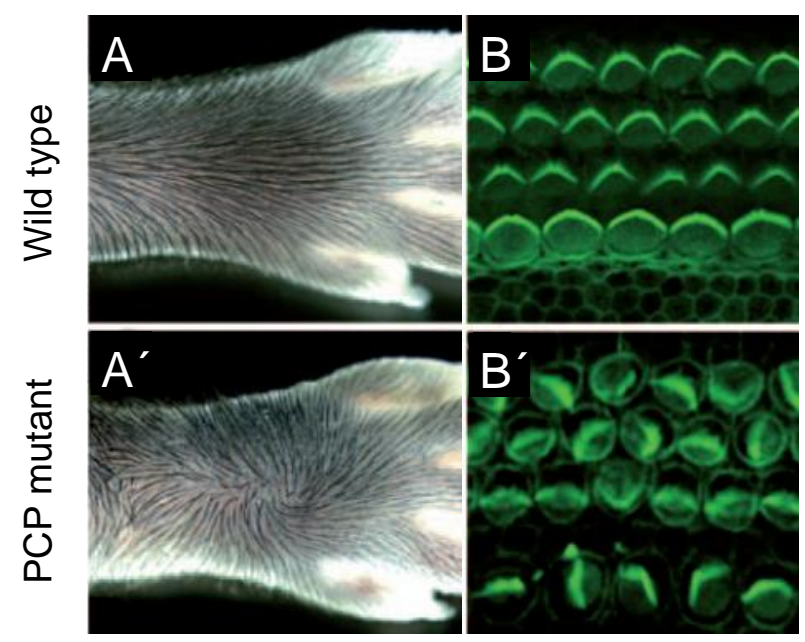

Figure 11. Processes regulated by the PCP signaling pathway in mammals. $A, A^{\prime}$ ) Proximaldistal orientation of mouse hairs. A) In a wild type mouse, hairs uniformly point in distal direction. $A^{\prime}$ ) In a PCP mutant mouse, hairs form swirls and waves. A Fz6 mutant mouse paw is shown. B, $\left.B^{\prime}\right)$ Sensory hair cells in mouse inner ear generate organized bundles of actin-based stereocilia (actin is labeled in green through phalloidin staining). B) In a wild type mouse, inner ear actin bundles are polarized. $\mathrm{B}^{\prime}$ ) In a Vangl2 PCP mutant mouse, inner ear actin bundles are randomly distributed and polarity is lost (from (Seifert and Mlodzik 2007)). 


\section{PCP in various cell contexts}

\section{Molecular mechanism of non-canonical Wnt signaling pathway}

The core PCP genes have a conserved role in the regulation of PCP in many aspects of development (Wang and Nathans 2007). The asymmetric localization of core PCP proteins is a prerequisite for changes in cell morphology (Vladar et al. 2009), but the initial establishment of the PCP pathway is not completely understood. In vertebrates some members of this conserved regulatory pathway interact with different Wnt molecules to establish PCP (Wallingford et al. 2002; Wallingford and Harland 2002; Wang and Nathans 2007; van Amerongen and Berns 2008). However, in Drosophila loss-of-function (LOF) and gain-of-function (GOF) of different or multiple Wnts caused no defects in PCP (McNeill 2010). Activation of this pathway is triggered by the binding of Wnts to the Fz receptor, which results in a translocation of DSH to the plasma membrane (Strutt et al. 1997; Boutros et al. 1998). The cytoplasmic domain of Fz activates DSH during this process (Axelrod et al. 1998; Rothbacher et al. 2000; Wong et al. 2003). DSH interacts with several members of the PCP pathway (Jessen et al. 2002; Park and Moon 2002; Bastock et al. 2003; Jenny et al. 2005; Wallingford and Habas 2005), which activates downstream signaling events. For example, DSH associates and activates Rac a small GTPase member, followed by an activation of the N-terminal jun kinase (JNK) (Boutros et al. 1998; Li et al. 1999; Habas et al. 2003). Furthermore, DSH is associated with DAAM1 (Disheveled-associated activator of morphogenesis 1), which activates RhoA and next ROCK (Rho associated protein kinase). This activates actin cytoskeleton rearrangements and actin polymerization, which drives morphogenetic cell movements (Habas et al 2001 (Habas et al. 2001) and determines epithelial polarity (Fig.: 12).

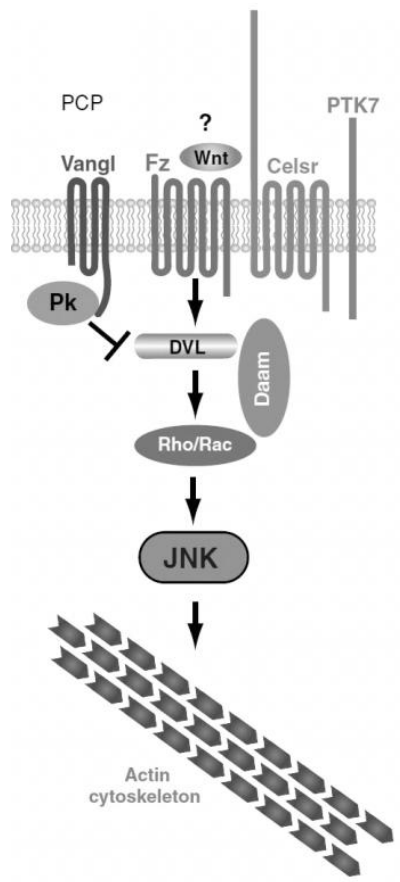

Figure 12. The non-canonical Wnt/Fz PCP pathway. The pathway is activated via Wnt and Fz. It includes different components like transmembrane molecules: Van Gogh like (vangl), Frizzled (Fz), Celsr, PTK7 and membrane associated molecules like Dishevelled (DVL, DSH) and Prickle (PK). After activation, DSH translocates to the plasma membrane and activates downstream signaling via the small GTPases Rho and Rac. This drives actin cytoskeleton rearrangement and establishes cell polarity. (modified from (Montcouquiol et al. 2006)). 
The role of PCP in the regulation of neural morphogenesis is demonstrated by neural tube and convergent extension defects.

Mutant mice with affected PCP core-PCP components, like Dvl1/2 and Dvl2/3, the mouse ortholog of Dsh (Hamblet et al. 2002), Vangl, the mouse ortholog of Vang (Kibar et al. 2001), Celsr1, the mouse ortholog of Fmi (Curtin et al. 2003), Fz3/6 (Wang et al. 2006) and PTK7 (Lu et al. 2004) show craniorachischisis, the most severe PCP phenotype, where the whole spinal cord remains open. As an example, mouse PCP mutants, which have a double mutation in Fz3/6 show such a phenotype (Fig.: 13)

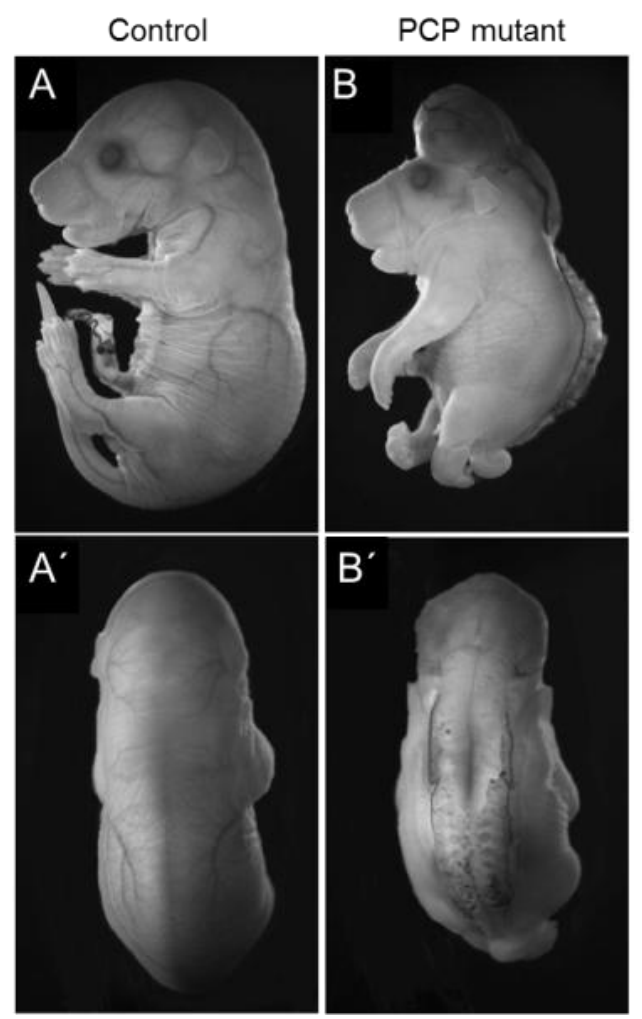

Figure 13. Mouse PCP mutants have open neural tube (craniorachischisis). Lateral $(A)$ and dorsal view $\left(A^{\prime}\right)$ of a wild type mouse embryo. In the wild type mouse the neural tube is completely closed. Lateral (B) and dorsal view ( $\left.\mathrm{B}^{\prime}\right)$ of a PCP mutant mouse embryo. In the PCP mutant mouse the neural tube remains open from the midbrain/hindbrain boundary throughout the whole spinal cord. Fz3/Fz6 mutant is shown (from (Wang et al. 2006)).

For the essential role of PCP signaling in convergent extension (CE) movements more and more evidence has been collected (Carmona-Fontaine et al. 2008a; Matthews et al. 2008; Roszko et al. 2009). The PCP pathway regulates the changes in the polarity of tissues and additionally the protrusion formation of the cells during CE (Fig.: 14). Involvement of PCP in CE in vertebrates could be shown using mutants and knock-down experiments in mouse, frog and zebrafish (Wallingford 2005; Barrow 2006; Montcouquiol et al. 2006). First evidences came from Xenopus experiments where the disruption of DSH caused CE defects, which led to disturbed NT closure (Sokol 1996; Wallingford et al. 2002). In mouse Vangl2, Scribble and PTK7 mutants show disturbed CE movements 
resulting in severe NT defects (Kibar et al. 2001; Murdoch et al. 2001; Montcouquiol et al. 2003; Lu et al. 2004). Zebrafish show a shorter anterior posterior axis if members of the PCP pathways are mutated, for example trilobite (Zebrafish homolog of Vang) (Jessen et al. 2002), pipetail (Wnt5) (Kilian et al. 2003) and silberblick (Wnt11) (Ulrich et al. 2003).

Communication between cells is a complicated process, which takes place during any kind of development, and in particular during gastrulation, the closure of the neural tube and the migration of neural crest cells. The cells receive, provide and recognize divers cues which drive cellular processes like direct movements by activation of the planar-cell polarity (PCP) pathway and others. To respond to signals the cell has to use receptors which allow the cell to trigger intracellular processes.
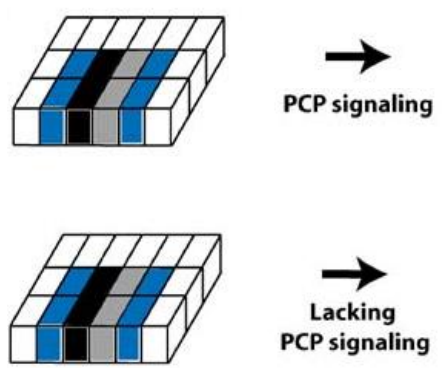
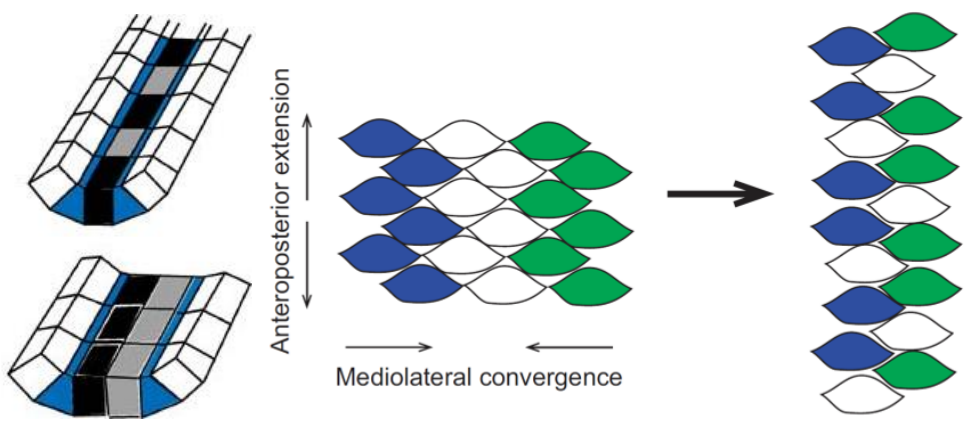

Figure 14. Principle of convergent extension movements. A) Convergence of the midline (gray and black cells) contributes to neural tube closure, by decreasing the distance between the neural folds. B) If PCP signaling is disturbed, convergent extension fails which leads to neural tube defects. (modified after Wallingford 2005); A model of the morphogenetic process convergent extension during neural tube closure and gastrulation. Cells become polarized, intercalate and converge together on the mediolateral axis leading to extension of the developing tissue on the anteroposterior axis (from (Kibar et al. 2007)). 


\section{The role of PCP signaling in neural crest migration}

A second example of the importance of PCP signaling during morphogenesis is the migration of neural crest (NC) cells. PCP signaling regulates cell polarity, which is a prerequisite for cell migration (Carmona-Fontaine et al. 2008; Matthews et al. 2008; Roszko et al. 2009).

Analysis of neural crest migration showed that core-PCP genes such as Van Gogh like (vangl), prickle (pk) and daam are expressed in cranial neural crest cells (Bekman and Henrique 2002; Darken et al. 2002; Goto and Keller 2002; Nakaya et al. 2004), indicating that the PCP signaling cascade could be active. Additionally, the repression of important members of the PCP pathway including Fz7, DSH and Wnt11 leads to a disturbed NC migration in Xenopus (De Calisto et al. 2005; Kuriyama and Mayor 2008). A DSH mutant for example, which lacks PCP activity inhibits neural crest migration and on the other hand a DSH mutant, which activates PCP signaling in neural crest cells, restores migration due to loss of Wnt11 function (De Calsito et al. 2005). Furthermore, the PCP pathway directs the formation of lamellipodia and filopodia in migrating neural crest cells.

In general during cell migration the cells form protrusion at the leading edge, which marks the direction of migration followed by a newly formed actin network and adhesions for adhesive cell-substratum interactions. Two different types of protrusions exist, the large and broad lamellipodia and the thin, spike-like filopodia. The formation of these structures is driven by actin polymerization (Pollard and Borisy 2003) and stabilized by adhesions with the extracellular matrix. Additionally, adjacent cells linked to the actin cytoskeleton via transmembrane receptors could contribute to the stabilization of protrusions. At the front of cells, the newly formed adhesions serve as traction sites for migration movements and at the same time they are disassembled at the cell rear, which leads to a detachment. This allows the cell to move forward (Fig.: 15).

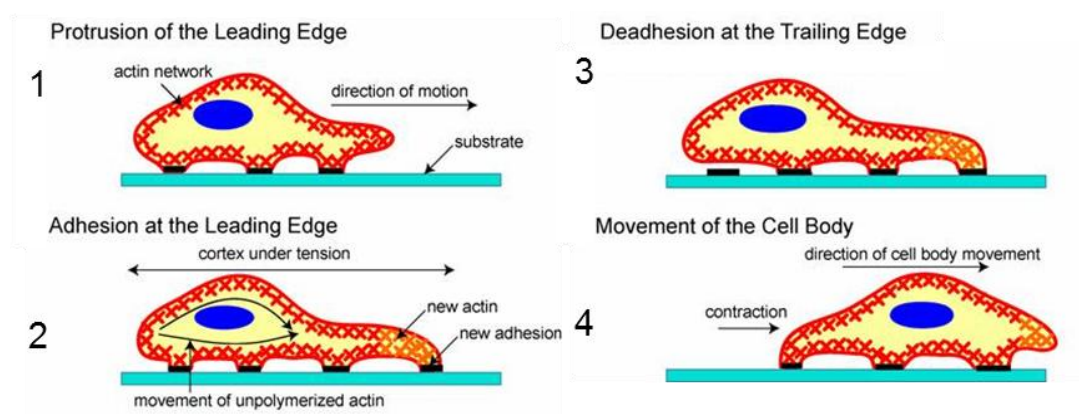

Figure 15. The basic steps in directed cell migration. 1) protrusion of the leading edge, 2) adhesion at the leading edge, 3) detachment at the trailing edge, 4) movement of the cell in a distinct direction (from (Ananthakrishnan and Ehrlicher 2007)). 
To reach distinct areas in the embryo a directional cell migration is needed. For this the cells must interpret, during migration, different guiding cues. After they start to migrate the cells receive information from their environment and the same time they receive signals through interactions with their direct neighbors.

Contact inhibition of locomotion (CIL) is a process by which migrating cells change their direction of migration after they have contact with another cell and was first described by Abercrombie (Abercrombie and Heaysman 1953; Abercrombie and Dunn 1975).

In general, neural crest cells start to migrate as a cluster of cells. During this collective cell migration the cells at the free edge of a cluster are the leading cells, which are followed by the inner cells. After some time single cells migrate out of the cluster and start to migrate alone. Upon cell contact with other NC cells they changed their direction of migration. In Xenopus and zebrafish embryos it could be demonstrated, that CIL can accounts for the directional migration of neural crest cells. When two migrating neural crest cells contact each other, they stop and change direction (Carmona-Fontaine et al. 2008b). CIL can be subdivided into four phases when individual cells collide: (1) cell-cell contact, (2) inhibition of cell protrusive activities at the site of contact, (3) generation of a new protrusion away from the site of cell contact and (4) migration in the direction of the new protrusion (Fig.: 16 A, numbers 1-4). The sequence of these phases can be modified by different factors, if for example two cells contact each other but one does not response, only one cell will be redirected. The situation is different in a cell cluster where only the cells at the free edge form protrusions. Inner cells which are in contact with others will generate smaller and more transient protrusions. This inhibition of cell protrusions is caused by CIL (Fig.: $16 \mathrm{~B}$ ). This shift of the motility from the inner to the outer cells can lead to directional migration of the whole cluster (Abercrombie and Heaysman 1954; Abercrombie and Ambrose 1962). As a consequence, cells that exhibit CIL do not move on top or below their neighboring cells, leading to monolayer formation in groups and to dispersed single cells. A typical protrusion during migration is the lammelipodium used to sense the adjacent cells during CIL. Additionally, it is also possible that different cell protrusions could be involved. Indeed, filopodia are suggested to be the actual sensory structure in CIL (Heckman 2009). This thin and spike like filopodia could mediate CIL over longer distances than the cell body size. A direct contact between the cell bodies is not necessary for collapse and change of cell protrusions. In fact, in vivo studies with migrating NC cells show that cells establish filopodia-like contacts with neighboring cells and that this contact is sufficient to promote CIL (Teddy and Kulesa 2004) and (Carmona-Fontaine et al. 2008b). 

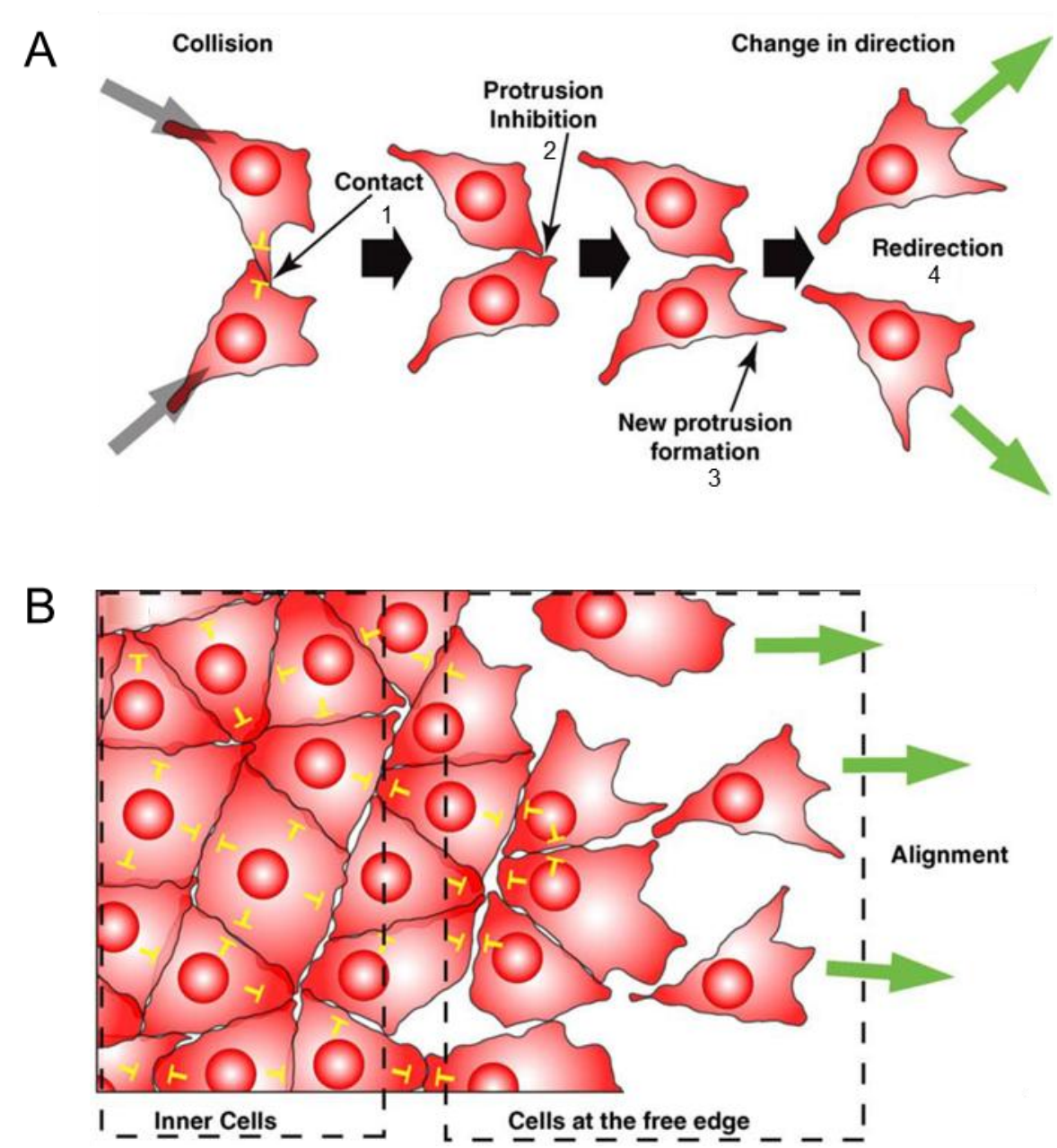

Figure 16. Contact inhibition of locomotion between single and clustered cells. The process of CIL is represented by yellow (inhibitory) arrows. A) The four phases of CIL indicated by the numbers 1-4. (1) Collision between two single cells leads to CIL and causes the collapse of cell protrusion after contact (2), a change in the direction of migration (4, green arrows) and newly formed protrusions in an opposite direction to each other (3). B) CIL in cell clusters. At cell-cell contacts the inner cells show inhibition of protrusions caused by CIL (yellow, inhibitory signs). CIL between the leader cells at the free edge can lead to cell polarization and directional migration (green arrows). (modified from (Mayor and Carmona-Fontaine 2010)) 
During migration the cells receive multiple signal inputs which have to be interpreted and translated into intracellular modifications to promote efficient directional migration.

\section{Contact inhibition of locomotion (CIL) can control cell polarity}

In Xenopus $\mathrm{CIL}$ is mediated by an $\mathrm{N}$-cadherin-dependent cell-cell interaction that triggers the PCP pathway (De Calisto et al. 2005; Carmona-Fontaine et al. 2008a; Matthews et al. 2008; Theveneau and Mayor 2010). Both, N- cadherin and PCP influence the activity levels of the small GTPases RhoA and Rac1 during cell-cell contacts (Fig.: $17 \mathrm{~B}$ ) (Carmona-Fontaine et al. 2008a; Theveneau and Mayor 2010). Upon cell-cell contacts the cells get polarized because $\mathrm{N}$-cadherin inhibits Rac1 at cell contacts and increase the RhoA activity at the contact site (Fig.: 17). As a consequence Rac1 accumulates at the free edges of the cells involved in cytoskeletal dynamics and acts as a key regulator for the formation and the stabilization of cell protrusions. At the same time RhoA is involved in the formation of focal adhesions and stress fibers at cell-cell contacts (Fig.: 17 A) (Ridley and Hall 1992; Ridley et al. 1992; Ridley et al. 2003). If N-cadherin and/or PCP are affected, the cells are no longer able to migrate in a specific direction, which support the fact of such a Rho GTPase network. (Carmona-Fontaine et al. 2008b; Theveneau et al. 2010). Small GTPases are required to establish cell polarity and to regulate protrusion formation upon cell contact. It seems that these molecules involved in the PCP pathway play a central role in signal integration, which is one of the first steps of CIL.
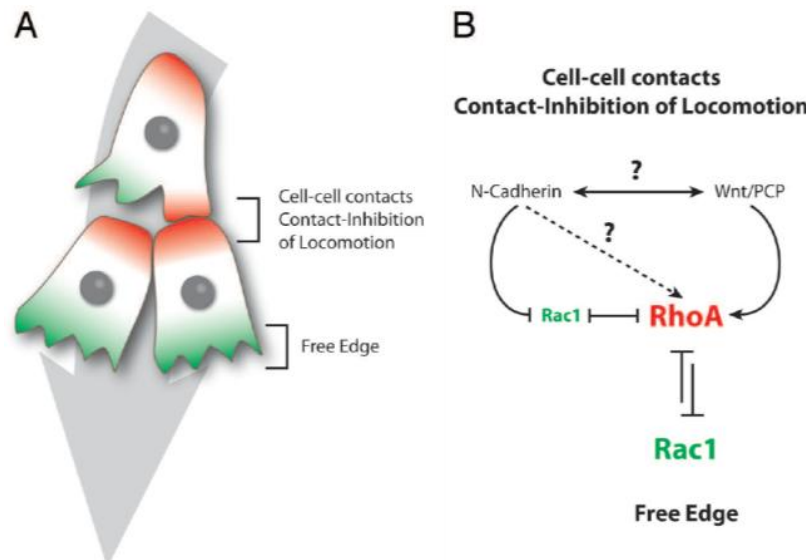

Figure 17. Contact inhibition of locomotion in Xenopus cephalic neural crest cells. A) Contact-Inhibition of Locomotion is triggered by cell-cell interactions. The cells get polarized according to their free edges (green) and their cell-cell contacts (red). B) CIL is mediated by $\mathrm{N}$ Cadherin and Wnt/PCP signaling. At cell-cell junctions $\mathrm{N}$-Cadherin is required for a local inhibition of Rac1. At the same time and place the Wnt/PCP pathway induces an increase in RhoA activity. $\mathrm{N}$-Cadherin and Wnt/PCP maintain high RhoA and low Rac1 activities at cell-cell contacts which lead to a Rac1 activity at the free edge (from (Theveneau and Mayor 2011)). 
During CIL, important members of the PCP pathway are asymmetrically localized at the sites of cell-cell contacts (Fig.: 18). DSH for example, co-localizes at direct cell contacts together with $\mathrm{Fz}$ and Wnt11 in migrating neural crest cells and activates RhoA, leading to a remodeling of the cytoskeleton network and in consequence to a change in the direction of migration. Overexpression of a DSH mutant, which lacks the ability to activate PCP in NC cells, also affects CIL. Therefore, PCP signaling via core-PCP components influences $\mathrm{CIL}$ and plays a role in the migration behavior of NC cells (Carmona-Fontaine et al. 2008a).

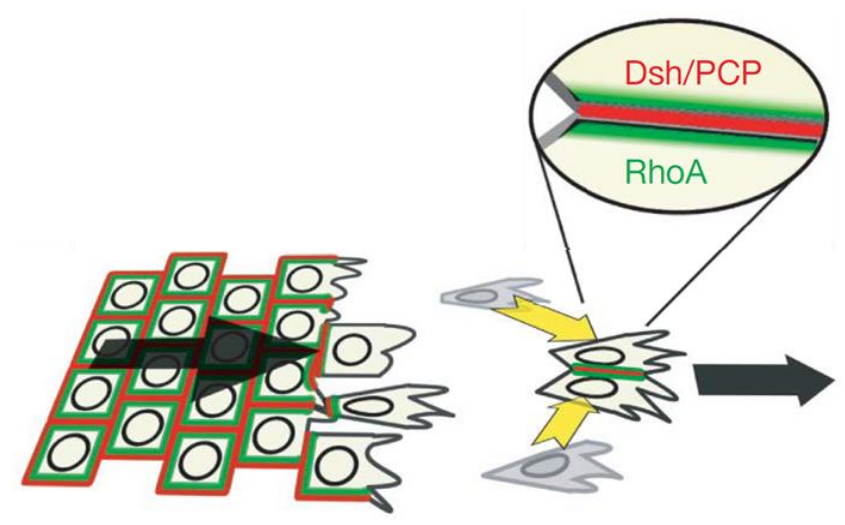

Figure 18. Contact inhibition of locomotion is controlled by localization of PCP members. During neural crest migration DSH co-localizes with Fz and Wnt11 at cell-cell contacts (red). This leads to an activation of RhoA at these contacts (green) and causes cytoskeletal rearrangements leading to directional migration (black arrows) (from (Carmona-Fontaine 2008)). 


\subsection{Protein tyrosine kinase 7 functions in PCP signaling and regulates neural tube closure and neural crest migration}

PTK7 is a known regulator of PCP signaling. It is required for cell polarity and cell movements during development as determined from analysis of its role in neural tube (NT) closure and neural crest (NC) migration. Loss-of-function in mouse leads to defects in neural tube closure and stereociliar bundle orientation (Fig.: 19 A) (Lu et al. 2004; Paudyal et al. 2010). Additionally, the knock-down of PTK7 shows genetic interactions with a mutation in the mouse Van Gogh homologue vangl2 (Lu et al. 2004) and the expression of PTK7 was clearly reduced in caudal-type homeobox (Cdx) genes Cdx1Cdx2 double mutant mice, which show an open neural tube typical of PCP phenotypes (Savory et al. 2011). Furthermore, during mouse gastrulation it could be shown that PTK7 is essential for convergent extension movements and polarized cell motility (Yen et al. 2009). PTK7 function is also conserved in Xenopus and Zebrafish development. Knockdown of PTK7 in Xenopus leads to defects in convergent extension movements resulting in open neural tubes and shorter body axis (Fig.: 19 B) (Lu at al. 2004). A similar phenotype was shown in Zebrafish where the PTK7 loss-of-function led to embryos with shortened body axes (Fig.: 19 C) (Golubkov et al. 2010).

As mentioned earlier, PTK7 functions are not limited to morphogenetic movements during NT closure and it is not exclusively expressed in the neural tube area. It is also expressed in migrating cranial neural crest cells and PTK7 loss-of-function leads to defects in neural crest migration (Fig.: $19 \mathrm{D}, \mathrm{E}$ ). It was also shown that the intracellular domain of PTK7 is required to recruit DSH to the plasma membrane (Fig.: $19 \mathrm{~F}$ ) (Shnitsar and Borchers 2008). In an overexpression situation, PTK7 was able to recruit DSH to the plasma membrane in ectodermal explants. This recruitment lead to activation of PCP signaling (Tree et al. 2002b; Bastock et al. 2003; Simons et al. 2009) and as a consequence, to neural crest migration (Fig.: 19 F, left) (Shnitsar and Borchers 2008). The DSH recruitment can be abolished if a mutant of PTK7 lacking the intracellular kinase homology domain is used, which causes a disturbed NC migration (Fig.: $19 \mathrm{~F}$, right). 

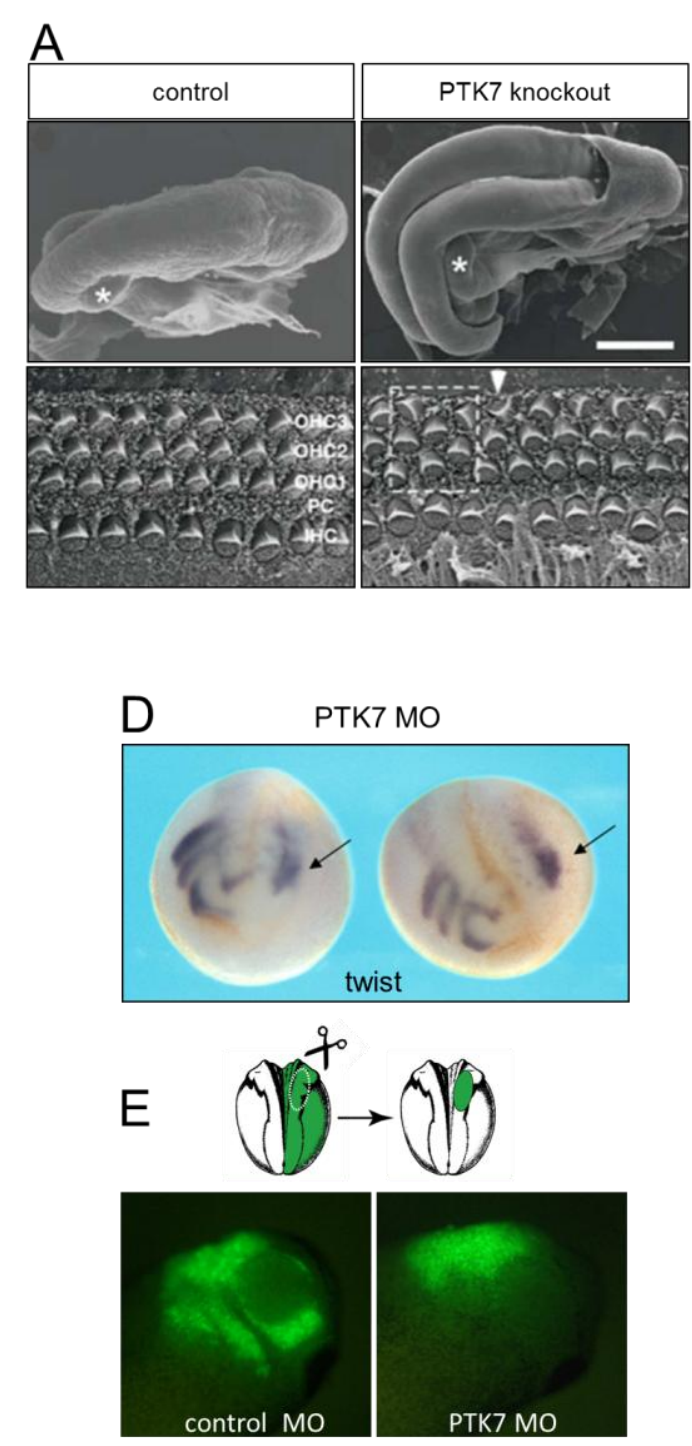

B

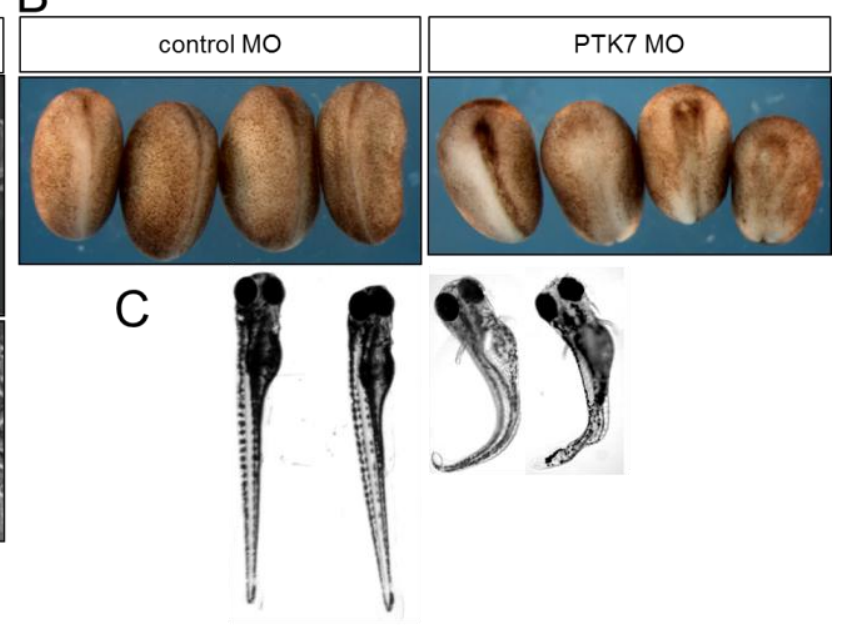

$\mathrm{F}$

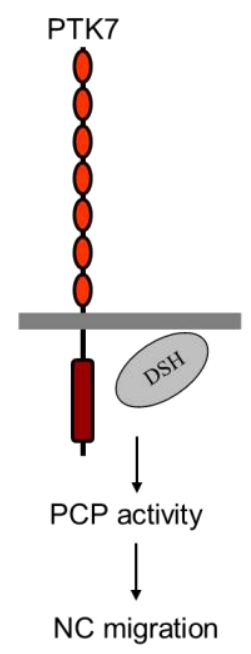

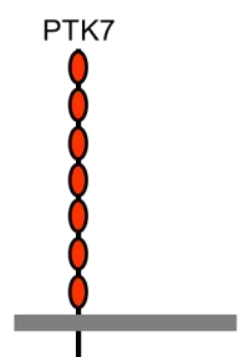

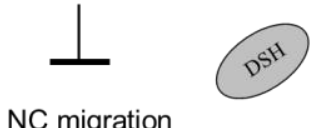

NC migration

Figure 19. PTK7 functions in planar-cell-polarity in vertebrates. A) PTK7 knockout-mice show open neural tubes and misorientated inner ear stereociliary bundles of sensory hair cells compared to control mice (modified from (Lu et al. 2004)). B) The PTK7 loss-of-function caused by morpholino injections show open neural tubes in Xenopus embryos while in embryos injected with control morpholino the neural tube is completely closed (modified from (Lu et al. 2004)). C) In Zebrafish PTK7 MO induces a CE phenotype, the embryos remain shorter (modified from Golubkov et al. 2010). D,E) PTK7 loss-of-function causes NC migration defects. D) Embryos injected with PTK7 MO in one side of the embryo show a disturbed NC migration phenotype (black arrows) compared to the un-injected side where the cells migrate normally. E) Xenopus transplantation assay experiments. Premigratory NC cells from Xenopus embryos injected with control MO and 100 pg GFP RNA were transplanted into un-injected embryos and show a normal migration behavior. In PTK7 MO injected NC cells the migration is reduced. From the un-injected control embryos the endogenous NC cells were removed. F) Model of the role of PTK7 in neural crest migration. Overexpression of PTK7 could recruit DSH to the plasma membrane. This leads to an activation of PCP signaling and thereby to neural crest migration (left). A mutant of PTK7 which lacks the intracellular kinase homology domain could not recruit DSH to the membrane and inhibits NC migration (right). (modified from (Shnitsar and Borchers 2008)). 
An open question is how PTK7 signaling affects the processes of neural tube closure and neural crest migration. PTK7 participates in the regulation of non-canonical Wnt/planar cell polarity (PCP) signaling related processes during mouse and frog embryonic development (Lu et al. 2004; Shnitsar and Borchers 2008). It functions in recruiting DSH to the plasma membrane which is a prerequisite for PCP activation (Tree et al. 2002b; Bastock et al. 2003; Shnitsar and Borchers et al 2008; Simons et al. 2009). Additionally, it was shown that PTK7 is an interaction partner for Wnt proteins in Drosophila and Xenopus and that PTK7 inhibits canonical Wnt signaling (Peradziryi et al. 2011) while it activates the PCP pathway. Contrary to this, another study demonstrates that PTK7 interacts with B-catenin in yeast and human cell culture to promote canonical Wnt signaling (Puppo et al. 2011). Taken together, PTK7 plays an important role during development to regulate polarity, NT closure and NC cell migration by activating PCP signaling and inhibiting canonical signaling.

Human protein tyrosine kinase 7 (hPTK7) was first identified in cancer cell lines with high metastatic potential and was named accordingly colon carcinoma kinase 4 (CCK4) (Mossie et al. 1995). In such cancer tissue the expression of PTK7 is often misregulated (Easty et al. 1997; Endoh et al. 2004; Muller-Tidow et al. 2004). PTK7 is a highly conserved gene which was found in a wide range of organisms from cnidaria to human. It belongs to a class of genes that encode for receptor protein-tyrosine kinase (RTK). Structurally, the molecule contains seven extracellular immunoglobulin-like domains, a transmembrane (TM) domain and a cytoplasmic part with a conserved tyrosine kinase homology domain (Fig.: 20). The DFG triplet, which is necessary for catalytic activity of the kinase domain of PTK7, is mutated (Miller and Steele 2000; Kroiher et al. 2001) and until now no kinase activity was observed in Hydra (Miller and Steele 2000), chicken (Chou and Hayman 1991), mouse (Jung et al. 2004) or human (Mossie et al. 1995).

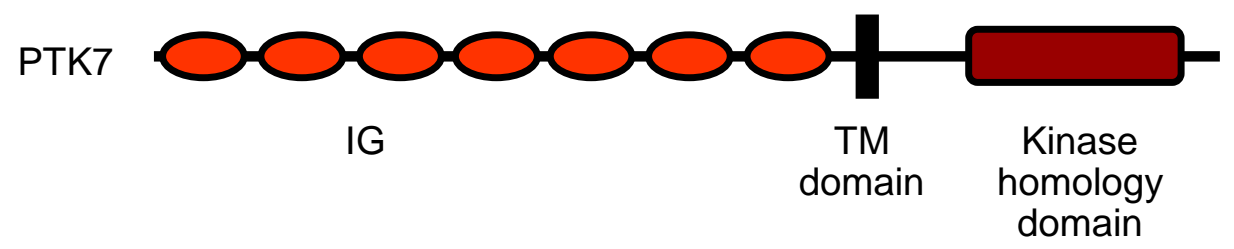

Figure 20. Structure of PTK7. Schematic view of the PTK7 molecule. IG: immunoglobulin-like; TM: transmembrane 


\section{RACK1, a new interaction partner of PTK7}

We recently, screened for intracellular binding partners of PTK7. The most interesting candidate from this screen was RACK1. RACK1 is a highly conserved $36-k D$ protein, identified on the basis of its ability to bind to the activated form of PKC (Mochly-Rosen et al. 1991; Ron et al. 1994). RACK1 serves as both, an anchor protein for PKC and a scaffold protein that recruits PKC and other proteins into a signaling complex. This possible interaction could be confirmed by Co-immunoprecipitation (Co-IP) assays using a deletion mutant of PTK7 lacking the extracellular domain ( $\triangle E$ EPTK7). These Co-IP assays were done in two different systems, firstly in Xenopus lysates and secondly, using an in vitro translation assay (TNT) system (Fig.: 21) suggesting direct binding of PTK7 and RACK1.
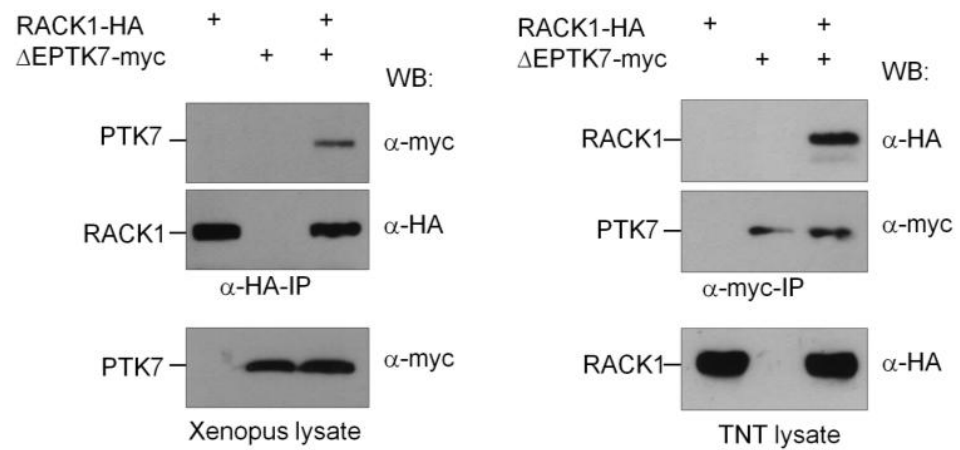

Figure 21. RACK1 interacts with PTK7 in co-immunoprecipitation assays. A) RACK1 coimmunoprecipitates a deletion mutant of PTK7 that lacks the extracellular domain ( $\triangle E P T K 7)$ in lysates of embryos injected with $300 \mathrm{pg} H \mathrm{HA}$-tagged RACK1 RNA and $500 \mathrm{pg}$ myc-tagged $\triangle E P T K 7$ RNA. (B) In vitro translated myc-tagged $\triangle E P T K 7$ protein precipitates translated HA-tagged RACK1 protein in vitro. WB: western blot.

Additionally, it was shown that RACK1 is required for PTK7-mediated DSH membrane localization. Normally, PTK7 is able to recruit DSH to the plasma membrane (Shnitsar and Borchers 2008) but knock-down of RACK1 could reduce this localization of DSH. In summary, RACK1 interacts with PTK7 and is required for PTK7 mediated DSH recruitment. DSH is a core component of the PCP pathway and its localization to the plasma membrane is a prerequisite for activation of the PCP pathway (Tree et al. 2002a; Bastock et al. 2003; Simons et al. 2009).

Structurally, RACK1 adopts a seven-bladed B-propeller structure and contains seven consecutive 41-48 amino acid long WD repeats (Fig.: 22) (Coyle et al. 2009). The protein is highly conserved between protozoa, yeast, plants, insects, fungi, vertebrates and mammals (Wang et al. 2003). RACK1 facilitates protein binding (Brandon et al. 2002), plays a significant role in shuttling proteins in the cell (Ron et al. 1999), acts as an anchoring protein at particular locations (Ron et al. 1994) and stabilizes protein activity 
(Kiely et al. 2008). It interacts with the ribosomal machinery (Ben-Shem et al. 2010), with several cell surface receptors (Geijsen et al. 1999) and with proteins in the nucleus (Neasta et al. 2012). In summary, RACK1 is a key mediator of various pathways and contributes to numerous aspects of cellular functions for example development ( $\mathrm{Li}$ et al. 2011), cell migration (McCahill et al. 2002; Sklan et al. 2006), central nervous system (CN) function and circadian rhythm and it has an important function in disease (Adams et al. 2011).

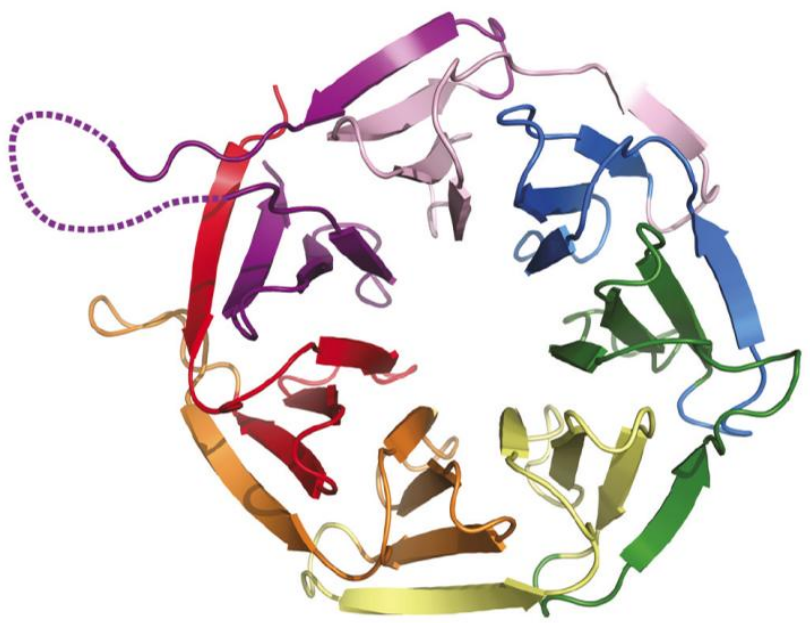

Figure 22. Structure of the RACK1 protein. Crystal structure of RACK1A from $A$. thaliana illustrating the seven-bladed $\beta$-propeller structure (from (Adams et al. 2011)). 


\section{Aims:}

PTK7 is a known regulator of planar cell polarity (PCP) required for neural tube closure and convergent extension movements in mouse and Xenopus. Recently, we identified RACK1 as a new interaction partner of PTK7, which may contribute to PTK7 function in these processes. The aim of this work is to characterize the molecular and functional interaction of PTK7 and RACK1 in neural morphogenesis. As PTK7 is required for the recruitment of DSH to the plasma membrane, which is a prerequisite for the activation of the PCP pathway, the first aim is to analyze if RACK1 contributes to this process. This will be analyzed by monitoring the localization of tagged constructs in ectodermal explants in combination with loss-of-function studies. The second aim is to characterize the in vivo relevance of the PTK7/RACK1 interaction in Xenopus neural tube closure and neural crest migration. Gain of function and loss-of-function experiments will be used to define the role of RACK1 in these processes. Further, to determine the function of RACK1 and PTK7 on a cellular level high-resolution live-cell imaging of explanted neural crest cells will be performed. 


\section{Material and Methods}

\subsection{Model Organism}

In this work the African clawed frog Xenopus laevis (X. laevis) was used as model organism. Adult frogs were purchased from Nasco (Ft. Atkinson, WI, USA).

\subsection{Bacteria}

All cloning was done with the E.coli strain XL1-Blue from the Stratagene company. The genotype is: recA1 endA1 gyrA96 thi-1 hsdR17 supE44 relA1 lac [F' proAB laclqZ $Z M 15$ Tn10 (Tetr)] and the cells are resistant against Tetracycline.

\subsection{Chemicals, Buffers and Media}

\subsubsection{Chemicals}

The chemicals used in this work were purchased from the following companies: Roth (Karlsruhe), Sigma (Munich), Applichem (Darmstadt), Calbiochem (Darmstadt), Invitrogen (Darmstadt), Biochrom (Berlin), Roche (Mannheim) and Biomol (Hamburg).

\subsubsection{Additional chemical substances and reagents}

Fibronectin (from bovine plasma): F1141-5MG, Sigma;

DNA ladder: Low, Middle, High-Range, Fermentas;

Human chorionic gonadotropin (HCG), Sigma;

NBT and BCIP (NBT: $\mathrm{C}_{40} \mathrm{H}_{30} \mathrm{Cl}_{2} \mathrm{~N}_{10} \mathrm{O}_{6}, \mathrm{BCIP}: \mathrm{C}_{8} \mathrm{H}_{6} \mathrm{NO}_{4} \mathrm{BrCIP} \times \mathrm{C}_{7} \mathrm{H}_{9} \mathrm{~N}$ ), Roche;

Protein ladder: PageRuler Prestained Protein Ladder \#SM0671, MBI Fermentas;

X-gal (5-Bromo-4-chloro-3-indolyl a-D-galactopyranoside), Roche.

\section{Media and Buffers}

The buffers and media were prepared using deionized water (MiliQ, Sartorius). If necessary the media and buffers were sterilized by autoclaving $120^{\circ} \mathrm{C}$ for $20 \mathrm{~min}$. Antibiotics were added only at appropriate temperatures of the buffers and media.

\subsubsection{Media}

Luria-Bertani (LB)-Medium: 1\% (w/v) Bacto-Trypton (DIFCO), $0.5 \%(\mathrm{w} / \mathrm{v})$ yeast extract (DIFCO), $1 \%(\mathrm{w} / \mathrm{v}) \mathrm{NaCl}, \mathrm{pH} 7.5$

LB-Agar: $1.5 \%(\mathrm{w} / \mathrm{v})$ agar (DIFCO) in liquid LB-medium

Ampicillin: $50 \mathrm{mg} / \mathrm{ml}$ in $\mathrm{H}_{2} \mathrm{O}, 500 x$ Stock (Biomol); Kanamycin: $50 \mathrm{mg} / \mathrm{ml}$ in $\mathrm{H}_{2} \mathrm{O}, 1000 \mathrm{x}$ Stock (Biomol) 


\subsubsection{Buffers}

Alkaline phosphatase buffer (APB): $100 \mathrm{mM}$ Tris- $\mathrm{HCl}$ (pH 9.5), $50 \mathrm{mM} \mathrm{MgCl}, 100 \mathrm{mM}$ $\mathrm{NaCl}, 0.1 \%$ Tween 20

Blocking solution: 1x PBS, $5 \%(\mathrm{w} / \mathrm{v})$ non-fat dry milk powder and $0.1 \%$ Tween20

Co-IP buffer I: $10 \mathrm{mM}$ Tris-HCl, pH 7.5, $100 \mathrm{mM} \mathrm{NaCl}, 2 \mathrm{mM}$ EDTA, 1 mM EGTA, 0.5\% $(\mathrm{v} / \mathrm{v}) \mathrm{NP}-40,10 \%(\mathrm{v} / \mathrm{v})$ glycerol, protease inhibitor cocktail (1 tablet per $50 \mathrm{ml}$ of the buffer, Roche)

Co-IP buffer: $50 \mathrm{mM}$ Tris- $\mathrm{HCl}, \mathrm{pH} 7.5 ; 150 \mathrm{mM} \mathrm{NaCl}, 0.5 \% \mathrm{NP}-40$, protease inhibitor cocktail (1 tablet per $50 \mathrm{ml}$ of the buffer, Roche)

Co-IP lysis-buffer $50 \mathrm{ml}$ of Co-IP buffer, $1 \mathrm{mM} \mathrm{NaF}, 1 \mathrm{mM} \beta$-glycerolphosphate, $1 \mathrm{mM}$ Sodium orthovanadate, 1 tablet of Complete-Protease inhibitor mix EDTA free (Roche)

Cystein solution: $2 \%$ L-Cystein hydrochloride, $\mathrm{pH} 8.0$

Danylchik's for Amy (DFA) medium: $53 \mathrm{mM} \mathrm{NaCl}, 5 \mathrm{mM} \mathrm{Na}_{2} \mathrm{CO}_{3}$, potassium gluconate $4.5 \mathrm{mM}$, sodium gluconate $32 \mathrm{mM}, \mathrm{MgSO}_{4} 1 \mathrm{mM}, \mathrm{CaCl}_{2} 1 \mathrm{mM}, \mathrm{BSA} 0.1 \%$, sterile filtered

Ficoll: 10\% (w/v) Ficoll PM 400 (Sigma), sterile filtered

Hybridization mix (Hyb-mix): 50\% (v/v) Formamid, 5xSSC, $1 \mathrm{mg} / \mathrm{ml}$ Torula RNA (Sigma), $100 \mu \mathrm{g} / \mathrm{ml}$ Heparin, 1x Denhards, 0.1\% (v/v) Tween20, 0.1\% (w/v) CHAPS (Sigma)

Injection buffer: 1x MBS, 2\% Ficoll 400 (Sigma)

Laemmli buffer (Gel running) (10x): $250 \mathrm{mM}$ Tris-base, $2.5 \mathrm{M}$ Glycine, 0.1\% SDS

Laemmli buffer (Gel loading) (6x): $350 \mathrm{mM}$ Tris- $\mathrm{HCl} \mathrm{pH} \mathrm{6.8,} \mathrm{9.3 \%} \mathrm{Dithiotreit,} \mathrm{30 \%} \mathrm{(v/v)}$ Glycerol, $10 \%$ SDS, $0.02 \%$ Bromphenolblue

MAB: 100 mM Maleic acid; $150 \mathrm{mM} \mathrm{NaCl,} \mathrm{pH} 7.5$

MBS Buffer (1x): $10 \mathrm{mM}$ Hepes pH 7.4, $88 \mathrm{mM} \mathrm{NaCl}, 1 \mathrm{mM} \mathrm{KCl}, 2.4 \mathrm{mM} \mathrm{NaHCO}$, 0.2 $\mathrm{mM} \mathrm{MgSO}_{4}, 0.41 \mathrm{mM} \mathrm{CaCl}_{2}, 0.66 \mathrm{mM} \mathrm{KNO}_{3}$

MEM: $100 \mathrm{mM}$ MOPS, $2 \mathrm{mM}$ EGTA, $1 \mathrm{mM} \mathrm{MgSO}_{4}$

MEMFA: 1x MEM with 3.7\% (v/v) Formaldehyde

Nile blue: $0.01 \%(w / v)$ Nile blue in $0.1 \times$ MBS

PBS (10x): 8\% (w/v) NaCl, 2\% (w/v) KCl, $65 \mathrm{mM} \mathrm{Na}_{2} \mathrm{HPO}_{4}, 18 \mathrm{mM} \mathrm{KH}_{2} \mathrm{PO}_{4}, \mathrm{pH} 7.4$

Ptw buffer: 1xPBS with $0.1 \%$ Tween 20

SSC: $150 \mathrm{mM} \mathrm{NaCl}, 15 \mathrm{mM}$ Sodium citrate, $\mathrm{pH} 7.4$

TAE (Tris/Acetat/EDTA): 40 mM Tris-Acetate (pH 8.5), 2 mM EDTA

TBS/Tween: $20 \mathrm{mM}$ Tris-HCl (pH 7.5), $150 \mathrm{mM} \mathrm{NaCl,} \mathrm{0.05 \%} \mathrm{Tween}$ 
TE-Buffer: $10 \mathrm{mM}$ Tris-HCl pH 8.0, 1 mM EDTA

Transfer buffer: $25 \mathrm{mM}$ Tris, $192 \mathrm{mM}$ Glycine, 20\% (v/v) Methanol

Tris- $\mathrm{HCl}(\mathrm{pH} 6.8,7.5,8.2,8.8$, or 9.5): $1 \mathrm{M}$ Tris- $\mathrm{HCl}, \mathrm{pH}$ adjusted with $37 \% \mathrm{HCl}$

Western blotting buffer: $3.03 \mathrm{~g}$ Tris-base, $14.4 \mathrm{~g}$ Glycine, $200 \mathrm{ml}$ methanol, $800 \mathrm{ml} \mathrm{H}_{2} \mathrm{O}$

X-gal staining solution: $1 \mathrm{mg} / \mathrm{ml}$ X-gal, $5 \mathrm{mM} \mathrm{K}_{3} \mathrm{Fe}(\mathrm{CN})_{6}, 5 \mathrm{mM} \mathrm{K}_{4} \mathrm{Fe}(\mathrm{CN})_{6}, 2 \mathrm{mM} \mathrm{MgCl}_{2}$

\section{$2.4 \quad$ Enzymes and Kits}

Big Dye Terminator v1.1 Cycle Sequencing Kit, Applied Biosystems;

DNase I (1 U/ $\mu$ l): MBI Fermentas;

ECL Kit Super Signal Dura West, Pierce;

High Fidelity PCR Enzyme Mix (5 U/ul), MBI Fermentas;

Illustra ${ }^{\mathrm{TM}}$ Plasmid Prep Midi Flow Kit, GE Healthcare;

Illustra ${ }^{T M}$ Plasmid Prep Mini Spin Kit, GE Healthcare;

Pfu DNA Polymerase (2.5 U/ $\mu \mathrm{l})$, MBI Fermentas;

Proteinase K $(20 \mathrm{mg} / \mathrm{ml})$, Merck;

Pyrophosphatase $(0,1 \mathrm{U} / \mu \mathrm{l})$, Fermentas;

Restriction Endonucleases, MBI Fermentas and New England Biolabs (NEB);

Reverse Transkriptase (50U/ $\mu \mathrm{l})$, Applied Biosystems;

RNA In Vitro Transcription Kit, Stratagene;

RNase A (100U/ $\mu l)$, Sigma;

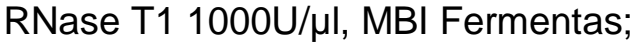

SP6, T3 and T7 mMESSAGE mMACHINE Kits, Ambion Inc.;

SP6, T3, T7 RNA Polymerases (20U/ $\mu$ l), Fermentas;

T4 DNA Ligase (1 U/ $\mu \mathrm{l})$, MBI Fermentas;

\section{$2.5 \quad$ Vectors and Constructs}

\subsubsection{Vectors}

pCS2+ is an expression vector used in the Xenopus model system. It contains a strong promoter/enhancer region (simian CMV IE94), polylinker and SV40 viral polyadenylation signal, including SP6 viral promoter for in vitro transcription of sense polyadenylated mRNA for microinjections and T7 viral promoter for in vitro transcription of antisense RNA for in situ hybridization (Rupp et al. 1994).

pCS2+/MT is a pCS2+ vector variant with 6x Myc-tag (MT) sequence inserted into BamHI/Clal sites for the expression of tagged proteins (Klisch et al. 2006).

pCS2+/HA is a pCS2+ vector variant containing a HA-tag sequence inserted via Xba1 site for the expression of tagged proteins (Damianitsch et al. 2009). 
pCS2+/GFP is a pCS2+ vector variant containing GFP sequence inserted into Xbal/Xhol sites for the expression of GFP-tagged proteins for using in this work.

\subsubsection{Expression constructs}

Table 1 includes the list of the expression constructs used in this work and table 2 includes information about enzymes used for the linearization of DNA constructs and polymerases used for in vitro transcription. The constructs were used in this work for preparation of mRNA for microinjections in Xenopus embryos and generation of antisense RNA for whole mount in situ hybridization.

Table 1. Expression constructs

\begin{tabular}{|c|c|c|c|}
\hline Name & Vector & Insert description & Cloning strategy \\
\hline $\begin{array}{l}\Delta \mathrm{kPTK} 7 \\
\text { GFP }\end{array}$ & pCS2+/GFP & $\begin{array}{l}\text { Xenopus laevis PTK7 } \\
\text { without intracellular } \\
\text { kinase-homology } \\
\text { domain with GFP-tag }\end{array}$ & (Wehner et al. 2011) \\
\hline $\begin{array}{l}\Delta \mathrm{kPTK} 7- \\
\text { MT }\end{array}$ & pCS2+/MT & $\begin{array}{l}\text { Xenopus laevis PTK7 } \\
\text { without intracellular } \\
\text { kinase-homology } \\
\text { domain with Myc-tag }\end{array}$ & (Shnitsar and Borchers 2008) \\
\hline DSH-GFP & pCS2+ & $\begin{array}{l}\text { Dishevelled } \\
\text { (X.laevis) with GFP-tag }\end{array}$ & (Yang-Snyder et al. 1996) \\
\hline DSH-MT & pCS2+/MT & $\begin{array}{l}\text { full length Xenopus } \\
\text { laevis disheveled with } \\
\text { Myc-tag }\end{array}$ & (Sokol 1996) \\
\hline DSH-myc & pCS2+ & $\begin{array}{l}\text { Dishevelled } \\
\text { (X. laevis) } \\
\text { with Myc-tag }\end{array}$ & (Sokol 1996) \\
\hline Frizzled7 & pCS2+ & $\begin{array}{l}\text { full length Xenopus } \\
\text { laevis Frizzled7 }\end{array}$ & (Medina et al. 2000) \\
\hline $\begin{array}{l}\text { Frizzled7- } \\
\text { MT }\end{array}$ & pCS2+/MT & $\begin{array}{l}\text { full length Xenopus } \\
\text { laevis Frizzled7 with } \\
\text { Myc-tag }\end{array}$ & (Winklbauer et al. 2001) \\
\hline $\begin{array}{l}\text { hRACK1- } \\
\text { HA }\end{array}$ & & $\begin{array}{ll}\text { Receptor of } & \text { activated } \\
\text { PKC-1 } & \text { (RACK1), } \\
\text { human } & \\
\end{array}$ & (Wehner et al. 2011) \\
\hline lacZ & pCS2+ & $\begin{array}{l}\text { bacterial } \quad \beta- \\
\text { galactosidase }\end{array}$ & (Smith and Harland 1991) \\
\hline mCherry & pCS2+ & $\begin{array}{l}\text { Cherry with GAP43 } \\
\text { myristilation signal, } \\
\text { membrane associated }\end{array}$ & Provided by Jubin Kashef \\
\hline mGFP & pCS2+ & $\begin{array}{l}\text { GFP with GAP43 } \\
\text { myristilation signal, } \\
\text { membrane associated }\end{array}$ & $\begin{array}{l}\text { Provided by Dr. Alexandra } \\
\text { Schambony }\end{array}$ \\
\hline
\end{tabular}




\begin{tabular}{|c|c|c|c|}
\hline Name & Vector & Insert description & Cloning strategy \\
\hline PAX3 & & $\begin{array}{l}\text { full length }(X \text {. laevis }) \\
\text { Sox2 }\end{array}$ & (Bang et al. 1999) \\
\hline $\begin{array}{l}\text { PKC } 81- \\
\text { GFP }\end{array}$ & pCS2+ & PKC $\delta 1$ (X. laevis) GFP & (Sivak et al. 2005) \\
\hline $\begin{array}{l}\text { PTK7- } \\
\text { GFP }\end{array}$ & pCS2+/GFP & $\begin{array}{l}\text { full length Xenopus } \\
\text { laevis PTK7 with GFP } \\
\text { tag }\end{array}$ & $\begin{array}{l}\text { Myc tag was cut off from PTK7-MT } \\
\text { construct with Clal and Xbal. GFP } \\
\text { sequence amplified from pEGFP-C1 } \\
\text { plasmid with primers Gfp1F Clal and } \\
\text { Gfp1R Xbal was inserted into the } \\
\text { same sites. }\end{array}$ \\
\hline PTK7-HA & $\mathrm{pCS} 2+/ \mathrm{HA}$ & $\begin{array}{l}\text { full length } \begin{array}{l}\text { Xenopus } \\
\text { laevis PTK7 }\end{array} \\
\text { tag with HA }\end{array}$ & (Shnitsar and Borchers 2008) \\
\hline PTK7-MT & pCS2+/MT & $\begin{array}{l}\text { full length } \begin{array}{r}\text { Xenopus } \\
\text { laevis PTK7 with Myc- } \\
\text { tag }\end{array} \\
\end{array}$ & (Shnitsar and Borchers 2008) \\
\hline SOX2 & Sox2 & $\begin{array}{l}\text { full length }(X \text {. laevis }) \\
\text { Sox2 }\end{array}$ & (Mizuseki et al. 1998) \\
\hline XBF-2 & & $\begin{array}{l}\text { Xenopus Brain Factor } \\
2 \text { (XBF-2) }\end{array}$ & (Mariani and Harland 1998) \\
\hline xRACK1 & pCS105 & $\begin{array}{l}\text { Receptor of activated } \\
\text { PKC } 1 \text { (RACK) } \\
\text { (X. laevis) }\end{array}$ & $\begin{array}{l}\text { obtained from the NIBB/ XDB3 } \\
\text { http://xenopus.nibb.ac.jp } \\
\text { clone XL422i22ex }\end{array}$ \\
\hline $\begin{array}{l}\text { XRACK1- } \\
\text { HA }\end{array}$ & pCS2+ HA & $\begin{array}{l}\text { Receptor of activated } \\
\text { PKC } 1 \text { (RACK) } \\
\text { (X. laevis) }\end{array}$ & (Wehner et al. 2011) \\
\hline xTwist & pGEM-T & $\begin{array}{l}\text { full length Xenopus } \\
\text { laevis twist }\end{array}$ & (Hopwood et al. 1989) \\
\hline $\begin{array}{l}\Delta \mathrm{k}-\mathrm{PTK} 7- \\
\mathrm{xR}-\mathrm{HA}\end{array}$ & & $\begin{array}{l}\text { Fusion construct: } \\
\text { Xenopus laevis PTK7 } \\
\text { without intracellular } \\
\text { kinase-homology } \\
\text { domain and Receptor } \\
\text { of activated PKC } 1 \\
\text { (RACK) } \\
(\text { X. laevis) }\end{array}$ & (Wehner et al. 2011) \\
\hline
\end{tabular}


Table 2. Linearization of DNA constructs and in vitro transcription

\begin{tabular}{|c|c|c|c|c|}
\hline \multirow{2}{*}{$\begin{array}{c}\text { Construct } \\
\text { name }\end{array}$} & \multicolumn{2}{|c|}{ sense RNA } & \multicolumn{2}{|c|}{ antisense RNA } \\
\hline & Restriction enzyme & Polymerase & Restriction enzyme & Polymerase \\
\hline$\Delta \mathrm{kPTK7-MT}$ & Notl & SP6 & & \\
\hline Dsh-GFP & Notl & SP6 & & \\
\hline Dsh-MT & Notl & SP6 & & \\
\hline Dsh-MT & Notl & SP6 & & \\
\hline Dsh-myc & Notl & SP6 & & \\
\hline Frizzled7 & Notl & SP6 & & \\
\hline Frizzled7 & Notl & SP6 & & \\
\hline Frizzled7 & Notl & SP6 & & \\
\hline Frizzled7-MT & Notl & SP6 & & \\
\hline Frizzled7-MT & Notl & SP6 & & \\
\hline Frizzled7-MT & Notl & SP6 & & \\
\hline hRACK1-HA & Notl & SP6 & & \\
\hline lacZ & Notl & SP6 & & \\
\hline lacZ & Notl & SP6 & & \\
\hline mCherry & Notl & SP6 & & \\
\hline mGFP & Notl & SP6 & & \\
\hline PAX3 & & & EcoRI & T7 \\
\hline PTK7-GFP & Notl & SP6 & & \\
\hline PTK7-HA & Notl & SP6 & & \\
\hline PTK7-MT & Notl & SP6 & & \\
\hline SOX2 & & & EcoRI & $\mathrm{T} 7$ \\
\hline XBF-2 & Notl & SP6 & & \\
\hline xRACK1-HA & Notl & SP6 & & \\
\hline xTwist & & & EcoRI & $\mathrm{T} 7$ \\
\hline
\end{tabular}




\subsection{Oligonucleotides}

The oligonucleotides used in this work include sequencing primers and sequences for antisense morpholinos.

\subsubsection{Sequencing primers}

The sequencing primers used during this work are listed in Table 3. The DNA oligonucleotides were ordered in a lyophilized form from Sigma Aldrich and were diluted till $100 \mu \mathrm{M}$ with RNAse-free water.

Table 3. Sequencing primers

\begin{tabular}{|c|c|c|c|}
\hline $\begin{array}{l}\text { Constructs } \\
\text { Vectors }\end{array}$ & / Primer & Primer sequence $5^{\prime} \rightarrow 3^{\prime}$ & $\begin{array}{l}\text { Gene } \\
\text { position }\end{array}$ \\
\hline \multirow{3}{*}{ pCS2+ } & SP6 & TTAGGTGACACTATAGAATAC & \\
\hline & T7 & TCTACGTAATACGACTCACTATAG & \\
\hline & T3 & AATTAACCCTCACTAAAGGG & \\
\hline \multirow{8}{*}{ PTK7 } & ABO & AGAACTAGGAGTCGATGC & $1-18$ \\
\hline & AB1 & TTCAGAGATGGGACGCCGTTA & $535-555$ \\
\hline & AB2 & TGGAGGTGGTATTCAAACCC & $1151-1170$ \\
\hline & AB3 & AGGGATGCTGGGAACTACAC & $1717-1736$ \\
\hline & AB4 & CCATTGTTCTCTCTGTGGTTG & $2129-2149$ \\
\hline & AB5 & GCATCTGGCTAACAGTCG & $2751-2769$ \\
\hline & AB6 & GGGAGCTGCCTTATACCT & $3002-3022$ \\
\hline & AB7 & TCCTATTGCCCTTAGTAGTGC & $4893-4913$ \\
\hline
\end{tabular}

\subsubsection{Morpholino oligonucleotides}

The sequences of the morpholinos used in this study are listed in table 4. The morpholino blocking oligonucleotides (MO) were produced by Gene Tools LLC (Philomath, USA). Upon arrival the oligos were dissolved in RNAse-free water, diluted to a final concentration of $8 \mu \mathrm{g} / 10 \mathrm{nl}$ and stored at $+4^{\circ} \mathrm{C}$. The $\mathrm{MO}$ were dissolved and heated up at $65^{\circ} \mathrm{C}$ for $10 \mathrm{~min}$ prior to the use every time.

Table 4. Antisense Morpholino oligonucleotides

\begin{tabular}{|l|l|l|l|}
\hline $\begin{array}{l}\text { Morpholino } \\
\text { name }\end{array}$ & Target gene & Sequence 5' $\rightarrow 3^{\prime}$ & $\begin{array}{l}\text { Working } \\
\text { concentration }\end{array}$ \\
\hline PTK7MO2 & $\begin{array}{l}\text { Xenopus laevis } \\
\text { PTK7 }\end{array}$ & TGCATCGCGGCCTCTCCCCTCAC & $\begin{array}{l}5-10 \\
\text { ng/embryo }\end{array}$ \\
\hline
\end{tabular}




\begin{tabular}{|c|c|c|c|}
\hline $\begin{array}{l}\text { Morpholino } \\
\text { name }\end{array}$ & Target gene & Sequence 5 ' $\rightarrow 3^{\prime}$ & $\begin{array}{l}\text { Working } \\
\text { concentration }\end{array}$ \\
\hline PTK7MO3 & $\begin{array}{l}\text { Xenopus laevis } \\
\text { PTK7 }\end{array}$ & TTCCTGCCCCGGATCCTCTCACTGC & $\begin{array}{l}\text { 5-10 } \\
\text { ng/embryo }\end{array}$ \\
\hline PTK7mmMO2 & $\begin{array}{l}\text { mutated } \\
\text { PTK7MO2, } \\
\text { which does not } \\
\text { bind the target } \\
\text { sequence }\end{array}$ & TGgATCcCGcCCTCTgCCgTCA & $\begin{array}{l}\text { 5-10 } \\
\text { ng/embryo }\end{array}$ \\
\hline PTK7mmMO3 & $\begin{array}{l}\text { mutated } \\
\text { PTK7MO3, } \\
\text { which does not } \\
\text { bind the target } \\
\text { sequence }\end{array}$ & TTgCTcCCCCGcATCCTgTCAgTGC & $\begin{array}{l}\text { 5-10 } \\
\text { ng/embryo }\end{array}$ \\
\hline PKC $1 \mathrm{MO} 1$ & $\begin{array}{l}\text { Xenopus laevis } \\
\text { PKC } \delta 1\end{array}$ & AGGATATGCGTAGGAAGGAGACATG & $\begin{array}{l}10-20 \\
\text { ng/embryo }\end{array}$ \\
\hline PKC $11 \mathrm{MO} 2$ & $\begin{array}{l}\text { Xenopus laevis } \\
\text { PKC } \delta 1\end{array}$ & AGGATAAGCGTAGGAAAGGAGCCAT & $\begin{array}{l}10-20 \\
\text { ng/embryo }\end{array}$ \\
\hline RACK1 MO1 & $\begin{array}{l}\text { MO1 targets } \\
\text { CDS, starting } \\
\text { from the } \\
\text { translation start } \\
\text { (ATG) }\end{array}$ & CCCGAAGTGTCATTTGCTCAGTCAT & $\begin{array}{l}10-20 \\
\text { ng/embryo }\end{array}$ \\
\hline RACK1 MO2 & $\begin{array}{l}\text { MO2 targets 5'- } \\
\text { UTR }\end{array}$ & CTGAAACCGCTCCACCGACTAAGGA & $\begin{array}{l}10-20 \\
\text { ng/embryo }\end{array}$ \\
\hline control Mo & no target & ССТСТTAССТСАGTTAСААТTTATA & $\begin{array}{l}\text { 5-20 } \\
\text { ng/embryo }\end{array}$ \\
\hline
\end{tabular}




\subsection{Antibodies}

The antibodies used during this study are listed in table 5 .

Table 5. Antibodies

\begin{tabular}{|c|c|c|c|c|c|}
\hline \multirow{2}{*}{ Name } & \multirow{2}{*}{$\begin{array}{l}\text { Company, } \\
\text { catalogue } \\
\text { number }\end{array}$} & \multirow{2}{*}{ Description } & \multicolumn{3}{|l|}{ Dilution } \\
\hline & & & WB & IP & IF \\
\hline HA.11 & $\begin{array}{l}\text { Covance, } \\
\text { MMS-101P }\end{array}$ & $\begin{array}{l}\text { Primary mouse monoclonal } \\
\text { antibody recognizes HA-tag } \\
\text { (peptide CYPYDVPDYASL) }\end{array}$ & 1:1000 & $1: 150$ & $1: 100$ \\
\hline $\begin{array}{l}\text { HA.11- } \\
\text { FITC }\end{array}$ & $\begin{array}{l}\text { Covance, } \\
\text { FITC-101L }\end{array}$ & $\begin{array}{l}\text { HA. } 11 \text { antibody directly coupled } \\
\text { with FITC fluorescent dye }\end{array}$ & & & $1: 100$ \\
\hline 9E10 MT & Sigma, M4439 & $\begin{array}{l}\text { Primary mouse monoclonal } \\
\text { antibody, recognizes Myc-tag } \\
\text { (peptide corresponding to } \\
\text { residues } 408-439 \text { of the human } \\
\text { cMyc protein) }\end{array}$ & $1: 5000$ & $1: 500$ & \\
\hline $\begin{array}{l}\text { 9E10 } \\
\text { MT-Cy3 }\end{array}$ & Sigma, C6594 & $\begin{array}{l}\text { 9E10 MT antibody directly } \\
\text { coupled with Cy3 fluorescent dye }\end{array}$ & & & $1: 100$ \\
\hline MT & $\begin{array}{l}\text { Abcam } \\
\text { ab19234 }\end{array}$ & $\begin{array}{l}\text { Primary goat polyclonal against } \\
\text { Myc-tag (recognizes peptide } \\
\text { EQKLISEEDL) }\end{array}$ & $1: 10000$ & & \\
\hline GFP & $\begin{array}{l}\text { Roche, } \\
11814460001\end{array}$ & $\begin{array}{l}\text { Primary mouse monoclonal } \\
\text { against GFP }\end{array}$ & $1: 1000$ & & \\
\hline GFP 1 & Abcam, ab290 & $\begin{array}{l}\text { Primary rabbit polyclonal against } \\
\text { GFP }\end{array}$ & & & $1: 1000$ \\
\hline $\operatorname{actin} \mathrm{C} 4$ & $\begin{array}{l}\text { Millipore, } \\
\text { MAB1501 }\end{array}$ & $\begin{array}{l}\text { Primary mouse monoclonal } \\
\text { against actin }\end{array}$ & $1: 10000$ & & \\
\hline $\begin{array}{l}\text { Phalloidin } \\
\text { TRITC }\end{array}$ & Sigma, P1951 & $\begin{array}{l}\text { Fungal toxin of Amanita } \\
\text { phalloides, binds specifically to } \\
\text { f-actin coupled with TRITC } \\
\text { fluorescent dye }\end{array}$ & & & $1: 500$ \\
\hline
\end{tabular}




\begin{tabular}{|c|c|c|c|c|c|}
\hline \multirow[b]{2}{*}{ Name } & \multirow{2}{*}{$\begin{array}{l}\text { Company, } \\
\text { catalogue } \\
\text { number }\end{array}$} & \multirow[b]{2}{*}{ Description } & \multicolumn{3}{|c|}{ Dilution } \\
\hline & & & WB & IP & IF \\
\hline $\begin{array}{l}\text { a-mouse- } \\
\text { Alexa } \\
488\end{array}$ & $\begin{array}{l}\text { Invitrogen, } \\
\text { A11029 }\end{array}$ & $\begin{array}{l}\text { Secondary goat anti mouse lgG } \\
\text { coupled with Alexa } 488 \text { dye }\end{array}$ & & & 1:200 \\
\hline $\begin{array}{l}\text { a-mouse- } \\
\text { Alexa } \\
596\end{array}$ & $\begin{array}{l}\text { Invitrogen, } \\
\text { A11005 }\end{array}$ & $\begin{array}{l}\text { Secondary goat anti mouse lgG } \\
\text { coupled with Alexa } 596 \text { dye }\end{array}$ & & & $1: 200$ \\
\hline $\begin{array}{l}\text { a-rabbit- } \\
\text { FITC }\end{array}$ & Sigma, F7367 & $\begin{array}{l}\text { Secondary goat anti rabbit lgG } \\
\text { coupled with FITC dye }\end{array}$ & & & $1: 200$ \\
\hline $\begin{array}{l}\text { a-rabbit- } \\
\text { HRP }\end{array}$ & $\begin{array}{l}\text { Cell Signaling, } \\
7074\end{array}$ & $\begin{array}{l}\text { Secondary anti rabbit lgG } \\
\text { coupled with HRP }\end{array}$ & & $1: 2000$ & \\
\hline $\begin{array}{l}\text { a-mouse- } \\
\text { HRP }\end{array}$ & $\begin{array}{l}\text { Santa Cruz, sc- } \\
2005\end{array}$ & $\begin{array}{l}\text { Secondary goat anti mouse lgG } \\
\text { coupled with HRP }\end{array}$ & & $1: 5000$ & \\
\hline $\begin{array}{l}\text { a-goat- } \\
\text { HRP }\end{array}$ & $\begin{array}{l}\text { Santa Cruz } \\
\text { SC-2020 }\end{array}$ & $\begin{array}{l}\text { Secondary donkey anti goat IgG } \\
\text { coupled with HRP }\end{array}$ & & $1: 10000$ & \\
\hline
\end{tabular}

\subsection{Xenopus Methods}

\subsubsection{Xenopus embryo culture, micromanipulation and microinjection}

\subsubsection{Preparation of Xenopus laevis testis}

The Xenopus male frog was placed into a $0.05 \%$ benzocaine/water solution at room temperature for $30 \mathrm{~min}$. The frog was decapitated and the testes were removed. Testes were washed 3 times with $1 \times \mathrm{MBS}$ and stored in $1 \times \mathrm{MBS}$ buffer at $4^{\circ} \mathrm{C}$.

\subsubsection{Embryo microinjection and culture}

Xenopus laevis female frogs were injected into the dorsal lymph sac with1000 units human chorionic gonadotropin (hCG, Sigma Aldrich) hormone. After approximately 12 hours the frogs lay eggs. Laid eggs were fertilized in vitro with a piece of macerated testis in $0.1 \times$ MBS. Fertilized embryos were treated with $2 \%$ cysteine hydrochloride, $\mathrm{pH} 8.0$ for 3-5 min to remove the jelly coat. The embryos were cultured in $0.1 \mathrm{X}$ MBS at $12.5-18^{\circ} \mathrm{C}$. Albino embryos were stained with Nile-Blue vital dye for 5-10 min prior to injection for better differentiation of the animal and vegetal pole and later to differentiate the 
developmental stages. For injections the eggs were placed in injection buffer on a cooling plate. The solutions for microinjections were loaded into glass capillaries with microloader tips (Eppendorf). The glass capillaries were prepared with a needle puller. For the injections the Microinjector 5242 (Eppendorf) was used. The mRNA and morpholino oligonucleotides were injected animally into the prospective ectodermal tissues. Depending on the experiment the injections were performed at 1-, 2-, 4- or 8-cell stages. The injected volume differs from 4 to $10 \mathrm{nl}$. The Injected embryos were kept for 1 up to 2 hours in the injection buffer to allow the heeling after the injection procedure. Afterwards the embryos were washed twice in $0.1 \times$ MBS and cultured in $0.1 \times$ MBS. The developmental stages were defined according to Nieuwkoop and Faber (Nieuwkoop 1991) normal table of Xenopus laevis (Daudin). For neural crest migration experiments the embryos were injected animally into one blastomere of a two-cell stage embryo. To analyze neural tube defects embryos were injected into the animal pole at one-cell stage or into the dorsal blastomere at 8-cell .

\subsubsection{Xenopus ectodermal explant assay (animal cap assay)}

To investigate the intracellular localization of proteins the animal cap assay was employed (Wallingford and Harland, 2001). For ectodermal explant assays the RNA encoding tagged protein constructs or morpholino blocking oligonucleotides were injected animally at one-cell stage. Xenopus embryos were grown till stage 8 and excised with forceps on $1 \%$ agarose-coated Petri dishes in 0,8x MBS buffer according the protocol described by Wallingford and Harland. At stage 10.5 - 14 animal caps were fixed in MEMFA for 45 min and immunostained for confocal analysis.

\subsubsection{Cranial neural crest (NC) explants}

The neural crest explants were performed as described in Borchers, 2001. The embryos were grown till neurula stages (stage 16-17) and placed on 1\% agarose-coated Petri dishes in fresh prepared 0,8x MBS buffer. The vitellin membrane as well the epithelial tissue covering the area of the cranial neural crest cells were removed with forceps. With the help of an eyebrow-knife or forceps the neural crest cells were explanted and placed on a fibronectin coated chambers filled with DFA medium with the mesodermal side at the bottom. The neural crest migration was observed for 6-14 $\mathrm{h}$ on different microscopes or the NC explants were fixed in MEMFA, immunostained and analyze by LSM confocal imaging. Fibronectin coated chambers were made as follows: liquid bovine fibronectin (Sigma) with a concentration of $1 \mathrm{mg} / \mathrm{ml}$ were diluted to $10 \mu \mathrm{g} / \mathrm{ml}$ with freshly made $1 \mathrm{X}$ PBS. The fibronectin solution was applied on Lab-Tek TM Chambered Cover glass Object slides over night at $4^{\circ} \mathrm{C}$. Directly before the explantation starts the fibronectin solution was replaced with DFA. 


\subsubsection{Immunofluorescence staining}

\subsubsection{Immunostaining of the ectodermal explants (animal caps)}

Upon the MEMFA fixation the ectodermal explants were washed 3 times with PBS containing $0.1 \%$ Tween20 (PTw) and stained according to the following protocol:

Blocking with $10 \%$ fetal calf serum (FCS, Difco) in PTw for $1 \mathrm{~h}$ at room temperature Rinse one time with PTw, apply the primary antibody ( $\alpha$-GFP, $\alpha$-HA, $\alpha$-pJNK,

$\alpha-\beta 1$ integrin), diluted in PTw for $2-3 \mathrm{~h}$ at room temperature or at $4^{\circ} \mathrm{C}$ overnight. Wash with PTw to remove the unbound primary antibody for 15 min, 3 times.

Apply the secondary antibody ( $\alpha$-myc-Cy3, $\alpha$-rabbit-FIC, $\alpha$-mouse-Alexa488, $\alpha$-mouse-

Cy5), diluted in Ptw for 1-2 $\mathrm{h}$ at room temperature.

Wash with PTw to remove the unbound secondary antibody for $7 \mathrm{~min}, 3$ times.

Optional:

For DAPI staining the ectodermal explants should be rinsed one time with PBS, incubated in $1 \mu \mathrm{g} / \mathrm{ml}$ DAPI PBS solution for 7-10 min and washed 2 times with PBS. The protein localization was analyzed by laser scanning microscopy on different microscopes.

\subsubsection{Immunostaining of the gelatin-albumin sections}

Vibratome sectioning (Hollemann and Pieler 1999)

Embryos were embedded in gelatin-albumin (GA), which was polymerized by mixing $2 \mathrm{ml}$ of GA with $125 \mu \mathrm{l}$ of $25 \%$ glutaraldehyde. $50 \mu \mathrm{m}$ vibratome sections were made using a Leica VT1000S Vibratome. Sectioned tissue samples were placed on microscope slides and immunostained according to the ectodermal explant protocol.

Gelatin/albumin was made with $4.88 \mathrm{mg} / \mathrm{ml}$ gelatin, $0.3 \mathrm{~g} / \mathrm{ml}$ bovine serum albumin and $0.2 \mathrm{mg} / \mathrm{ml}$ sucrose in PBS. The gelatin was first dissolved by heating the solution to $60^{\circ} \mathrm{C}$ before albumin and sucrose were added, filtered with a 0.45 $\mu \mathrm{m}$ filter (Satorius) and stored at $-20^{\circ} \mathrm{C}$.

Mowiol was made with $5 \mathrm{~g}$ Mowiol which was stirred overnight in $20 \mathrm{ml}$ PBS. After addition of $10 \mathrm{ml}$ glycerol, the solution was stirred overnight. Not dissolved Mowiol was removed by centrifugation of the solution for $30 \mathrm{~min}$ at $20,000 \mathrm{~g}$. The supernatant was adjusted to $\mathrm{pH} 7.0$ (using $\mathrm{pH}$ stripes) and stored at $-20^{\circ} \mathrm{C}$. 


\subsubsection{Whole-mount in situ hybridization (WISH) and X-gal staining}

\section{X-gal staining}

For X-gal staining B-galactosidase (lacZ) mRNA was co-injected as a lineage tracer. This is used for whole-mount in situ hybridization (WISH) experiments to determine the lacZ RNA-injected regions of the embryo (Hardcastle et al. 2000). Before staining the Xenopus embryos were fixed one hour in MEMFA and afterwards washed 3 times in 1x PBS and stained with X-gal solution in the dark until the desired level of staining was achieved. The X-gal solution was removed by washing 3-4 times with PBS and the embryos were fixed again in MEMFA for 45 min. Later the embryos were transferred in 100\% ethanol for longterm storage at $-20^{\circ} \mathrm{C}$. All steps were done at room temperature.

\section{Whole-mount in situ hybridization (WISH)}

Whole-mount in situ hybridization (WISH) was performed as described (Harland 1991). All steps were performed at room temperature with mild agitation.

Detailed protocol of Whole-mount in situ hybridization (WISH)

\section{WISH day 1.}

\section{Rehydration of embryos}

Prior to WISH embryos were rehydrated, as described below.

\section{Rehydration of embryos}

\begin{tabular}{|c|l|c|}
\hline $\begin{array}{c}\text { Step } \\
\text { Number }\end{array}$ & Solution & $\begin{array}{c}\text { Incubatio } \\
\text { n time }\end{array}$ \\
\hline 1 & $100 \%$ ethanol & $3 \mathrm{~min}$ \\
\hline 2 & $75 \%$ ethanol in water & $3 \mathrm{~min}$ \\
\hline 3 & $50 \%$ ethanol in water & $3 \mathrm{~min}$ \\
\hline 4 & $25 \%$ ethanol in PTw & $3 \mathrm{~min}$ \\
\hline 5 & PTw & $3 \mathrm{~min}$ \\
\hline
\end{tabular}

\section{Proteinase K treatment}

To make the embryos accessible for RNA probes, they were treated with proteinase $\mathrm{K}(10 \mu \mathrm{g} / \mathrm{ml})$ in PTw. The proteinase $\mathrm{K}$ incubation time was chosen depending on the embryo stage. 
Proteinase $\mathrm{K}$ treatment procedure

\begin{tabular}{|c|c|c|}
\hline $\begin{array}{c}\text { Developmental } \\
\text { stage of Xenopus } \\
\text { embryos }\end{array}$ & $\begin{array}{c}\text { Incubation time } \\
(\mathbf{m i n})\end{array}$ & Temperature \\
\hline $9-10.5$ & $6-8$ & room temperature \\
\hline $14-16$ & $8-10$ & room temperature \\
\hline $20-25$ & $15-18$ & room temperature \\
\hline 36 & $22-25$ & room temperature \\
\hline 40 & $17-20$ & $37^{\circ} \mathrm{C}$ \\
\hline $42-43$ & $27-30$ & $37^{\circ} \mathrm{C}$ \\
\hline 46 & $32-35$ & $37^{\circ} \mathrm{C}$ \\
\hline
\end{tabular}

\section{Acetylation and refixation}

Acetylation of embryos was performed as described below.

\section{Acetylation of Xenopus embryos}

\begin{tabular}{|c|c|c|}
\hline $\begin{array}{c}\text { Step } \\
\text { Number }\end{array}$ & Buffer & $\begin{array}{c}\text { Incubation } \\
\text { time }\end{array}$ \\
\hline 1 & $1 \mathrm{M}$ Triethanolamine chlorid, $\mathrm{pH} 7.0$ & $2 \times 5 \mathrm{~min}$ \\
\hline 2 & $1 \mathrm{M}$ TEA with $0.3 \%$ acetic anhydride & $5 \mathrm{~min}$ \\
\hline 3 & $1 \mathrm{M}$ TEA with $0.6 \%$ acetic anhydride & $5 \mathrm{~min}$ \\
\hline 4 & PTw & $5 \mathrm{~min}$ \\
\hline
\end{tabular}

Upon acetylation, embryos were fixed for 20 minutes in PTw containing 4\% (v/v) formaldehyde and were washed 5 times with PTw buffer.

\section{Hybridization}

After the last washing step approximately $1 \mathrm{ml}$ of PTw was left in the tubes and $250 \mu \mathrm{l}$ Hyb-Mix were added. The solution was replaced immediately by $500 \mu$ of fresh HybMix and incubated for 10 minutes at $60^{\circ} \mathrm{C}$. The Hyb-Mix was exchanged again and embryos were incubated $4-5 \mathrm{~h}$ at $60^{\circ} \mathrm{C}$. The Hyb-Mix was replaced with the desired labeled RNA probe, diluted in Hyb-Mix solution. The hybridization was performed overnight at $60^{\circ} \mathrm{C}$.

\section{WISH day 2.}

\section{Washing and RNAse treatment}

To remove unbound RNA probe, the samples were washed and digested with RNAse A $(10 \mu \mathrm{g} / \mathrm{ml})$ and RNAse $\mathrm{T} 1(10 \mathrm{U} / \mathrm{ml})$ as described in the table below. 
Washing and RNAse treatment of Xenopus embryos

\begin{tabular}{|c|c|c|}
\hline $\begin{array}{c}\text { Step } \\
\text { Number }\end{array}$ & Solution & Incubation temperature and time \\
\hline 1 & Hyb Mix & $60^{\circ} \mathrm{C}, 10 \mathrm{~min}$ \\
\hline 2 & $2 \times \mathrm{SSC}$ & $60^{\circ} \mathrm{C}, 3 \times 15 \mathrm{~min}$ \\
\hline 3 & RNAse in $2 \times \mathrm{SSC}$ & $37^{\circ} \mathrm{C}, 60 \mathrm{~min}$ \\
\hline 4 & $2 \times \mathrm{SSC}$ & room temperature, $5 \mathrm{~min}$ \\
\hline 5 & $0.2 \times \mathrm{SSC}$ & $60^{\circ} \mathrm{C}, 2 \times 30 \mathrm{~min}$ \\
\hline 6 & $\mathrm{MAB}$ & room temperature, $2 \times 15 \mathrm{~min}$ \\
\hline
\end{tabular}

\section{Blocking and antibody reaction}

Embryos treated with MAB buffer, containing the Boehringer Mannheim Blocking Reagent (BMB) and horse serum to block unspecific binding, and incubated with Sheep Alkaline phosphatase-coupled anti-Dig antibody (Sigma) according to the table below.

\section{Blocking and antibody incubation}

\begin{tabular}{|c|c|c|}
\hline $\begin{array}{c}\text { Step } \\
\text { Number }\end{array}$ & Solution & Incubation temperature and time \\
\hline 1 & $\mathrm{MAB} / 2 \% \mathrm{BMB}$ & room temperature, $10 \mathrm{~min}$ \\
\hline 2 & $\mathrm{MAB} / 2 \% \mathrm{BMB} / 20 \%$ Horse serum & room temperature, $30 \mathrm{~min}$ \\
\hline 3 & $\begin{array}{c}\mathrm{MAB} / 2 \% \mathrm{BMB} / 20 \% \text { Horse serum } \\
1: 5000 \mathrm{\alpha}-\mathrm{DIG} \text { antibodies }\end{array}$ & room temperature, 4 hours \\
\hline 4 & $\mathrm{MAB}$ & room temperature, $3 \times 10 \mathrm{~min}$ \\
\hline 5 & $\mathrm{MAB}$ & $4^{\circ} \mathrm{C}$, overnight \\
\hline
\end{tabular}

\section{WISH day 3.}

\section{Staining reaction}

The alkaline phosphatase staining reaction was performed as described in the table below.

\section{Alkaline phosphatase staining reaction}

\begin{tabular}{|c|c|c|}
\hline Step Number & Solution & Incubation time \\
\hline 1 & MAB & $5 \times 5$ min, room \\
\hline 2 & APB & $3 \times 5 \mathrm{~min}$, room \\
\hline 3 & APB with $80 \mu \mathrm{g} / \mathrm{ml} \mathrm{NBT}$ \\
$175 \mu \mathrm{g} / \mathrm{ml} \mathrm{BCIP}$ & Up to three days, $4^{\circ} \mathrm{C}$ \\
\hline
\end{tabular}

Upon staining, albino embryos were fixed in MEMFA, washed with PTw, documented and stored in $100 \%$ ethanol. Pigmented embryos were bleached to remove the pigment, which can interfere with the specific WISH signal. 


\section{Bleaching}

The bleaching of pigmented embryos was performed as described in the table below.

\section{Bleaching of pigmented Xenopus embryos}

\begin{tabular}{|c|c|c|}
\hline $\begin{array}{c}\text { Step } \\
\text { Number }\end{array}$ & Solution & Incubation time \\
\hline 1 & $2 \times$ SSC & $3 \times 5$ min \\
\hline 2 & $2 \times S S C$ with $50 \%$ formamide, $1 \% \mathrm{H}_{2} \mathrm{O}_{2}$ & Until embryos loose pigment \\
\hline 3 & MEMFA & $30 \mathrm{~min}$ \\
\hline 4 & PTw & $3 \times 5 \mathrm{~min}$ \\
\hline
\end{tabular}

Bleached embryos were documented and stored in $100 \%$ ethanol.

\subsection{DNA Methods}

\subsubsection{Plasmid DNA preparation}

Isolation of plasmid DNA from bacteria cultures was performed in analytical scale using the Fermentas Gene Jet ${ }^{\text {TM}}$ Plasmid Miniprep Kit according to the manufacturer's instructions. Isolation of appropriate amounts of DNA was performed with the NucleoBond Xtra Midi Kit (Macherey and Nagel) according to the manufacturer's instructions. Quantification of DNA was carried out using the NanoDrop 2000c spectrophotometer (Thermo scientific) according to the manufacturer's instructions.

\subsubsection{DNA restriction digestion}

Restriction digest of DNA was carried out using Fermentas Life Sciences (St.Leon-Rot) restriction enzymes according to the manufacturer's instructions.

\subsubsection{Agarose gel electrophoresis}

To separate DNA fragments DNA fragments after restriction digest, ligation reaction or PCR amplification, standard agarose electrophoresis was used (Fisher and Dingman, 1971 (Fisher and Dingman 1971; Helling et al. 1974). As running buffer 1x Tris- acetate buffer (TAE) was used. The DNA was visualized with the ChemiDoc gel apparatus (BioRad) after adding $0.5 \mu \mathrm{g} / \mathrm{ml}$ Ethidium bromide to the agarose (Sharp et al. 1973).

\subsubsection{Purification of DNA fragments}

The purification of DNA fragments from agarose gel pieces or after enzymatic reactions like restriction digestion or ligations the Invisorb "Spin DNA extraction/Fragment cleanup" Kit (Invitek, Berlin) was used according to the manufacturer's instructions. 


\subsubsection{Polymerase chain reaction (PCR)}

To amplify DNA fragments, a standard PCR reaction was carried out (Sharp et al. 1973). DreamTag ${ }^{\mathrm{TM}}$ DNA polymerase ( $\left.5 \mathrm{U} / \mu \mathrm{l}\right)$ (Fermentas Life Sciences) was used for analytical PCR. High fidelity Pfu polymerase (2.5 U/ $\mu$ l, Fermentas Life Sciences) was used for the molecular cloning. All conditions were chosen according to the manufacturer's manuals.

The following program was used for DNA fragments amplification:

\begin{tabular}{|c|c|c|}
\hline $\begin{array}{c}\text { Number of } \\
\text { cycles }\end{array}$ & Function & Temperature and time \\
\hline 1 & Initial denaturation & $-95^{\circ} \mathrm{C}, 2 \mathrm{~min}$ \\
\hline 30 & \begin{tabular}{|} 
Denaturation \\
Primer annealing \\
Elongation
\end{tabular} & $\begin{array}{l}-95^{\circ} \mathrm{C}, 45 \mathrm{sec} \\
\text { - the temperature depends on primer GC content, } 45 \mathrm{sec} \\
-68^{\circ} \mathrm{C} \text { for Pfu polymerase, } \\
-72^{\circ} \mathrm{C} \text { for DreamTag }{ }^{\mathrm{TM}} \text { polymerase, } 1 \mathrm{~min} / 1000 \mathrm{bp} \text { of } \\
\text { target DNA fragment }\end{array}$ \\
\hline 1 & $\begin{array}{l}\text { Final elongation } \\
\text { step }\end{array}$ & $\begin{array}{l}-68^{\circ} \mathrm{C} \text { or } 72^{\circ} \mathrm{C} \text { depending on the polymerase used, } 10 \\
\min \end{array}$ \\
\hline
\end{tabular}

\subsubsection{DNA ligation}

For molecular cloning the DNA ligation steps were performed using T4 Ligase (Fermentas Life Sciences) according to the manufacturer's instructions. The molar ratio of vector DNA and insert DNA during ligation was 1:3 and the total amount of vector DNA 50 ng. For a $20 \mu$ reaction mixture $2 \mu \mathrm{l}$ of T4 DNA ligase $(5 \mathrm{U} / \mu \mathrm{l})$ was used. The ligation reaction time for insert length shorter than $1000 \mathrm{bp}$ was1 hour at room temperature and for inserts longer than $1000 \mathrm{bp}$ overnight at $16^{\circ} \mathrm{C}$. After the ligation process the ligase was inactivated for $10 \mathrm{~min}$ at $65^{\circ} \mathrm{C}$ before the transformation could start.

\subsubsection{Chemical transformation of bacterial cells}

For chemical transformation 60-100 $\mu \mathrm{l}$ of chemically-competent E.coli XL1blue cells were thawed on ice for $5 \mathrm{~min}$. Afterwards 1- $2 \mu \mathrm{l}$ of a ligation mix or $100-500 \mathrm{ng}$ of plasmid DNA were added and incubated for 30-60 min on ice followed by a heat-shock for $90 \mathrm{~s}$ at $42^{\circ} \mathrm{C}$. Immediately after the heat shock the cells were incubated for 2 minutes on ice before 1 $\mathrm{ml}$ preheated $\left(37^{\circ} \mathrm{C}\right)$ LB medium was added. After incubation at $37{ }^{\circ} \mathrm{C}$ for $45-60 \mathrm{~min}$ (Mandel and Higa 1970) the transformed bacterial cells were pelleted upon a short centrifugation step. Bacterial pellets were seeded on LB agar plates supplemented with appropriate antibiotics for the selection of transformed cells $(0.1 \mathrm{mg} / \mathrm{ml}$ ampicillin (Biomol), $0.05 \mathrm{mg} / \mathrm{ml}$ kanamycin (Biomol). The LB agar plates were grown overnight at $37^{\circ} \mathrm{C}$ (Mandel and Riga 1970). 


\subsubsection{Electro transformation of bacterial cells}

For electro-transformation 40-60 $\mu$ of electro-competent E.coli XL1blue cells were thawed on ice for $5 \mathrm{~min}$. Afterwards 1 - $2 \mu \mathrm{l}$ of a ligation mix or $100-500 \mathrm{ng}$ of plasmid DNA were added to the cells, mixed and transferred into an ice cold $2 \mathrm{~mm}$ electroporation cuvette (Thermo Electron) and incubated for 1 min on ice. After application of an electric pulse of $1.8 \mathrm{kV}$ with $25 \mu \mathrm{F}$, the transformation reaction were immediately mixed with $0.5 \mathrm{ml}$ cold LB-medium and shook incubated at $37^{\circ} \mathrm{C}$ for $45-60$ min (Dower et al. 1988). After incubation the transformed bacterial cells were pelleted upon a short centrifugation step. Bacterial pellets were seeded on LB agar plates supplemented with appropriate antibiotics for the selection of transformed cells $(0.1 \mathrm{mg} / \mathrm{ml}$ ampicillin (Biomol), $0.05 \mathrm{mg} / \mathrm{ml}$ kanamycin (Biomol). The LB agar plates were incubated over night at $37^{\circ} \mathrm{C}$ (Mandel and Higa 1970).

\subsubsection{DNA sequencing analysis}

For sequencing the Dye-termination method was used, which was modified from (Sanger et al. 1977). The sequencing reaction was performed using the Big Dye ${ }^{\mathrm{TM}}$ Terminator Kit (Applied Biosystems) according to the manufacturer's instructions. The analysis of the sequences was carried out on the $\mathrm{ABI} 3100$ Automated Capillary DNA Sequencer (Applied Biosystems).

\section{The sequencing PCR mixture:}

\begin{tabular}{|c|c|}
\hline Component & Volume/ concentration \\
\hline DNA & $200-400 \mathrm{ng}$ \\
\hline Seq-mix & $1.5 \mu \mathrm{l}$ \\
\hline Seq-buffer & $1.5 \mu \mathrm{l}$ \\
\hline Primer & $8 \mathrm{pmol}$ \\
\hline HPLC water & up to $10 \mu \mathrm{l}$ \\
\hline
\end{tabular}

\section{The sequencing PCR}

\begin{tabular}{|c|c|}
\hline $\begin{array}{c}\text { Number of } \\
\text { cycles }\end{array}$ & Temperature and time \\
\hline & $96^{\circ} \mathrm{C}, 10 \mathrm{sec}$ \\
25 & $55^{\circ} \mathrm{C}, 15 \mathrm{sec}$ \\
& $60^{\circ} \mathrm{C}, 40 \mathrm{sec}$ \\
\hline
\end{tabular}


To purify the sequencing reaction $1 \mu$ of $125 \mathrm{mM}$ EDTA $(\mathrm{pH} 8.0), 1 \mu \mathrm{l}$ of $3 \mathrm{M}$ sodium acetate $(\mathrm{pH} 5.4)$ and $50 \mu \mathrm{l} 100 \%$ ethanol were added to the PCR mixture. The mixture was incubated for $5 \mathrm{~min}$ at room temperature followed by a 15 min centrifugation step at $14000 \mathrm{rpm}$. The obtained pellet was washed with $70 \mu \mathrm{l}$ of $70 \%$ ethanol, dried and diluted in $15 \mu \mathrm{l}$ of $\mathrm{HiDi}^{\mathrm{TM}}$ buffer (Applied Biosystems). The automated sequencing was performed by the Developmental Biochemistry sequencing lab using the $\mathrm{ABI} 3100$ Automated Capillary DNA Sequencer (Applied Biosystems).

\subsection{RNA Methods}

\subsubsection{In vitro synthesis of capped sense mRNA}

In vitro synthesis of sense capped mRNAs for microinjections into Xenopus embryos was performed with the SP6 or T7 mMessage mMachine kits ${ }^{T M}$ (Ambion) according to the manufacturer's manual. For a reaction volume of $20 \mu \mathrm{l} 0.5-1 \mu \mathrm{g}$ of linearized DNA template were used. The needed reaction time was $2-3$ hours at $37^{\circ} \mathrm{C}$ and was followed by an 15 min treatment with 5 units of TURBO DNAsel (Ambion) to remove the template DNA. The synthesized mRNA was cleaned up using the Illustra ${ }^{\mathrm{TM}}$ RNAspin Mini RNA Isolation Kit (GE Healthcare). The mRNA was quantified using the NanoDrop 2000c spectrophotometer (Thermo scientific).

\subsubsection{In vitro synthesis of labeled antisense RNA}

The following reaction mixture was used for the synthesis of Digoxigenin labeled antisense RNA for whole mount in situ experiments.

\begin{tabular}{|c|c|}
\hline Volume & Chemicals \\
\hline $5 \mu \mathrm{l}$ & of a 5x transcription buffer (Fermentas) \\
\hline $1 \mu \mathrm{l}$ & each 10 mM rATP, rCTP, rGTP (Roche) \\
\hline $0.64 \mu \mathrm{l}$ & $10 \mathrm{mM}$ rUTP (Roche) \\
\hline $0.36 \mu \mathrm{l}$ & digoxigenin-rUTP (Roche) \\
\hline $1 \mu \mathrm{l}$ & $0.75 \mathrm{M}$ DTT \\
\hline $0.5 \mu \mathrm{l}$ & RNAseOut (Invitrogen), \\
\hline $200-1000 \mathrm{ng}$ & linearized DNA template \\
\hline $1 \mu \mathrm{l}$ & T7 polymerase (20U/ $\mu \mathrm{l}$, Fermentas) \\
\hline \multicolumn{2}{|c|}{ RNAse-free water to the final volume of $25 \mu \mathrm{l}$} \\
\hline $25 \mu \mathrm{l}$ & \\
\hline
\end{tabular}

The reaction the reaction needed an incubation time of $2-3$ hours at $37^{\circ} \mathrm{C}$ followed by 15 min treatment with 5 units of TURBO DNAsel (Ambion) to remove the template DNA. The synthesized RNA was purified with RNeasy ${ }^{\mathrm{TM}}$ Mini Kit (Quiagen) according to manufacturer's manuals. 


\subsection{Protein techniques}

\section{SDS- polyacrylamide-gel-electrophoresis (SDS-PAGE)}

To separate denaturated proteins the SDS- polyacrylamide-gel-electrophoresis (SDSPAGE) was used (Laemmli 1970). Gels of the different acrylamid percentages were used for the analysis of the proteins with distinct molecular weights. Standard protocols were used to prepare polyacrylamide gels in a concentration-range from 8-12 percent (Russel 2001). The BioRad Mini Protean Tetra Cell was used according to the manufacturer's instructions.

The sizes of separated proteins and the percentages of the correspondent acrylamid gels

\begin{tabular}{|c|c|}
\hline Protein size, kDa & $\%$ of acrylamide \\
\hline $36-205$ & $5 \%$ \\
\hline $24-205$ & $7.5 \%$ \\
\hline $14-205$ & $10 \%$ \\
\hline $14-66$ & $12.5 \%$ \\
\hline $10-45$ & $15 \%$ \\
\hline
\end{tabular}

The protein samples were diluted 1:5 with $6 x$ Laemmli loading buffer and boiled for 5 min at $95^{\circ} \mathrm{C}$ before they were loaded on the gel. The gel run was performed in a BioRad ${ }^{\mathrm{TM}} \mathrm{gel}$ chambers filled with $1 \mathrm{x}$ Laemmli running buffer. For a precise separation of the proteins in the gel the voltage was applied to $70 \mathrm{~V}$ in the beginning. After the bromphenol-blue front reaches the separating gel, the voltage was raised to $120 \mathrm{~V}$.

\subsubsection{Lysis of Xenopus embryos for Western Blotting}

For each embryo $10 \mu \mathrm{l}$ of ColP buffer lysis buffer was used. The embryos were lysed with insulin syringes in Co-IP lysis buffer and lysates were centrifuged for $15 \mathrm{~min}$ at $16000 \mathrm{~g}$ at $4^{\circ} \mathrm{C}$. The achieved supernatants were diluted 1:5 with $6 x$ Laemmli loading buffer, boiled for $5 \mathrm{~min}$ at $95^{\circ} \mathrm{C}$ and loaded on the gel.

\subsubsection{Western Blotting}

For the transfer of proteins separated by SDS-Page to nitrocellulose membranes the Western-blot method was used (Towbin et al. 1979; Towbin and Gordon 1984; Towbin et al. 1992). After separation the proteins were transferred to a nitrocellulose membrane (0.45 $\mu \mathrm{m}$, Schleicher \& Schuell). The transfer process was carried out using the wet blot method. The transfer was performed using the BioRad Transfer-chamber in Western Blotting buffer for $70 \mathrm{~min}$ at $110 \mathrm{~V}$ at $4^{\circ} \mathrm{C}$ or on ice according to the manufacturer's instructions. After the transfer, the nitrocellulose membrane was blocked with a blocking solution to saturate unspecific binding sites. The membranes were blocked 3 times 
for $15 \mathrm{minusing} 5 \%(\mathrm{w} / \mathrm{v})$ milk powder solved in PTw buffer. The incubation with the primary antibody diluted in the blocking solution was carried out overnight at $4^{\circ} \mathrm{C}$. Afterwards, the membrane was washed 3 times for 15 min in blocking solution and the horseradish peroxidase coupled secondary antibody (HRP) was applied to the membrane in blocking solution. After $1 \mathrm{~h}$ incubation at room temperature the membrane was washed again with blocking solution 2 times for 15 min and one time in Ptw for $15 \mathrm{~min}$. The HRP signal was detected with the ECL Kit Super Signal Dura ${ }^{\mathrm{TM}}$ West Kit (Pierce) on exposure to X-ray films (Amersham).

\subsection{Laboratory equipment and software}

\section{Laboratory equipment:}

\begin{tabular}{|c|c|}
\hline Biofuge Fresco & Heraeus, \\
\hline Centrifuge 5415D & Eppendorf \\
\hline Centro LB 960 & Berthold technologies \\
\hline Concentrator 5301 & Eppendorf \\
\hline FBC 620 & Fisherbrand \\
\hline E. coli Pulser & BioRAD \\
\hline E143 & Consort \\
\hline Ice machine & Ziegra \\
\hline Needle puller & Sutter Instrument Company \\
\hline Genetic Analyzer 3130xl & Applied Biosystems Hitachi \\
\hline Water bath, heatable & GFL 1092 \\
\hline Incubator & Memmert \\
\hline Olympus U-RFL-T (UV-Lamp) & Olympus \\
\hline Olympus SZX12 (Microscope) & Olympus \\
\hline Microinjector 5242 & Eppendorf \\
\hline Opimax Typ TR & MS Laborgeräte \\
\hline Perfection 4990 Photo & Epson \\
\hline pH-meter & Sartorius \\
\hline Pneumatic Pico Pump PV820 & WPI \\
\hline PN-30 & Science Products $\mathrm{GmbH}$ \\
\hline PowerPacHC & Bio-RAD \\
\hline PowerPack P25 & Biometra \\
\hline RC5B Plus & Sorvall \\
\hline Steni 2000 & Zeiss \\
\hline T3 Thermocycler & Biometra \\
\hline Thermostat Plus & Eppendorf \\
\hline Vortex-Genie & Scientific Industries \\
\hline Ultrospec 1100 pro & Amersham Biosciences \\
\hline $\begin{array}{c}\text { Lab-Tek }^{\text {TM }} \text { Chambered Cover glass Object } \\
\text { slides }\end{array}$ & $\begin{array}{c}\text { NUNC, Thermo Fisher Scientific, } \\
\text { MA, USA }\end{array}$ \\
\hline Cold Light KL 1500 LCD & Carl Zeiss AG, Germany \\
\hline Vibratome, Type 1000 (Histology) & Pelco International \\
\hline Chemi Doc, gel documentation & BioRad \\
\hline Blotting chamber: Mini Protean Tetra Cell & BioRad \\
\hline Power Pac Basic Power Supply & BioRad \\
\hline $\begin{array}{c}\text { PCR-machines: UNOII Thermo block, } \\
\text { TRIO Thermo block }\end{array}$ & Biometra, Gottingen \\
\hline
\end{tabular}




\section{Optical devices:}

\begin{tabular}{|c|c|}
\hline Microscope & Company \\
\hline $\begin{array}{c}\text { Laser scanning Spinning Disk microscope: } \\
\text { Axio Observer.Z1 }\end{array}$ & $\begin{array}{c}\text { Carl Zeiss Microlmaging GmbH, } \\
\text { Germany }\end{array}$ \\
\hline $\begin{array}{l}\text { Laser scanning confocal microscope: } \\
\text { LSM510 META }\end{array}$ & $\begin{array}{c}\text { Carl Zeiss Microlmaging GmbH, } \\
\text { Germany }\end{array}$ \\
\hline $\begin{array}{l}\text { Laser scanning confocal microscope: } \\
\text { LSM780 }\end{array}$ & $\begin{array}{c}\text { Carl Zeiss Microlmaging } \mathrm{GmbH} \text {, } \\
\text { Germany }\end{array}$ \\
\hline $\begin{array}{c}\text { Fluorescent microscope: Lumar V12 } \\
\text { SteReo }\end{array}$ & $\begin{array}{c}\text { Carl Zeiss Microlmaging GmbH, } \\
\text { Germany }\end{array}$ \\
\hline Fluorescent microscope: Imager M1 & $\begin{array}{c}\text { Carl Zeiss Microlmaging } \mathrm{GmbH} \text {, } \\
\text { Germany }\end{array}$ \\
\hline Stereo Microscope: Steni 2000 & $\begin{array}{c}\text { Carl Zeiss Microlmaging GmbH, } \\
\text { Germany }\end{array}$ \\
\hline Fluorescent microscope: SZX12 & Olympus \\
\hline
\end{tabular}

\section{Software:}

Microsoft Office 2007-2010

SeqMan, DNASTAR Inc., Madison, USA

BLAST online system (Altschul et al. 1990)

Adobe Photoshop, Adobe systems Europe

AxioVision version 4.8.1, Carl Zeiss Microlmaging GmbH, Germany

Zen version 2010, 2011, Carl Zeiss Microlmaging GmbH, Germany

NanoDrop 3.01.1, Coleman Technologies Inc.

FIJI, based on ImageJ 


\section{$3 \quad$ Results}

\subsection{RACK1 loss-of-function causes neural tube closure defects}

Neurulation is an important morphogenetic process during embryonic development that forms the vertebrate central nervous system. If this process is disturbed this results in severe neural tube closure defects. As the knock-down of PTK7 leads to neural tube closure defects (Lu et al. 2004) this suggest that PTK7 play a role in this process. PTK7 likely functions via RACK1, since biochemical interaction for PTK7 and RACK1 were detected using in vitro transcription followed by co-immunoprecipitation. In vivo both are co-expressed in the area of the closing neural tube (Kwon et al. 2001; Lu et al. 2004). This is a hint that RACK1 has a function in neural tube closure like PTK7. To test these hypothesis two different morpholino oligonucleotides (MO1 and $\mathrm{MO} 2$ ) which block the translation of the RACK1 protein were used. The first morpholino (MO1) covers the ATG and the second (MO2) covers the 5'UTR region of the RACK1 gene. Both morpholinos were injected into Xenopus embryos at the one cell stage and the embryos were analyzed for neural tube closure phenotypes at neurula stages 17-18. The embryos developed normally until the start of neurulation. During neurulation both RACK1 morpholinos caused neural tube closure defects in approximately $70 \%$ of the embryos compared to control embryos injected with co MO were only $20 \%$ were affected (Fig.: $23 \mathrm{~A}$, B). Both sides of the neural tube failed to fuse and the length of the anterior posterior axis of the neural tube remained shorter. The results of these experiments suggest that RACK1, like PTK7, is required for neural tube closure because RACK1 loss-of-function using two different morpholinos shows the same phenotype as PTK7 loss-of-function.

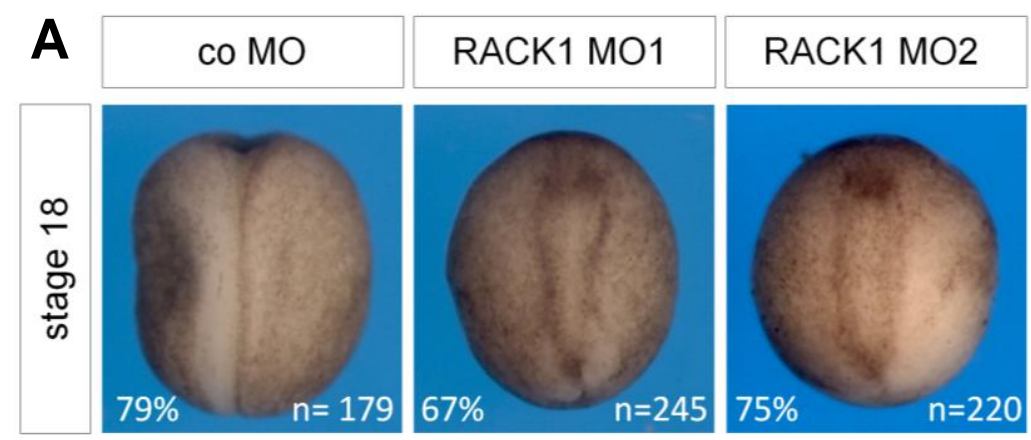




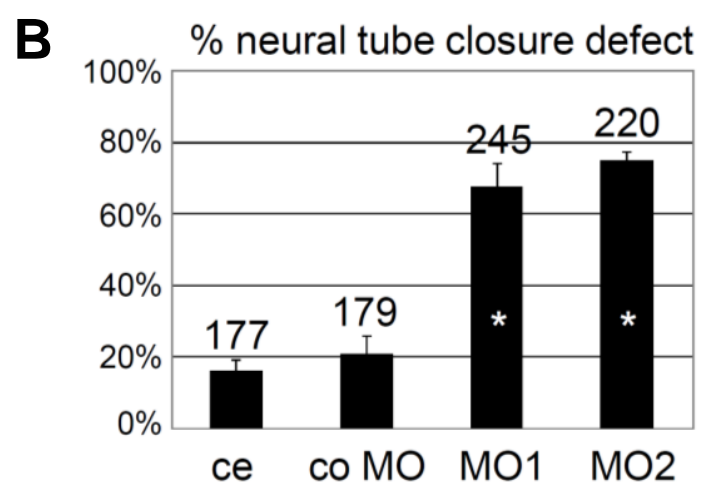

Figure 23. The RACK1 loss-of-function leads to neural tube defects. A) Embryos injected with $20 \mathrm{ng} \mathrm{MO} 1$ or MO2 show neural tube closure defects, whereas embryos injected with $20 \mathrm{ng}$ co MO display a closed neural tube. B) Bar chart summarizes the average percentage of neural tube closure phenotypes from three independent experiments (in A). The total number of injected embryos from all three batches and the s.e.m. are indicated for each condition/column. Neural tube closure defects were determined at stage 17/18. ce, un-injected control embryos. B) Neural tube closure defects caused by $20 \mathrm{ng}$ RACK1 MO1 or $20 \mathrm{ng} \mathrm{MO} 2$ are significantly different from phenotypes in embryos injected with $20 \mathrm{ng}$ control MO ( ${ }^{*}, \mathrm{P}<0.005$, Student's t-test). (B: experiments done by P. Wehner, and I. Shnitsar) (from Wehner et al. 2011)

The knock-down of RACK1 shows a disturbed neural tube closure (NTC) phenotype. To test if this phenotype is reversible expression constructs were injected which should restore the phenotype caused by the MOs. This was also tested in western blots (WB). To rescue the MO phenotype, only expression constructs, which are not recognized by the two different MOs, can be used. For MO1 the human homolog of RACK1 was tested which should not be affected by RACK1 MO1 due to a different ATG starting sequence compared to the Xenopus RACK1 gene. For MO2 the Xenopus RACK1 HA-tagged construct which lacks the 5'UTR was used. Embryos were injected at the one-cell stage and lysed to control the expression of the protein on WB with antibodies against HA-tag at gastrula stage (Fig.:24 A). Actin expression was used as a loading control and showed no difference in expression levels. The Xenopus RACK1-HA construct (xRACK1-HA) was blocked by RACK1 morpholino MO1 but not by a control MO (co MO) in Xenopus lysates. In contrast the translation of an HA-tagged human RACK1 construct (hRACK1-HA) was not affected by MO1 or control MO (Fig.: $24 \mathrm{~A}$ ). Additionally, embryos injected with MO1 and hRACK1 (Fig.: 24 B) or MO2 and xRACK1-HA (Fig.: 24 C) showed a rescue effect on neural tube closure. The co-injection of RNA which was not affected by the different MOs could rescue the morpholino neural tube closure defect. The rescue of these morpholino phenotypes by co-injection of RACK1 expression constructs that are not recognized by the morpholinos showed that the neural tube closure defects are caused by loss of RACK1 function in Xenopus. This is an indicator for a specific MO-effect. 


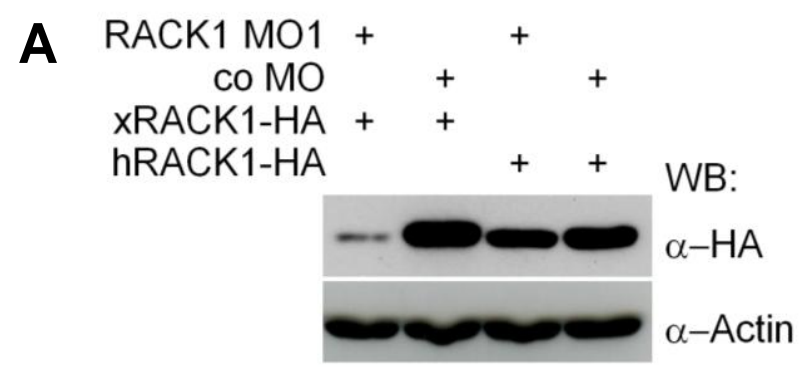

B \% neural tube closure defect

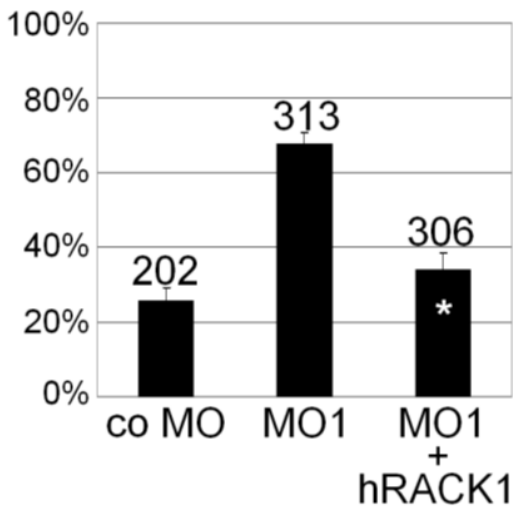

C $\%$ neural tube closure defect

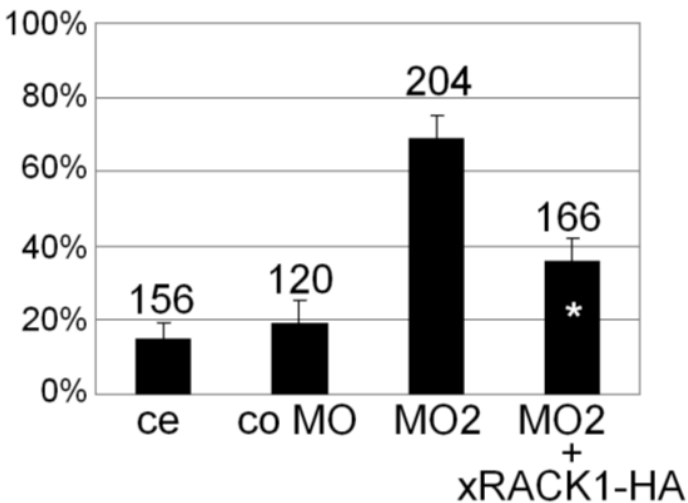

Figure 24. Different morpholinos of RACK1 caused neural tube closure defects and could be rescued by specific constructs. Bar charts summarize the average percentage of neural tube closure phenotypes from three independent experiments in Figure 23. The total number of injected embryos from all three batches and the s.e.m. are indicated for each condition/column. Neural tube closure defects were determined at stage 17/18. A) The translation of an HA-tagged Xenopus RACK1 construct (XRACK1) was inhibited by RACK1 MO1 but not by a control MO in Xenopus lysates. In contrast, the translation of an HA-tagged human RACK1 construct (hRACK1-HA) was not affected by RACK1 MO1 or the control MO. Embryos were injected at the one-cell stage with $10 \mathrm{ng}$ of the respective MOs in combination with $300 \mathrm{pg}$ RACK1 RNA. At stage 11, cells were lysed and protein expression was detected by western blotting using anti-HA antibodies. Actin expression served as a loading control. B) Human RACK1 (hRACK1) RNA (300 pg) rescues the neural tube closure defects caused by $10 \mathrm{ng}$ RACK1 MO1. Asterisk indicates that neural tube closure defects are significantly different from effects in embryos injected with MO1 $(P<0.005$, Student's $t$-test). C) Injection of $300 \mathrm{pg} x R A C K 1-H A$ RNA lacking the MO2 binding site rescues the neural tube closure defects caused by $20 \mathrm{ng} \mathrm{MO2}$. Asterisk indicates neural tube closure defects significantly different from effects in embryos injected with MO2 ( $P<0.01$, Student's $t$-test). ce: un-injected control embryos. (B, C: experiments done by P. Wehner, and I. Shnitsar) (from Wehner et al. 2011) 


\subsection{RACK1 and PTK7 loss-of-function lead to similar neural tube closure defects}

RACK1 and PTK7 loss-of-function (LOF) show both a neural tube closure phenotype. It seems that RACK1 plays like PTK7 an important role during the developmental process of neural tube closure. To monitor the individual knock-down phenotypes of PTK7 and RACK1 over time a time-lapse experiment was set up for direct comparison of RACK1 MO and PTK7 MO injected embryos. This should help to get a detailed view of the morphological changes during Xenopus development caused by the MO. The embryos were monitored from stage 15 to stage 21 . For a better visualization of the embryos the vitelline membranes were removed manually. Control MO (co MO) injected embryos were monitored as control. In general the PTK7 morphants showed a delay in neural tube closure (Fig.: 25). Neural plates were wider and more flat, the embryos are shorter compared to the control embryos. The direct comparison between PTK7 MO and RACK1 MO phenotypes showed similar defects in neural tube closure and axis elongation compared to the control embryos (Fig.: 25). In this respect we found the RACK1 loss-offunction phenotype resembles the PTK7 loss-of-function phenotype. This may indicate that both molecules act together during neural tube closure events.

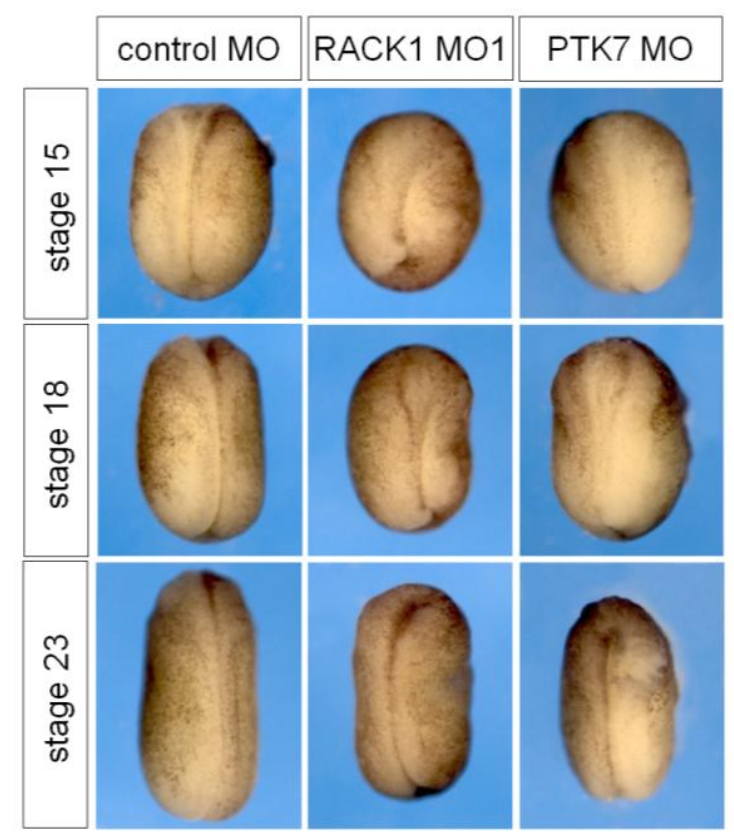

Figure 25. Time lapse pictures of embryos injected with RACK1 MO, PTK7 MO and control MO. Injected embryos showed a delay in neural tube closure accompanied by a defect in axis elongation, while control MO injected embryos developed normally. Xenopus embryos injected with $10 \mathrm{ng}$ control MO, RACK1 MO1 or PTK7 MO that were analyzed at stages 15,18 and 21 showed a similar delay in neural tube closure in the RACK1 and PTK7 morpholino injected embryos and the embryos remain shorter than the control. Embryos were injected at the one-cell stage and timelapse images were taken every 30 minutes from stage 15 to stage 21 (from Wehner et al. 2011). 
To check if the general cell fate decision was affected by MO knock-down of PTK7 and RACK1 two neural markers were used in in situ hybridization experiments, the pan-neural marker Sox2 and the lateral neural plate marker Pax3. Sox2 is a transcription factors, which is involved in the regulation of embryonic development and in the determination of cell fate. The Pax3 gene plays a critical role in the formation of tissues and organs during embryonic development and is active in neural crest cells. Xenopus embryos were injected with $\mathrm{MO}$ and later on the expression patterns of the marker genes were analyzed via in-situ hybridization. The result of these in-situ hybridizations shows that the markers are present and their expression pattern was in general not affected by PTK7 or RACK1 knock-down. The main differences that could be observed by Sox2 and Pax3 in-situ hybridization are wider neural plates and less closed neural tubes in RACK and PTK7 knock-down compared to controls (Fig.: 26). The marker expression is not changed only due to a broader neural plate the marker at each side of the embryo looks also extended compared to the expression pattern in the control MO injected embryos. This experiment shows that the injection of $\mathrm{MO}$ did not affect general cell fate decisions. The extended marker expression pattern most probably results from defects in morphogenetic cell movements like convergent extension (CE) of the neural plate.

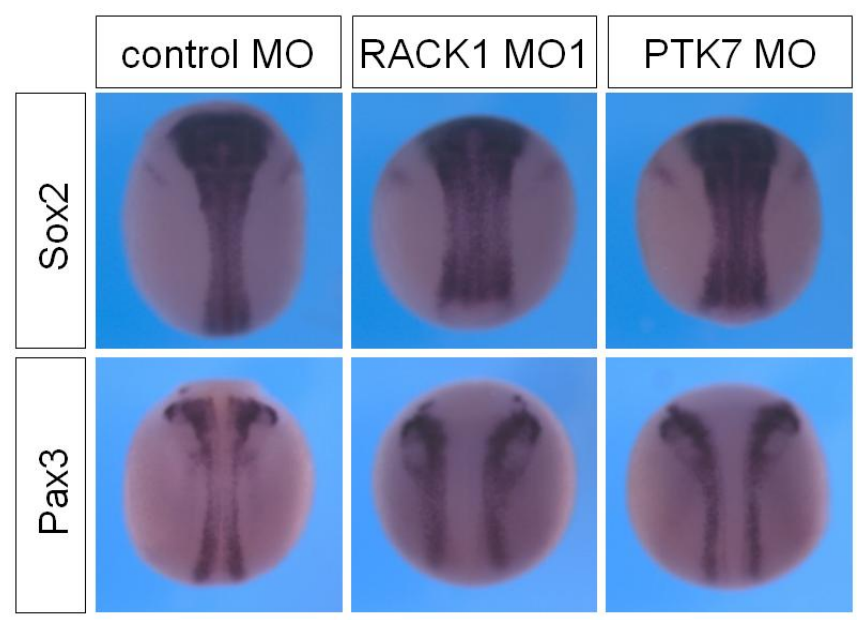

Figure 26. Like the PTK7 MO, RACK1 MO does not affect neural marker expression. The expression of SOX2 (pan-neural marker) and PAX3 (lateral neural plate marker) is expanded in stage 17-18 embryos injected with $10 \mathrm{ng}$ RACK1 MO1 or PTK7 MO compared with control embryos injected with control morpholinos. The expression pattern is not affected by MO injection of PTK7 and RACK1 (from Wehner et al. 2011).

Our data showed that PTK7 and RACK1 are both involved in the event of neural tube closure and there are indications that the LOF leads to a disturbed convergent extension movement during neural tube closure. To clarify if both molecules show a genetic interaction and act additive or synergistic we analyzed if co-injection of both MOs can influence the neural tube closure process. For this, low and high dose injections of PTK7 $\mathrm{MO}$ and RACK1 MO alone were compared with low doses of both MOs. From our result 
we conclude an additive effect of PTK7 and RACK1 knock-down as a combinations of low doses of both MO showed almost the same percentage of NTC defects as a high dose of PTK7 MO (Fig.: 27).

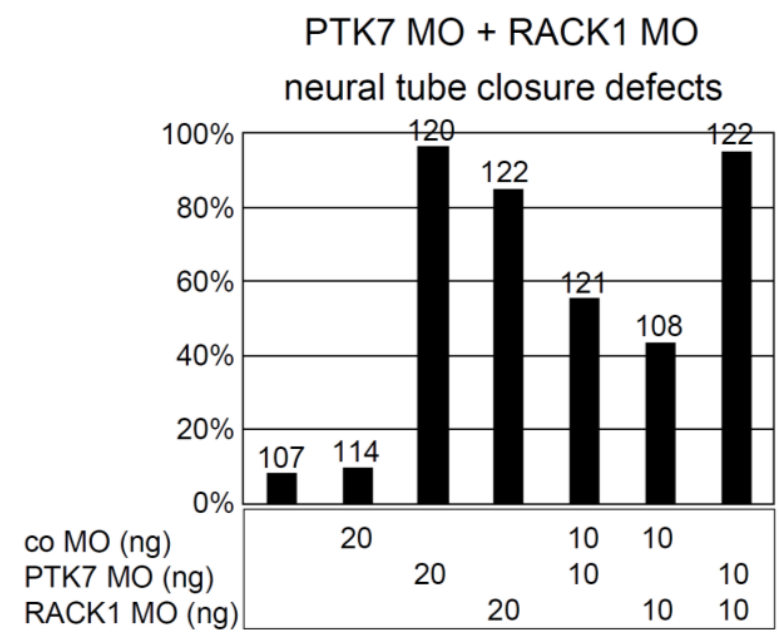

Figure 27. Neural tube closure defects of embryos injected with different combinations of PTK7 and RACK1 morpholinos. Embryos were injected at the one-cell stage and neural tube defects were determined at neurula stage 19-20. Control morpholino (co MO) injected embryos show almost no defects in neural tube closure. $20 \mathrm{ng}$ of PTK7 and RACK1 MO caused high percentages of NTC defects. Single low dose injections of each MO with a low dose of co MO lead to around $50 \%$ reduced defects. Additive effects are observed if $10 \mathrm{ng}$ RACK1 MO was co-injected with 10 ng PTK7 MO (from Wehner et al. 2011).

\subsection{RACK1 overexpression affects neural tube closure}

An important tissue movement during vertebrate embryogenesis, which is essential for neural tube closure, is convergent extension. In this process tissue narrows along one axis and lengthens in a perpendicular axis. A hallmark of effectors of convergent extension (CE) is that the gain-of-function (GOF) and loss-of-function (LOF) often result in the same phenotype (Keller 2002; Reynolds et al. 2010). Consistently, the inhibition, as well an over activation of the PCP pathway, lead to similar phenotypes like the gain-offunction and loss-of-function of CE regulators. To test if GOF of RACK1 results in the same phenotype as LOF of RACK1 overexpression experiments were performed. Different concentrations of RACK1 RNA were injected into the animal half of one-cell stage Xenopus embryos. At later stages the morphology of the embryos were analyzed. The embryos developed normally till neurula stage. Later the overexpression of RACK1 leads to mild and severe neural tube closure phenotypes. The neural tube was wider (Fig.:28 A, type 1) and in some cases the neural folds failed to fuse and the neural tubes remained open (Fig.: 28 A, type 2). The effect was concentration dependent and the different degrees of the phenotype correlate with the concentration gradient (Fig.: 28 B). The experiment could show that RACK1 overexpression lead to neural tube closure 
defects and that this effect was observed also at low doses of RNA, suggesting that RACK1 GOF is similar to RACK1 LOF. This indicates that RACK1 likely affects CE during neural tube closure in Xenopus.

A
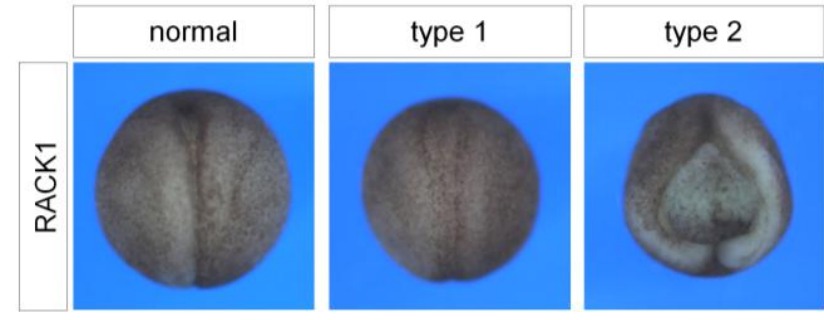

B

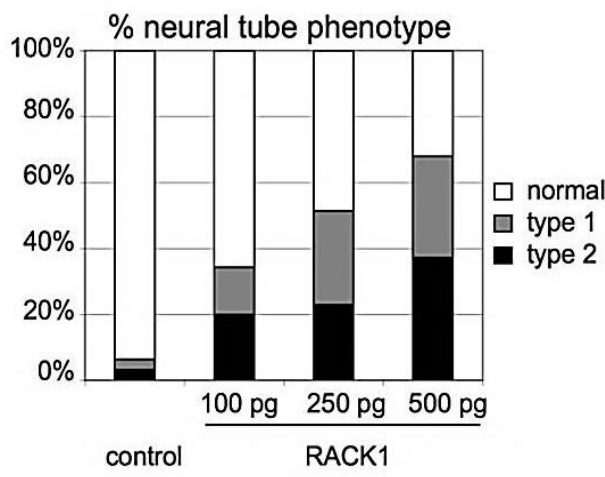

Figure 28. RACK1 overexpression caused neural tube closure phenotypes. Xenopus embryos were injected with different RACK1 RNA concentrations from 100-500 pg. Embryos were injected at one-cell stage and neural tube phenotypes were counted at neurula stage 19. A) Embryos show different neural tube closure phenotypes after injection with RACK1 RNA compared with normal developed embryos. B) Bar chart summarizes the average percentage of neural tube closure phenotypes of two independent experiments (grey represents a mild defect: type 1, black a strong: type 2)

\subsection{RACK1 and PTK7 affect convergent extension of the neural tube}

PTK7 regulates neural tube closure and convergent extension in Xenopus and mouse (Lu et al. 2004, Yen et al. 2009). The PTK7 and the RACK1 phenotypes are reminiscent of convergent extension (CE) defects. The observed similarities between PTK7 LOF and RACK1 LOF and GOF phenotypes: neural tube closure defects and a shorter body axis at later stages indicate a defect in convergent extension.

For a more detailed view, to observe possible changes at the cellular level injected embryos were sectioned and phalloidin stained. For this purpose the embryos were injected into one blastomere of a two cell stage embryo with a tracer and morpholino oligonucleotides against RACK1 or PTK7. The embryos were fixed at neurula stage and transverse microtome sections were cut. The slices were fixed on a microscope slide followed by phalloidin staining to stain the actin cytoskeleton. Analysis by confocal microscopy show that the neural plate of the injected side was wider compared to the un- 
injected control side of the embryo (Fig.: 29 B, C yellow arrows). Although the hinge point formation was normal (Fig.: 29 B, C white arrows) the actin accumulation and the arrangement of the cells looked different at the injected side compared to the control side. The notochord visible in the lower area of the embryo picture was unaffected. However, the $\mathrm{MO}$ injected sides of the embryos showed a different morphology and the neural plate tissue persisted wide and failed to converge on the injected side. This indicates that RACK1 and PTK7 loss-of-function lead to defect convergent extension movements and both molecules are required for convergent extension of the neural tube.
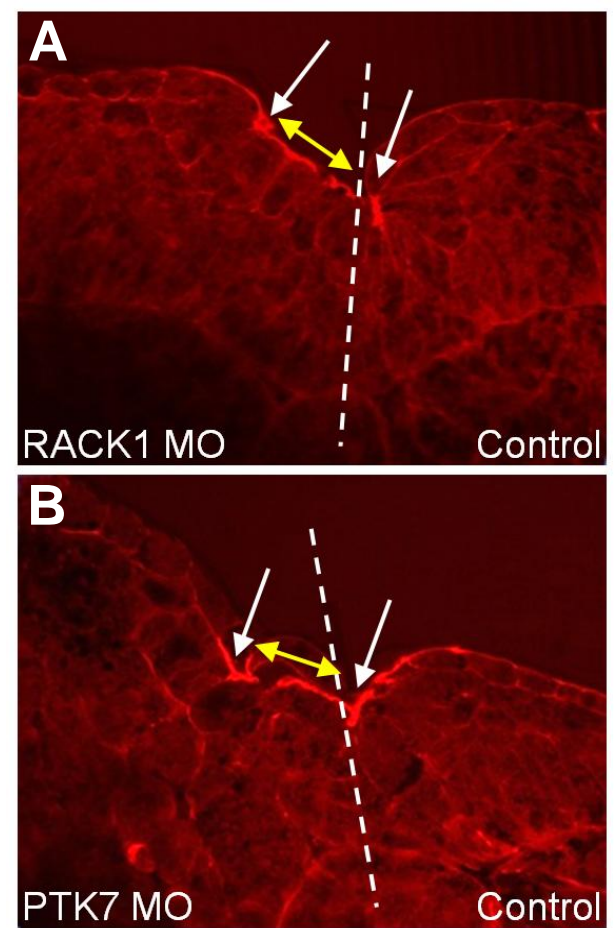

Figure 29. PTK7 and RACK1 are required for convergent extension of the neural tube. Transverse sections of stage 18 embryos injected with $20 \mathrm{ng}$ RACK1 MO (A) or PTK7 MO (B). Embryos were injected into one blastomere at the two-cell stage; the dashed line demarcates the injected from the control side of the embryo. Phalloidin staining (red) marks the actin cytoskeleton. Actin accumulation, indicating hinge point formation (white arrows), is seen on the injected and control sides. The neural plate remains wide on the injected side (yellow arrow), indicating a defect in convergent extension (from Wehner et al. 2011).

To further verify if RACK1 and PTK7 are especially necessary for neural convergent extension we used an XBF-2 explant assay (Mariani and Harland 1998). To this end the embryos were injected at the one-cell stage with $X B F-2$ RNA and the animal caps were cut at blastula stage. The explants were cultivated till neurula stage, fixed and analyzed (Fig.: $30 \mathrm{~A}$ ). XBF-2 is a transcriptional repressor that converts ectoderm into neural tissue. It induces hindbrain and spinal cord cell fates in ectodermal explants (Mariani and Harland, 1998). This posterior neural tissue undergoes convergent extension movements leading to various degrees of explant elongation (Wallingford and Harland 2001; Borchers et al. 2006). The co-injection of RACK1 or PTK7 MOs was used to investigate whether 
they influence the convergent extension movements caused by XBF-2. XBF-2 injections lead to explant elongation (Fig.: $30 \mathrm{C}, \mathrm{F}$ ), which is the proof for a positive working XBF-2 animal cap assay, while un-injected control explants did not extend at all (Fig.: $30 \mathrm{~B}, \mathrm{~F}$ ). Explants injected with RACK1 MO or PTK7 MO both showed an impaired explant elongation (Fig.: $30 \mathrm{D}-\mathrm{F}$ ) indicating that RACK1 and PTK7 are both required for neural convergent extension.

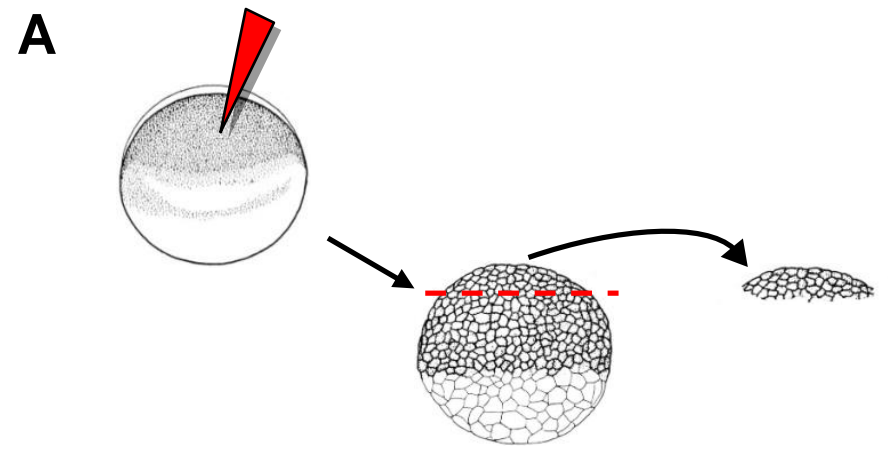

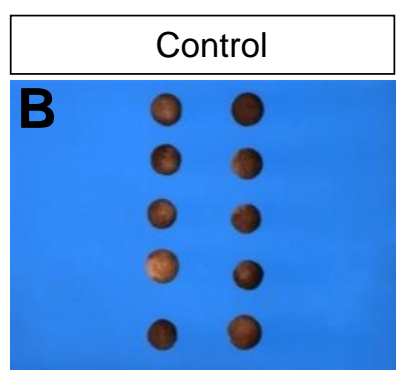
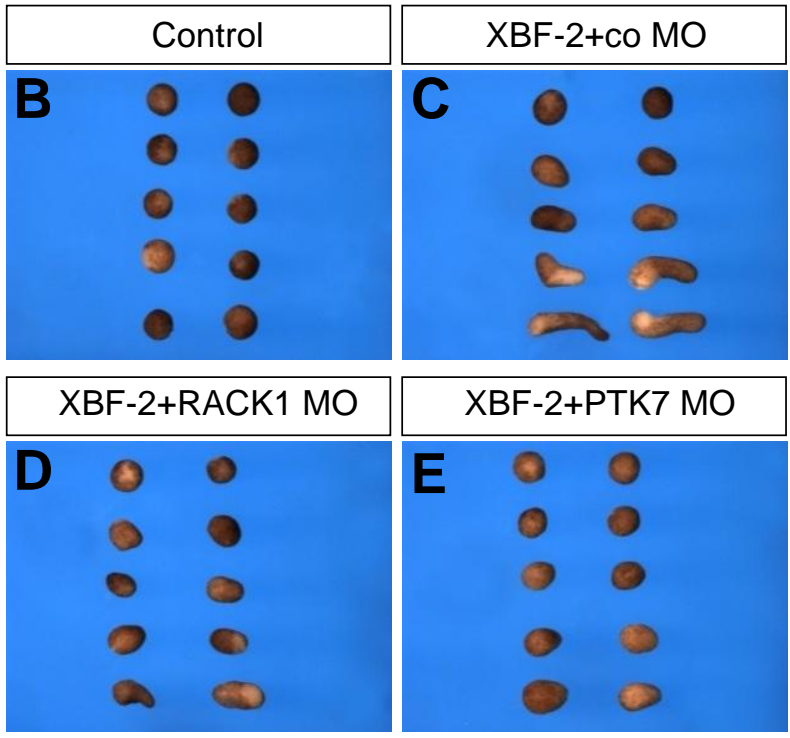

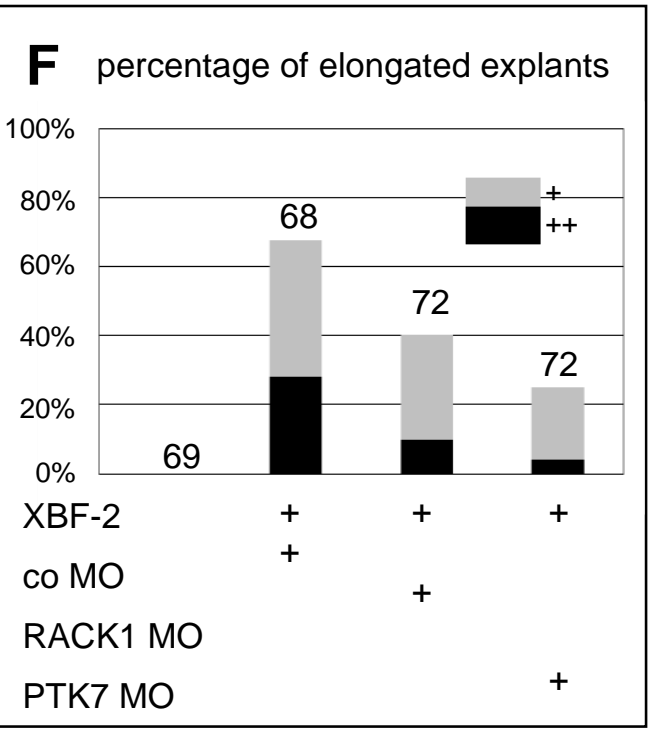

Figure 30. PTK7 and RACK1 inhibit convergent extension of XBF-2 expressing animal caps. A) Schematic scheme of the animal cap assay (Wallingford and Harland 2001). B-E) Neural convergent extension was analyzed in ectodermal explants (animal caps). The embryos were injected with $450 \mathrm{pg}$ XBF-2 RNA. Explant elongation was analyzed when control embryos reached stage 20. B) Un-injected control caps did not elongate. C) Explants injected with XBF-2 and $20 \mathrm{ng}$ control MO showed various degrees of elongation. D) Co-injection of $20 \mathrm{ng}$ RACK1 MO inhibited explant elongation. E) Co-injection of $20 \mathrm{ng}$ PTK7 MO inhibited elongation of ectodermal explants. F) The percentages of elongated explants from the experiments illustrated in B-E. Black indicates a strong elongation, gray a mild elongation. The number of explants is indicated for each condition. Bar chart summarizing the percentage of elongated explants (black represents a strong elongation, grey a mild). Numbers of analyzed explants are indicated. (from Wehner et al. 2011) 


\subsection{PTK7 recruits RACK1 to the plasma membrane}

As RACK1 and PTK7, show phenotypic interaction they likely also play a functional role. Previously, it was shown that PTK7 recruits DSH to the cell membrane (Shnitsar and Borchers, 2008) and that RACK1 assist PTK7 for this process (Shnitsar 2009). In this case RACK1 should be recruited by PTK7 to the cell membrane. To test this hypothesis RACK1 and PTK7 were co-injected in one cell stage embryos and animal caps assays were performed. The ectodermal explants were immunostained and analyzed by confocal microscopy. Indeed, in the control situation RACK1 alone is located in the cytoplasm of the ectodermal explants (Fig.: $31 \mathrm{~A}, \mathrm{D}, \mathrm{E}$ ) but if PTK7 is present RACK1 is recruited to the cell membrane (Fig.: $31 \mathrm{~B}, \mathrm{D}, \mathrm{E})$. In contrast to this, a mutant of PTK7, which lacks the intracellular kinase homology domain ( $\triangle \mathrm{kPTK} 7$ ) and does not recruit DSH (Shnitsar and Borchers, 2008), had no ability to recruit RACK1 to the plasma membrane (Fig.: $31 \mathrm{C}, \mathrm{D}$, E). In summary, additionally to the biochemically experiments which showed that PTK7 binds RACK1 (Shnitsar 2009), PTK7 recruits RACK1 to the plasma membrane via its intracellular kinase homology domain. These result supports that RACK1 is required for the PTK7 mediated DSH localization at the plasma membrane.
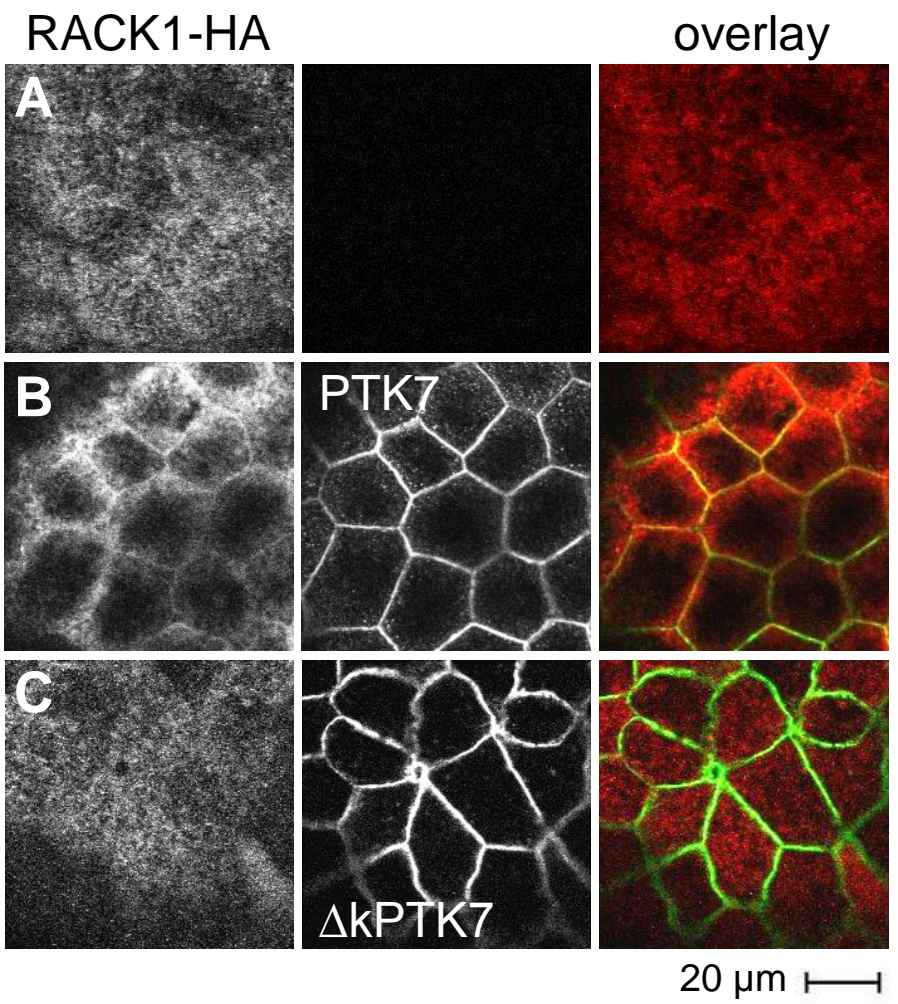


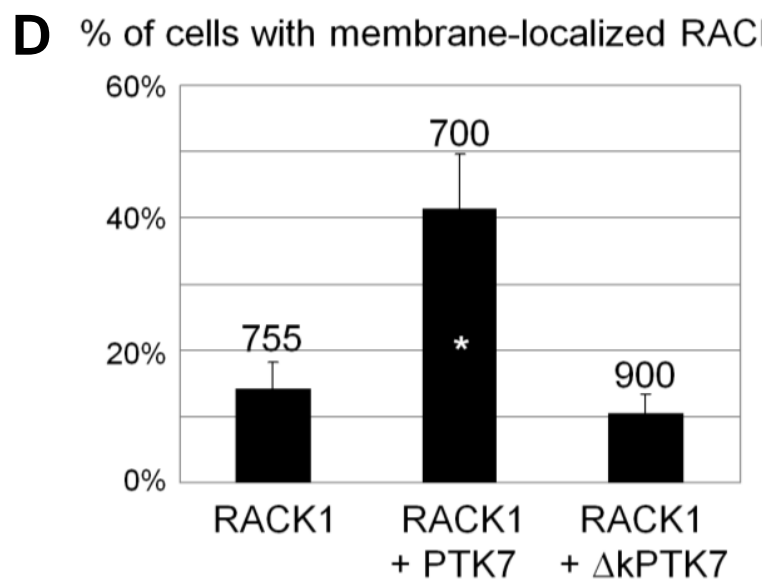

\section{$\mathbf{E}$}

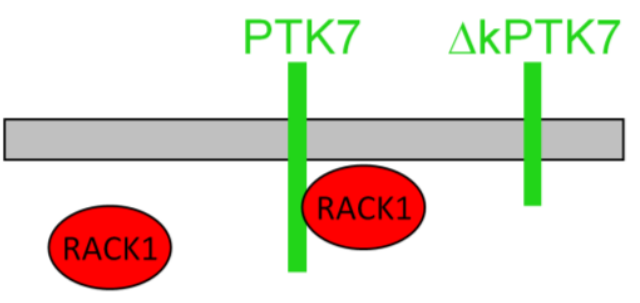

Figure 31. In animal cap cells RACK1 is actively recruited to the plasma membrane via PTK7. A-C) Confocal microscopy images of ectodermal explants of Xenopus embryos expressing RACK1 (left panel, 250pg, HA-tagged RNA, red) and/or PTK7 (B) and/or $\triangle \mathrm{kPTK} 7$ (C) (middle panel, 500pg, GFP-tagged RNA, green). A) RACK1 injected alone is localized in the cytoplasm of ectodermal explants. (B) Co-expression of PTK7 recruits RACK1 to the plasma membrane. C) PTK7 which lacks the intracellular kinase homology domain part ( $\triangle \mathrm{KPTK} 7)$ abolishes membrane recruitment of RACK1. Embryos were co-injected with $250 \mathrm{pg}$ RACK1-HA RNA (B) and $500 \mathrm{pg}$ PTK7GFP-RNA (C) or $\triangle K P T K 7-G F P$ RNA. D) Bar chart summarized the percentages of cells with membrane localized RACK1 from four independent experiments in A-C. $\left({ }^{*} p<0.005\right.$, student $t-$ test). Cell number and s.e.m. are indicated for each column. Asterisk indicates that RACK1 membrane localization in presence of PTK7 is significantly different from explants injected with RACK1 mRNA alone. E) Model shows that the intracellular kinase homology domain of PTK7 is required to recruit RACK1 to the cell membrane. (A-D: experiments done by P. Wehner, and I. Shnitsar) (from Wehner et al. 2011) 


\subsection{Membrane recruitment of RACK1 by PTK7 is sufficient to translocate DSH to the plasma membrane}

PTK7 is necessary to localize DSH to the plasma membrane and the kinase domain of PTK7 is involved in this process (Shnitsar and Borchers, 2008). Additionally, we showed that this kinase homology domain is also required to recruit RACK1 to the plasma membrane of ectodermal explants and we know that the DSH recruitment by PTK7 is RACK1 mediated (Shnitsar 2009). To prove that the recruitment of RACK1 is the crucial step for the translocation of $\mathrm{DSH}$ and that the kinase homology domain of PTK7 is responsible for this function a fusion construct was made. In this construct the intracellular kinase homology domain of PTK7 was replaced by Xenopus RACK1 ( $\triangle$ KPTK7-R, Fig.: 32 A). The DSH localization was tested in ectodermal explant assays using this construct. The RNA for DSH and the constructs shown in Fig.: $32 \mathrm{~A}$ were injected in one cell stage embryos. The ectodermal explants were immunostained and analyzed by confocal microscopy. In the control situation DSH was mainly expressed in the cytosol (Fig.: $32 \mathrm{~B}$, F). If PTK7 is present DSH was shifted to the membrane (Fig.: $32 \mathrm{C}$, F). The DSH membrane localization was impaired if the $\triangle$ KPTK7 mutant is injected (Fig.: $32 \mathrm{D}, \mathrm{F}$ ). Interestingly, the fusion construct of $\triangle \mathrm{KPTK} 7$ and RACK1 was able to recruit DSH to the plasma membrane (Fig.: $32 \mathrm{E}, \mathrm{F}$ ). This data proved that the kinase homology domain of PTK7 is necessary to recruit RACK1. With this approach we showed the importance of RACK1 recruitment for the PTK7 mediated DSH localization since the fusion protein of the kinase deletion mutant of PTK7 and RACK1 recruits DSH to the plasma membrane. In summary this data supports a model whereby PTK7 interacts with RACK1 to translocate $\mathrm{DSH}$ to the plasma membrane.

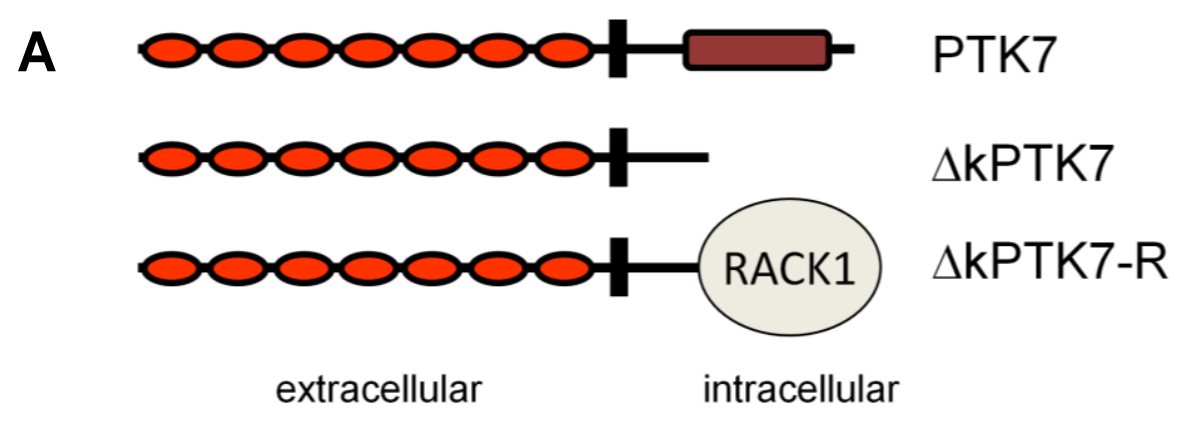



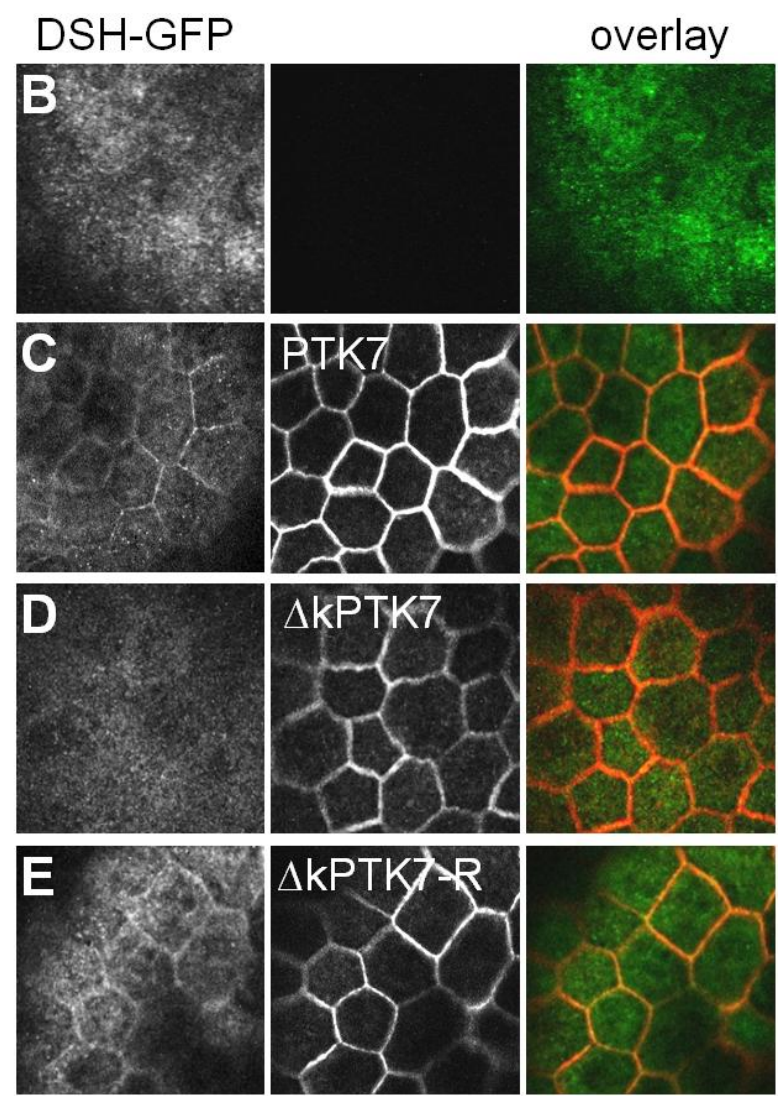

$20 \mu \mathrm{m} \longmapsto$

\section{F \% of cells with membrane-localized DSH}

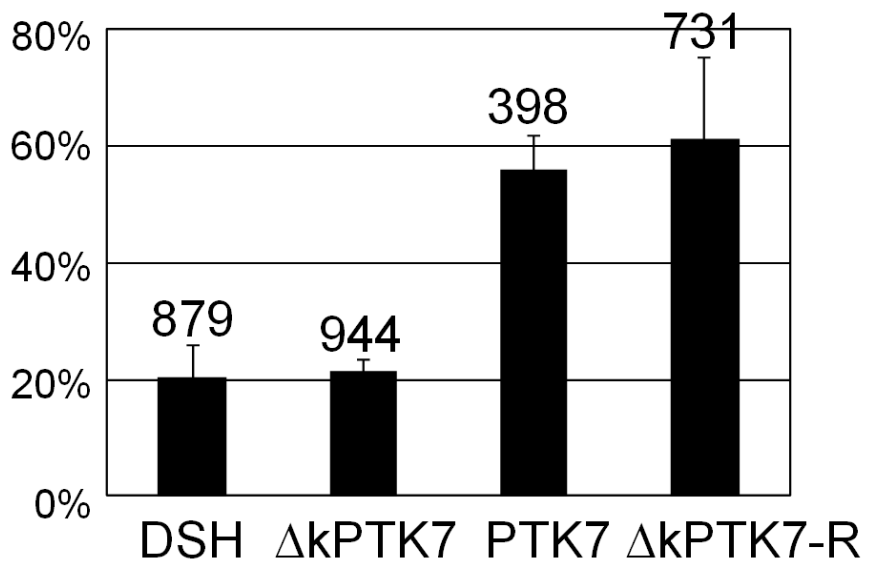

Figure 32. RACK1 assists PTK7 to recruit DSH to the plasma membrane in ectodermal explants. A) Structure of PTK7 and PTK7 which lacks the kinase domain ( $\triangle \mathrm{kPTK} 7$ ), in $\triangle \mathrm{kPTK} 7-\mathrm{R}$ the kinase homology domain of PTK7 is substituted by Xenopus RACK1. B-E) Confocal microscopy images of ectodermal explants of Xenopus embryos, which show the effect of different PTK7 constructs on DSH membrane localization. Left column: expressing $100 \mathrm{pg} D S H$-GFP RNA (green). Middle column: expressing $500 \mathrm{pg}$ PTK7 or $300 \mathrm{pg} \triangle K P T K 7$ or 300 pg $\triangle K P T K 7-R$ RNA (red). Right column: overlay of the injected constructs in the left and middle columns corresponding rows. B) DSH alone is mainly localized in the cytoplasm of ectodermal. C) If PTK7 RNA is coexpressed DSH is translocated to the plasma membrane. D) The kinase deletion mutant of PTK7 does not recruit DSH if both are co-injected. E) The fusion construct $\triangle \mathrm{kPTK} 7-\mathrm{R}$ recruits $\mathrm{DSH}$ to the membrane. $(F)$ Bar chart summarizes the percentage of cells with membrane localized DSH in Xenopus ectodermal explants injected with DSH and the different PTK7 constructs in A. Number of cells and s.e.m. are indicated for each column (from Wehner et al. 2011). 


\subsection{Verification of the PTK7/RACK1/PKC $\delta$ model}

The recruitment of RACK1 via the kinase homology domain of PTK7 is a crucial step for the localization of DSH to the plasma membrane in ectodermal explants. Nothing is known about the function of this recruitment. Co-immunoprecipitation experiments with RACK1 and DSH could not confirm a direct binding between both molecules (data not shown). RACK1 (receptor of activated protein-kinase-C) received its name originally from MochlyRosen who identified RACK1 as a protein that recruits the active form of PKC (MochlyRosen et al. 1991). From a member of the PKC family PKC 81 it is known to bind DSH and to have a function in non-canonical Wnt signaling regulating Xenopus convergent extension movements (Kinoshita et al. 2003). Indeed, an interaction of PKC $\delta 1$ and RACK1 could be shown in co-IP assays and RACK1 is also necessary for the recruitment of PKC 81 by PTK7 to the plasma membrane in ectodermal explants (Shnitsar 2009). This suggests that RACK1 mediates the DSH membrane recruitment and interacts with DSH via PKC $\delta 1$. To prove our hypothesis, $\mathrm{PKC} \delta 1$ knock-down experiments were done to test if it is required for the PTK7-mediated DSH localization. In control situations, DSH was localized at the cytoplasm of ectodermal explants (Fig.: 33 A, F). If PTK7 and control morpholino (co MO) were co-injected DSH localizes at the cell membrane (Fig.: $33 \mathrm{~B}, \mathrm{~F}$ ). If PTK7 was co-injected with PKC $11 \mathrm{MO}$, the membrane recruitment of DSH by PTK7 was abolished (Fig.: $33 \mathrm{C}, \mathrm{F}$ ). Thus data supports that $\mathrm{PKC} \delta 1$ is required for $\mathrm{DSH}$ membrane localization by PTK7 and RACK1.

Finally, to prove our model that the PTK7-DSH interaction via PKC $\delta 1$ was mediated by RACK1 the fusion construct $\triangle$ KPTK7-R (Fig.: 32 A) was tested. Co-injection of the fusion construct and DSH lead to a DSH recruitment to the cell membrane (Fig.: $33 \mathrm{D}, \mathrm{G}$ ). Co $\mathrm{MO}$ was co-injected as control. Interestingly, in the presence of PKC $\delta 1 \mathrm{MO}$ the membrane localization of DSH was decreased (Fig.: $33 \mathrm{E}, \mathrm{G}$ ). Summarizing the data, PKC $\delta 1$ is needed for the PTK7-RACK1-mediated DSH localization. This result fits to the hypothesis that RACK1 assist PTK7 in the PKC $\delta 1$ dependent localization of DSH. 


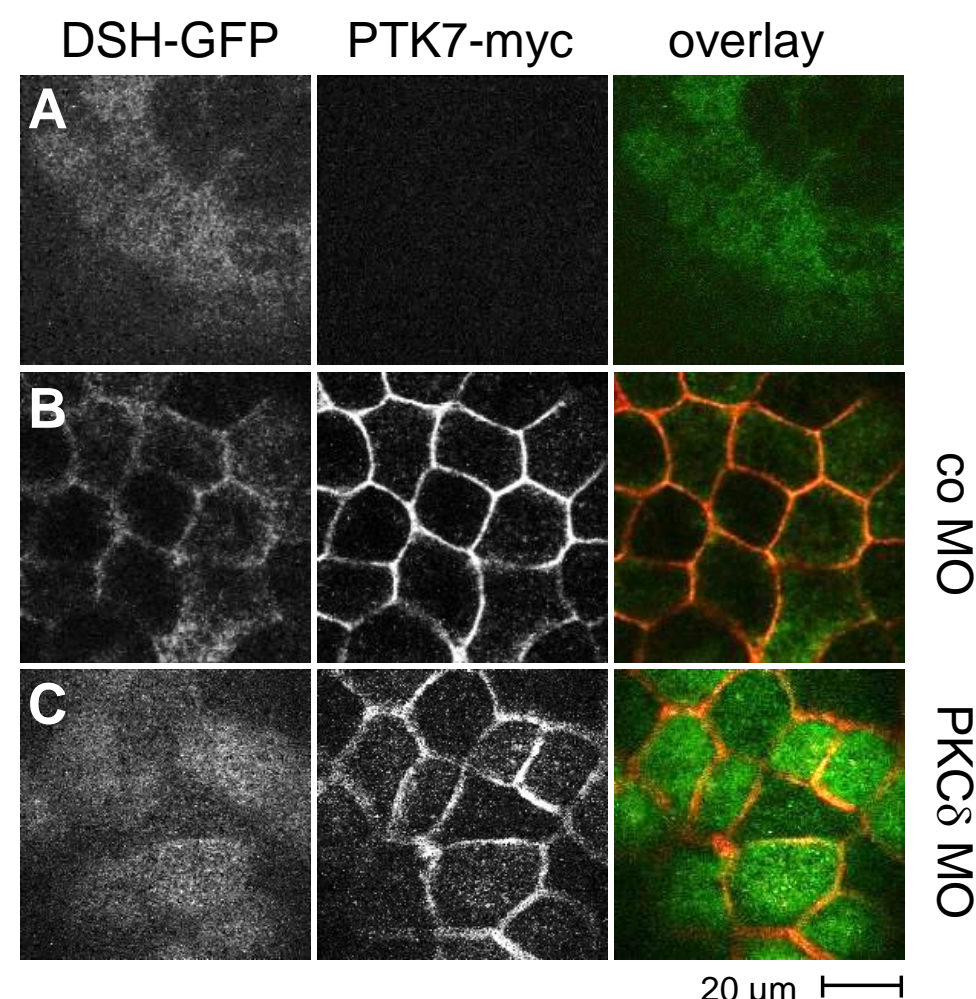

DSH-GFP $\triangle \mathrm{kPTK} 7 \times \mathrm{R} 1-\mathrm{HA}$ overlay
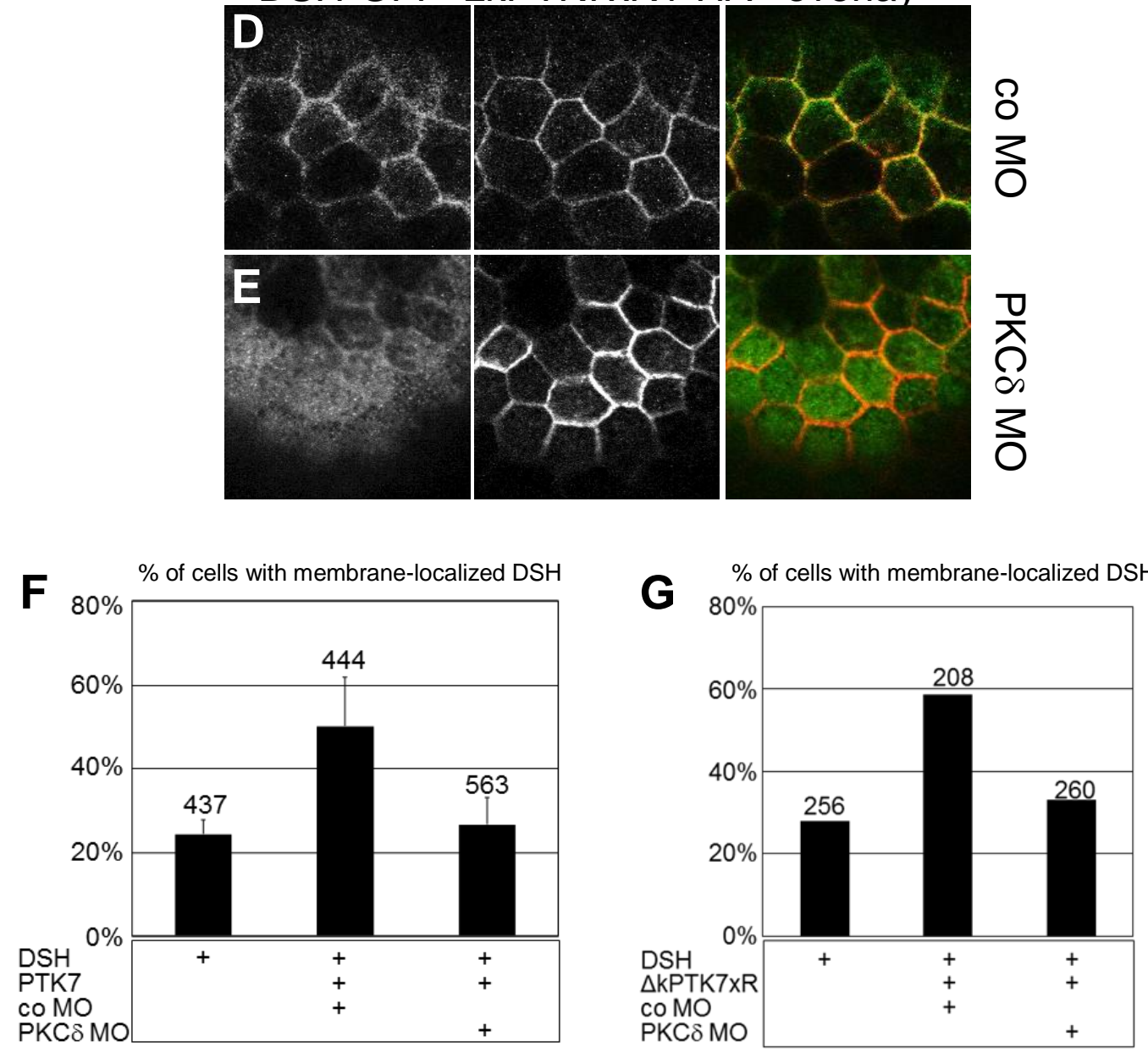
Figure 33. PKC $\delta 1$ loss-of-function inhibits the PTK7-RACK1-mediated DSH localization. A-E) Confocal microscopy images of ectodermal explants of Xenopus embryos, which show the effect of different PTK7 constructs and MOs on DSH membrane localization. Left column: expressing 100pg $D S H$-GFP RNA (green in overlay). Middle column: expressing 500pg PTK7-myc (B, C) or $300 \mathrm{pg}$ $\triangle K P T K 7-R-H A$ RNA (D, E) (red in overlay). A) Explants injected with DSH-GFP RNA express DSH mainly in the cytoplasm. B) Co-expression of PTK7 and $20 \mathrm{ng}$ control MO translocates DSH to the plasma membrane. C) Co-injection of $20 \mathrm{ng}$ PKC $\delta$ MO inhibits the PTK7-mediated DSH membrane recruitment. D) If $\triangle K P T K 7-R-H A$ instead of PTK7 RNA was injected DSH is also shifted to the membrane. E) $20 \mathrm{ng}$ PKC $\delta \mathrm{MO}$ abolished the DSH localization. F, G) Bar charts summarize the percentages of cells with membrane-localized DSH-GFP in A-E. Numbers of analyzed cells are indicated. F) S.e.m. from three independent experiments are indicated for each column (one repeat carried out by I. Shnitsar). G) Numbers from two independent experiments are indicated. (A-C, F from Wehner et al. 2011)

\subsection{RACK1, PTK7 and PKC 81 interact in the regulation of neural morphogenesis}

RACK1 was first identified as a protein, which recruits the activated form of PKC (MochlyRosen et al. 1991). PKC 1 1, a member of the PKC family, is known to regulate Xenopus convergent extension movements (Kinoshita et al. 2003). To further characterize our model in the context of neural tube closure genetic interaction studies with the possible members were done. To clarify if the molecules show a genetic interaction and act additive or synergistic we analyzed if co-injection of MO can influence the NTC process. The percentages of NTC phenotypes caused by high doses of MO were compared with the phenotypes caused by the combination of low doses of both $\mathrm{MO}$. The genetic interaction was tested between PKC $\delta 1 \mathrm{MO}$ and PTK7 MO or RACK1 MO.

From our result we conclude an synergistic effect between PKC $\delta 1$ and PTK7 knock-down as the co-injection of low doses of both MOs show a dramatic increase in the percentage of neural tube defects (Fig.: $34 \mathrm{~A}$ ). For the co-injection of PKC $\delta 1 \mathrm{MO}$ with the RACK1 MO an additive effect was shown (Fig.: 34 B) as the percentages of NT closure defects for both $\mathrm{MO}$ alone show in summary the same percentage of NT closure defects as for low doses of both $\mathrm{MO}$. The strength of neural tube closure defects was highly variable between different batches. The discrimination between low and high doses of MO was difficult. However, the general tendency indicates genetic interaction between PKC $\delta 1$ and RACK1 and in particularly between PKC $\delta 1$ and PTK7. 

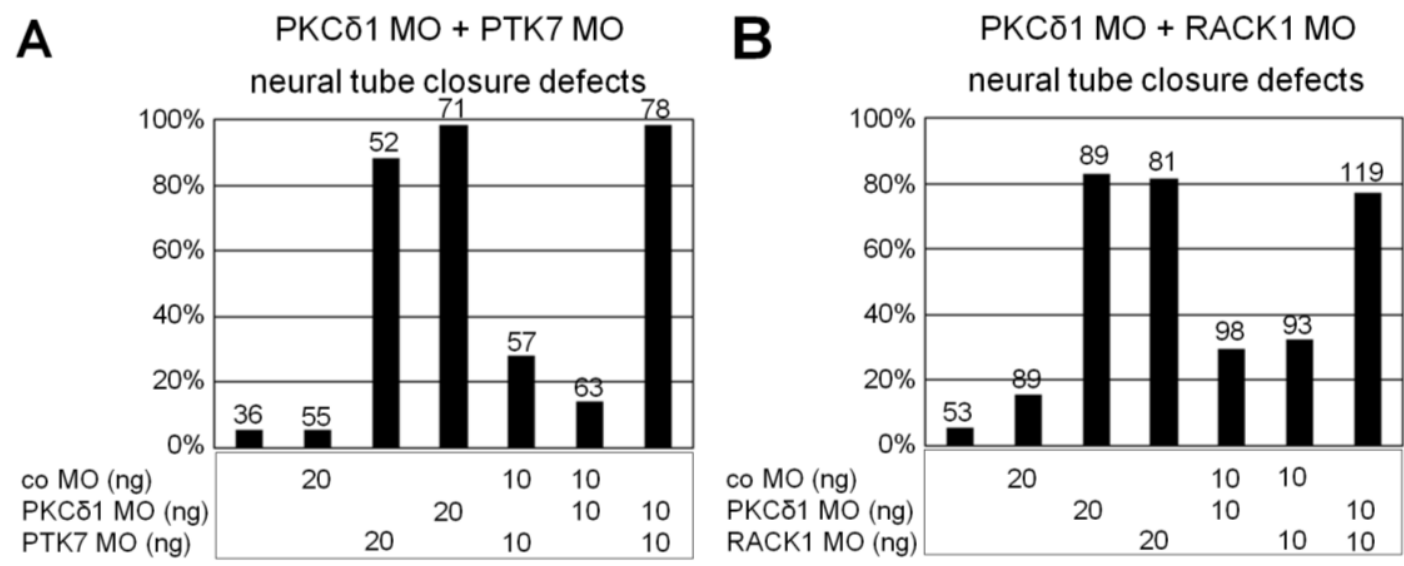

Figure 34. Neural tube closure defects of embryos injected with different combinations of PTK7, RACK1 and PKC $\delta 1$ morpholinos. Embryos were injected at the one-cell stage and neural tube defects were determined at neurula stage 19-20. A) Co-injection of $10 \mathrm{ng} \mathrm{PKC} \delta 1 \mathrm{MO}$ and 10 ng PTK7 MO support a synergistic interaction of PKC $\delta 1$ with PTK7. B) Additive effects are also seen if $10 \mathrm{ng}$ RACK1 MO were injected with $10 \mathrm{ng}$ PKC $\delta 1 \mathrm{MO}$. One representative experiment for each condition is shown. (from Wehner et al. 2011)

\subsection{PTK7/RACK1-mediated DSH localization is independent of frizzled}

Previously it was shown that PTK7 is required for the Fz7-mediated DSH localization. Fz7 loss-of-function did not affect the PTK7-mediated DSH localization (Shnitsar 2009). To test if RACK1 play a role in this process and what exactly is the role of Fz different experiments were done.

\subsubsection{RACK1 is not required for Fz7-mediated DSH localization and phosphorylation}

Co-localization and interaction of $\mathrm{Fz7}$ and $\mathrm{DSH}$ at the plasma membrane in Xenopus ectodermal explants have been shown previously (Yanagawa et al. 1995; Axelrod et al. 1998; Sheldahl et al. 1999; Medina et al. 2000; Medina and Steinbeisser 2000). Furthermore, it is known that PTK7 is required fort the Fz7-mediated DSH localization (Shnitsar and Borchers 2008). Our new data shows that RACK1 assists PTK7 to recruit DSH but it is unknown if RACK1 influences the Fz7-dependent DSH localization. To clarify this question RACK1 LOF experiments were done in ectodermal explants. In the control situation DSH was expressed alone and the protein was localized in the cytoplasm (Fig.: 35). Co-expression of Fz7 recruits DSH to the cell membrane (Fig.: 35) and PTK7 morpholino injection abolished this recruitment (Fig.: 35). The knock-down of RACK1 did not disturb the Fz7-dependent DSH localization (Fig.: 35) leading to the conclusion that RACK1 is not involved in the Fz7-dependent process of DSH localization. 


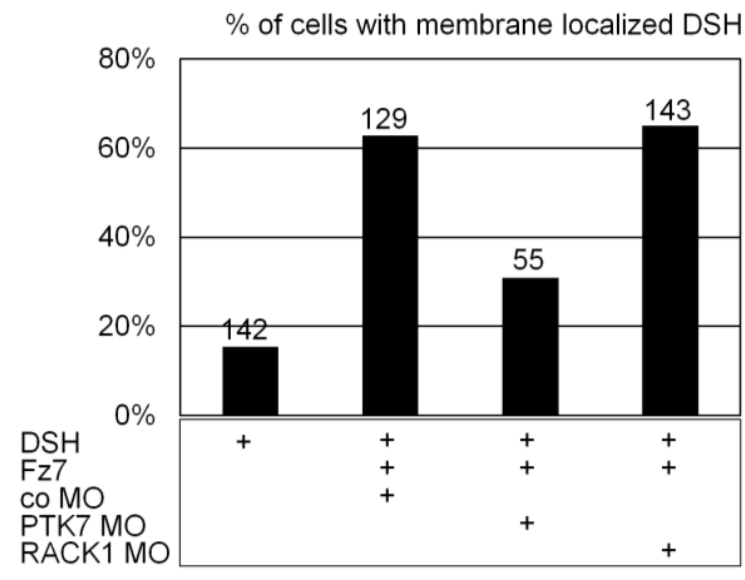

Figure 35. RACK1 LOF had no influence on the Fz7 mediated DSH localization. In ectodermal-explants from embryos injected with $100 \mathrm{pg} D S H$ RNA the DSH protein was almost localized in the cytoplasm. If $300 \mathrm{pg} F z$ RNA is co-injected together with $20 \mathrm{ng} \mathrm{co} \mathrm{MO}$, DSH is recruited at the cell membrane. PTK7 MO abolished this recruitment. RACK1 MO had no influence on the Fz mediated DSH localization. The graph shows one representative experiment and numbers of analyzed cells are indicated.

Additionally, the Fz7-dependent hyperphosphorylation of DSH is a readout for DSH activity and is not affected by RACK1 LOF. DSH is a phosphoprotein that can be phosphorylated due to activation (Yanagawa et al. 1995; Lee et al. 1999). Expression on its own in whole Xenopus embryos results in two bands in western-blot detection. Due to the co-expression of $\mathrm{Fz7}$ a third higher molecular band arises as a result of DSH hyperphosphorylation. As control PTK7 mismatch $(\mathrm{mm}) \mathrm{MO}$ was injected that was not able to disturb this process of phosphorylation. The overexpression of RACK1 itself had no effect on the DSH phosphorylation and was not able to cause the formation of the third band. Since RACK1 LOF had no effect on the Fz7-mediated DSH localization it was not surprising that RACK1 knock-down had also no effect on the Fz7-dependent DSH hyperphosphorylation (Fig.: 36). In summary, Fz7-mediated DSH membrane localization and hyperphosphorylation are not RACK1 dependent.

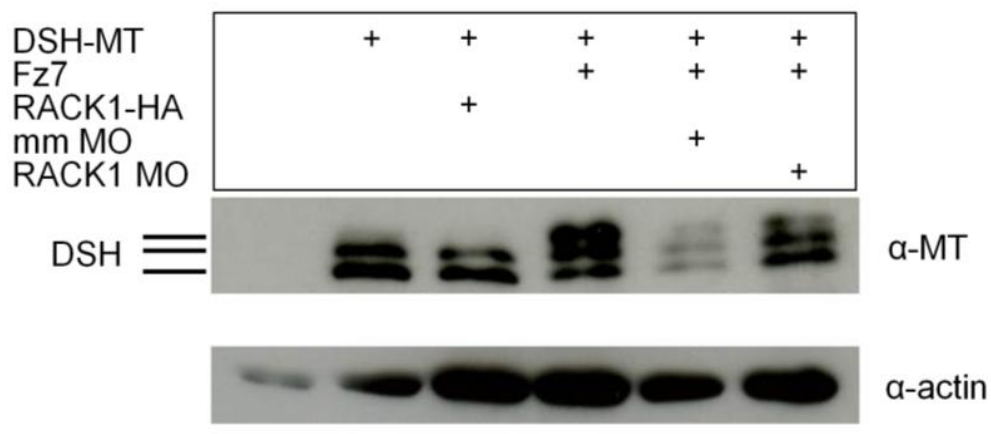

Figure 36. RACK1 is not required for the Fz dependent hyperphosphorylation of DSH. Embryos were injected with $100 \mathrm{pg}$ DSH-myc RNA, 100 pg Fz7 RNA, 300 pg RACK1-HA RNA, 20 ng PTK7 mismatch $(\mathrm{mm}) \mathrm{MO}$ or $20 \mathrm{ng}$ RACK1 MO. Whole embryos were lysed at stage 10.5 and analyzed by western blotting using a-MT antibodies. Hyperphosphorylated form of DSH was detected as a third high molecular band and $\alpha$-actin was shown as loading control. 


\subsubsection{The RACK1 localization is not Fz7-dependent}

From previous experiments we known that RACK1 does not have any influence on the Fzdependent DSH localization (Fig.: 37) for which PTK7 is required (Shnitsar and Borchers 2008). Additional, my data shows that the process of RACK1 recruitment to the plasma membrane by PTK7 seems to be a crucial step for DSH localization. It is unknown if Fz influences the localization of RACK1 and affects in this way the PTK7-dependent DSH recruitment via RACK1. To clarify this question RACK1 and Fz7 were co-expressed in ectodermal explants and animal cap assays were performed. The ectodermal explants were immunostained and analyzed by confocal microscopy. In the control situation RACK1 was expressed alone and the protein was mainly localized in the cytoplasm (Fig.: 37). The co-injection of $\mathrm{Fz} 7$ was not able to recruit RACK1 to the plasma membrane (Fig.: 37). Overall, $F z 7$ does not translocate RACK1 to the plasma membrane of ectodermal explants, indicating that RACK1 localization is independent of Fz7.

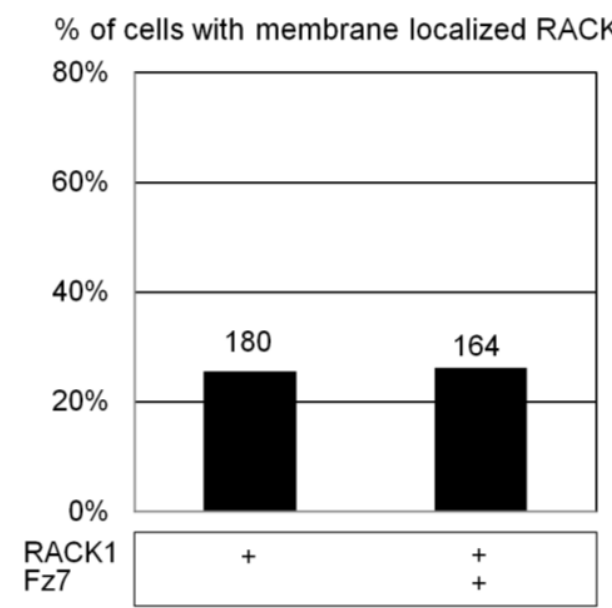

Figure 37. Fz7 did not recruit RACK1 to the cell membrane in ectodermal explants. In ectodermal-explants injected with $300 \mathrm{pg}$ RACK1-HA RNA the protein was almost localized in the cytoplasm. Co-injection of 300 pg Fz7-MT RNA did not changed the RACK1 localization. Fz7 had no influence on the RACK1 localization. The graph shows one representative experiment and numbers of analyzed cells are indicated. 


\subsection{Is the PTK7/RACK1 interaction conserved during neural crest migration?}

\subsubsection{RACK1 and PTK7 are co-expressed in neural crest cells in Xenopus embryos}

PTK7 is expressed in cranial neural crest cells and is a known regulator of neural crest migration (Shnitsar and Borchers 2008). PTK7 LOF blocks the migration of the neural crest cells in vitro and in vivo. This important role of PTK7 during the process of NC migration raised the question if RACK1 is also involved in this process. At first we check by in situ hybridization if and where the RACK1 protein is present during neural crest induction and migration stages in Xenopus embryos. Indeed, the expression pattern of RACK1 is similar to the expression pattern of PTK7 (Fig.: 38). RACK1 is expressed like PTK7, in the neural plate and pre-migratory neural crest cells in neurula stage embryos and later in migrating neural crest cells at tadpole stage (Fig.: 38, black arrows). This observation could indicate that both molecules may act together during neural crest migration.

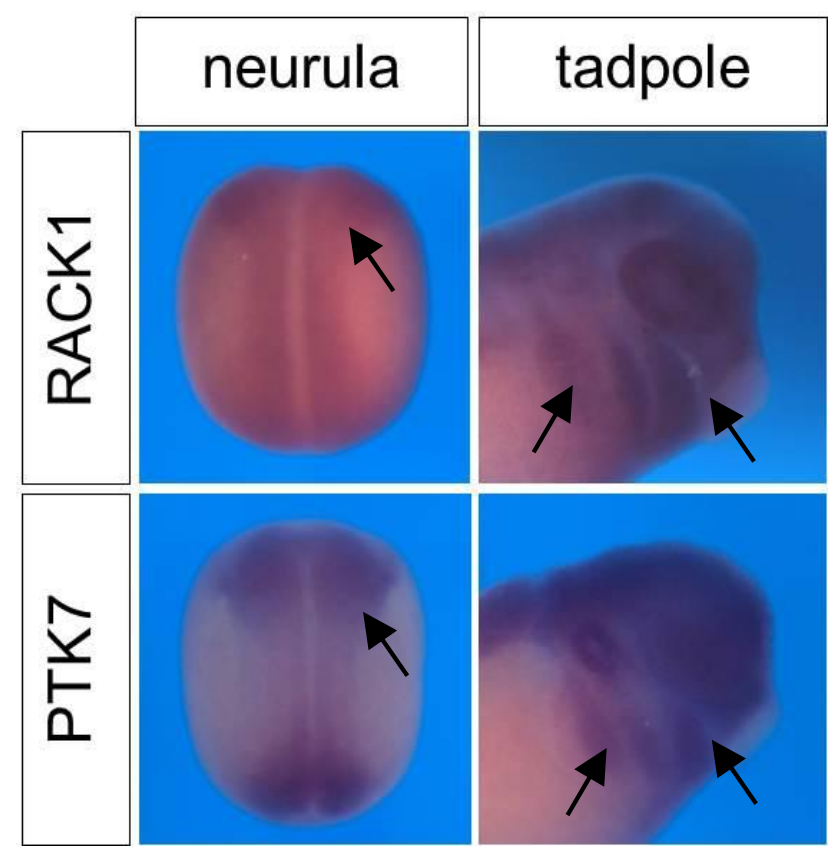

Figure 38. RACK1 and PTK7 show a similar expression pattern in Xenopus embryos. In situ hybridization pictures of RACK1 and PTK7 expression pattern. RACK1 and PTK7 are both expressed in the same areas of neurula and tadpole stage Xenopus embryos. At neurula stage both are expressed in the neural plate and pre-migratory neural crest cells (black arrows). At tadpole stage both are expressed in the migrating neural crest cells (black arrows). 


\subsubsection{RACK1 regulates neural crest migration}

RACK1 and PTK7 are co-expressed in the area of neural plate, pre-migratory and migratory neural crest cells. Additionally, RACK1 binds PTK7 a known regulator of neural crest migration in co-immunoprecipitation assays and is recruited by PTK7 to the plasma membrane. Altogether, it is very likely that RACK1 is also involved in the process of neural crest migration. To test this RACK1 LOF studies were performed. RACK1 MO or control $\mathrm{MO}$ (co MO) was injected in one blastomere of two-cell stage embryos. At neurula stage the embryos were analyzed by in situ hybridization for expression of the marker Twist. Twist is a neural crest marker, which is specifically expressed in the cranial neural crest cells. Indeed, knock-down of RACK1 inhibited the migration of NC cells (Fig.: 39 A, red arrow) while in control situation the neural crest cells migrate normally (Fig.: 39 B, red arrow). This result could show that the knock-down of RACK1 decrease the migration of NC cells in Xenopus embryos.

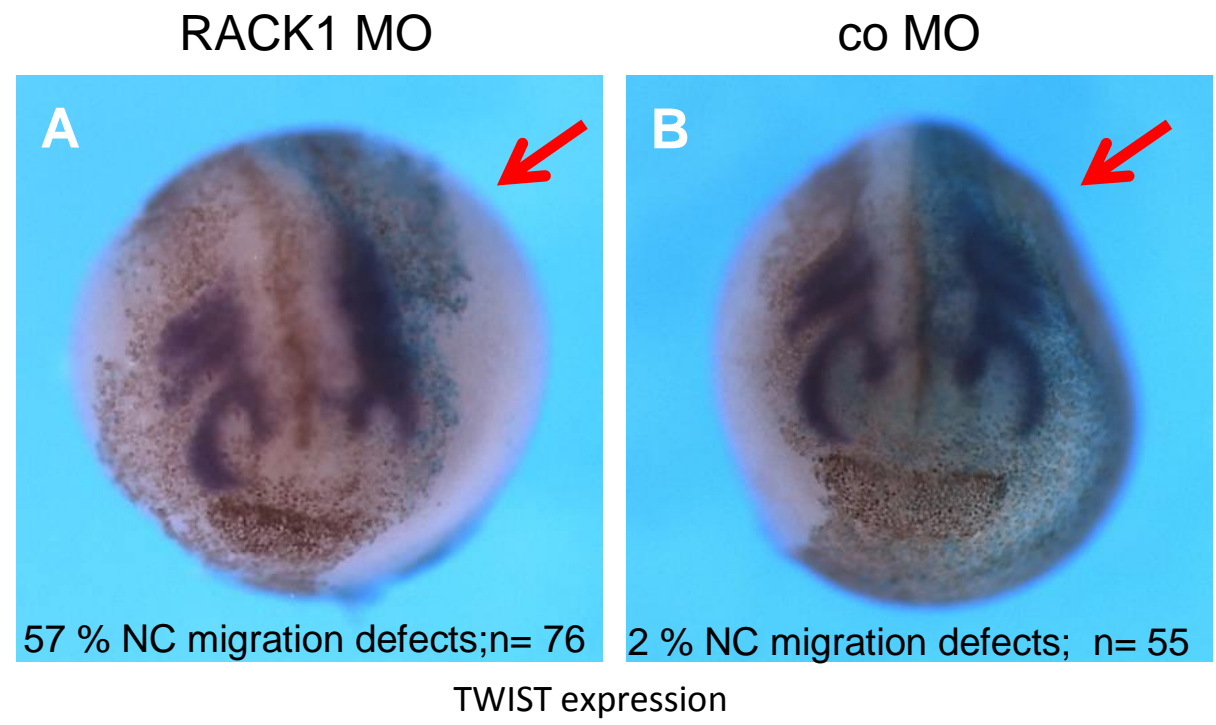

Figure 39. The knock-down of RACK1 inhibit neural crest cell migration in Xenopus embryos. Embryos were injected with $10 \mathrm{pg}$ RACK1 MO at two cell stage in one blastomere. As lineage tracer $60 \mathrm{pg}$ of B-Gal RNA were co-injected (blue dots at the injected sides of the embryos, left marked by red arrows). The embryos were cultured till neurula stages, fixed and stained for Twist expression by in situ hybridization technique. A) The red arrow marks the RACK1 MO injected side where the NC cell migration is disturbed in almost $60 \%$ of the embryos compared to the un-injected side. B) Embryos injected with a control MO show a normal migration behavior of the NC cells on both sides of the embryo. 


\subsubsection{PTK7 shows a restricted localization pattern at cell-cell contacts in migrating neural crest cells}

PTK7 is a membrane protein which has an extracellular part, a transmembrane domain and an intracellular kinase homology domain. Normally, PTK7 is localized at the cell membrane and there are indications from experiments using light microscopy techniques that PTK7 is enriched in cell-cell contacts of migrating neural crest (NC) cells. To check if this is true localization experiments using confocal microscopy on living NC cells were done. For this purpose mRNA coding for fluorescent labeled proteins were injected into one blastomere of a two cell stage Xenopus embryo. The NC cells of the injected side of the embryo were explanted at stage 16-17 and placed on fibronectin-coated chambers. The dynamic localization of fluorescently labeled PTK7 was monitored using laser scanning microscopy over the time with different intervals. For better evaluation of the confocal images of the migrating NC cells, different z-stacks were recorded and later processed. The images below show a maximum intensity projection (ZEN Software 2011, Carl Zeiss Microlmaging $\mathrm{GmbH}$ ) of all z-stacks of the cells (Fig.: 40-54). To avoid overexpression side effects the amounts of injected RNA were reduced to the detectable minimum. All pictures were imaged with a Carl-Zeiss LSM 780 or a Carl-Zeiss SpinningDisk Microscope.

After analyzing the pictures we noticed an unequal expression of PTK7 at the cell membranes in migrating NC cells (Fig.: 40 A). At cell-cell contacts the protein was expressed only in parts of the membrane of NC cells (Fig.: 40 B, D, red arrows). Interestingly, PTK7-GFP was enriched in restricted areas compared to control NC cells, only injected with membrane GFP (mGFP), where the GFP protein was uniformly expressed and not enriched at cell-cell contacts (Fig.: $40 \mathrm{C}$ ). The mechanism by which PTK7 is enriched and its effect on cell behavior is unknown. 

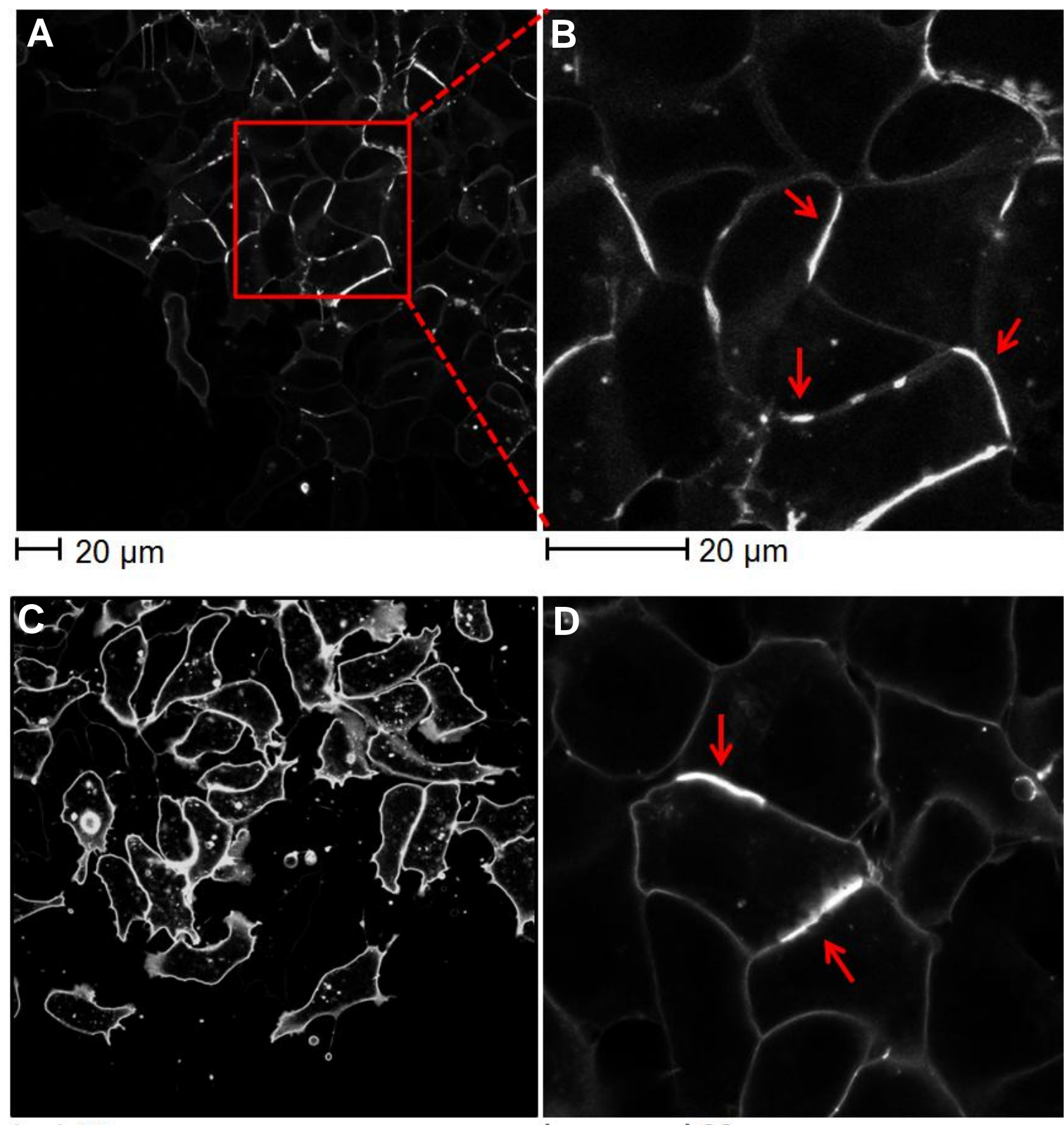

$\longmapsto 20 \mu \mathrm{m}$

$20 \mu \mathrm{m}$

Figure 40. PTK7 is enriched in restricted parts of the membrane of NC cells during cell-cell contact. Embryos were injected with 250 pg PTK7-GFP RNA into one blastomere of a two-cell stage Xenopus embryo. The NC cells of the injected side were explanted and placed onto fibronectin coated chambers. Migration was monitored for a couple of hours. A) NC cells show a distinct localization pattern of PTK7-GFP after 3 hours of migration. B) Zoomed area of image in A. The red arrows mark the area of the cell-cell contacts in which PTK7-GFP is enriched. C) NC cells expressing mGFP show a uniform expression of GFP at the membrane and no accumulation at cell-cell contacts after 3 hours of migration. D) High resolution picture of a migrating NC cells with accumulated PTK7 at the cell-cell contacts (red arrows).

NC cells at the leading edge of a cell cluster show an accumulation of PTK7-GFP at the lateral cell-cell contact sides (Fig.: 41, red arrows). This enrichment of PTK7 was stable during the migration process. Surprisingly, the accumulation was not present at the back 
of the cells (Fig.: 41, green arrows). A detailed view on this localization is shown in Fig.: 42. As control mGFP was used which showed an equal expression at the cell-cell contacts of clustered and single migrating neural crest cells (Fig.: 47).

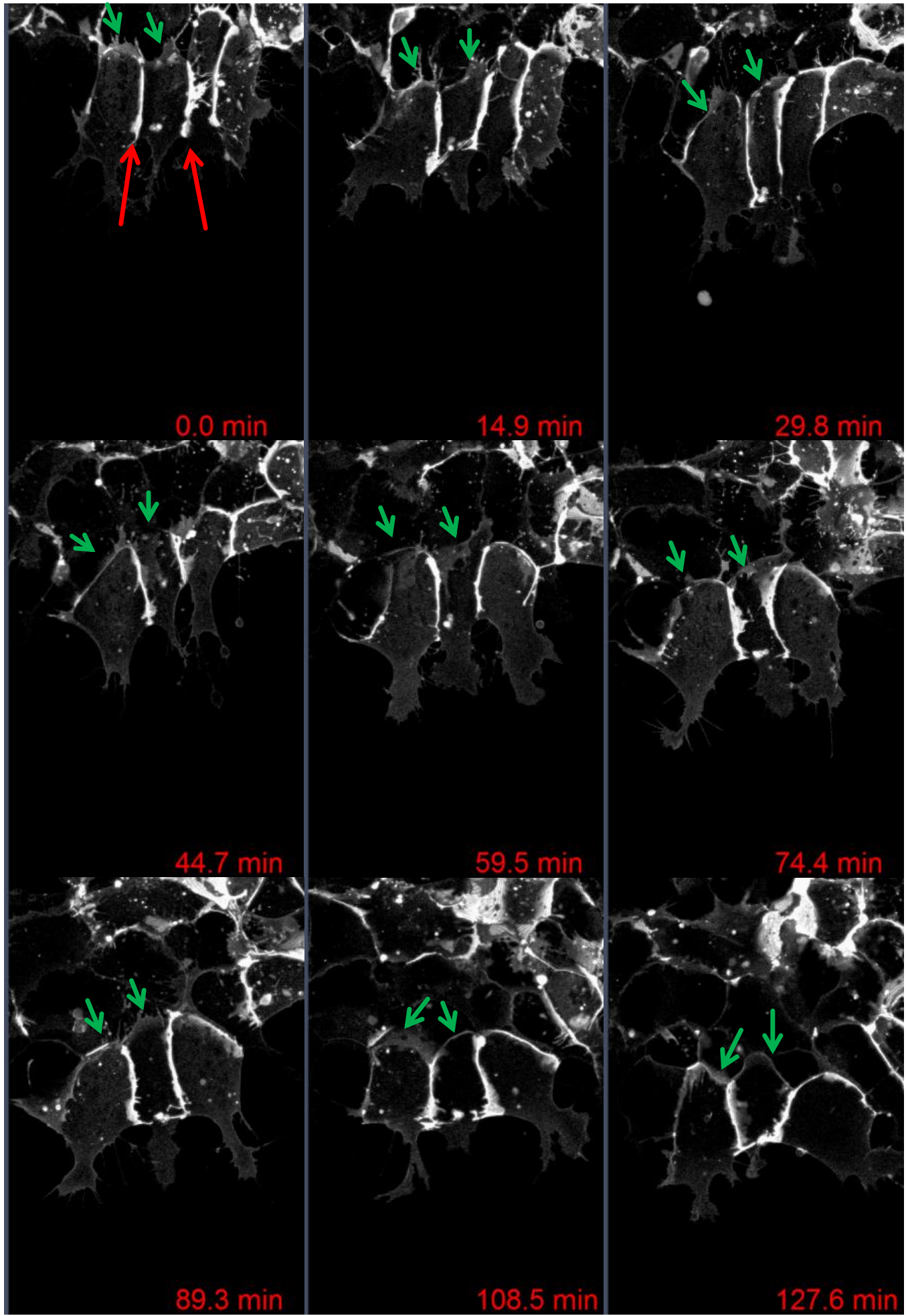

Figure 41. PTK7 is enriched at lateral cell-cell contacts of clustered migrating NC cells. Embryos were injected with $250 \mathrm{pg}$ PTK7-GFP RNA in one blastomere of a two-cell stage Xenopus embryo. The NC cells of the injected side were explanted and placed onto fibronectin coated chambers, the migration was monitored for four hours. The migration time in minutes (min) is indicated. The red arrows mark the lateral accumulation of PTK7-GFP and the arrows in green 
mark the back of the cells were no accumulation was present.

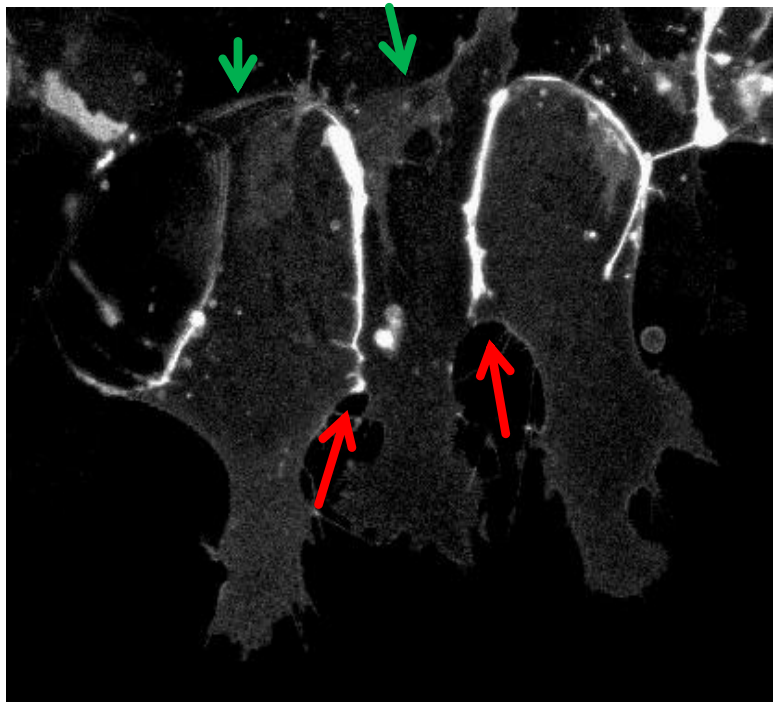

Figure 42. PTK7 is enriched at the lateral sides of migrating NC cells at the migration front. Detailed view of time point $59.5 \mathrm{~min}$ of figure 41 . The red arrows mark the lateral accumulation of PTK7-GFP and the arrows in green mark the back of the cells were no accumulation was present. 


\subsubsection{PTK7 localizes at cell-cell contacts of two migrating single neural crest cells}

Explanted neural crest (NC) cells first migrate in a cluster and the cells at the leading edge are polarized. Later the NC cells migrate out of the cell cluster and dissociate into single cells. These leading neural crest cells migrate in the front of the cell cluster and guide the other cells (Mayor and Carmona-Fontaine 2010), which is an important event during migration of NC cells. To check if PTK7 is expressed and/or accumulates in such single cells further experiments were done. Indeed, an accumulation of PTK7-GFP was also detectable at cell-cell contacts of two single migrating NC cells (Fig.: $43 \mathrm{~A}, \mathrm{~B}$, red arrows). This enrichment of PTK7 was only stable while the cell-cell contact was present. For a more detailed view see Fig.: $43 \mathrm{~B}$.
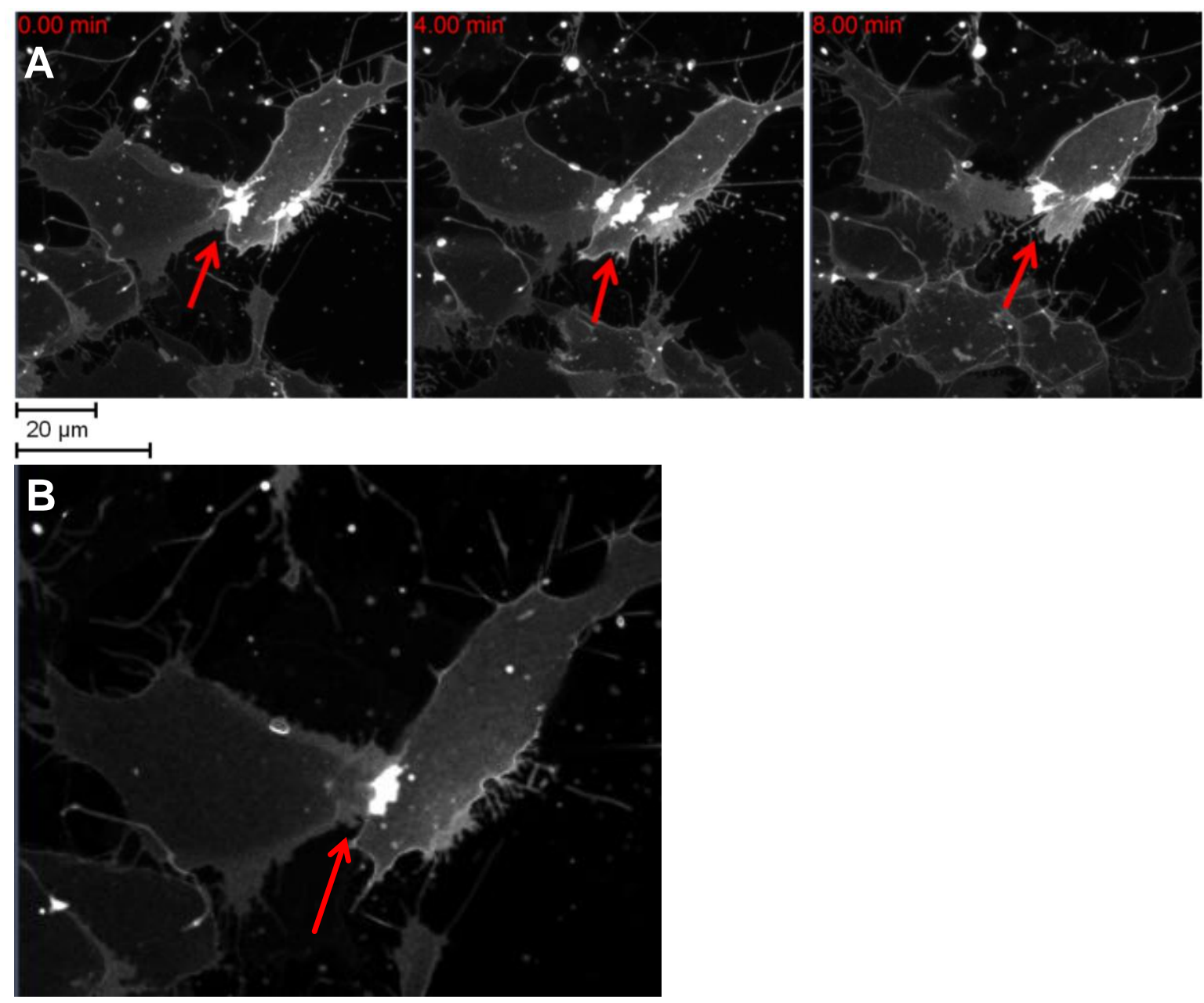

Figure 43. PTK7 is enriched at cell-cell contacts of two single migrating NC cells. Time lapse pictures of a cell-cell contact of two NC cells. A). PTK7-GFP is enriched at the cell-cell contact. B) Enlarged picture of the connected cells where PTK7-GFP accumulates at cell-cell contacts. Embryos were injected with $250 \mathrm{pg}$ of PTK7-GFP RNA into one blastomere of a two-cell stage Xenopus embryo. 


\subsubsection{PTK7 localizes at cell-cell contacts in migrating single neural crest cells during contact inhibition of locomotion}

The process of Contact Inhibition of Locomotion (CIL) was originally discovered by Abercrombie. He looked at the behavior of fibroblast cells confronting each other. After the cells had contact they retracted their protrusions and changed their direction of migration (Abercrombie 1953, 1954). The process of CIL was also observed in migrating NC cells (Carmona-Fontaine 2008). We decided to analyze, using Spinning Disk and Laser Scanning Microscope (LSM) confocal microscopes, the observed localization/accumulation of PTK7 in cells undergoing CIL. PTK7 accumulation was visible if a new contact between migrating single NC cells was formed (Fig.: 44, 45, 46 red rectangle) followed by the process of contact inhibition of locomotion of the NC cells. First, this was observed by confocal Spinning-Disk microscopy where we could detect that after two single cells have contact with each other the cells changed their orientation and moved into opposed direction (Fig.: 44, red arrows) which indicate CIL. To get a better resolution and a more detailed view of the PTK7 accumulation at these cell-cell contacts and the process of CIL we used the LSM microscope for further experiments.

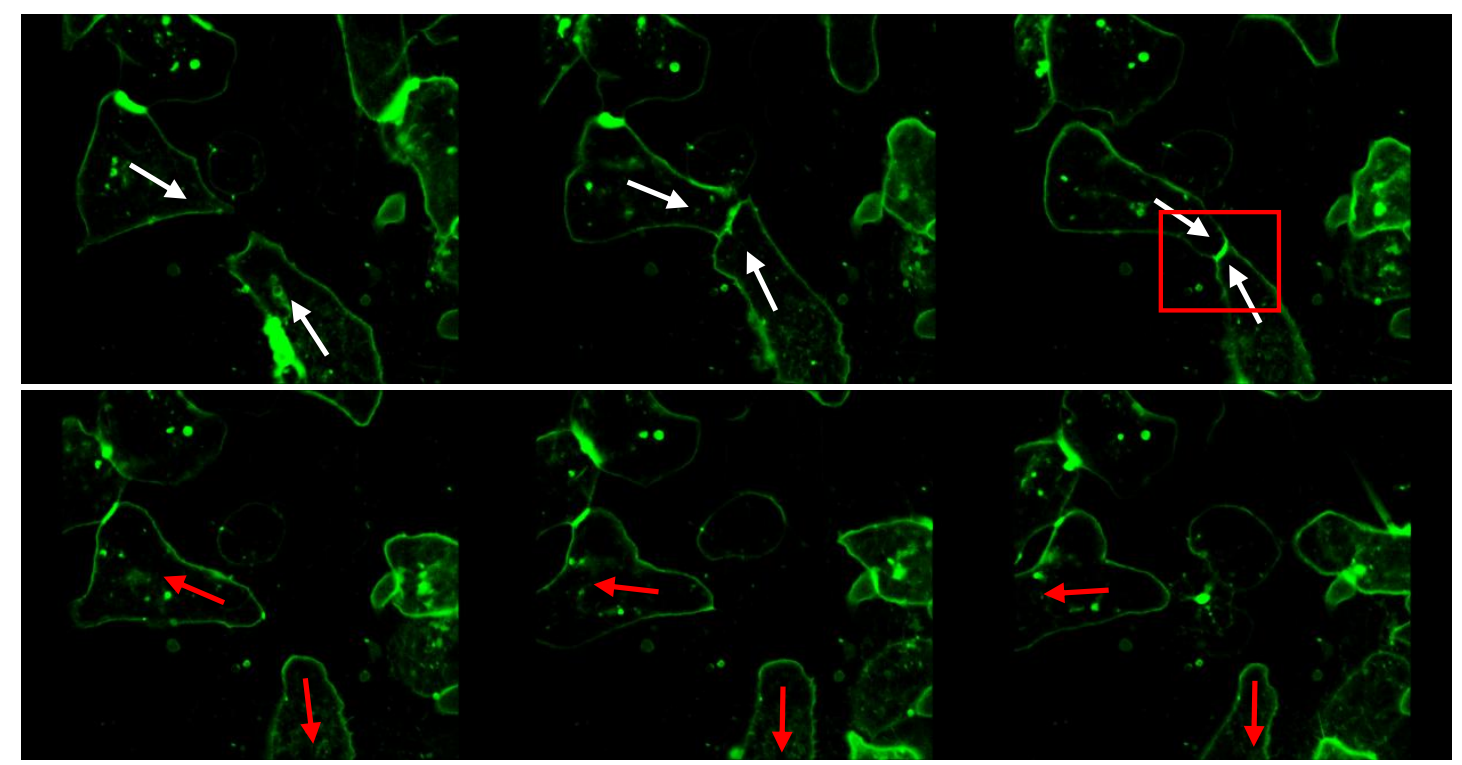

Figure 44. PTK7 is enriched at cell-cell contacts during CIL (Spinning disk images). Time lapse pictures made with a spinning disk microscope of migrating NC cells. The white arrows indicate the direction of migration before cell contact of both NC cells. The red arrows indicate the changed direction after the cell-cell contact. The red rectangles mark the place where the two cells contact each other and PTK7 accumulates in the cell-cell contact. Embryos were injected with 500 pg PTK7-GFP RNA into one blastomere of a two-cell stage Xenopus embryo.

The same process was observed in a moment when the NC cells start to migrate as single cells out of a cluster and have contact directly afterwards (Fig.: 45, white arrows). At the contact sides PTK7 accumulation was detected (Fig.: 45, red rectangles) and both cell changed their direction of migration after afterwards (Fig.: 45, red arrows). The same 
PTK7 accumulation (Fig.: 46, red rectangles) and the process of CIL (Fig.: 46, white and red arrows) were observed if two single cells contact each other (Fig.: 46). Control NC cells expressing mGFP show a uniform expression of GFP at the membrane and no accumulation at cell-cell contacts (Fig.: 47).

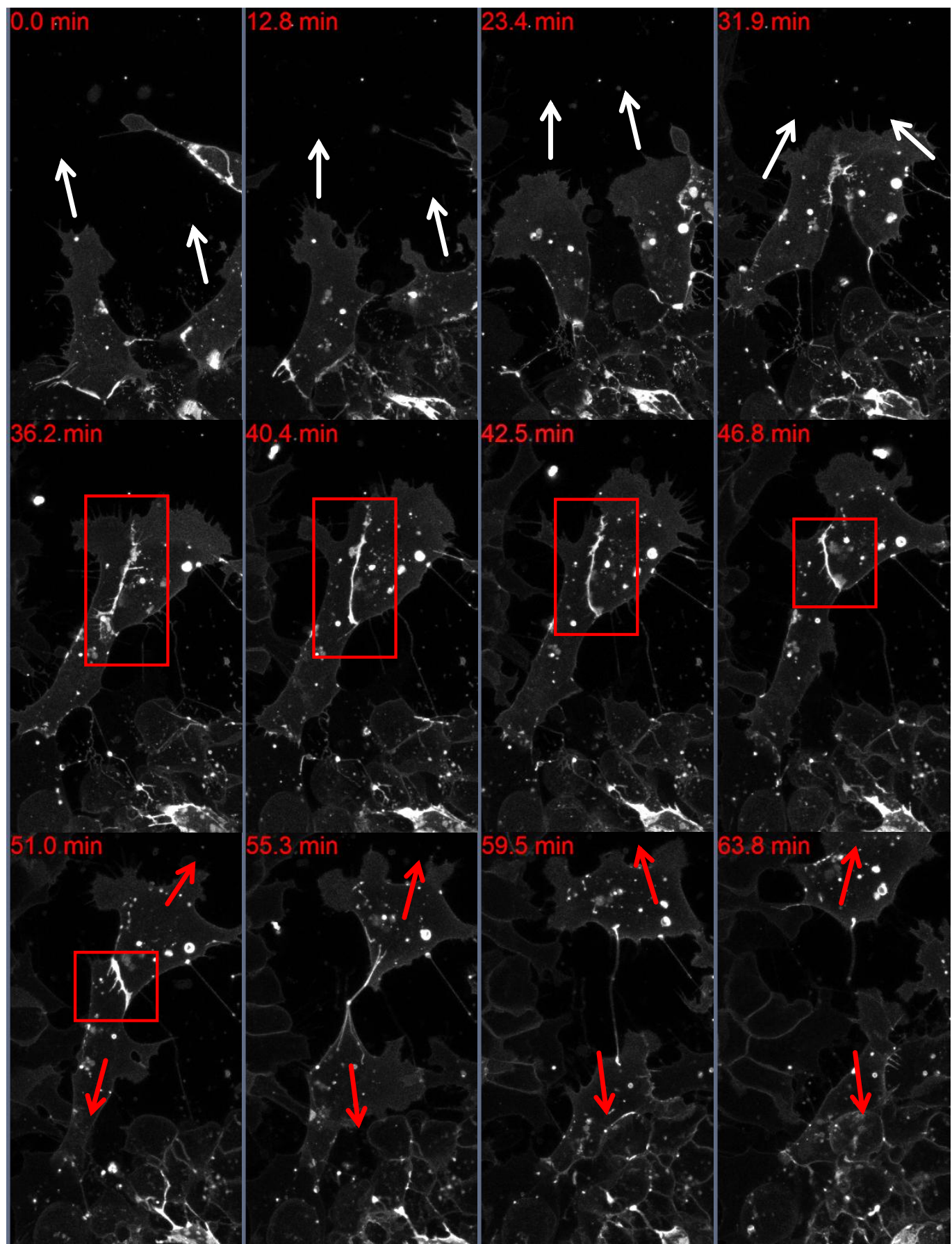

Figure 45. PTK7 is enriched at cell-cell contacts during CIL of two single migrating NC cells which migrate directly out of a cell cluster (LSM images). Time lapse pictures of migrating NC cells. The migration time in minutes $(\mathrm{min})$ is indicated. The white arrows indicate the direction of migration before cell contact of both NC cells. The red arrows indicate the changed direction after the cell-cell contact. The red rectangles mark the place where the two cells contact each other and PTK7 accumulates at this cell-cell contact. Embryos were injected with 250 pg of PTK7-GFP RNA into one blastomere of a two-cell stage Xenopus embryo. 


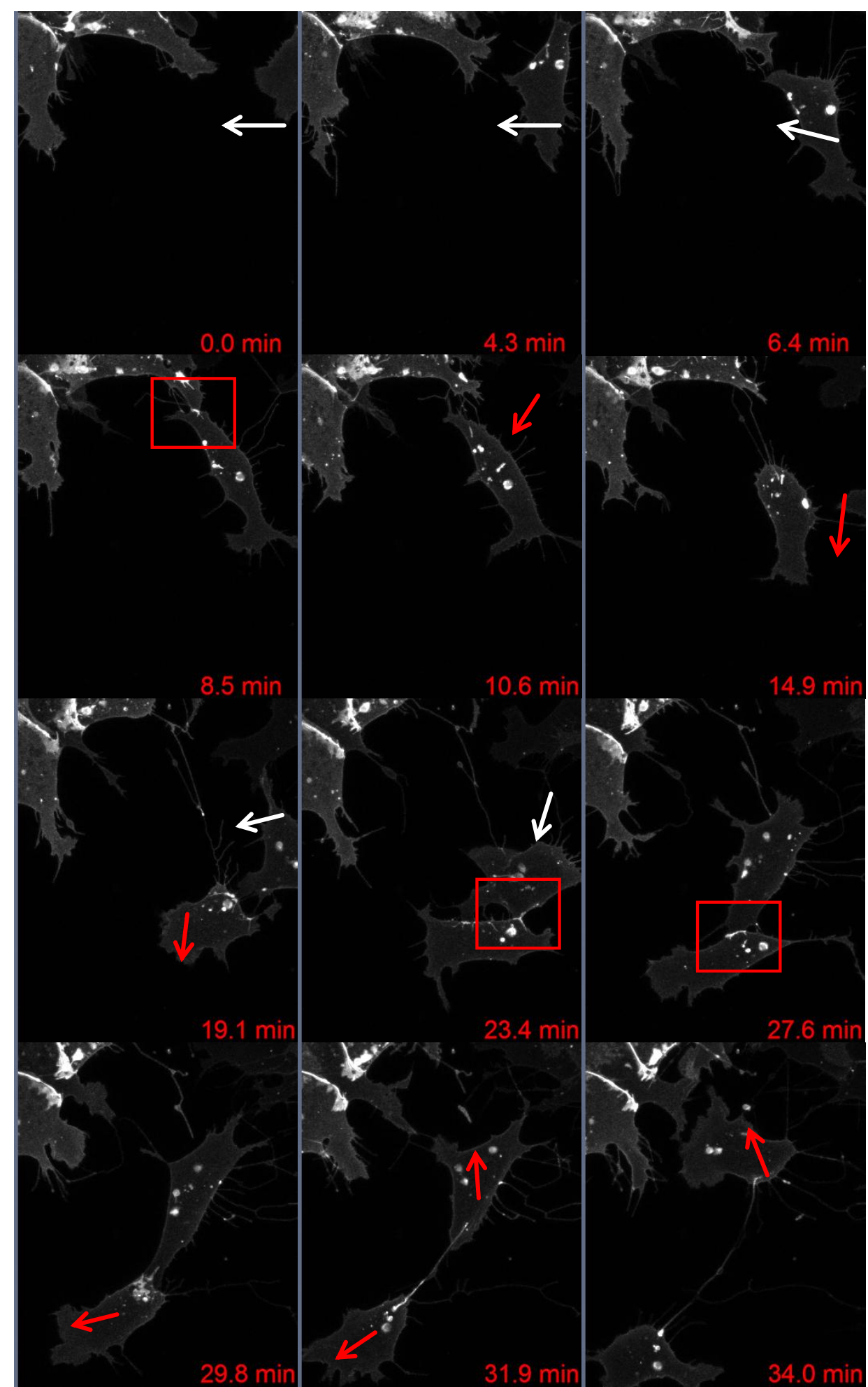

Figure 46. PTK7 is enriched at cell-cell contacts in migrating single cells during CIL (LSM images). Time lapse pictures made with a LSM microscope of migrating NC cells. The migration time in minutes $(\mathrm{min})$ is indicated. The white arrows show the direction of migration of different NC cells before their contact, the red arrows indicate the changed direction of migration after the cell contact. The red rectangles mark the time and place where the two cell contact each other and PTK7 accumulate at this cell-cell contact. Embryos were injected with $250 \mathrm{pg}$ of PTK7-GFP RNA into one blastomere of a two-cell stage Xenopus embryo. 


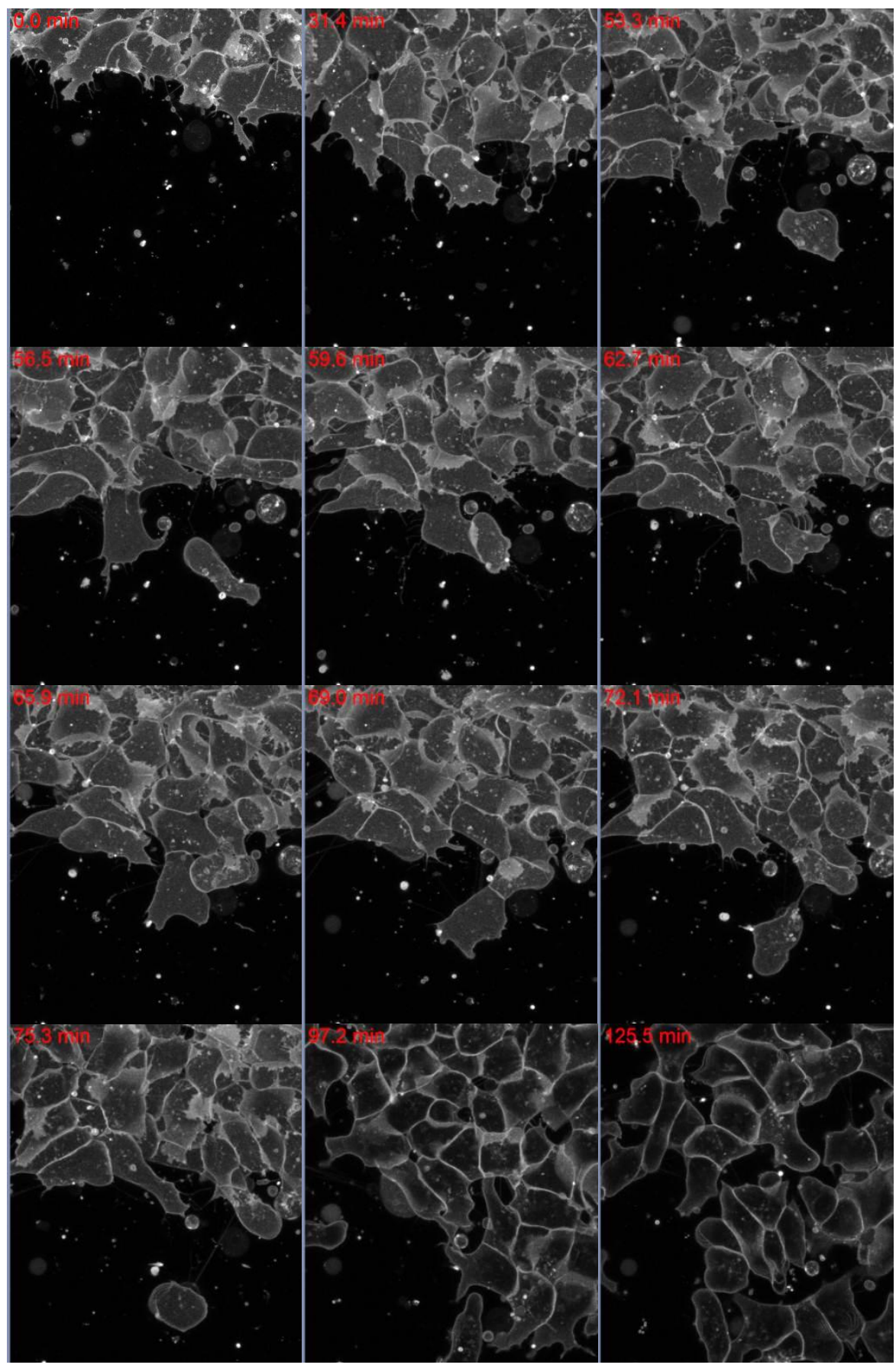

Figure 47. Membrane GFP expressing cells shows no enrichment at cell-cell contacts. Time lapse pictures of migrating NC cells. The NC cells show no accumulation of mGFP at the membrane during cell-cell contacts in cell clusters or between two single cells. The migration time in minutes (min) is indicated. Embryos were injected with $30 \mathrm{pg}$ of mGFP RNA into one blastomere of a two-cell stage Xenopus embryo. 


\subsection{6 $\Delta \mathrm{kPTK} 7$ accumulates at cell-cell contacts, in vesicles and at unspecific membrane parts}

The expression of $\triangle \mathrm{kPTK} 7$ in neural crest cells inhibits the migration of these cells (Shnitsar and Borchers 2008). $\triangle \mathrm{kPTK} 7$ lacks the intracellular part of PTK7 and it is not known if this affects the localization of $\triangle \mathrm{kPTK} 7$ in migrating NC cells compared to the full length PTK7 expression. To test this, a GFP-tagged construct of $\triangle \mathrm{KPTK} 7$ was expressed in neural crest cells, which were analyzed during migration by confocal microscopy. Overall, $\triangle$ KPTK7-GFP shows a similar membrane accumulation like full-length PTK7 because it was enriched at cell-cell contacts (Fig.: 48, yellow arrows). Contrary to this it was obvious that $\triangle \mathrm{kPTK} 7$-GFP injected NC cells showed more $\triangle \mathrm{kPTK} 7$ accumulating vesicles compared to the amount of vesicles observed in PTK7-GFP injected expressing cells (Fig.: 48, red arrows). In $\triangle \mathrm{kPTK} 7$ expressing NC cells the membrane localization is not only restricted to the cell-cell contacts (Fig.: 48, green arrow) like seen in full length PTK7 expressing cells (Fig.: 40, 42).

Embryos injected with $\triangle \mathrm{KPTK} 7$ show a defect in neural crest migration in Xenopus embryos and in explanted NC cells (Shnitsar and Borchers 2008). However, in our localization experiment the cells migrate (Fig.: 48). To avoid protein accumulation caused by overexpression we kept the injected levels rather low. This could be the reason why the $\triangle \mathrm{kPTK} 7$ effect was not strong enough to inhibit the function of the endogenous protein. The accumulation pattern of $\triangle \mathrm{kPTK} 7$ in migrating NC cells seems to be similar to that one seen for full length PTK7 (Fig.: 48, yellow arrows) but the precise protein accumulation at specific cell membrane areas, like it was seen in PTK7 expressing cells, is missing. Additionally, $\triangle \mathrm{kPTK} 7$ accumulates in vesicles (Fig.: 48, red arrows) and at parts of the cell membrane which do not have any contact with another cell (Fig.: 48, green arrows). 


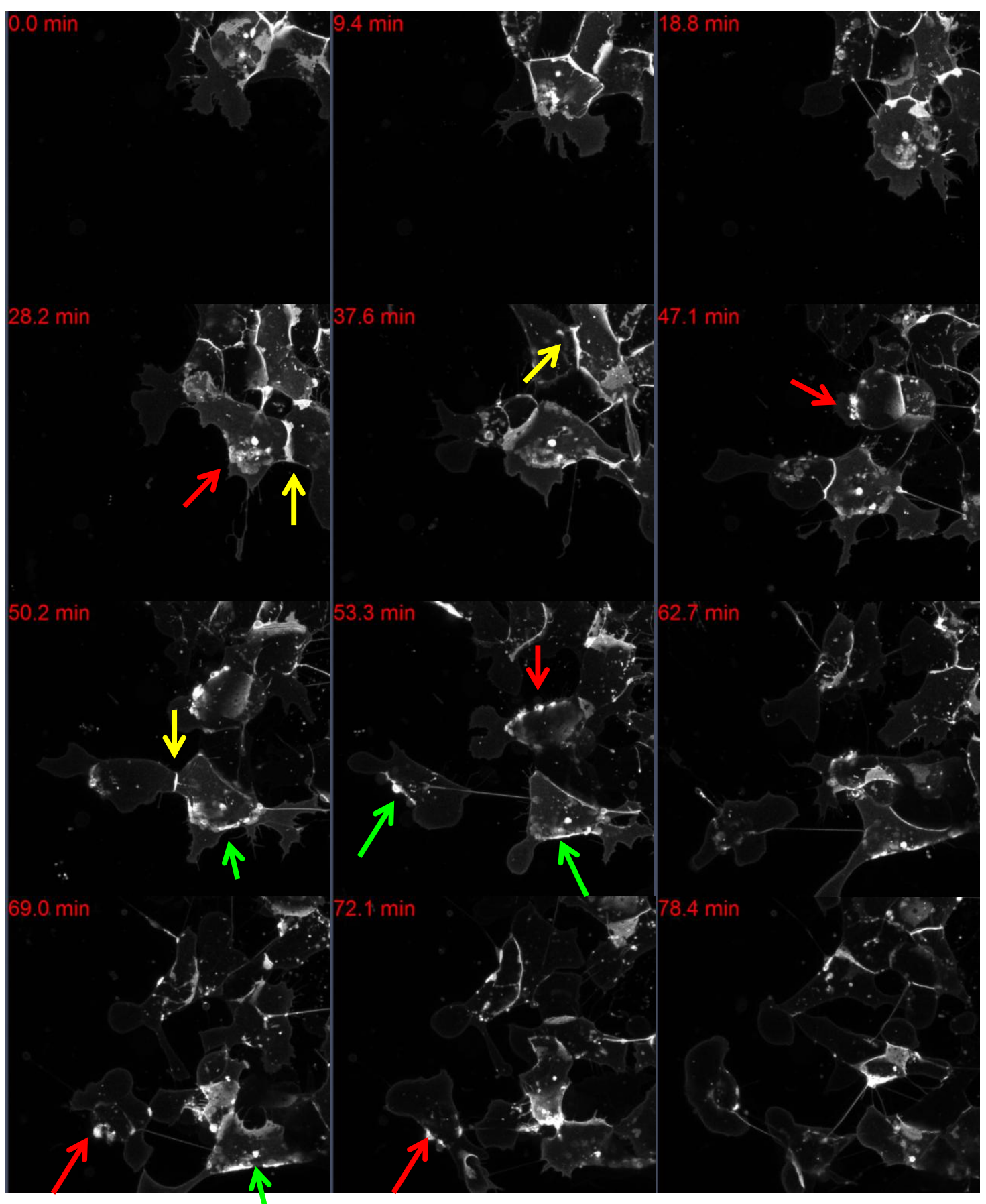

Figure 48. $\Delta$ kPTK7-GFP enriched at cell-cell contacts in clustered and single migrating NC cells. Time lapse pictures of migrating NC cells. The migration time in minutes $(\mathrm{min})$ is indicated. The yellow arrows label cell-cell contacts where $\triangle$ KPTK7-GFP where expressed like full-length PTK7-GFP. The red arrows label vesicles where $\triangle$ KPTK7-GFP accumulates. The green arrows mark cells where $\triangle$ KPTK7-GFP was expressed at the cell membrane without any cell-cell contacts. Embryos were injected with $100 \mathrm{pg} \triangle K P T K 7-G F P$ RNA into one blastomere of a two-cell stage Xenopus embryo. 


\subsection{RACK1 and PTK7 co-localize in migrating neural crest (NC) cells}

PTK7 recruits RACK1 to the plasma membrane in ectodermal explant assays and both proteins interact biochemically with each other. However, nothing is known about the function of both molecules in the process of neural crest migration. NC cells were explanted at neurula stage 17 onto fibronectin coated chambers and after 8 hours of migration the cells were fixed and immunostained. Afterwards the cells were analyzed by confocal microscopy. HA-tagged RACK1 alone was mainly expressed in the cytoplasm of NC cells (Fig.: 49 A) while MT-tagged PTK7 alone was localized at the cell-cell contacts of migrating NC cells (Fig.: $49 \mathrm{~B}$ ). If both proteins were co-expressed they co-localized with each other at cell-cell contacts in migrating NC cells (Fig.: $49 \mathrm{C}, \mathrm{D}$ ). 


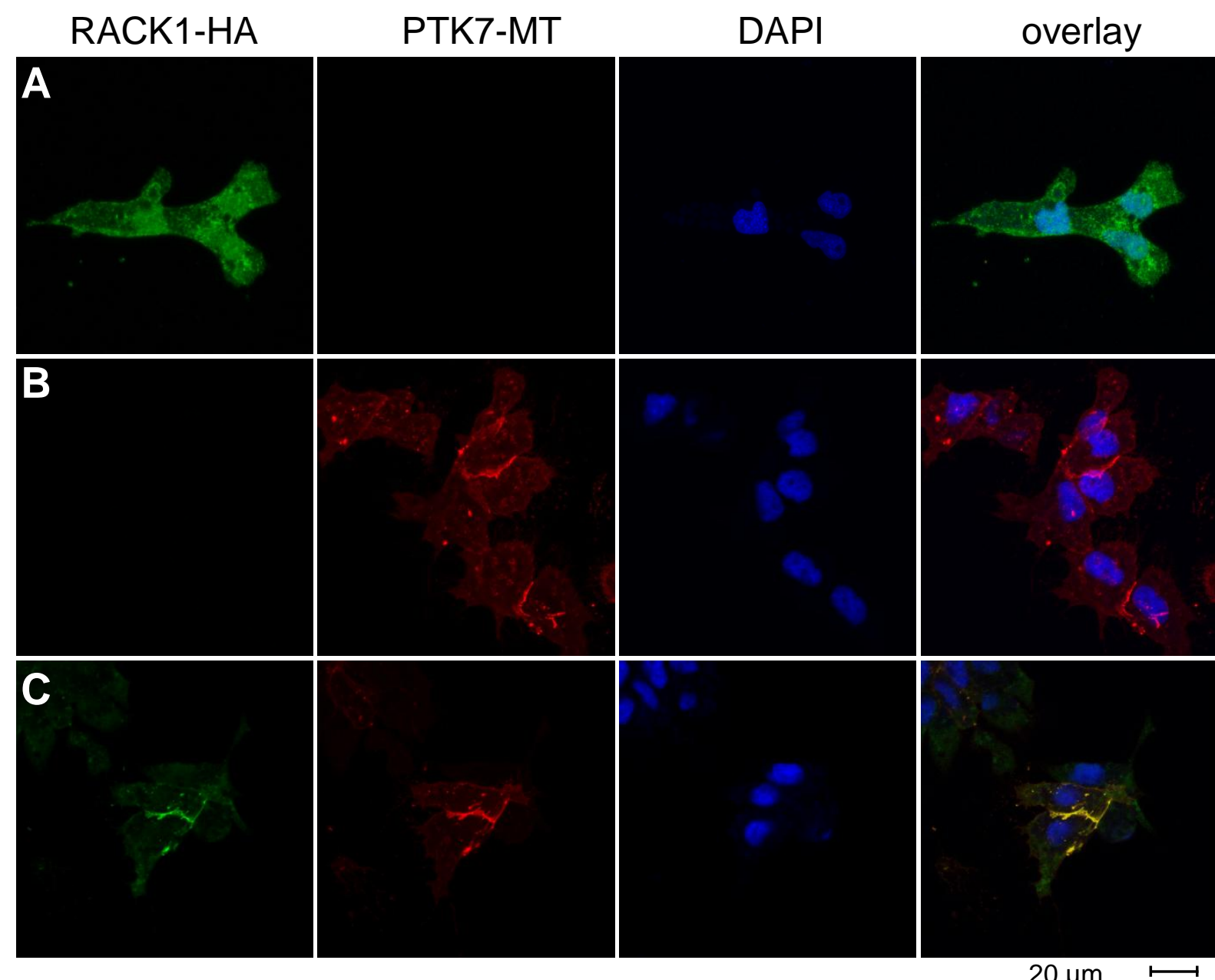

RACK1-HA

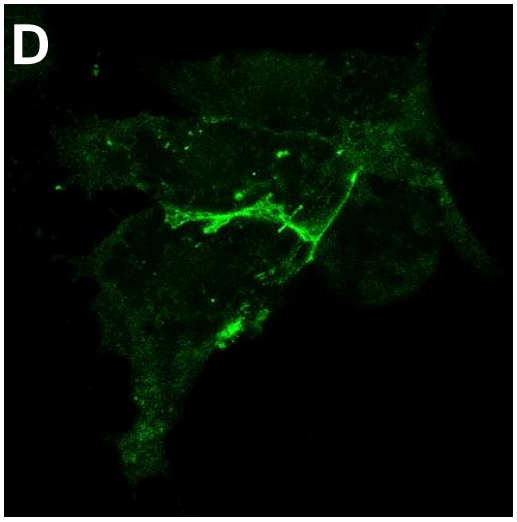

PTK7-MT

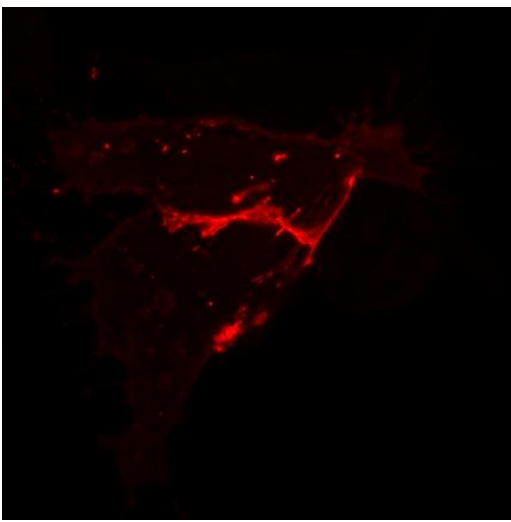

\section{overlay}

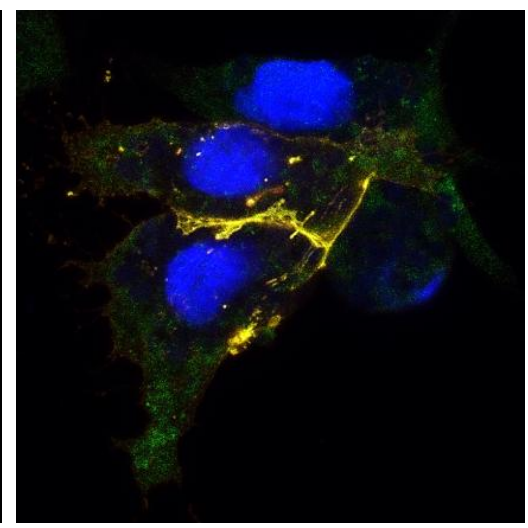

$20 \mu \mathrm{m}$

Figure 49. PTK7 and RACK1 co-localize in migrating neural crest cells. Explanted neural crest cells (NC cells) 10 hours after migration on fibronectin coated dish. The embryos were injected with $300 \mathrm{pg}$ RACK1-HA RNA or/and PTK7-MT RNA. A) RACK1 alone is similar to what we saw in ectodermal explants mainly expressed in the cytoplasm. B) PTK7 alone is especially expressed in cell-cell contacts. C) If both are co-expressed they co-localize in cell-cell contacts. D) Detailed view of cells from C. Embryos were injected with $300 \mathrm{pg}$ PTK7-MT RNA or/and $300 \mathrm{pg}$ RACK1-HA RNA into one blastomere of a two-cell stage Xenopus embryo. 


\subsection{PTK7MO and RACK1MO migration phenotype}

PTK7 is required for the NC migration in vivo and in vitro (Shnitsar and Borchers 2008, Shnitsar 2009). To further characterize the function of PTK7 in migrating neural crest cells, neural crest explants were analyzed by confocal microscopy and time-lapse movies were recorded. Neural crest cells injected with $10 \mathrm{ng}$ of PTK7 morpholino and membrane GFP as a tracer showed almost a normal shape morphology directly after explantation (Fig.: 50, 0 min). Strikingly, the explanted cells were surrounded by some round cells, which look dead. Close to the time the cells start to migrate they round up and loose their contacts with each other followed by a short blebbing phase and finally they stay round (Fig.: 50, $87 \mathrm{~min}$ ). PTK7 loss-of-function (LOF) leads to a disturbed migration process of neural crest cells. 


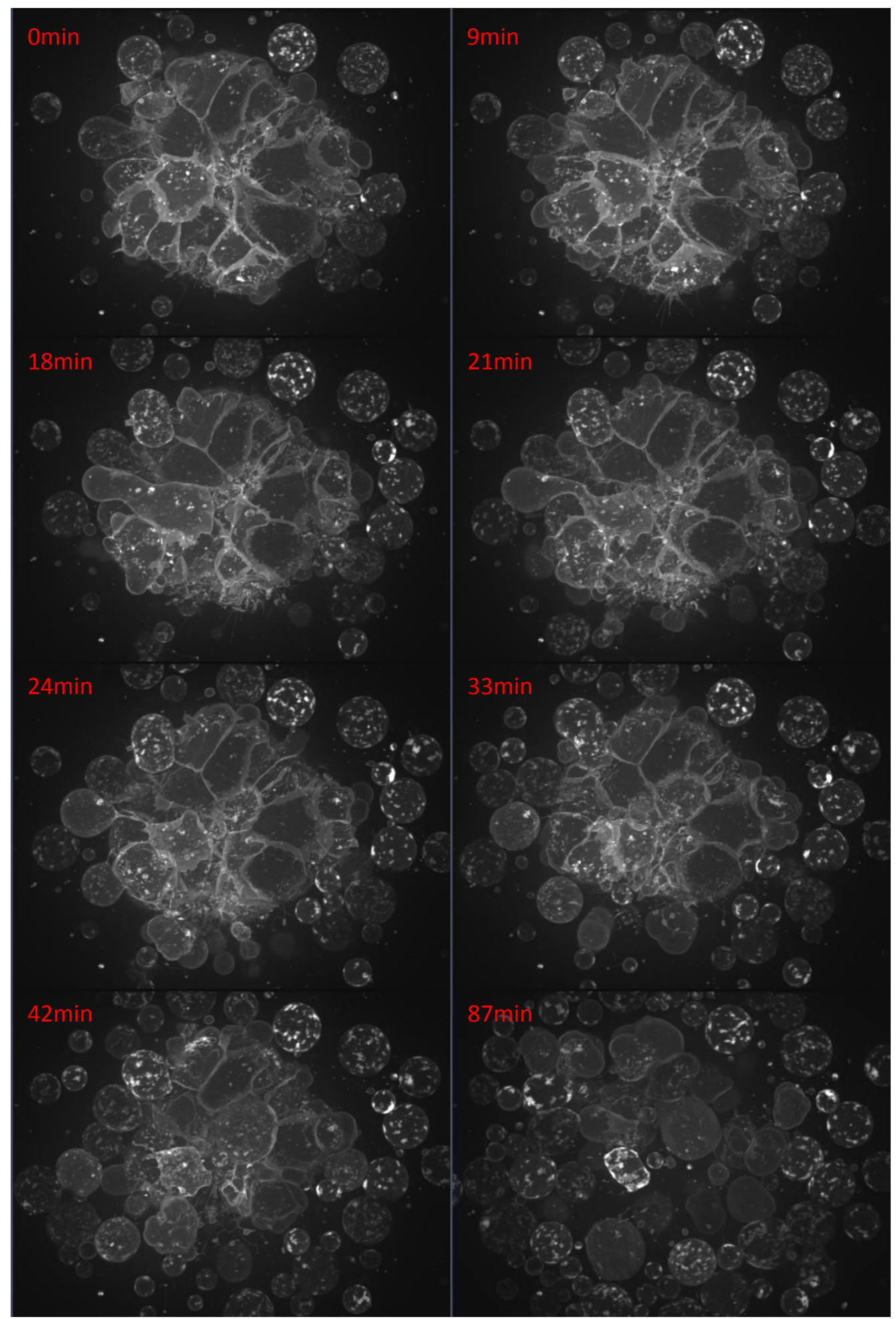

Figure 50. PTK7 MO injected NC cells show a disturbed migration. Time lapse pictures of migrating NC cells. The migration time in minutes ( $\mathrm{min}$ ) is indicated.10 $\mathrm{ng}$ of PTK7 MO and $50 \mathrm{pg}$ of mGFP were co-injected into one blastomere of a two-cell stage Xenopus embryo. The cells start to migrate but later they loose cell-cell contact and after a short blebbing phase they round up. 
We showed that PTK7 and RACK1 interact with each other and that RACK1 works downstream of PTK7. Both molecules were expressed in the same area in neurula and tadpole stage embryos, namely pre-migratory and migrating NC cells. Since, a PTK7 LOF affects the migration of neural crest cells RACK1 LOF could lead to the same defects. Indeed, direct after explantation the RACK1 MO injected NC cells show a similar morphology like seen before for the PTK7 MO (Fig.: 50 compare to Fig.: 51). Later most of the cells start to migrate and some round up (Fig.: 51). In general if RACK1 is down regulated the migration of the NC cells can still happen but different to cells injected with control MO (co MO) (Fig.: 52). It looks like that the RACK1 LOF reduces the migration speed of the NC cells. Some of the cells show also blebbing and stay round but not as severe as in PTK7 knock-down experiment (compare Fig.: 50 and 51). 


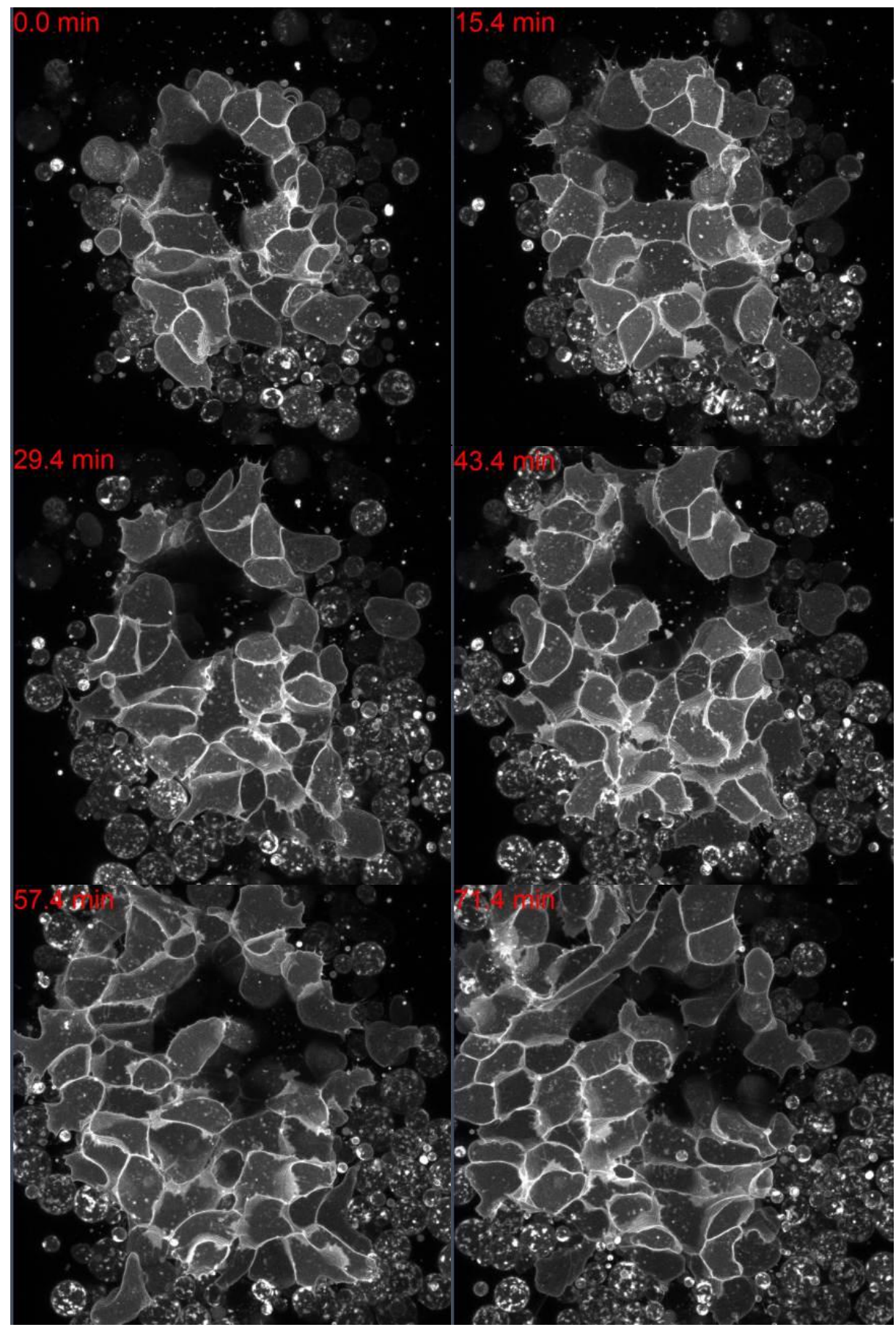

Figure 51. RACK1 loss-of-function did not disturb the migration process of NC cells in general. Time lapse pictures of migrating NC cells. The migration time in minutes $(\mathrm{min})$ is indicated.10 ng of RACK1 MO plus $50 \mathrm{pg}$ of mGFP-RNA as a tracer were co-injected into one blastomere of a two-cell stage Xenopus embryo. The RACK1 MO injected cells migrate relatively normal only a few of them start to blebb and round up. 


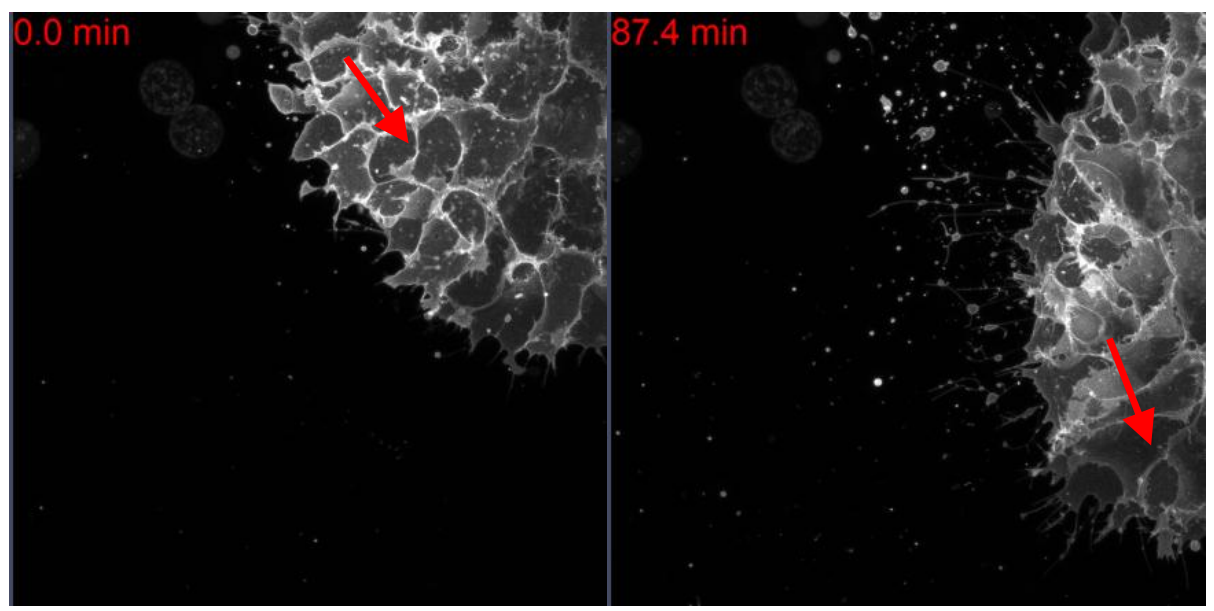

Figure 52. Control MO injected NC cells show a normal migration behaviour over time. Time lapse pictures of migrating NC cells. The migration time in minutes (min) is indicated. 50pg of mGFP-RNA were injected into one blastomere of a two-cell stage Xenopus embryo. The red arrows mark the direction of migration of the whole NC explant.

\subsection{PTK7 but not RACK1 are required for Contact Inhibition of Locomotion}

PTK7 is enriched at cell-cell contacts during contact inhibition of locomotion (CIL) and colocalizes with RACK1 in migrating neural crest (NC) cells. It is not known if PTK7 or RACK1 are necessary for the process of contact-inhibition. To test this confrontation assays were performed. NC explants equal in size taken from embryos injected with PTK7 MO or RACK1 MO were placed opposite to an explant injected with co MO. The embryos were co-injected with different fluorescent lineage tracers (mGFP, mCherry) to distinguish both explants. The migration behavior was observed over several hours by Spinning Disk microscopy. Under normal conditions the NC cells undergo CIL, which means if cells from the opposite explant contact each other they changed their direction of migration. If the process of contact inhibition is disturbed the control explants do not change their migration direction and move into the area of the NC cells with disturbed CIL (Carmona-Fontaine et al. 2008). The confrontation assay with PTK7 MO and mCherry injected cells (in red) showed a disturbed CIL, mGFP injected control cells (in green) moved into or overrun the PTK7 knock-down NC cells. The area in which the two different explant cells overlap each other is visualized in yellow. Since the mCherry expression was too low the overlapping area which should be yellow is a bit green but it was seen that the "green" cells migrate into the "red" explant (Fig.: 53 A-D). It was also seen that the PTK7 MO injected cells did not migrate similar to what we observed for PTK7 MO injected NC cells (Fig.: 50).

In contrast, the RACK1 MO injected NC cells show the process of CIL. Both explants show almost no overlapping yellow area (Fig.: 54 A-D). It looks like RACK1 MO injected 
cells migrate slower compared to the co MO injected neural crest cells which fits to the observation we saw before for RACK1 MO injected NC cells (Fig.: 51). In summary, it is likely that PTK7 is necessary for CIL but interestingly RACK1 not.
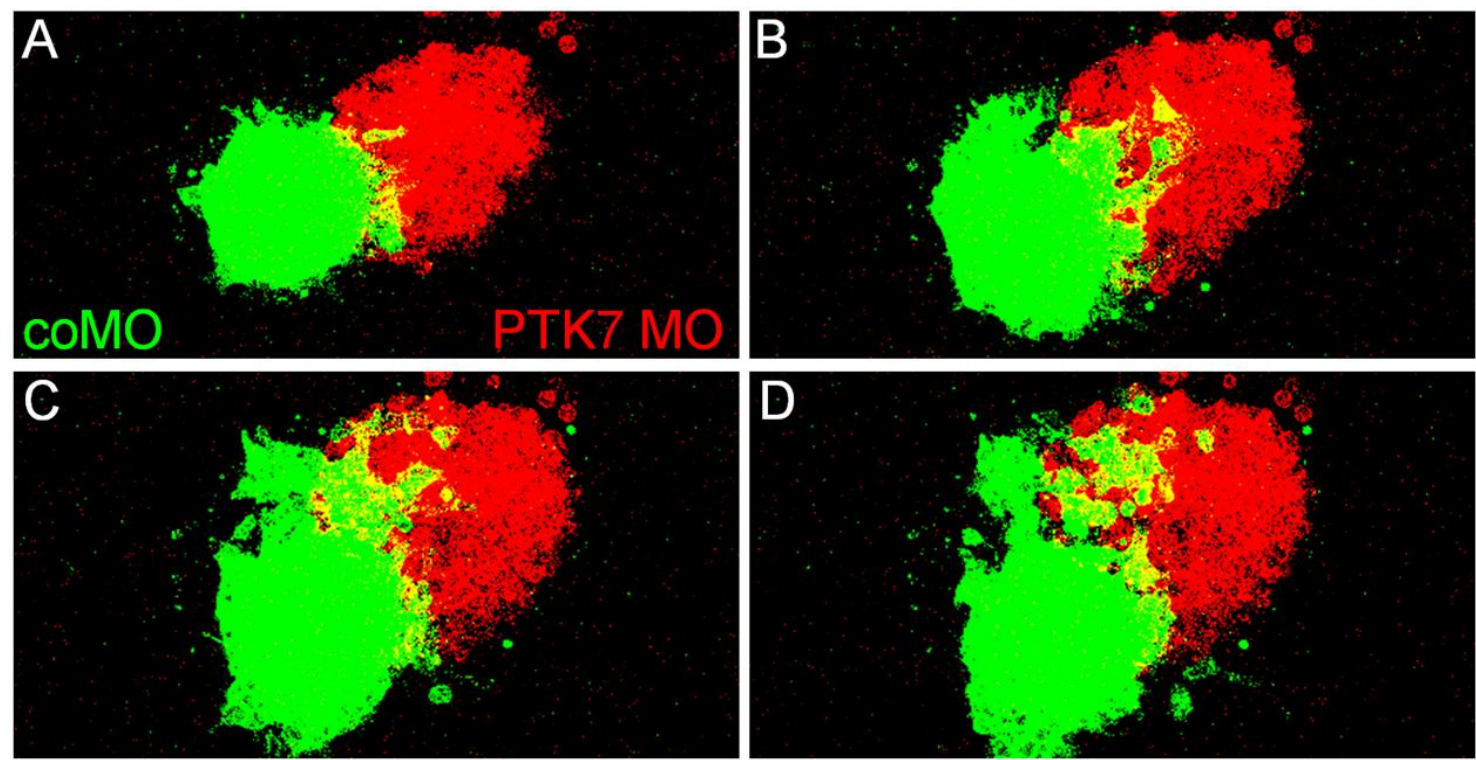

Figure 53. PTK7 loss-of-function disturbed contact inhibition of locomotion. The embryos for the confrontation assay were injected with $10 \mathrm{ng}$ PTK7 MO and mCherrry (red) or control MO (co MO) and mGFP (green). The migration was monitored over a time period of 10 hours. The pictures show four hours of migration at one hour intervals.
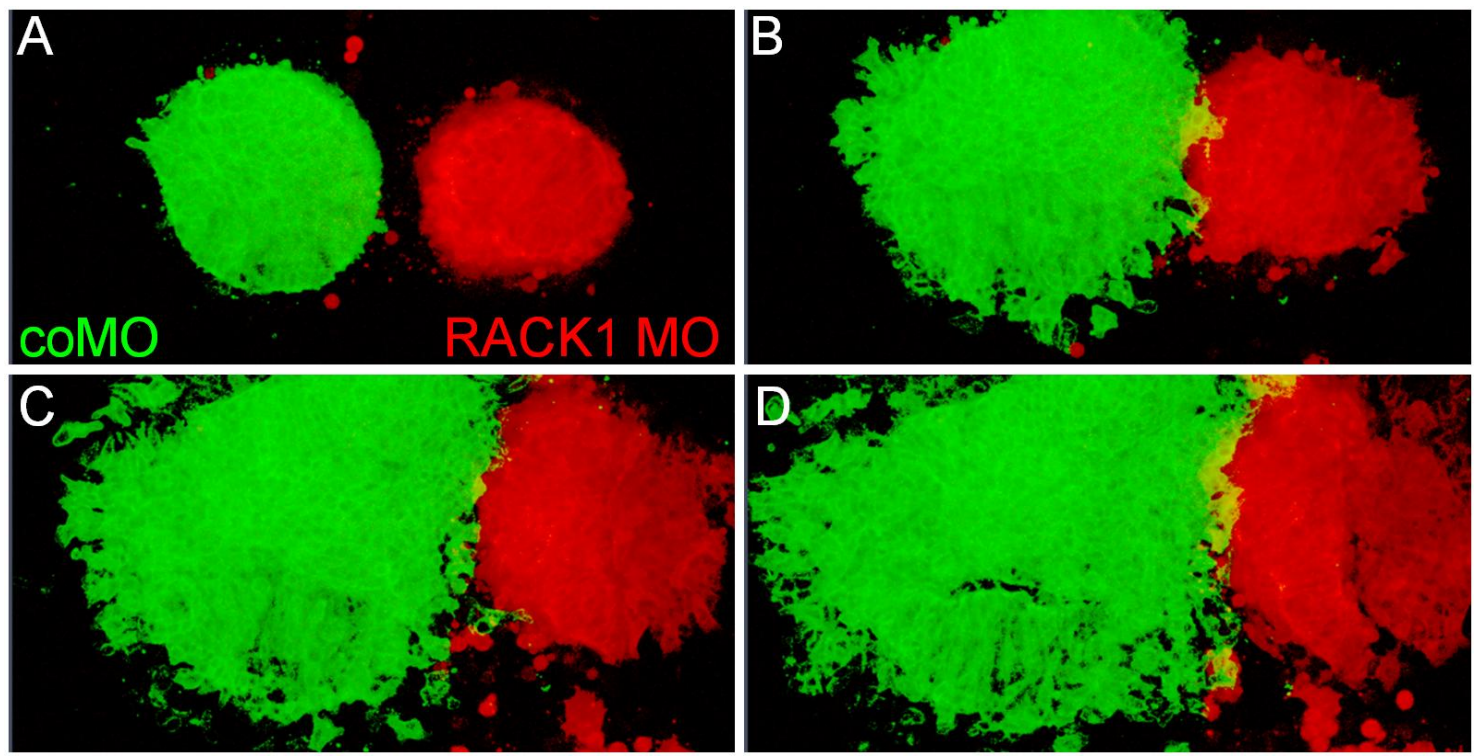

Figure 54. RACK1 loss-of-function does not affect contact inhibition of locomotion. The embryos for the confrontation assay were injected with $10 \mathrm{ng}$ RACK1 MO and mCherry (red) or control MO (co MO) and mGFP (green). The migration was monitored over a time period of 10 hours. The pictures show four hours of migration at one hour intervals. 


\section{Discussion}

The development of the central nervous system is driven by morphogenetic movements. Failure in the regulation of these basal cell movements during embryonic development results in severe phenotypes. From PTK7 we know that it takes part in the regulation of neural morphogenesis processes including neural tube closure (NTC) and neural crest (NC) migration. However, the downstream signaling of PTK7 is largely unknown. Here I present new insight into these processes where PTK7 signaling is assisted by RACK1 (receptor of activated protein kinase $\mathrm{C}$ ) to regulate morphogenesis.

\subsection{RACK1 and PTK7 mediate DSH localization and regulate PCP}

Almost nothing is known about the PTK7 signaling mechanism. Recently, it was shown that the intracellular domain of PTK7 is required to recruit DSH to the plasma membrane in Xenopus (Shnitsar and Borchers 2008) but the mechanism was unknown. This translocation to the membrane is a prerequisite for activation of the PCP pathway (Park et al. 2005), which regulates morphogenetic events. In this work I present RACK1 a new mediator of this important process. Previously it was shown that RACK1 and PTK7 interact with each other (Shnitsar 2009). The recruitment of molecules to the membrane seems to be the essential step during the activation of the PCP pathway. In my experiments I could show that PTK7 was able to recruit RACK1 to the plasma membrane in ectodermal explants. RACK1 is normally expressed in the cytoplasm but in the presence of PTK7 it is shifted to the membrane. Together with the previous experiments, this supports the idea that RACK1 is directly involved in DSH localization by PTK7.

\section{The kinase domain of PTK7 functions by recruiting RACK1}

The next question is how PTK7 functions in the recruitment of these molecules? PTK7 is a transmembrane protein and has among others an intracellular kinase homology domain. This domain is mutated and so far no catalytic activity was shown in any organism tested (Chou and Hayman 1991; Jung et al. 2004; Miller and Steele 2000; Mossie et al. 1995). Interestingly, in Xenopus it could be shown that this domain is necessary for DSH membrane localization (Shnitsar and Borchers 2008). A PTK7 mutant lacking the intracellular kinase homology domain $(\triangle \mathrm{kPTK} 7)$ was not able to recruit $\mathrm{DSH}$ to the membrane. My data suggest that the recruitment of RACK1 to the plasma membrane is also mediated by this domain and that this recruitment is necessary to recruit DSH to the plasma membrane. Full length PTK7 was able to recruit RACK1 to the plasma membrane, unlike the mutant version, $\triangle \mathrm{kPTK} 7$. Additionally, a construct where RACK1 was fused to the $\triangle \mathrm{kPTK} 7$ mutant was able to recruit $\mathrm{DSH}$ to the plasma membrane ( $\triangle \mathrm{kPTK} 7 \mathrm{xR})$ 
indicating that the recruitment of RACK1 is the essential step for DSH membrane localization. Additionally, RACK1 loss-of-function (LOF) resulted in disruption of DSH membrane localization. These results indicate that the recruitment of RACK1 is a prerequisite for the DSH localization and that the fusion of RACK1 to the intracellular part of the transmembrane protein PTK7, which is necessary for RACK1 translocation, actively brings RACK1 to the membrane. This active process is able to establish the DSH membrane localization needed for activation of the PCP pathway (Park et al. 2005).

\section{PTK7/RACK1-mediated DSH localization: a mechanistic explanation for its function}

As a direct binding between RACK1 and DSH could not be observed (data not shown) it was possible that the structure of RACK1 could help to find a possible mediator for the PTK7/RACK1 dependent DSH localization. RACK1 (receptor of activated protein kinase C) is an evolutionary conserved adapter protein, first identified as a receptor of activated protein kinase C 1 (PKC) (Mochly-Rosen et al. 1991). Previous studies have shown that RACK1 functions as an anchor and as a scaffold protein. It recruits active PKC and other additional proteins in a signaling complex and acts as key mediator of various pathways and contributes too many functions for example during development (Li et al. 2011) or cell migration (McGahill et al. 2002; Sklan et al. 2006). PKC belongs to a family of proteinkinase enzymes and plays important roles in several signal transduction cascades (Nishizuka 1995; Mellor and Parker 1998). From one candidate of the PKC family, PKC $\delta$ it is known that it binds to DSH, activates c-Jun N-terminal kinase (JNK) and functions in PCP pathway regulating Xenopus convergent extension movements (Kinoshita et al. 2003). From its function it is possible that PKC $\delta$ is involved in the RACK1/PTK7 mediated DSH localization. Previous experiments could show that that PTK7 was able to recruit $\mathrm{PKC} \delta$ to the plasma membrane and RACK1 binds to it in Xenopus. Additionally, RACK1 LOF reduces the membrane localization of PKC $\delta$ (Shnitsar 2009). To clarify if PKC $\delta$ is only an additional molecule, which could be translocated by the PTK7/RACK1 complex, PKC $\delta$ LOF studies were performed. These showed that PKC $\delta$ was able to abolish the PTK7/RACK1 mediated DSH localization. Additionally the active recruitment of RACK1 to the membrane by the fusion construct was not able to restore the DSH membrane localization. These data suggest that RACK1 interacts with DSH via PKC $\delta$ and is needed in the PTK7/RACK1 complex to shift DSH to the membrane, which could possibly activate the PCP pathway.

It could be that $\mathrm{PKC} \delta$ affects DSH localization through its kinase function or only by mediating binding. It is not known if PKC $\delta$ is activated in the PTK7/RACK complex but it seems so since several other PKC isoforms bind RACK1 in the activated form (Pass et al. 2001; McCahill et al. 2002; Haberman et al. 2011). If PKC $\delta$ is active in the PTK7/RACK1 
complex it could possibly be activating JNK signaling. This is interesting because PTK7 overexpression in Xenopus animal caps activates the phosphorylation of JNK (Shnitsar and Borchers 2008) indicating PCP activity (Boutros et al. 1998; Li et al. 1999; Yamanaka et al. 2002; Habas et al. 2003). Further, an ATF2-based luciferase reporter assay with the ability to monitor activation of PCP signaling could show that PTK7 activates PCP signaling in Xenopus (Peradziryi et al. 2011). This could explain why PTK7 signals without a functional kinase domain because it may recruit other molecules to its intracellular domain, which results in the activation of signaling cascades.

Another indication for a function of RACK1 in PCP signaling came from a study were it was shown that RACK1 is an interaction partner of Vangl2 ( $\mathrm{Li}$ et al. 2011) an essential core-PCP component (Wu and Mlodzik 2009). The others could show that RACK1 is required for Vangl2 membrane localization and could play a role in cell polarization, oriented cell division and convergent extension (CE) in zebrafish indicating an important role for RACK1 in PCP signaling. For future experiments it will be interesting to see if the RACK1/Vangl2 and RACK1/PTK7 interaction converge at the level of RACK1 or compete with each other. Taken together these phenotypic as well as mechanistic data support a role for RACK1 in the activation of PCP signaling. This could explain that PTK7 regulates PCP signaling possibly with the help of RACK1.

\section{PTK7/RACK1-mediated DSH localization is independent of frizzled}

DSH membrane localization and hyperphosphorylation is connected to the activation of the PCP pathway. This could be mediated by frizzled $(\mathrm{Fz})$ another core-component of the PCP pathway (Sheldahl et al. 1999; Axelrod et al. 1998; Medina et al. 2000; Medina and Steinbeisser 2000; Rothbacher et al. 2000). In this work I propose a different way of DSH localization, which is independent from the Fz7 mediated one. First I could show that the $\mathrm{Fz7}$ protein was not able to recruit RACK1 to the plasma membrane of ectodermal explants, which is needed for RACK1 mediated DSH localization via PTK7. In a second experiment the data show that RACK1 is not required for Fz7-mediated DSH localization and hyperphosphorylation. RACK1 LOF did not influence the Fz7-mediated DSH localization and additionally the Fz7-dependent hyperphosphorylation was not changed. The results indicate that RACK1 is not required for this process and does not function in the DSH localization via Fz7, supporting a Fz7 independent DSH localization process by PTK7/RACK1/PKC $\delta$. Contrary to this hypothesis, previously it was shown that PTK7 is required for Fz7-mediated membrane localization and hyperphosphorylation of DSH (Shnitsar and Borchers 2008). A possible explanation that PTK7 also plays a role in the Fz mediated DSH recruitment could be that PTK7 simply stabilizes the Fz-DSH complex. If PTK7 is not present this Fz/DSH complex gets destabilized and DSH could not be stably 
recruited to the membrane. This is supported by the findings that Fz LOF was not able to inhibit PTK7-mediated DSH localization (Shnitsar 2009).

In summary, the DSH recruitment by PTK7, which is RACK1-dependent, is different from the mechanism where DSH gets localized by Fz in a PTK7-dependent manner. Probably the new found mechanism of $\mathrm{DSH}$ localization represents a parallel molecular mechanism. It is unclear if both complexes affect similar or different downstream signaling events. For the PTK7/RACK1/PKC $\delta / D S H$ interaction it could be speculated that it affects JNK signaling because PTK7 leads to an increase in JNK phosphorylation (Shnitsar and Borchers 2008) and RACK1 mediates activation of JNK by PKC (Lopez-Bergami et al. 2005). Thus, I suggest the following model where PTK7/RACK1/PKC $\delta$ interact to recruit $\mathrm{DSH}$ at the plasma membrane, which result in PCP activity and regulates morphogenesis (Fig.: 55).

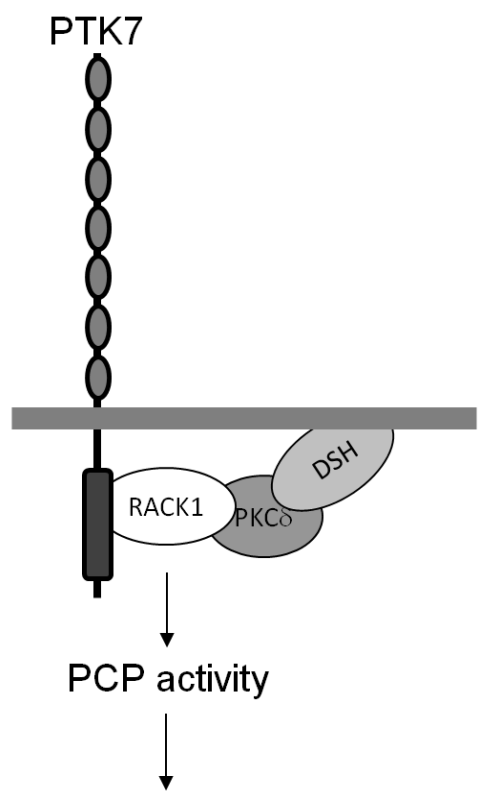

Figure 55. The model of PTK7 signaling. The intracellular domain of PTK7 functions by recruiting RACK1 to the plasma membrane. During their interaction they recruit PKC $\delta$ and $\mathrm{DSH}$ together to the plasma membrane. DSH membrane recruitment is needed for the activation of the PCP pathway (Park et al. 2005).

morphogenesis

\subsection{RACK1 and PTK7 regulate neural morphogenesis}

\section{RACK1 as a novel regulator of neural morphogenesis}

Miss-regulation of the PCP pathway frequently results in disturbed morphogenetic movements. Loss-of-function function studies of core-components of the PCP-pathway show disturbed neural morphogenesis processes, like open neural tubes and failure in convergent extension movements. PTK7 LOF studies in Xenopus result in embryos with open neural tubes and disturbed convergent extension movements ( $L u$ et al. 2004). RACK1 and PTK7 are both expressed in the area of the neural tube (Kwon et al. 2001; Lu 
et al. 2004) and play a role in the regulation of the PCP pathway. In Xenopus RACK1 and PTK7 show the same neural tube closure phenotype. RACK1 LOF results in a significant increase in NT closure defects, which was shown for the first time for RACK1 in vertebrates. Furthermore, the direct comparisons between PTK7 and RACK1 LOF phenotypes by time lapse imaging shows similarities between both neural tube closure defects. The neural tube was not closed and the embryos have a shorter body axis. This indicates that both interact to regulate NT closure.

A common cell movement during neural tube closure is convergent extension and the similarities between the RACK LOF and PTK7 LOF phenotypes indicate that they regulate convergent extension. Convergent extension is a process where cells intercalate and extend along the longitudinal body axis. A hallmark of effectors of CE is that gain-offunction and the loss-of-function often results in the same phenotype. Consistent with this, the inhibition as well the over-activation of the PCP pathway leads to similar phenotypes. This is problematic because both conditions can lead to failure in neural morphogenetic movements and generate identical phenotypes (Wallingford and Habas 2005). Consistent with this, both RACK1 GOF and LOF result in disturbed neural tube closure. The overexpression of RACK1 shows defects in neural tube closure ranging from mild to severe and this effect was concentration-dependent, indicating that RACK1 is an important regulator of neural morphogenesis movements.

\section{RACK1 and PTK7 affect convergent extension of the neural tube}

The similarities between PTK7 and RACK1 during loss-of-function studies indicate a defect in convergent extension. Targeted injections to only one side of the Xenopus embryo demonstrate that RACK1 as well as PTK7 are required for convergent extension movements during neural tube closure. Both sides, affected and un-affected could be directly compared to get a detailed view on changes at the cellular level. Sections demonstrate that RACK1 and PTK7 affect cell morphology in the neural plate tissue in a similar way. At the affected side, the orientation of the cells to each other was disturbed and they look un-organized indicating a defect in PCP. The neural plate was wider, which resulted in an open neural tube phenotype. However, the hinge point formation, important during the neural tube closure process was not affected indicating that no general processes like convergent extension were disturbed. This phenotype is reminiscent to one, which was observed in zebrafish when RACK1 was knocked-out ( $\mathrm{Li}$ et al. 2011). During gastrulation in zebrafish, the cells in the notochord are unpolarized and the orientation of cell division was disrupted. The cells look disorganized and are not assembled similar to the cells in the affected side in Xenopus.

Targeted injections and explant assays demonstrate that RACK1 and PTK7 are required for convergent extension movements during neural tube closure. Additional morphological 
studies could further define the role of RACK1 during neural tube closure and convergent extension.

An XBF-2 assay showed that both RACK1 and PTK7 are required for neural convergent extension. XBF-2 converts ectoderm into neural tissue, which undergoes convergent extension movements. This morphogenetic movement was reduced if RACK1 and PTK7 were knocked-out indicating that RACK1 and PTK7 are both required for neural convergent extension.

\section{RACK1, PTK7 and PKC $\delta$ show a genetic interaction in neural tube closure}

It is known that RACK1 affects convergent extension during zebrafish gastrulation resulting from disturbed PCP signaling. Additionally, in the same study, a synergistic genetic interaction between RACK1 and the core-PCP protein Vangl2 was shown (Li et al. 2011), which supports the role of RACK1 as a regulator of the PCP pathway. To clarify the possible genetic interaction between members of our model, knock-down experiments between PTK7-RACK1, PTK7-PKC $\delta$ and RACK1-PKC $\delta$ were performed. For PTK7 and RACK1 I could observe an additive effect during neural tube closure because a combination of low doses of both morpholinos show almost the same percentage of neural tube closure defects as high dose of PTK7 or RACK1 MOs. Interestingly, the studies show a synergistic interaction between PTK7 and PKC $\delta$. The combination of low doses of both MOs show a dramatic increase in the percentage of neural tube defects compared to neural tube defects caused by low doses of PTK7 or RACK1. Between RACK1 and PKC $\delta$ LOF studies, only an additive effect was shown. An explanation for this could be that PKC $\delta$ has an active role during the activation of the PCP pathway associated with its kinase domain, whereas PTK7 and RACK1 have a passive role as adaptor and stabilizer proteins of the complex. It could also be shown that the RACK1 LOF was not so dramatic because RACK1 is expressed highly in the cell (Adams et al. 2011) and the endogenous levels of RACK1 are high enough for the function of the protein.

As a direct comparison of RACK1 LOF and PTK7 LOF show the same NT closure and convergent extension phenotype the question was raised as to whether RACK1 GOF could rescue the PTK7 LOF phenotype. To address this, the fusion construct ( $\triangle \mathrm{kPTK} 7 \mathrm{xR}$ ) was used since the RACK1 GOF results in severe open neural tube defects. Finally, it could be shown that this construct was able to restore the PTK7 LOF NT closure phenotype, indicating a functional relevance for the PTK7/RACK1 interaction. 


\section{PTK7 and RACK1 loss-of-function did not affect cell fate decision in general}

RACK1 and PTK7 LOF result in neural tube closure phenotypes, which may affect later developmental processes. It could be shown that the expression of neural markers was not disturbed if RACK1 and PTK7 were down-regulated by MO injections, indicating that no general cell fate decision is affected. Since cell fate was not affected, as shown by in situ hybridization, it could be that PTK7 and RACK1 are specific regulators of cell polarity, because only morphogenetic processes are disrupted by RACK1 LOF and PTK7 LOF. This indicates that RACK1 and PTK7 affect convergent extension movements in ectodermal explants and whole embryos and participate in the regulation of the PCP pathway. RACK1 functions by interaction with PTK7 supporting a common function in neural tube closure. A future challenge will be to analyze the downstream signaling events leading to neural tube closure and convergent extension phenotypes.

\subsection{PTK7 and RACK1 function in neural crest migration}

Another important morphogenetic movement during development of the central nervous system is the migration of neural crest (NC) cells. This process was shown to be regulated by the PCP pathway (De Calisto et al. 2005). PTK7 as a regulator of PCP is also required for neural crest migration (Shnitsar and Borchers 2008), and for RACK1, several hints exists that it is also involved in the process of cell migration (Adams et al. 2011). RACK1 and PTK7 interact in the regulation of morphogenetic movements including the closure of the neural tube. In this work I could show that RACK1 affects neural crest migration and get a more detailed view of now PTK7 functions in migrating NC cells.

\section{RACK1 and PTK7 play a role in neural crest cell migration}

The RACK1 protein is essential for cell migration, and binds to many components of the cell migration machinery including kinases, phosphatases and the cytoplasmic domains of cell surface receptors (McGahill et al. 2002; Sklan et al. 2006). RACK1 and PTK7 bind biochemically and interact in DSH membrane recruitments, which is important for the activation of PCP signaling, which drives morphogenetic movements. These facts raised the question as to whether I could find evidence for a function of RACK1 in the process of cell migration. RACK1 and PTK7 are both expressed in neurula stages of Xenopus embryos (Kwon et al. 2001; Lu et al. 2004) but a direct functional comparison was missing. I checked if both are expressed in neurula and tadpole stage embryos and indeed I could show that both are expressed in pre-migrating and migrating neural crest cells indicating a function in neural crest migration. As RACK1 LOF did not change neural marker expression, the neural crest migration defect is likely directly caused by RACK1 LOF. The embryos were analyzed by in situ hybridization with neural crest specific markers. After analyzing these embryos we could show that RACK1 affects the migration 
of neural crest cells. The neural marker Twist was reduced in RACK1 MO injected embryos indicating a function in neural crest migration. A future challenge will be to test the endogenous interaction of PTK7 and RACK1. Indeed, I find that both RACK1 and PTK7 co-localize in explanted migrating neural crest cells. RACK1 was mainly expressed in the cytoplasm similar to those seen in ectodermal explants. Interestingly, RACK1 expression was shifted to the cell membrane if PTK7 was present. They both co-localize at cell-cell contacts of migrating neural crest cells. It is also known that DSH is localized at the cell membrane during NC cell migration (Carmona-Fontaine et al. 2008). Therefore, this suggests that the RACK1 and PTK7 dependent DSH membrane recruitment is may also be relevant for the migration of neural crest cells.

The analysis of explanted migrating neural crest cells by microscopic techniques during migration enables a detailed view of the migratory behavior of NC cells. From PTK7 it is known that loss-of-function blocks migration of NC cells in transplantation experiment in Xenopus and PTK7 LOF inhibits migration in explanted neural crest cells. From RACK1 LOF studies it is known that it blocks NC migration in whole embryos. Using real-time, high-resolution microscopic techniques I found that PTK7 LOF leads to disturbed migration, whereas RACK1 LOF leads to a likely slower migration different from the migration of control NC cells. The precise view of RACK1 and PTK7 knock-out NC cells provides new insight into the phenotype of the NC cells. PTK7 LOF NC cells loose the cell-cell contacts with each other relatively quickly after explantation and later they stay round. It appears that PTK7 LOF leads to disruption of cell-cell connections. This is likely not to be caused by apoptosis, because TUNEL staining assays could not confirm an increase in apoptotic cell death in NC cells in whole Xenopus embryos injected with PTK7 MO. However, there are hints that PTK7 could be involved in apoptotic cell death (Prebet et al. 2010). PTK7-knockdown induces apoptosis in human cancer cells driven by inhibition of apoptosis regulation. A precise amount of the amount of $\mathrm{MO}$ used will be necessary to get a detailed look at the cell migration behavior of PTK7 LOF. Combined injections with fluorescence labeled Histon-H2B constructs in migrating neural crest cells should prove if the cells are alive. Histone-H2B stains the chromatin in the nucleus and cell division can be detected easily. Additionally, rescue experiments could be performed to clarify if the NC phenotype is caused by loss of PTK7 or RACK1 functions. The rescue of the RACK1/PTK7 LOF caused by MO injections will be done with a construct, which is not affected by the MO. Additionally it could be observed that the RACK1 LOF probably leads to slower migrating cells. To prove this, additional migration behavior studies are necessary, for example, a direct comparison of the migrating speed of control NC cells is needed. As RACK1 is essential for cell migration it could be that important processes regulated by RACK1 are disturbed. 


\section{RACK1 and PTK7 play a role in the assembly of focal adhesions}

RACK1 is a key regulator of focal adhesion assembly (Adams et al. 2011) and is located in areas of cell protrusion and can increase the phosphorylation of FAK (Onishi et al. 2007). Focal adhesions are large dynamic macromolecular assemblies with both mechanical and cell signaling components (Chrzanowska-Wodnicka and Burridge 1996; Martin 1996; Petit and Thiery 2000; Lo 2006; Romer et al. 2006) and act as a mechanical link between the cell and the extra cellular matrix (ECM) during migration. The interaction of RACK1 with FAK and the ability of RACK1 to regulate FAK activity is disrupted by suppression of RACK1 expression, which has a direct influence on cell adhesion and cell spreading, two essential steps during cell migration (Kiely et al. 2005; Onishi et al. 2007; Kiely et al. 2009). RACK1 is involved in migration processes and is needed for basal functions during migration, like the formation of focal adhesions. This could explain why down regulation of RACK1 leads to a disturbed migration behavior. This could be tested by RACK1 LOF studies detecting the formation of focal adhesions. With the help of specific markers, like FAK, changes in the formation and assembly of focal adhesions could be detected. I assume that RACK1 LOF could influence the formation of focal adhesions in migrating neural crest cells leading likely to a reduced migration speed. This could also be explained by insufficient RACK1 protein down-regulation. If the expression level of the protein remains high enough, then the amount of RACK1 protein may be sufficient for its function in the assembly of focal adhesions although in a reduced manner. Regarding PTK7, it is known that its extracellular domain (soluble PTK7; sPTK7) blocks activation of FAK and paxillin as well as formation of actin stress fibers in human umbilical vein endothelial cells (HUVEC) (Shin et al. 2008). Additionally, PTK7 is required for VEGF-induced Flt-1 phosphorylation and the following downstream events like phosphorylation of focal adhesion kinase (FAK) and Akt (Lee et al. 2011). This supports the role of PTK7 as an important molecule required for the migration of cells.

\section{PTK7 accumulates during cell migration at cell-cell contacts}

From previous work it is known that PTK7, a known regulator of neural crest migration, show homophilic binding and is likely enriched at cell-cell contacts in migrating neural crest cells (Shnitsar 2009). In this work I could show that full-length PTK7 and $\triangle \mathrm{kPTK} 7$ are enriched at cell-cell contacts during different migration steps and processes. Further $\triangle \mathrm{kPTK} 7$ shows additional nonspecific membrane accumulation indicating that the extracellular part of PTK7 is responsible for accumulation at restricted parts of the membrane in migrating neural crest cells.

To address the role of PTK7 during cell migration I performed experiments where fluorescence labeled PTK7 was overexpressed in migrating NC cells. To avoid 
overexpressing artifacts I injected low amounts of PTK7 RNA, reduced to the minimum detectable level. The NC cells were found to migrate, like control NC cells while they were monitored by confocal microscopy. At first I found that PTK7 localizes at cell-cell contacts in NC cell clusters only at restricted parts of the membrane and that PTK7 is enriched at these cell-cell contacts. In a control situation another membrane protein was uniformly expressed at the cell membrane and not enriched at cell-cell contacts. This phenotype of the enrichment of PTK7 at restricted parts of the cell membrane is a novel observation. Why PTK7 is enriched/accumulates and why this occurs only at restricted parts of the membrane at cell-cell contacts is unknown.

An explanation for the enrichment could be that PTK7 as a homophilic binding molecule is clustered at cell-cell contacts. To prove the homophilic binding of PTK7, bimolecular fluorescence complementation (BiFC) constructs could be used to validate protein interactions. Two proteins are fused to unfolded complementary fragments of a fluorescent reporter protein and expressed in living cells. If both differentially labeled proteins interact, this will bring the fluorescent fragments within proximity, allowing the reporter protein to reform in its native three-dimensional structure and emit its fluorescent signal. Furthermore the emitted intensity of the fluorescence is proportional to the strength of the interaction (Kerppola 2006). This technique can also be used to check the association of fluorescent protein fragments that are attached to components of the same macromolecular complex for example to confirm the RACK1-PTK7 interaction.

The unequal distribution of PTK7 only at restricted parts of the membrane during cell-cell contacts cannot be explained at this time and needs further studies. It will be interesting to know how stable and restricted the PTK7 accumulation is at the cell-cell contacts and what happens if this accumulation would be disrupted. One possible technique that can be used is fluorescence recovery after photobleaching (FRAP). It is an optical technique capable of quantifying the two dimensional lateral diffusion of a molecularly thin film containing fluorescently labeled probes and is used to study cell membrane diffusion and protein binding in biological systems (Axelrod et al. 1976; Sprague et al. 2004). The fluorescent part of the molecule is destroyed by high energy laser impulses in a specific part of the membrane. In this bleached area the repopulation of the fluorescent molecules from other parts of the membrane into the bleached area can reveal information about protein interaction partners, organelle continuity and protein trafficking. The measurement of the diffusion speed with different mutant versions of PTK7 could help to clarify this asymmetric distribution of PTK7 at cell-cell contacts.

Additionally two NC explants expressing different fluorescently labeled PTK7 constructs could be placed directly to each other. After the cells have contact it is easy to check if there is an overlay in the two different signals and if this signal is increased at the cell-cell 
contact side indicating an interaction based accumulation of PTK7. This is also possible using different mutant versions of PTK7 to check if this disrupts the accumulation, indicating which structural part of PTK7 is needed for the possible homophilic binding.

Experiments with $\triangle \mathrm{kPTK} 7$ show a similar accumulation during cell-cell contact of migrating NC cells indicating that the extracellular domain of PTK7 is required for the possible homophilic binding of PTK7 at cell-cell contacts. Additionally the protein accumulates at various locations in the cells. It localizes in vesicles and at cell membrane parts, which have no contact with another cell. In summary, this leads to the assumption that the intracellular domain of PTK7 is necessary for a precise membrane accumulation and that this precise accumulation is needed for the proper migration behavior of the NC cells since overexpression of $\triangle \mathrm{kPTK} 7$ inhibit NC migration. However, in my experiments the $\triangle \mathrm{kPTK} 7$ expressing cells migrate. This could be explained with the fact that the endogenous PTK7 level is possibly high enough for migration because I inject only low amounts of $\triangle \mathrm{KPTK} 7$ reduced to an endogenous level, which did not block migration.

Furthermore, an asymmetric distribution of PTK7 accumulation was seen in migrating neural crest cells at the migrating front of a cell cluster. Why PTK7 is enriched only at lateral sides of migrating cells at the leading edge is unknown. It is known that an asymmetrical distribution of the core-PCP proteins $\mathrm{Fz}$ and DSH in migrating NC cell is present during migration (Carmona-Fontaine et al. 2008) and this activates downstream effectors like RhoA and Rac1, needed for proper migration processes of the NC cells. It could be speculated that a distinct localization of PTK7 in cells at the leading edge is needed for migration. One approach to test how PTK7 affects PCP downstream effectors is the FRET analysis of the RhoA activity to check if the asymmetrical distribution of PTK7 influences the localized activation of RhoA. During cell contact of two migrating NC cells, RhoA activity is localized at the cell-cell contact sides, which is a prerequisite for cell migration and mediation of further intracellular processes (Carmona-Fontaine et al. 2008). Further studies are necessary to clarify the role of PTK7 during NC cell migration concerning its expression and accumulation at the lateral sides of migrating NC cells at the migrating front of a cell cluster.

After some time the cells migrate out of the cell cluster and migrate as single cells. If two single cells have contact with each other I also observe a PTK7 accumulation at the cellcell contact sides in the membrane. This enrichment is only stable and occurs while the cells have contact. No enrichment was seen in the control situation where NC cells express membrane-GFP. The process of this enrichment and how this is regulated by intracellular processes is not known. As mentioned before, one explanation could be a possible homophilic binding of PTK7. 
In summary, it could be shown that PTK7 is enriched at cell-cell contact sides during migration of NC cells and that this enrichment is possibly established by its extracellular domain. This suggests homophilic binding of PTK7 could only stabilize the binding of the cells upon cell-cell contact or activate intracellular processes or both. It could be shown that membrane proteins stabilize cell-cell contacts with its extracellular domains and there are hints that this is also possible for PTK7.

But how PTK7 signals after the cell-cell contact? From previous studies it is known that PTK7 binds to Plexin, which is also expressed in NC cells and is required for neural crest migration (Wagner et al. 2010) but it is still unknown how PTK7 affects downstream Plexin signaling. During NC migration PTK7 is enriched at cell-cell contacts and it is possible that PTK7 signals upon its binding to Plexin. Plexins are transmembrane proteins and similar to PTK7 kinase lack activity and act as a receptor for extracellular semaphorin ligands. Additionally it is known that they can become tyrosine phosphorylated (Maestrini et al. 1996; Tamagnone et al. 1999). It is possible that after PTK7 binds to the Plexin/Semaphorin complex both could together signal by recruiting a catalytically active kinase. The possible kinase might phosphorylate Plexin to transduce a signal. This is possible since for RYK/Derailed, another member of the receptor tyrosine family, which lacks kinase activity and functions in axon guidance, a similar signaling mechanism has been reported (Callahan et al. 1995; Bonkowsky et al. 1999). To clarify the signaling mechanism of the PTK7/Plexin/Semaphorin receptor complex additional studies are necessary. What is known about the Plexins/Semaphorin signaling is that Plexin, after binding to different Semaphorin ligands, transduces signals leading to cytoskeleton reorganization, which affects cell shape, motility and cell-cell interactions (Comeau et al. 1998; Winberg et al. 1998; Takahashi et al. 1999; Tamagnone et al. 1999). The after Semaphorin binding activated cell-cell signaling is important for the homeostasis and morphogenesis of many tissues and is widely studied for its role in neural connectivity, cancer, cell migration and immune responses (Kruger et al. 2005). In summary it seems to be possible that PTK7 signals via Plexin during NC migration.

\section{PTK7 but not RACK1 is required for contact inhibition of locomotion}

Another process, which is important for directed cell-migration is contact inhibition of locomotion (CIL). The process describes how NC cells change their direction of migration after they come into contact with each other (Carmona-Fontaine et al. 2008). In this work I found that during CIL, when the cells make contact, PTK7 is enriched at theses cell-cell contact sides. Furthermore, I could show that PTK7 is required for the process of CIL and that possibly RACK 1 is not.

To address the role of PTK7 in the process of CIL, I overexpressed a fluorescently labeled PTK7 construct in migrating NC cells. During migration single cells were chosen, which 
show the CIL migration behavior and during this process the PTK7 expression at cell-cell contact sides was monitored. Indeed, I found that PTK7 accumulates at these cell-cell contacts indicating that PTK7 plays a role during CIL.

But how important is this accumulation of PTK7 and how does it signal? To further address the role of PTK7 in CIL, confrontation-assays with neural crest cells were performed. This was done with PTK7 and with its interaction partner RACK1. The NC explants where PTK7 was knocked-down show no CIL because in the case of contact with a control explant, the control cells did not change their direction of migration. RACK1 knock-down of neural crest cells show CIL, in example they changed their direction of migration after contact with the control NC cells. In a control experiment the cells changed their direction of migration after they made contact. It seems that PTK7 is required for the process of CIL and RACK1 is not, since only PTK7 LOF and not RACK1 LOF disturbs CIL. One explanation for the missing CIL in PTK7 knock-down experiments and functional CIL in RACK1 knock-down experiments is that the intracellular signaling of PTK7 is redundant, suggesting that the extracellular domain of PTK7 is necessary for CIL and the intracellular is not. This is supported by the fact that over-expression in NC cells of a PTK7 mutant, which lacks the intracellular domain ( $\triangle \mathrm{kPTK} 7)$, blocks NC migration (Shnitsar and Borchers 2008) and shows a disturbed cell-cell contact accumulation. In contrast, PTK7 and RACK1 are able to recruit DSH to the plasma membrane and this recruitment of DSH is required for the process of CIL (Carmona-Fontaine et al. 2008). However, it appears that the process of CIL is independent of RACK1 and PTK7 signals via another route.

\section{PTK/Plexin signaling has a possible relevance in contact inhibition of locomotion}

From PTK7 it is known that it is involved in PCP signaling and acts as a co-receptor for Plexin-A1 in Xenopus NC cells (Shnitsar and Borchers 2008; Wagner et al. 2010), suggesting that it might be involved in CIL and Semaphorin signaling. From PlexinD1, the sole member of the vertebrate-specific PlexinD (PlxnD1) it is known that in the absence of ligand-mediated activation PIxnD1 stimulates the assembly of actin filaments to support cell migration and promotes integrin-mediated adhesion to the extracellular matrix (ECM) and mediates additional downstream signaling events. Binding of PlxnD1 to its Sema3 ligand leads to the collapse of the actin-based cytoskeleton leading to retraction and/or turning responses (Gay et al. 2011). If PTK7 is involved in this Sema3/PIxnD1-mediated repulsion this could explain why PTK7 is enriched at the cell-cell contacts. During the process of CIL, the cells retract their protrusions directly after they have made contact with another cell. This is also seen after PTK7 accumulates at the cell-cell contacts. The possibility that PTK7 does not signal by RACK1 during CIL is supported by the fact that the RACK1 LOF in NC cells did not completely block the migration. 


\section{PTK7 gets likely endocytosed during contact inhibition of locomotion}

After analyzing the migration of the neural crest cells during CIL there are indications that PTK7 signals in another way. What I observe is that PTK7 gets internalized after cell-cell contact followed by the process of CIL. After cell-cell contact, the cells retract their protrusions and at this moment it could be observed that PTK7 accumulates in vesicles which moved from the cell membrane into the cytoplasm. This has to be further analyzed and proven by additional experiments, which are focused on this aspect of PTK7 function in neural crest cells during migration. Interestingly, endocytosis of ligand-receptor complex is required for the activation of PCP signaling in various systems (Chen et al. 2003; Kim and Han 2007; Yu et al. 2007; Kikuchi et al. 2009; Yu et al. 2010). From further experiments it is known that PTK7 can be endocytosed through a caveolin-dependent route in Xenopus animal caps and human cell culture and the number of PTK7-positive vesicles is increased in the presence of canonical Wnts (Peradziryi 2011). Additionally, PTK7 gets internalized after it binds to the external aptamer sgc8 in T-cell lymphoblastic leukemia cells (Xiao et al. 2008). The possibility that PTK7 signals through internalization and if this dependent on ligand binding has to be proven by high resolution time lapse imaging with confocal microscopy focused on the cell-cell contact sides during CIL.

\section{Future experiments}

The explantation of the NC cells on fibronectin is an artificial system, which could only simulate the natural environment of the cells. In embryos the cells are surrounded by other cells, which express different proteins, which rise in different membrane surface proteins or external signals (Theveneau et al. 2010). It was shown that the chemokine attractant Sdf1 amplify and stabilizes contact-dependent cell polarity, resulting in directional collective migration. These reveal a mechanism of chemoattraction likely to function during embryogenesis and cancer metastasis. The transplantation of NC cells in a living Xenopus embryo is a better choice for further studies. Long time recording of transplanted NC cells in the embryo by confocal microscopy show up new insight into the various and complex processes during migration (Kashef et al. 2009) and could be important to understand the mechanistic role of the process of cell migration, especially during cancer development (Theveneau and Mayor 2012). 


\section{Conclusion}

Loss-of-function analysis shows that RACK1 - like PTK7 - is required for neural tube closure and neural crest migration. Concerning neural tube closure time-lapse imaging and explant assays demonstrate that both molecules affect neural convergent extension, a process required for neural tube closure. PTK7 and RACK1 likely interact in the regulation of neural tube closure, as genetic interaction could be demonstrated. In addition to neural tube closure, the data presented here suggest that these molecules may also interact in the regulation of neural crest migration.

On a mechanistic level our data indicate that PTK7 recruits RACK1 by its intracellular domain and that this interaction is required for PTK7-mediated DSH localization. Additionally, RACK1 and PTK7 require $\mathrm{PKC} \delta$ to recruits $\mathrm{DSH}$. In vivo evidence for a PTK7/RACK1 interaction could be confirmed in explanted neural crest cells where RACK1 and PTK7 co-localize at cell-cell contacts implicating functional relevance. In addition neural crest explant assays provide a better understanding of the cellular function of PTK7 in neural crest cells. In collectively migrating neural crest cells PTK7 is enriched at distinct cell-cell contact sides. Interestingly, single migrating neural crest cells show a similar accumulation of PTK7 at the plasma membrane if they make contact with each other. Following this cell-cell contact they change their direction of migration and move away from each other, a process called contact inhibition of locomotion (CIL). The data presented here suggest that PTK7 may play a role in CIL, as loss-of-function of PTK7 abolished this process. Interestingly, RACK1 loss-of-function did not inhibit CIL suggesting that intracellular PTK7 signaling is not required for CIL. Thus, these data provide evidence for the in vivo relevance of the PTK7/RACK1 interaction, but also suggest that there are RACK1-independet functions of PTK7. 


\section{Bibliography}

Abercrombie, M. and E. J. Ambrose (1962) The surface properties of cancer cells: a review. Cancer research. 22, 525-48.

Abercrombie, M. and G. A. Dunn (1975) Adhesions of fibroblasts to substratum during contact inhibition observed by interference reflection microscopy. Experimental cell research. 92, 57-62.

Abercrombie, M. and J. E. Heaysman (1953) Observations on the social behaviour of cells in tissue culture. I. Speed of movement of chick heart fibroblasts in relation to their mutual contacts. Experimental cell research. 5, 111-31.

Abercrombie, M. and J. E. Heaysman (1954) Observations on the social behaviour of cells in tissue culture. II. Monolayering of fibroblasts. Experimental cell research. 6, 293-306.

Adams, D. R., D. Ron and P. A. Kiely (2011) RACK1, A multifaceted scaffolding protein: Structure and function. Cell communication and signaling : CCS. 9, 22.

Adler, P. N. (1992) The genetic control of tissue polarity in Drosophila. Bioessays. 14, 735-41.

Altschul, S. F., W. Gish, W. Miller, E. W. Myers and D. J. Lipman (1990) Basic local alignment search tool. J Mol Biol. 215, 403-10.

Ananthakrishnan, R. and A. Ehrlicher (2007) The forces behind cell movement. International journal of biological sciences. 3, 303-17.

Axelrod, D., D. E. Koppel, J. Schlessinger, E. Elson and W. W. Webb (1976) Mobility measurement by analysis of fluorescence photobleaching recovery kinetics. Biophysical journal. 16, 1055-69.

Axelrod, J. D., J. R. Miller, J. M. Shulman, R. T. Moon and N. Perrimon (1998) Differential recruitment of Dishevelled provides signaling specificity in the planar cell polarity and Wingless signaling pathways. Genes Dev. 12, 2610-22.

Bang, A. G., N. Papalopulu, M. D. Goulding and C. Kintner (1999) Expression of Pax3 in the lateral neural plate is dependent on a Wnt-mediated signal from posterior nonaxial mesoderm. Dev Biol. 212, 366-80.

Barembaum, M. and M. Bronner-Fraser (2005) Early steps in neural crest specification. Semin Cell Dev Biol. 16, 642-6.

Barrow, J. R. (2006) Wnt/PCP signaling: a veritable polar star in establishing patterns of polarity in embryonic tissues. Semin Cell Dev Biol. 17, 185-93.

Bassuk, A. G. and Z. Kibar (2009) Genetic basis of neural tube defects. Seminars in pediatric neurology. 16, 101-10.

Bastock, R., H. Strutt and D. Strutt (2003) Strabismus is asymmetrically localised and binds to Prickle and Dishevelled during Drosophila planar polarity patterning. Development. 130, 3007-14.

Bayly, R. and J. D. Axelrod (2011) Pointing in the right direction: new developments in the field of planar cell polarity. Nat Rev Genet. 12, 385-91.

Bekman, E. and D. Henrique (2002) Embryonic expression of three mouse genes with homology to the Drosophila melanogaster prickle gene. Mech Dev. 119 Suppl 1, S77-81.

Ben-Shem, A., L. Jenner, G. Yusupova and M. Yusupov (2010) Crystal structure of the eukaryotic ribosome. Science. 330, 1203-9.

Bolande, R. P. (1997) Neurocristopathy: its growth and development in 20 years. Pediatric pathology \& laboratory medicine : journal of the Society for Pediatric 
Pathology, affiliated with the International Paediatric Pathology Association. 17, 1 25.

Bonkowsky, J. L., S. Yoshikawa, D. D. O'Keefe, A. L. Scully and J. B. Thomas (1999) Axon routing across the midline controlled by the Drosophila Derailed receptor. Nature. 402, 540-4.

Bonstein, L., S. Elias and D. Frank (1998) Paraxial-fated mesoderm is required for neural crest induction in Xenopus embryos. Dev Biol. 193, 156-68.

Borchers, A., R. David and D. Wedlich (2001) Xenopus cadherin-11 restrains cranial neural crest migration and influences neural crest specification. Development. 128, 3049-60.

Borchers, A., Y. Fonar, D. Frank and J. C. Baker (2006) XNF-ATc3 affects neural convergent extension. Development. 133, 1745-55.

Botto, L. D., C. A. Moore, M. J. Khoury and J. D. Erickson (1999) Neural-tube defects. The New England journal of medicine. 341, 1509-19.

Boutros, M., N. Paricio, D. I. Strutt and M. Mlodzik (1998) Dishevelled activates JNK and discriminates between JNK pathways in planar polarity and wingless signaling. Cell. 94, 109-18.

Bradley, L. C., A. Snape, S. Bhatt and D. G. Wilkinson (1993) The structure and expression of the Xenopus Krox-20 gene: conserved and divergent patterns of expression in rhombomeres and neural crest. Mech Dev. 40, 73-84.

Brandon, N. J., J. N. Jovanovic, T. G. Smart and S. J. Moss (2002) Receptor for activated $\mathrm{C}$ kinase-1 facilitates protein kinase $\mathrm{C}$-dependent phosphorylation and functional modulation of $\operatorname{GABA}(\mathrm{A})$ receptors with the activation of G-proteincoupled receptors. The Journal of neuroscience : the official journal of the Society for Neuroscience. 22, 6353-61.

Callahan, C. A., M. G. Muralidhar, S. E. Lundgren, A. L. Scully and J. B. Thomas (1995) Control of neuronal pathway selection by a Drosophila receptor proteintyrosine kinase family member. Nature. 376, 171-4.

Cano, A., M. A. Perez-Moreno, I. Rodrigo, A. Locascio, M. J. Blanco, M. G. del Barrio, F. Portillo and M. A. Nieto (2000) The transcription factor snail controls epithelialmesenchymal transitions by repressing E-cadherin expression. Nat Cell Biol. 2, 76-83.

Carmona-Fontaine, C., H. Matthews and R. Mayor (2008a) Directional cell migration in vivo: Wnt at the crest. Cell adhesion \& migration. 2, 240-2.

Carmona-Fontaine, C., H. K. Matthews, S. Kuriyama, M. Moreno, G. A. Dunn, M. Parsons, C. D. Stern and R. Mayor (2008b) Contact inhibition of locomotion in vivo controls neural crest directional migration. Nature. 456, 957-61.

Carmona-Fontaine, C., E. Theveneau, A. Tzekou, M. Tada, M. Woods, K. M. Page, M. Parsons, J. D. Lambris and R. Mayor (2011) Complement fragment C3a controls mutual cell attraction during collective cell migration. Dev Cell. 21, 102637.

Chen, W., D. ten Berge, J. Brown, S. Ahn, L. A. Hu, W. E. Miller, M. G. Caron, L. S. Barak, R. Nusse and R. J. Lefkowitz (2003) Dishevelled 2 recruits beta-arrestin 2 to mediate Wnt5A-stimulated endocytosis of Frizzled 4. Science. 301, 1391-4.

Cheung, M., M. C. Chaboissier, A. Mynett, E. Hirst, A. Schedl and J. Briscoe (2005) The transcriptional control of trunk neural crest induction, survival, and delamination. Dev Cell. 8, 179-92.

Chou, Y. H. and M. J. Hayman (1991) Characterization of a member of the immunoglobulin gene superfamily that possibly represents an additional class of growth factor receptor. Proc Natl Acad Sci U S A. 88, 4897-901. 
Chrzanowska-Wodnicka, M. and K. Burridge (1996) Rho-stimulated contractility drives the formation of stress fibers and focal adhesions. J Cell Biol. 133, 140315.

Colas, J. F. and G. C. Schoenwolf (2001) Towards a cellular and molecular understanding of neurulation. Dev Dyn. 221, 117-45.

Comeau, M. R., R. Johnson, R. F. DuBose, M. Petersen, P. Gearing, T. VandenBos, L. Park, T. Farrah, R. M. Buller, J. I. Cohen, L. D. Strockbine, C. Rauch and M. K. Spriggs (1998) A poxvirus-encoded semaphorin induces cytokine production from monocytes and binds to a novel cellular semaphorin receptor, VESPR. Immunity. 8, 473-82.

Cooper, M. S. and R. E. Keller (1984) Perpendicular orientation and directional migration of amphibian neural crest cells in dc electrical fields. Proc Natl Acad Sci US A. 81, 160-4.

Copp, A. J., N. D. Greene and J. N. Murdoch (2003a) Dishevelled: linking convergent extension with neural tube closure. Trends in neurosciences. 26, 453-5.

Copp, A. J., N. D. Greene and J. N. Murdoch (2003b) The genetic basis of mammalian neurulation. Nat Rev Genet. 4, 784-93.

Coyle, S. M., W. V. Gilbert and J. A. Doudna (2009) Direct link between RACK1 function and localization at the ribosome in vivo. Mol Cell Biol. 29, 1626-34.

Curtin, J. A., E. Quint, V. Tsipouri, R. M. Arkell, B. Cattanach, A. J. Copp, D. J. Henderson, N. Spurr, P. Stanier, E. M. Fisher, P. M. Nolan, K. P. Steel, S. D. Brown, I. C. Gray and J. N. Murdoch (2003) Mutation of Celsr1 disrupts planar polarity of inner ear hair cells and causes severe neural tube defects in the mouse. Curr Biol. 13, 1129-33.

Dabdoub, A., M. J. Donohue, A. Brennan, V. Wolf, M. Montcouquiol, D. A. Sassoon, J. C. Hseih, J. S. Rubin, P. C. Salinas and M. W. Kelley (2003) Wnt signaling mediates reorientation of outer hair cell stereociliary bundles in the mammalian cochlea. Development. 130, 2375-84.

Dabdoub, A. and M. W. Kelley (2005) Planar cell polarity and a potential role for a Wnt morphogen gradient in stereociliary bundle orientation in the mammalian inner ear. Journal of neurobiology. 64, 446-57.

Damianitsch, K., J. Melchert and T. Pieler (2009) XsFRP5 modulates endodermal organogenesis in Xenopus laevis. Dev Biol. 329, 327-37.

Darken, R. S., A. M. Scola, A. S. Rakeman, G. Das, M. Mlodzik and P. A. Wilson (2002) The planar polarity gene strabismus regulates convergent extension movements in Xenopus. Embo J. 21, 976-85.

Davy, A., J. Aubin and P. Soriano (2004) Ephrin-B1 forward and reverse signaling are required during mouse development. Genes Dev. 18, 572-83.

De Calisto, J., C. Araya, L. Marchant, C. F. Riaz and R. Mayor (2005) Essential role of non-canonical Wnt signalling in neural crest migration. Development. 132, 2587-97.

De Marco, P., E. Merello, S. Mascelli and V. Capra (2006) Current perspectives on the genetic causes of neural tube defects. Neurogenetics. 7, 201-21.

Delaune, E., P. Lemaire and L. Kodjabachian (2005) Neural induction in Xenopus requires early FGF signalling in addition to BMP inhibition. Development. 132, 299-310.

DeLuca, S. M., J. Gerhart, E. Cochran, E. Simak, J. Blitz, M. Mattiacci-Paessler, K. Knudsen and M. George-Weinstein (1999) Hepatocyte growth factor/scatter factor promotes a switch from $\mathrm{E}$ - to N-cadherin in chick embryo epiblast cells. Experimental cell research. 251, 3-15. 
Dias, M. S. and M. Partington (2004) Embryology of myelomeningocele and anencephaly. Neurosurgical focus. 16, E1.

Dower, W. J., J. F. Miller and C. W. Ragsdale (1988) High efficiency transformation of E. coli by high voltage electroporation. Nucleic acids research. 16, 6127-45.

Easty, D. J., P. J. Mitchell, K. Patel, V. A. Florenes, R. A. Spritz and D. C. Bennett (1997) Loss of expression of receptor tyrosine kinase family genes PTK7 and SEK in metastatic melanoma. Int $J$ Cancer. 71, 1061-5.

Eickholt, B. J. (2008) Functional diversity and mechanisms of action of the semaphorins. Development. 135, 2689-94.

Eickholt, B. J., S. L. Mackenzie, A. Graham, F. S. Walsh and P. Doherty (1999) Evidence for collapsin-1 functioning in the control of neural crest migration in both trunk and hindbrain regions. Development. 126, 2181-9.

Endoh, H., S. Tomida, Y. Yatabe, H. Konishi, H. Osada, K. Tajima, H. Kuwano, T. Takahashi and T. Mitsudomi (2004) Prognostic model of pulmonary adenocarcinoma by expression profiling of eight genes as determined by quantitative real-time reverse transcriptase polymerase chain reaction. $J$ Clin Oncol. 22, 811-9.

Etienne-Manneville, S. (2011) Control of polarized cell morphology and motility by adherens junctions. Semin Cell Dev Biol. 22, 850-7.

Fisher, M. P. and C. W. Dingman (1971) Role of molecular conformation in determining the electrophoretic properties of polynucleotides in agaroseacrylamide composite gels. Biochemistry. 10, 1895-9.

Gammill, L. S., C. Gonzalez and M. Bronner-Fraser (2007) Neuropilin 2/semaphorin $3 \mathrm{~F}$ signaling is essential for cranial neural crest migration and trigeminal ganglion condensation. Developmental neurobiology. 67, 47-56.

Gay, C. M., T. Zygmunt and J. Torres-Vazquez (2011) Diverse functions for the semaphorin receptor PlexinD1 in development and disease. Dev Biol. 349, 1-19.

Geijsen, N., M. Spaargaren, J. A. Raaijmakers, J. W. Lammers, L. Koenderman and P. J. Coffer (1999) Association of RACK1 and PKCbeta with the common betachain of the IL-5/IL-3/GM-CSF receptor. Oncogene. 18, 5126-30.

Gilbert, S. F. (2000) Developmental Biology. 6th edition. . Sunderland (MA): Sinauer Associates.

Glickman, N. S., C. B. Kimmel, M. A. Jones and R. J. Adams (2003) Shaping the zebrafish notochord. Development. 130, 873-87.

Glickman, N. S. and D. Yelon (2002) Cardiac development in zebrafish: coordination of form and function. Semin Cell Dev Biol. 13, 507-13.

Golubkov, V. S., A. V. Chekanov, P. Cieplak, A. E. Aleshin, A. V. Chernov, W. Zhu, I. A. Radichev, D. Zhang, P. D. Dong and A. Y. Strongin (2010) The Wnt/planar cell polarity protein-tyrosine kinase-7 (PTK7) is a highly efficient proteolytic target of membrane type-1 matrix metalloproteinase: implications in cancer and embryogenesis. J Biol Chem. 285, 35740-9.

Goto, T. and R. Keller (2002) The planar cell polarity gene strabismus regulates convergence and extension and neural fold closure in Xenopus. Dev Biol. 247, 165-81.

Gubb, D., C. Green, D. Huen, D. Coulson, G. Johnson, D. Tree, S. Collier and J. Roote (1999) The balance between isoforms of the prickle LIM domain protein is critical for planar polarity in Drosophila imaginal discs. Genes Dev. 13, 2315-27.

Habas, R., I. B. Dawid and X. He (2003) Coactivation of Rac and Rho by Wnt/Frizzled signaling is required for vertebrate gastrulation. Genes Dev. 17, 295-309. 
Habas, R., Y. Kato and X. He (2001) Wnt/Frizzled activation of Rho regulates vertebrate gastrulation and requires a novel Formin homology protein Daam1. Cell. 107, 843-54.

Haberman, Y., L. T. Alon, E. Eliyahu and R. Shalgi (2011) Receptor for activated C kinase (RACK) and protein kinase $\mathrm{C}(\mathrm{PKC})$ in egg activation. Theriogenology. 75 , 80-9.

Hadeball, B., A. Borchers and D. Wedlich (1998) Xenopus cadherin-11 (Xcadherin11) expression requires the Wg/Wnt signal. Mech Dev. 72, 101-13.

Hall, B. K. (2008) The neural crest and neural crest cells: discovery and significance for theories of embryonic organization. Journal of biosciences. 33, 781-93.

Hamblet, N. S., N. Lijam, P. Ruiz-Lozano, J. Wang, Y. Yang, Z. Luo, L. Mei, K. R. Chien, D. J. Sussman and A. Wynshaw-Boris (2002) Dishevelled 2 is essential for cardiac outflow tract development, somite segmentation and neural tube closure. Development. 129, 5827-38.

Hardcastle, Z., A. D. Chalmers and N. Papalopulu (2000) FGF-8 stimulates neuronal differentiation through FGFR-4a and interferes with mesoderm induction in Xenopus embryos. Curr Biol. 10, 1511-4.

Harland, R. (2000) Neural induction. Curr Opin Genet Dev. 10, 357-62.

Harland, R. M. (1991) In situ hybridization: an improved whole-mount method for Xenopus embryos. Methods in cell biology. 36, 685-95.

Harrington, M. J., E. Hong and R. Brewster (2009) Comparative analysis of neurulation: first impressions do not count. Molecular reproduction and development. 76, 954-65.

Harris, M. J. and D. M. Juriloff (2007) Mouse mutants with neural tube closure defects and their role in understanding human neural tube defects. Birth defects research. Part A, Clinical and molecular teratology. 79, 187-210.

Harris, M. J. and D. M. Juriloff (2010) An update to the list of mouse mutants with neural tube closure defects and advances toward a complete genetic perspective of neural tube closure. Birth defects research. Part A, Clinical and molecular teratology. 88, 653-69.

Heckman, C. A. (2009) Contact inhibition revisited. Journal of cellular physiology. 220, 574-5.

Helling, R. B., H. M. Goodman and H. W. Boyer (1974) Analysis of endonuclease REcoRI fragments of DNA from lambdoid bacteriophages and other viruses by agarose-gel electrophoresis. Journal of virology. 14, 1235-44.

Hollemann, T. and T. Pieler (1999) Xpitx-1: a homeobox gene expressed during pituitary and cement gland formation of Xenopus embryos. Mech Dev. 88, 24952.

Hopwood, N. D., A. Pluck and J. B. Gurdon (1989) A Xenopus mRNA related to Drosophila twist is expressed in response to induction in the mesoderm and the neural crest. Cell. 59, 893-903.

Horstadius, S. (1950) The mechanics of sea urchin development. L' Annee biologique. 26, 381-98.

Jackson, R. E. and B. J. Eickholt (2009) Semaphorin signalling. Curr Biol. 19, R504-7.

Jacobson, A. G. and R. Gordon (1976) Changes in the shape of the developing vertebrate nervous system analyzed experimentally, mathematically and by computer simulation. The Journal of experimental zoology. 197, 191-246. 
Jenny, A., J. Reynolds-Kenneally, G. Das, M. Burnett and M. Mlodzik (2005) Diego and Prickle regulate Frizzled planar cell polarity signalling by competing for Dishevelled binding. Nat Cell Biol. 7, 691-7.

Jessen, J. R., J. Topczewski, S. Bingham, D. S. Sepich, F. Marlow, A. Chandrasekhar and L. Solnica-Krezel (2002) Zebrafish trilobite identifies new roles for Strabismus in gastrulation and neuronal movements. Nat Cell Biol. 4, 610-5.

Jung, J. W., W. S. Shin, J. Song and S. T. Lee (2004) Cloning and characterization of the full-length mouse Ptk7 cDNA encoding a defective receptor protein tyrosine kinase. Gene. 328, 75-84.

Kalcheim, C., Y. Cinnamon and N. Kahane (1999) Myotome formation: a multistage process. Cell and tissue research. 296, 161-73.

Kashef, J., A. Kohler, S. Kuriyama, D. Alfandari, R. Mayor and D. Wedlich (2009) Cadherin-11 regulates protrusive activity in Xenopus cranial neural crest cells upstream of Trio and the small GTPases. Genes Dev. 23, 1393-8.

Keller, R. (2002) Shaping the vertebrate body plan by polarized embryonic cell movements. Science. 298, 1950-4.

Keller, R., L. Davidson, A. Edlund, T. Elul, M. Ezin, D. Shook and P. Skoglund (2000) Mechanisms of convergence and extension by cell intercalation. Philosophical transactions of the Royal Society of London. 355, 897-922.

Keller, R. and D. Shook (2008) Dynamic determinations: patterning the cell behaviours that close the amphibian blastopore. Philosophical transactions of the Royal Society of London. 363, 1317-32.

Keller, R. E. (1981) An experimental analysis of the role of bottle cells and the deep marginal zone in gastrulation of Xenopus laevis. The Journal of experimental zoology. 216, 81-101.

Kerosuo, L. and M. Bronner-Fraser (2012) What is bad in cancer is good in the embryo: Importance of EMT in neural crest development. Semin Cell Dev Biol.

Kerppola, T. K. (2006) Design and implementation of bimolecular fluorescence complementation (BiFC) assays for the visualization of protein interactions in living cells. Nature protocols. 1, 1278-86.

Kibar, Z., C. M. Bosoi, M. Kooistra, S. Salem, R. H. Finnell, P. De Marco, E. Merello, A. G. Bassuk, V. Capra and P. Gros (2009) Novel mutations in VANGL1 in neural tube defects. Human mutation. 30, E706-15.

Kibar, Z., V. Capra and P. Gros (2007) Toward understanding the genetic basis of neural tube defects. Clinical genetics. 71, 295-310.

Kibar, Z., S. Salem, C. M. Bosoi, E. Pauwels, P. De Marco, E. Merello, A. G. Bassuk, V. Capra and P. Gros (2011) Contribution of VANGL2 mutations to isolated neural tube defects. Clinical genetics. 80, 76-82.

Kibar, Z., K. J. Vogan, N. Groulx, M. J. Justice, D. A. Underhill and P. Gros (2001) Ltap, a mammalian homolog of Drosophila Strabismus/Van Gogh, is altered in the mouse neural tube mutant Loop-tail. Nature genetics. 28, 251-5.

Kiely, P. A., G. S. Baillie, R. Barrett, D. A. Buckley, D. R. Adams, M. D. Houslay and R. O'Connor (2009) Phosphorylation of RACK1 on tyrosine 52 by c-Abl is required for insulin-like growth factor I-mediated regulation of focal adhesion kinase. J Biol Chem. 284, 20263-74.

Kiely, P. A., G. S. Baillie, M. J. Lynch, M. D. Houslay and R. O'Connor (2008) Tyrosine 302 in RACK1 is essential for insulin-like growth factor-I-mediated competitive binding of PP2A and beta1 integrin and for tumor cell proliferation and migration. J Biol Chem. 283, 22952-61. 
Kiely, P. A., M. Leahy, D. O'Gorman and R. O'Connor (2005) RACK1-mediated integration of adhesion and insulin-like growth factor I (IGF-I) signaling and cell migration are defective in cells expressing an IGF-I receptor mutated at tyrosines 1250 and 1251. J Biol Chem. 280, 7624-33.

Kikuchi, A., H. Yamamoto and A. Sato (2009) Selective activation mechanisms of Wnt signaling pathways. Trends in cell biology. 19, 119-29.

Kilian, B., H. Mansukoski, F. C. Barbosa, F. Ulrich, M. Tada and C. P. Heisenberg (2003) The role of Ppt/Wnt5 in regulating cell shape and movement during zebrafish gastrulation. Mech Dev. 120, 467-76.

Kim, G. H. and J. K. Han (2007) Essential role for beta-arrestin 2 in the regulation of Xenopus convergent extension movements. Embo J. 26, 2513-26.

Kinoshita, N., H. lioka, A. Miyakoshi and N. Ueno (2003) PKC delta is essential for Dishevelled function in a noncanonical Wnt pathway that regulates Xenopus convergent extension movements. Genes Dev. 17, 1663-76.

Klein, T. J. and M. Mlodzik (2004) A conserved signaling cassette regulates hair patterning from Drosophila to man. Proc Natl Acad Sci U S A. 101, 9173-4.

Klein, T. J. and M. Mlodzik (2005) Planar cell polarization: an emerging model points in the right direction. Annu Rev Cell Dev Biol. 21, 155-76.

Klisch, T. J., J. Souopgui, K. Juergens, B. Rust, T. Pieler and K. A. Henningfeld (2006) Mxi1 is essential for neurogenesis in Xenopus and acts by bridging the pan-neural and proneural genes. Dev Biol. 292, 470-85.

Knecht, A. K. and M. Bronner-Fraser (2002) Induction of the neural crest: a multigene process. Nat Rev Genet. 3, 453-61.

Kroiher, M., M. A. Miller and R. E. Steele (2001) Deceiving appearances: signaling by "dead" and "fractured" receptor protein-tyrosine kinases. Bioessays. 23, 69-76.

Kruger, R. P., J. Aurandt and K. L. Guan (2005) Semaphorins command cells to move. Nature reviews. 6, 789-800.

Kuriyama, S. and R. Mayor (2008) Molecular analysis of neural crest migration. Philosophical transactions of the Royal Society of London. 363, 1349-62.

Kwon, H. J., S. Bae, Y. H. Son and H. M. Chung (2001) Expression of the Xenopus homologue of the receptor for activated C-kinase 1 (RACK1) in the Xenopus embryo. Development genes and evolution. 211, 195-7.

LaBonne, C. and M. Bronner-Fraser (2000) Snail-related transcriptional repressors are required in Xenopus for both the induction of the neural crest and its subsequent migration. Dev Biol. 221, 195-205.

Laemmli, U. K. (1970) Cleavage of structural proteins during the assembly of the head of bacteriophage T4. Nature. 227, 680-5.

Lee, H. K., S. K. Chauhan, E. Kay and R. Dana (2011) Flt-1 regulates vascular endothelial cell migration via a protein tyrosine kinase-7-dependent pathway. Blood. 117, 5762-71.

Lee, J. S., A. Ishimoto and S. Yanagawa (1999) Characterization of mouse dishevelled (Dvl) proteins in Wnt/Wingless signaling pathway. J Biol Chem. 274, 21464-70.

Lei, Y. P., T. Zhang, H. Li, B. L. Wu, L. Jin and H. Y. Wang (2010) VANGL2 mutations in human cranial neural-tube defects. The New England journal of medicine. 362, 2232-5.

Li, L., H. Yuan, W. Xie, J. Mao, A. M. Caruso, A. McMahon, D. J. Sussman and D. Wu (1999) Dishevelled proteins lead to two signaling pathways. Regulation of LEF-1 and C-Jun N-terminal kinase in mammalian cells. J Biol Chem. 274, 129-34. 
Li, S., R. Esterberg, V. Lachance, D. Ren, K. Radde-Gallwitz, F. Chi, J. L. Parent, A. Fritz and P. Chen (2011) Rack1 is required for Vangl2 membrane localization and planar cell polarity signaling while attenuating canonical Wnt activity. Proc Natl Acad Sci U S A. 108, 2264-9.

Linker, C., M. Bronner-Fraser and R. Mayor (2000) Relationship between gene expression domains of Xsnail, Xslug, and Xtwist and cell movement in the prospective neural crest of Xenopus. Dev Biol. 224, 215-25.

Linker, C. and C. D. Stern (2004) Neural induction requires BMP inhibition only as a late step, and involves signals other than FGF and Wnt antagonists. Development. 131, 5671-81.

Liu, J. P. and T. M. Jessell (1998) A role for rhoB in the delamination of neural crest cells from the dorsal neural tube. Development. 125, 5055-67.

Lo, S. H. (2006) Focal adhesions: what's new inside. Dev Biol. 294, 280-91.

Lopez-Bergami, P., H. Habelhah, A. Bhoumik, W. Zhang, L. H. Wang and Z. Ronai (2005) RACK1 mediates activation of JNK by protein kinase C [corrected]. Mol Cell. 19, 309-20.

Lu, X., A. G. Borchers, C. Jolicoeur, H. Rayburn, J. C. Baker and M. Tessier-Lavigne (2004) PTK7/CCK-4 is a novel regulator of planar cell polarity in vertebrates. Nature. 430, 93-8.

Maestrini, E., L. Tamagnone, P. Longati, O. Cremona, M. Gulisano, S. Bione, F. Tamanini, B. G. Neel, D. Toniolo and P. M. Comoglio (1996) A family of transmembrane proteins with homology to the MET-hepatocyte growth factor receptor. Proc Natl Acad Sci U S A. 93, 674-8.

Mancilla, A. and R. Mayor (1996) Neural crest formation in Xenopus laevis: mechanisms of Xslug induction. Dev Biol. 177, 580-9.

Mandel, M. and A. Higa (1970) Calcium-dependent bacteriophage DNA infection. $J$ Mol Biol. 53, 159-62.

Marchant, L., C. Linker, P. Ruiz, N. Guerrero and R. Mayor (1998) The inductive properties of mesoderm suggest that the neural crest cells are specified by a BMP gradient. Dev Biol. 198, 319-29.

Marcinkevicius, E., R. Fernandez-Gonzalez and J. A. Zallen (2009) Q\&A: quantitative approaches to planar polarity and tissue organization. Journal of biology. 8, 103.

Mariani, F. V. and R. M. Harland (1998) XBF-2 is a transcriptional repressor that converts ectoderm into neural tissue. Development. 125, 5019-31.

Martin, G. M. (1996) Fak and focal adhesions. Japanese journal of cancer research : Gann. 87, inside front cover.

Matthews, H. K., L. Marchant, C. Carmona-Fontaine, S. Kuriyama, J. Larrain, M. R. Holt, M. Parsons and R. Mayor (2008) Directional migration of neural crest cells in vivo is regulated by Syndecan-4/Rac1 and non-canonical Wnt signaling/RhoA. Development. 135, 1771-80.

Mayor, R. and C. Carmona-Fontaine (2010) Keeping in touch with contact inhibition of locomotion. Trends in cell biology. 20, 319-28.

Mayor, R., R. Morgan and M. G. Sargent (1995) Induction of the prospective neural crest of Xenopus. Development. 121, 767-77.

McCahill, A., J. Warwicker, G. B. Bolger, M. D. Houslay and S. J. Yarwood (2002) The RACK1 scaffold protein: a dynamic cog in cell response mechanisms. Molecular pharmacology. 62, 1261-73. 
McCusker, C., H. Cousin, R. Neuner and D. Alfandari (2009) Extracellular cleavage of cadherin-11 by ADAM metalloproteases is essential for Xenopus cranial neural crest cell migration. Molecular biology of the cell. 20, 78-89.

McNeill, H. (2010) Planar cell polarity: keeping hairs straight is not so simple. Cold Spring Harbor perspectives in biology. 2, a003376.

Medina, A., W. Reintsch and H. Steinbeisser (2000) Xenopus frizzled 7 can act in canonical and non-canonical Wnt signaling pathways: implications on early patterning and morphogenesis. Mech Dev. 92, 227-37.

Medina, A. and H. Steinbeisser (2000) Interaction of Frizzled 7 and Dishevelled in Xenopus. Dev Dyn. 218, 671-80.

Mellor, H. and P. J. Parker (1998) The extended protein kinase C superfamily. The Biochemical journal. 332 ( Pt 2), 281-92.

Meulemans, D. and M. Bronner-Fraser (2004) Gene-regulatory interactions in neural crest evolution and development. Dev Cell. 7, 291-9.

Milet, C. and A. H. Monsoro-Burq (2012) Neural crest induction at the neural plate border in vertebrates. Dev Biol.

Miller, M. A. and R. E. Steele (2000) Lemon encodes an unusual receptor proteintyrosine kinase expressed during gametogenesis in Hydra. Dev Biol. 224, 286-98.

Mizuseki, K., M. Kishi, M. Matsui, S. Nakanishi and Y. Sasai (1998) Xenopus Zicrelated-1 and Sox-2, two factors induced by chordin, have distinct activities in the initiation of neural induction. Development. 125, 579-87.

Mochly-Rosen, D., H. Khaner and J. Lopez (1991) Identification of intracellular receptor proteins for activated protein kinase C. Proc Natl Acad Sci U S A. 88, 3997-4000.

Montcouquiol, M., E. B. Crenshaw, 3rd and M. W. Kelley (2006) Noncanonical Wnt signaling and neural polarity. Annu Rev Neurosci. 29, 363-86.

Montcouquiol, M., R. A. Rachel, P. J. Lanford, N. G. Copeland, N. A. Jenkins and M. W. Kelley (2003) Identification of Vangl2 and Scrb1 as planar polarity genes in mammals. Nature. 423, 173-7.

Mossie, K., B. Jallal, F. Alves, I. Sures, G. D. Plowman and A. Ullrich (1995) Colon carcinoma kinase-4 defines a new subclass of the receptor tyrosine kinase family. Oncogene. 11, 2179-84.

MRC (1991) Prevention of neural tube defects: results of the Medical Research Council Vitamin Study. MRC Vitamin Study Research Group. Lancet. 338, 131-7.

Muller-Tidow, C., J. Schwable, B. Steffen, N. Tidow, B. Brandt, K. Becker, E. SchulzeBahr, H. Halfter, U. Vogt, R. Metzger, P. M. Schneider, T. Buchner, C. Brandts, W. E. Berdel and H. Serve (2004) High-throughput analysis of genome-wide receptor tyrosine kinase expression in human cancers identifies potential novel drug targets. Clin Cancer Res. 10, 1241-9.

Murdoch, J. N., K. Doudney, C. Paternotte, A. J. Copp and P. Stanier (2001) Severe neural tube defects in the loop-tail mouse result from mutation of Lpp1, a novel gene involved in floor plate specification. Human molecular genetics. 10, 2593601.

Myers, D. C., D. S. Sepich and L. Solnica-Krezel (2002) Bmp activity gradient regulates convergent extension during zebrafish gastrulation. Dev Biol. 243, 8198.

Nakagawa, S. and M. Takeichi (1995) Neural crest cell-cell adhesion controlled by sequential and subpopulation-specific expression of novel cadherins. Development. 121, 1321-32. 
Nakatsu, T., C. Uwabe and K. Shiota (2000) Neural tube closure in humans initiates at multiple sites: evidence from human embryos and implications for the pathogenesis of neural tube defects. Anatomy and embryology. 201, 455-66.

Nakaya, M. A., R. Habas, K. Biris, W. C. Dunty, Jr., Y. Kato, X. He and T. P. Yamaguchi (2004) Identification and comparative expression analyses of Daam genes in mouse and Xenopus. Gene expression patterns : GEP. 5, 97-105.

Neasta, J., P. A. Kiely, D. Y. He, D. R. Adams, R. O'Connor and D. Ron (2012) Direct interaction between scaffolding proteins RACK1 and 14-3-3zeta regulates brainderived neurotrophic factor (BDNF) transcription. J Biol Chem. 287, 322-36.

Neave, B., N. Holder and R. Patient (1997) A graded response to BMP-4 spatially coordinates patterning of the mesoderm and ectoderm in the zebrafish. Mech Dev. 62, 183-95.

Nelms, B. L. and P. A. Labosky (2010). Transcriptional Control of Neural Crest Development San Rafael (CA)

Nguyen, V. H., B. Schmid, J. Trout, S. A. Connors, M. Ekker and M. C. Mullins (1998) Ventral and lateral regions of the zebrafish gastrula, including the neural crest progenitors, are established by a bmp2b/swirl pathway of genes. Dev Biol. 199, 93-110.

Nieto, M. A. (2002) The snail superfamily of zinc-finger transcription factors. Nature reviews. 3, 155-66.

Nieto, M. A., L. C. Bradley, P. Hunt, R. Das Gupta, R. Krumlauf and D. G. Wilkinson (1992) Molecular mechanisms of pattern formation in the vertebrate hindbrain. Ciba Foundation symposium. 165, 92-102; discussion 102-7.

Nieto, M. A., M. G. Sargent, D. G. Wilkinson and J. Cooke (1994) Control of cell behavior during vertebrate development by Slug, a zinc finger gene. Science. 264, 835-9.

Nieuwkoop, P. D. F., J. (1991) Normal table of Xenopus laevis. (Daudin) (NorthHolland, Amsterdam, 1967).

Nishizuka, Y. (1995) Protein kinase $C$ and lipid signaling for sustained cellular responses. The FASEB journal : official publication of the Federation of American Societies for Experimental Biology. 9, 484-96.

O'Rahilly, R. and F. Muller (2002) The two sites of fusion of the neural folds and the two neuropores in the human embryo. Teratology. 65, 162-70.

Ohta, K., G. Lupo, S. Kuriyama, R. Keynes, C. E. Holt, W. A. Harris, H. Tanaka and S. Ohnuma (2004) Tsukushi functions as an organizer inducer by inhibition of BMP activity in cooperation with chordin. Dev Cell. 7, 347-58.

Olesnicky Killian, E. C., D. A. Birkholz and K. B. Artinger (2009) A role for chemokine signaling in neural crest cell migration and craniofacial development. Dev Biol. 333, 161-72.

Onishi, I., P. J. Lin, G. H. Diering, W. P. Williams and M. Numata (2007) RACK1 associates with NHE5 in focal adhesions and positively regulates the transporter activity. Cellular signalling. 19, 194-203.

Osborne, N. J., J. Begbie, J. K. Chilton, H. Schmidt and B. J. Eickholt (2005) Semaphorin/neuropilin signaling influences the positioning of migratory neural crest cells within the hindbrain region of the chick. Dev Dyn. 232, 939-49.

Park, K. S. and B. M. Gumbiner (2010) Cadherin 6B induces BMP signaling and deepithelialization during the epithelial mesenchymal transition of the neural crest. Development. 137, 2691-701.

Park, M. and R. T. Moon (2002) The planar cell-polarity gene stbm regulates cell behaviour and cell fate in vertebrate embryos. Nat Cell Biol. 4, 20-5. 
Park, T. J., R. S. Gray, A. Sato, R. Habas and J. B. Wallingford (2005) Subcellular localization and signaling properties of dishevelled in developing vertebrate embryos. Curr Biol. 15, 1039-44.

Pass, J. M., J. Gao, W. K. Jones, W. B. Wead, X. Wu, J. Zhang, C. P. Baines, R. Bolli, Y. T. Zheng, I. G. Joshua and P. Ping (2001) Enhanced PKC beta II translocation and PKC beta II-RACK1 interactions in PKC epsilon-induced heart failure: a role for RACK1. American journal of physiology. Heart and circulatory physiology. 281, H2500-10.

Patthey, C., T. Edlund and L. Gunhaga (2009) Wnt-regulated temporal control of BMP exposure directs the choice between neural plate border and epidermal fate. Development. 136, 73-83.

Paudyal, A., C. Damrau, V. L. Patterson, A. Ermakov, C. Formstone, Z. Lalanne, S. Wells, X. Lu, D. P. Norris, C. H. Dean, D. J. Henderson and J. N. Murdoch (2010) The novel mouse mutant, chuzhoi, has disruption of Ptk7 protein and exhibits defects in neural tube, heart and lung development and abnormal planar cell polarity in the ear. BMC developmental biology. 10, 87.

Peradziryi, H. (2011) Identification and functional characterization of PTK7 ligands in Xenopus laevis. Ph.D. Thesis.

Peradziryi, H., N. A. Kaplan, M. Podleschny, X. Liu, P. Wehner, A. Borchers and N. S. Tolwinski (2011) PTK7/Otk interacts with Wnts and inhibits canonical Wnt signalling. Embo J.

Petit, V. and J. P. Thiery (2000) Focal adhesions: structure and dynamics. Biology of the cell / under the auspices of the European Cell Biology Organization. 92, 47794.

Pollard, T. D. and G. G. Borisy (2003) Cellular motility driven by assembly and disassembly of actin filaments. Cell. 112, 453-65.

Prebet, T., A. C. Lhoumeau, C. Arnoulet, A. Aulas, S. Marchetto, S. Audebert, F. Puppo, C. Chabannon, D. Sainty, M. J. Santoni, M. Sebbagh, V. Summerour, Y. Huon, W. S. Shin, S. T. Lee, B. Esterni, N. Vey and J. P. Borg (2010) The cell polarity PTK7 receptor acts as a modulator of the chemotherapeutic response in acute myeloid leukemia and impairs clinical outcome. Blood. 116, 2315-23.

Puppo, F., V. Thome, A. C. Lhoumeau, M. Cibois, A. Gangar, F. Lembo, E. Belotti, S. Marchetto, P. Lecine, T. Prebet, M. Sebbagh, W. S. Shin, S. T. Lee, L. Kodjabachian and J. P. Borg (2011) Protein tyrosine kinase 7 has a conserved role in Wnt/beta-catenin canonical signalling. EMBO Rep. 12, 43-9.

Qian, D., C. Jones, A. Rzadzinska, S. Mark, X. Zhang, K. P. Steel, X. Dai and P. Chen (2007) Wnt5a functions in planar cell polarity regulation in mice. Dev Biol. 306, 121-33.

Raven, C. P. K., J. (1945) Induction by medial and lateral pieces of the archenteron roof with special reference to the determination of the neural crest. Acta Neerl. Morphol. 4, 348-362.

Rehimi, R., N. Khalida, F. Yusuf, F. Dai, G. Morosan-Puopolo and B. Brand-Saberi (2008) Stromal-derived factor-1 (SDF-1) expression during early chick development. Int J Dev Biol. 52, 87-92.

Reynolds, A., J. R. McDearmid, S. Lachance, P. De Marco, E. Merello, V. Capra, P. Gros, P. Drapeau and Z. Kibar (2010) VANGL1 rare variants associated with neural tube defects affect convergent extension in zebrafish. Mech Dev. 127, 38592.

Rida, P. C. and P. Chen (2009) Line up and listen: Planar cell polarity regulation in the mammalian inner ear. Semin Cell Dev Biol. 20, 978-85. 
Ridley, A. J. and A. Hall (1992) The small GTP-binding protein rho regulates the assembly of focal adhesions and actin stress fibers in response to growth factors. Cell. 70, 389-99.

Ridley, A. J., H. F. Paterson, C. L. Johnston, D. Diekmann and A. Hall (1992) The small GTP-binding protein rac regulates growth factor-induced membrane ruffling. Cell. 70, 401-10.

Ridley, A. J., M. A. Schwartz, K. Burridge, R. A. Firtel, M. H. Ginsberg, G. Borisy, J. T. Parsons and A. R. Horwitz (2003) Cell migration: integrating signals from front to back. Science. 302, 1704-9.

Robinson, A., S. Escuin, K. Doudney, M. Vekemans, R. E. Stevenson, N. D. Greene, A. J. Copp and P. Stanier (2012) Mutations in the planar cell polarity genes CELSR1 and SCRIB are associated with the severe neural tube defect craniorachischisis. Human mutation. 33, 440-7.

Romer, L. H., K. G. Birukov and J. G. Garcia (2006) Focal adhesions: paradigm for a signaling nexus. Circulation research. 98, 606-16.

Ron, D., C. H. Chen, J. Caldwell, L. Jamieson, E. Orr and D. Mochly-Rosen (1994) Cloning of an intracellular receptor for protein kinase $\mathrm{C}$ : a homolog of the beta subunit of G proteins. Proc Natl Acad Sci U S A. 91, 839-43.

Ron, D., Z. Jiang, L. Yao, A. Vagts, I. Diamond and A. Gordon (1999) Coordinated movement of RACK1 with activated betallPKC. J Biol Chem. 274, 27039-46.

Roszko, I., A. Sawada and L. Solnica-Krezel (2009) Regulation of convergence and extension movements during vertebrate gastrulation by the Wnt/PCP pathway. Semin Cell Dev Biol. 20, 986-97.

Rothbacher, U., M. N. Laurent, M. A. Deardorff, P. S. Klein, K. W. Cho and S. E. Fraser (2000) Dishevelled phosphorylation, subcellular localization and multimerization regulate its role in early embryogenesis. Embo J. 19, 1010-22.

Rupp, P. A. and P. M. Kulesa (2007) A role for RhoA in the two-phase migratory pattern of post-otic neural crest cells. Dev Biol. 311, 159-71.

Rupp, R. A., L. Snider and H. Weintraub (1994) Xenopus embryos regulate the nuclear localization of XMyoD. Genes Dev. 8, 1311-23.

Russel, S. a. (2001) Molecular Cloning: a laboratory manual 3rd ed., Cold Spring Harbour Laboratory Press,

Cold Spring Harbour, New York

Sadaghiani, B. and C. H. Thiebaud (1987) Neural crest development in the Xenopus laevis embryo, studied by interspecific transplantation and scanning electron microscopy. Dev Biol. 124, 91-110.

Sanger, F., S. Nicklen and A. R. Coulson (1977) DNA sequencing with chainterminating inhibitors. Proc Natl Acad Sci U S A. 74, 5463-7.

Sasai, Y. and E. M. De Robertis (1997) Ectodermal patterning in vertebrate embryos. Dev Biol. 182, 5-20.

Sasai, Y., B. Lu, H. Steinbeisser and E. M. De Robertis (1995) Regulation of neural induction by the Chd and Bmp-4 antagonistic patterning signals in Xenopus. Nature. 377, 757.

Sauka-Spengler, T. and M. Bronner-Fraser (2008) A gene regulatory network orchestrates neural crest formation. Nature reviews. 9, 557-68.

Sauka-Spengler, T., D. Meulemans, M. Jones and M. Bronner-Fraser (2007) Ancient evolutionary origin of the neural crest gene regulatory network. Dev Cell. 13, 40520. 
Savory, J. G., M. Mansfield, F. M. Rijli and D. Lohnes (2011) Cdx mediates neural tube closure through transcriptional regulation of the planar cell polarity gene Ptk7. Development. 138, 1361-70.

Schechtman, A. M. (1942) Gastrulation-promoting interactions between various regions of an anuran egg (Hyla regilla), University of California press, Berkeley and Los Angeles,

Scherson, T., G. Serbedzija, S. Fraser and M. Bronner-Fraser (1993) Regulative capacity of the cranial neural tube to form neural crest. Development. 118, 104962.

Schwarz, Q., K. E. Waimey, M. Golding, H. Takamatsu, A. Kumanogoh, H. Fujisawa, H. J. Cheng and C. Ruhrberg (2008) Plexin A3 and plexin A4 convey semaphorin signals during facial nerve development. Dev Biol. 324, 1-9.

Sefton, M., S. Sanchez and M. A. Nieto (1998) Conserved and divergent roles for members of the Snail family of transcription factors in the chick and mouse embryo. Development. 125, 3111-21.

Seifert, J. R. and M. Mlodzik (2007) Frizzled/PCP signalling: a conserved mechanism regulating cell polarity and directed motility. Nat Rev Genet. 8, 126-38.

Selleck, M. A. and M. Bronner-Fraser (1995) Origins of the avian neural crest: the role of neural plate-epidermal interactions. Development. 121, 525-38.

Serbedzija, G. N., M. Bronner-Fraser and S. E. Fraser (1989) A vital dye analysis of the timing and pathways of avian trunk neural crest cell migration. Development. 106, 809-16.

Serbedzija, G. N., M. Bronner-Fraser and S. E. Fraser (1992) Vital dye analysis of cranial neural crest cell migration in the mouse embryo. Development. 116, 297307.

Serbedzija, G. N., S. E. Fraser and M. Bronner-Fraser (1990) Pathways of trunk neural crest cell migration in the mouse embryo as revealed by vital dye labelling. Development. 108, 605-12.

Sharp, P. A., B. Sugden and J. Sambrook (1973) Detection of two restriction endonuclease activities in Haemophilus parainfluenzae using analytical agarose-ethidium bromide electrophoresis. Biochemistry. 12, 3055-63.

Sheldahl, L. C., M. Park, C. C. Malbon and R. T. Moon (1999) Protein kinase C is differentially stimulated by Wnt and Frizzled homologs in a G-protein-dependent manner. Curr Biol. 9, 695-8.

Shin, W. S., Y. S. Maeng, J. W. Jung, J. K. Min, Y. G. Kwon and S. T. Lee (2008) Soluble PTK7 inhibits tube formation, migration, and invasion of endothelial cells and angiogenesis. Biochemical and biophysical research communications. 371, 793-8.

Shnitsar, I. (2009) The function of PTK7 during Xenopus neural crest migration. Ph.D. Thesis.

Shnitsar, I. and A. Borchers (2008) PTK7 recruits dsh to regulate neural crest migration. Development. 135, 4015-24.

Shum, A. S. and A. J. Copp (1996) Regional differences in morphogenesis of the neuroepithelium suggest multiple mechanisms of spinal neurulation in the mouse. Anatomy and embryology. 194, 65-73.

Simons, M., W. J. Gault, D. Gotthardt, R. Rohatgi, T. J. Klein, Y. Shao, H. J. Lee, A. L. Wu, Y. Fang, L. M. Satlin, J. T. Dow, J. Chen, J. Zheng, M. Boutros and M. Mlodzik (2009) Electrochemical cues regulate assembly of the Frizzled/Dishevelled complex at the plasma membrane during planar epithelial polarization. Nat Cell Biol. 11, 286-94. 
Sivak, J. M., L. F. Petersen and E. Amaya (2005) FGF signal interpretation is directed by Sprouty and Spred proteins during mesoderm formation. Dev Cell. 8, 689-701.

Sklan, E. H., E. Podoly and H. Soreq (2006) RACK1 has the nerve to act: structure meets function in the nervous system. Progress in neurobiology. 78, 117-34.

Smith, A., V. Robinson, K. Patel and D. G. Wilkinson (1997) The EphA4 and EphB1 receptor tyrosine kinases and ephrin-B2 ligand regulate targeted migration of branchial neural crest cells. Curr Biol. 7, 561-70.

Smith, J. L. and G. C. Schoenwolf (1997) Neurulation: coming to closure. Trends in neurosciences. 20, 510-7.

Smith, W. C. and R. M. Harland (1991) Injected Xwnt-8 RNA acts early in Xenopus embryos to promote formation of a vegetal dorsalizing center. Cell. 67, 753-65.

Sokol, S. Y. (1996) Analysis of Dishevelled signalling pathways during Xenopus development. Curr Biol. 6, 1456-67.

Sprague, B. L., R. L. Pego, D. A. Stavreva and J. G. McNally (2004) Analysis of binding reactions by fluorescence recovery after photobleaching. Biophysical journal. 86, 3473-95.

Steventon, B., C. Araya, C. Linker, S. Kuriyama and R. Mayor (2009) Differential requirements of BMP and Wnt signalling during gastrulation and neurulation define two steps in neural crest induction. Development. 136, 771-9.

Steventon, B., C. Carmona-Fontaine and R. Mayor (2005) Genetic network during neural crest induction: from cell specification to cell survival. Semin Cell Dev Biol. 16, 647-54.

Strutt, D. I., U. Weber and M. Mlodzik (1997) The role of RhoA in tissue polarity and Frizzled signalling. Nature. 387, 292-5.

Takahashi, T., A. Fournier, F. Nakamura, L. H. Wang, Y. Murakami, R. G. Kalb, H. Fujisawa and S. M. Strittmatter (1999) Plexin-neuropilin-1 complexes form functional semaphorin-3A receptors. Cell. 99, 59-69.

Tamagnone, L., S. Artigiani, H. Chen, Z. He, G. I. Ming, H. Song, A. Chedotal, M. L. Winberg, C. S. Goodman, M. Poo, M. Tessier-Lavigne and P. M. Comoglio (1999) Plexins are a large family of receptors for transmembrane, secreted, and GPIanchored semaphorins in vertebrates. Cell. 99, 71-80.

Taneyhill, L. A., E. G. Coles and M. Bronner-Fraser (2007) Snail2 directly represses cadherin6B during epithelial-to-mesenchymal transitions of the neural crest. Development. 134, 1481-90.

Taylor, J., N. Abramova, J. Charlton and P. N. Adler (1998) Van Gogh: a new Drosophila tissue polarity gene. Genetics. 150, 199-210.

Teddy, J. M. and P. M. Kulesa (2004) In vivo evidence for short- and long-range cell communication in cranial neural crest cells. Development. 131, 6141-51.

Theisen, H., J. Purcell, M. Bennett, D. Kansagara, A. Syed and J. L. Marsh (1994) dishevelled is required during wingless signaling to establish both cell polarity and cell identity. Development. 120, 347-60.

Theveneau, E., L. Marchant, S. Kuriyama, M. Gull, B. Moepps, M. Parsons and R. Mayor (2010) Collective chemotaxis requires contact-dependent cell polarity. Dev Cell. 19, 39-53.

Theveneau, E. and R. Mayor (2010) Integrating chemotaxis and contact-inhibition during collective cell migration: Small GTPases at work. Small GTPases. 1, 113117.

Theveneau, E. and R. Mayor (2011) Collective cell migration of the cephalic neural crest: the art of integrating information. Genesis. 49, 164-76. 
Theveneau, E. and R. Mayor (2012) Neural crest delamination and migration: From epithelium-to-mesenchyme transition to collective cell migration. Dev Biol.

Thiery, J. P. (2002) Epithelial-mesenchymal transitions in tumour progression. Nature reviews. Cancer. 2, 442-54.

Thiery, J. P., H. Acloque, R. Y. Huang and M. A. Nieto (2009) Epithelial-mesenchymal transitions in development and disease. Cell. 139, 871-90.

Thiesen, H. J. and C. Bach (1993) DNA recognition of C2H2 zinc-finger proteins. Evidence for a zinc-finger-specific DNA recognition code. Annals of the New York Academy of Sciences. 684, 246-9.

Towbin, H. and J. Gordon (1984) Immunoblotting and dot immunobinding--current status and outlook. Journal of immunological methods. 72, 313-40.

Towbin, H., T. Staehelin and J. Gordon (1979) Electrophoretic transfer of proteins from polyacrylamide gels to nitrocellulose sheets: procedure and some applications. Proc Natl Acad Sci U S A. 76, 4350-4.

Towbin, H., T. Staehelin and J. Gordon (1992) Electrophoretic transfer of proteins from polyacrylamide gels to nitrocellulose sheets: procedure and some applications. 1979. Biotechnology. 24, 145-9.

Tree, D. R., D. Ma and J. D. Axelrod (2002a) A three-tiered mechanism for regulation of planar cell polarity. Semin Cell Dev Biol. 13, 217-24.

Tree, D. R., J. M. Shulman, R. Rousset, M. P. Scott, D. Gubb and J. D. Axelrod (2002b) Prickle mediates feedback amplification to generate asymmetric planar cell polarity signaling. Cell. 109, 371-81.

Tucker, J. A., K. A. Mintzer and M. C. Mullins (2008) The BMP signaling gradient patterns dorsoventral tissues in a temporally progressive manner along the anteroposterior axis. Dev Cell. 14, 108-19.

Ulrich, F., M. L. Concha, P. J. Heid, E. Voss, S. Witzel, H. Roehl, M. Tada, S. W. Wilson, R. J. Adams, D. R. Soll and C. P. Heisenberg (2003) Slb/Wnt11 controls hypoblast cell migration and morphogenesis at the onset of zebrafish gastrulation. Development. 130, 5375-84.

Vallin, J., J. M. Girault, J. P. Thiery and F. Broders (1998) Xenopus cadherin-11 is expressed in different populations of migrating neural crest cells. Mech Dev. 75, $171-4$.

van Amerongen, R. and A. Berns (2008) Targeted anticancer therapies: mouse models help uncover the mechanisms of tumor escape. Cancer cell. 13, 5-7.

Vinson, C. R. and P. N. Adler (1987) Directional non-cell autonomy and the transmission of polarity information by the frizzled gene of Drosophila. Nature. 329, 549-51.

Vladar, E. K., D. Antic and J. D. Axelrod (2009) Planar cell polarity signaling: the developing cell's compass. Cold Spring Harbor perspectives in biology. 1, a002964.

Wagner, G., H. Peradziryi, P. Wehner and A. Borchers (2010) PlexinA1 interacts with PTK7 and is required for neural crest migration. Biochemical and biophysical research communications. 402, 402-7.

Wallingford, J. B. (2005) Neural tube closure and neural tube defects: studies in animal models reveal known knowns and known unknowns. American journal of medical genetics. Part $C$, Seminars in medical genetics. 135C, 59-68.

Wallingford, J. B., S. E. Fraser and R. M. Harland (2002) Convergent extension: the molecular control of polarized cell movement during embryonic development. Dev Cell. 2, 695-706. 
Wallingford, J. B. and R. Habas (2005) The developmental biology of Dishevelled: an enigmatic protein governing cell fate and cell polarity. Development. 132, 442136.

Wallingford, J. B. and R. M. Harland (2001) Xenopus Dishevelled signaling regulates both neural and mesodermal convergent extension: parallel forces elongating the body axis. Development. 128, 2581-92.

Wallingford, J. B. and R. M. Harland (2002) Neural tube closure requires Dishevelleddependent convergent extension of the midline. Development. 129, 5815-25.

Wang, S., J. Z. Chen, Z. Zhang, S. Gu, C. Ji, R. Tang, K. Ying, Y. Xie and Y. Mao (2003) Cloning, expression and genomic structure of a novel human GNB2L1 gene, which encodes a receptor of activated protein kinase C (RACK). Molecular biology reports. 30, 53-60.

Wang, W., G. Mouneimne, M. Sidani, J. Wyckoff, X. Chen, A. Makris, S. Goswami, A. R. Bresnick and J. S. Condeelis (2006) The activity status of cofilin is directly related to invasion, intravasation, and metastasis of mammary tumors. $J$ Cell Biol. 173, 395-404.

Wang, W., J. B. Wyckoff, V. C. Frohlich, Y. Oleynikov, S. Huttelmaier, J. Zavadil, L. Cermak, E. P. Bottinger, R. H. Singer, J. G. White, J. E. Segall and J. S. Condeelis (2002) Single cell behavior in metastatic primary mammary tumors correlated with gene expression patterns revealed by molecular profiling. Cancer research. 62, 6278-88.

Wang, Y. and J. Nathans (2007) Tissue/planar cell polarity in vertebrates: new insights and new questions. Development. 134, 647-58.

Weinstein, D. C. and A. Hemmati-Brivanlou (1997) Neural induction in Xenopus laevis: evidence for the default model. Current opinion in neurobiology. 7, 7-12.

Wheeler, A. P. and A. J. Ridley (2004) Why three Rho proteins? RhoA, RhoB, RhoC, and cell motility. Experimental cell research. 301, 43-9.

Wilson, P. A. and A. Hemmati-Brivanlou (1995) Induction of epidermis and inhibition of neural fate by Bmp-4. Nature. 376, 331-3.

Wilson, P. A., G. Lagna, A. Suzuki and A. Hemmati-Brivanlou (1997) Concentrationdependent patterning of the Xenopus ectoderm by BMP4 and its signal transducer Smad1. Development. 124, 3177-84.

Winberg, M. L., J. N. Noordermeer, L. Tamagnone, P. M. Comoglio, M. K. Spriggs, M. Tessier-Lavigne and C. S. Goodman (1998) Plexin A is a neuronal semaphorin receptor that controls axon guidance. Cell. 95, 903-16.

Winklbauer, R., A. Medina, R. K. Swain and H. Steinbeisser (2001) Frizzled-7 signalling controls tissue separation during Xenopus gastrulation. Nature. 413, 856-60.

Wolff, T. and G. M. Rubin (1998) Strabismus, a novel gene that regulates tissue polarity and cell fate decisions in Drosophila. Development. 125, 1149-59.

Wong, H. C., A. Bourdelas, A. Krauss, H. J. Lee, Y. Shao, D. Wu, M. Mlodzik, D. L. Shi and J. Zheng (2003) Direct binding of the PDZ domain of Dishevelled to a conserved internal sequence in the C-terminal region of Frizzled. Mol Cell. 12, 1251-60.

Wong, L. L. and P. N. Adler (1993) Tissue polarity genes of Drosophila regulate the subcellular location for prehair initiation in pupal wing cells. J Cell Biol. 123, 20921.

$\mathrm{Wu}, \mathrm{J}$. and M. Mlodzik (2009) A quest for the mechanism regulating global planar cell polarity of tissues. Trends in cell biology. 19, 295-305. 
Wu, J., J. P. Saint-Jeannet and P. S. Klein (2003) Wnt-frizzled signaling in neural crest formation. Trends in neurosciences. 26, 40-5.

Xiao, Z., D. Shangguan, Z. Cao, X. Fang and W. Tan (2008) Cell-specific internalization study of an aptamer from whole cell selection. Chemistry. 14, 1769-75.

Yamanaka, H., T. Moriguchi, N. Masuyama, M. Kusakabe, H. Hanafusa, R. Takada, S. Takada and E. Nishida (2002) JNK functions in the non-canonical Wnt pathway to regulate convergent extension movements in vertebrates. EMBO Rep. 3, 6975.

Yanagawa, S., F. van Leeuwen, A. Wodarz, J. Klingensmith and R. Nusse (1995) The dishevelled protein is modified by wingless signaling in Drosophila. Genes Dev. 9, 1087-97.

Yang-Snyder, J., J. R. Miller, J. D. Brown, C. J. Lai and R. T. Moon (1996) A frizzled homolog functions in a vertebrate Wnt signaling pathway. Curr Biol. 6, 1302-6.

Ybot-Gonzalez, P., D. Savery, D. Gerrelli, M. Signore, C. E. Mitchell, C. H. Faux, N. D. Greene and A. J. Copp (2007) Convergent extension, planar-cell-polarity signalling and initiation of mouse neural tube closure. Development. 134, 789-99.

Yen, W. W., M. Williams, A. Periasamy, M. Conaway, C. Burdsal, R. Keller, X. Lu and A. Sutherland (2009) PTK7 is essential for polarized cell motility and convergent extension during mouse gastrulation. Development. 136, 2039-48.

Yu, A., J. F. Rual, K. Tamai, Y. Harada, M. Vidal, X. He and T. Kirchhausen (2007) Association of Dishevelled with the clathrin AP-2 adaptor is required for Frizzled endocytosis and planar cell polarity signaling. Dev Cell. 12, 129-41.

Yu, A., Y. Xing, S. C. Harrison and T. Kirchhausen (2010) Structural analysis of the interaction between Dishevelled2 and clathrin AP-2 adaptor, a critical step in noncanonical Wnt signaling. Structure. 18, 1311-20.

Yusuf, F., R. Rehimi, F. Dai and B. Brand-Saberi (2005) Expression of chemokine receptor CXCR4 during chick embryo development. Anatomy and embryology. 210, 35-41.

Zallen, J. A. (2007) Planar polarity and tissue morphogenesis. Cell. 129, 1051-63.

Zheng, L., J. Zhang and R. W. Carthew (1995) frizzled regulates mirror-symmetric pattern formation in the Drosophila eye. Development. 121, 3045-55. 


\section{List of Figures}

\begin{tabular}{|c|c|c|}
\hline Figure 1 & Different neural tube defects in human development. & 11 \\
\hline Figure 2 & Schematic diagram of neural plate bending and closure of the neural tube. & 15 \\
\hline Figure 3 & $\begin{array}{l}\text { Schematic scheme of the morphogenetic process of convergent extension of the } \\
\text { neural tube. }\end{array}$ & 16 \\
\hline Figure 4 & Cell migration of the pluripotent neural crest cells give rise to a variety of cell types. & 18 \\
\hline Figure 5 & Schematic representation of neural crest formation in vertebrates. & 19 \\
\hline Figure 6 & $\begin{array}{l}\text { Combination of signals pattern the neural border during gastrulation and } \\
\text { neurulation. }\end{array}$ & 20 \\
\hline Figure 7 & Steps till NC migration and the process of EMT. & 22 \\
\hline Figure 8 & Early migration steps of cephalic NC cells in Xenopus. & 23 \\
\hline Figure 9 & Cell-cell interactions and external signals regulating neural crest cell migration. & 25 \\
\hline Figure 10 & Planar cell polarity in the Drosophila wing and ommatidia. & 26 \\
\hline Figure 11 & Processes regulated by the PCP signaling pathway in mammals. & 27 \\
\hline Figure 12 & The non-canonical Wnt/Fz PCP pathway. & 28 \\
\hline Figure 13 & Mouse PCP mutants have open neural tube (craniorachischisis). & 29 \\
\hline Figure 14 & Principle of convergent extension movements. & 30 \\
\hline Figure 15 & The basic steps in directed cell migration. & 31 \\
\hline Figure 16 & CIL between single and clustered cells. & 33 \\
\hline Figure 17 & CIL in Xenopus cephalic NC cells. & 34 \\
\hline Figure 18 & CIL is controlled by localization of PCP members. & 35 \\
\hline Figure 19 & PTK7 functions in planar-cell-polarity in vertebrates. & 37 \\
\hline Figure 20 & Structure of PTK7. & 38 \\
\hline Figure 21 & RACK1 interacts with PTK7 in co-immunoprecipitation assays. & 39 \\
\hline Figure 22 & Structure of the RACK1 protein. & 40 \\
\hline Figure 23 & The RACK1 loss-of-function leads to neural tube defects. & 64 \\
\hline Figure 24 & $\begin{array}{l}\text { Different morpholinos of RACK } 1 \text { caused neural tube closure defects and could be } \\
\text { rescued by specific constructs. }\end{array}$ & 66 \\
\hline Figure 25 & $\begin{array}{l}\text { Time lapse pictures of embryos injected with RACK1 MO, PTK7 MO and control } \\
\text { MO. }\end{array}$ & 67 \\
\hline Figure 26 & Like the PTK7 MO, RACK1 MO does not affect neural marker expression. & 68 \\
\hline Figure 27 & $\begin{array}{l}\text { Neural tube closure defects of embryos injected with different combinations of PTK7 } \\
\text { and RACK1 morpholinos. }\end{array}$ & 69 \\
\hline Figure 28 & RACK1 overexpression caused neural tube closure phenotypes. & 70 \\
\hline
\end{tabular}




\begin{tabular}{|c|c|c|}
\hline Figure 29 & PTK7 and RACK1 are required for convergent extension of the neural tube. & 71 \\
\hline Figure 30 & PTK7 and RACK1 inhibit convergent extension of XBF-2 expressing animal caps. & 72 \\
\hline Figure 31 & In animal cap cells RACK1 is actively recruited to the plasma membrane via PTK7. & 73 \\
\hline Figure 32 & $\begin{array}{l}\text { RACK1 assists PTK } 7 \text { to recruit DSH to the plasma membrane in ectodermal } \\
\text { explants. }\end{array}$ & 76 \\
\hline Figure 33 & PKC 81 loss-of-function inhibits the PTK7-RACK1-mediated DSH localization. & 78 \\
\hline Figure 34 & $\begin{array}{l}\text { Neural tube closure defects of embryos injected with different combinations of } \\
\text { PTK7, RACK1 and PKC } \delta 1 \text { morpholinos. }\end{array}$ & 80 \\
\hline Figure 35 & RACK1 LOF had no influence on the Fz7 mediated DSH localization. & 81 \\
\hline Figure 36 & RACK1 is not required for the Fz dependent hyperphosphorylation of $\mathrm{DSH}$. & 81 \\
\hline Figure 37 & Fz7 did not recruit RACK1 to the cell membrane in ectodermal explants. & 82 \\
\hline Figure 38 & RACK1 and PTK7 show a similar expression pattern in Xenopus embryos. & 83 \\
\hline Figure 39 & The knock-down of RACK1 inhibit neural crest cell migration in Xenopus embryos. & 84 \\
\hline Figure 40 & $\begin{array}{l}\text { PTK7 is enriched in restricted parts of the membrane of NC cells during cell-cell } \\
\text { contact. }\end{array}$ & 86 \\
\hline Figure 41 & PTK7 is enriched at lateral cell-cell contacts of clustered migrating NC cells. & 87 \\
\hline Figure 42 & PTK7 is enriched at the lateral sides of migrating NC cells at the migration front. & 88 \\
\hline Figure 43 & PTK7 is enriched at cell-cell contacts of two single migrating NC cells. & 89 \\
\hline Figure 44 & PTK7 is enriched at cell-cell contacts during CIL (Spinning disk images). & 90 \\
\hline Figure 45 & $\begin{array}{l}\text { PTK7 is enriched at cell-cell contacts during CIL of two single migrating NC cells } \\
\text { which migrate directly out of a cell cluster (LSM images). }\end{array}$ & 91 \\
\hline Figure 46 & $\begin{array}{l}\text { PTK7 is enriched at cell-cell contacts in migrating single cells during CIL (LSM } \\
\text { images). }\end{array}$ & 92 \\
\hline Figure 47 & Membrane GFP expressing cells shows no enrichment at cell-cell contacts. & 93 \\
\hline Figure 48 & $\begin{array}{l}\Delta \mathrm{kPTK} 7-\mathrm{GFP} \text { enriched at cell-cell contacts in clustered and single migrating NC } \\
\text { cells. }\end{array}$ & 95 \\
\hline Figure 49 & PTK7 and RACK1 co-localize in migrating neural crest cells. & 97 \\
\hline Figure 50 & PTK7 MO injected NC cells show a disturbed migration. & 99 \\
\hline Figure 51 & RACK1 LOF did not disturb the migration process of NC cells in general. & 101 \\
\hline Figure 52 & Control MO injected NC cells show a normal migration behaviour over time. & 102 \\
\hline Figure 53 & PTK7 LOF disturbed CIL. & 103 \\
\hline Figure 54 & RACK1 LOF does not affect CIL. & 103 \\
\hline Figure 55 & The model of PTK7 signaling. & 107 \\
\hline
\end{tabular}




\section{Curriculum Vitae}

\section{Personal data}

Name: $\quad$ Peter Wehner 


\section{Acknowledgements}

First, I would like to thank my supervisor Dr. Annette Borchers for the topic and the possibility to do my thesis work in her group. I thank that she opens me the wide and interesting field of early developmental processes. She was kind to help me with all my questions and ideas. Many thanks to for her support, guidance and advice during the last years.

I would like to thank Prof. Dr. Tomas Pieler for giving me the opportunity to work in his department and for offering me a friendly, scientific environment.

Of course I would like to thank the members of my thesis committee, Prof. Dr. Andreas Wodarz and Prof. Dr. Gregor Bucher for co-supervising my thesis project and for their helpful questions, discussions and ideas during my time in Göttingen.

I would like to thank all my colleagues from the Developmental Biochemistry Department.

Thanks to all my present (Martina, Ewa, Hanna) and former (Hanna, Iryna, Gabriele, Susanna) group members. Especially, I would thank llona Wunderlich for her important, continuous support during my work.

Furthermore, I want to thank my collaboration partners who provided their techniques, knowledge and time.

Last but not least, thanks to the GGNB office during my time in the GGNB program. In particular, I would like to thank my friends and my family for their help and support.

Special thanks go to my wife Nora for her patience and love. 